\title{
A Multidimensional Perspective on Education in Developing Countries
}

Citation for published version (APA):

Momo, M. S. M. (2021). A Multidimensional Perspective on Education in Developing Countries. [Doctoral Thesis, Maastricht University]. Maastricht University. https://doi.org/10.26481/dis.20211018mm

Document status and date:

Published: 01/01/2021

DOI:

10.26481/dis.20211018mm

Document Version:

Publisher's PDF, also known as Version of record

\section{Please check the document version of this publication:}

- A submitted manuscript is the version of the article upon submission and before peer-review. There can be important differences between the submitted version and the official published version of record.

People interested in the research are advised to contact the author for the final version of the publication, or visit the DOI to the publisher's website.

- The final author version and the galley proof are versions of the publication after peer review.

- The final published version features the final layout of the paper including the volume, issue and page numbers.

Link to publication

\footnotetext{
General rights rights.

- You may freely distribute the URL identifying the publication in the public portal. please follow below link for the End User Agreement:

www.umlib.nl/taverne-license

Take down policy

If you believe that this document breaches copyright please contact us at:

repository@maastrichtuniversity.nl

providing details and we will investigate your claim.
}

Copyright and moral rights for the publications made accessible in the public portal are retained by the authors and/or other copyright owners and it is a condition of accessing publications that users recognise and abide by the legal requirements associated with these

- Users may download and print one copy of any publication from the public portal for the purpose of private study or research.

- You may not further distribute the material or use it for any profit-making activity or commercial gain

If the publication is distributed under the terms of Article $25 \mathrm{fa}$ of the Dutch Copyright Act, indicated by the "Taverne" license above, 


\section{A Multidimensional Perspective on Education in Developing Countries}

Michelle S. M. Momo 
Copyright (C) Michelle S. M. Momo, October 2021

Printing: ProefschriftMaken, Maastricht, the Netherlands

ISBN: 978-94-6423-424-4

All rights reserved. No part of this publication may be reproduced, stored in a retrieval system or transmitted, in any form or by any means, electronic, mechanical, photocopying, recording or otherwise, without prior permission of the author or the copyright-owning journals for previous published chapters. 


\title{
A Multidimensional Perspective on Education in Developing Countries
}

\author{
DISSERTATION
}

to obtain the degree of Doctor at Maastricht University, on the authority of the Rector Magnificus, Prof. Dr. Rianne M. Letschert, in accordance with the decision of the Board of Deans, to be defended in public on Monday 18 October 2021, at 16:00 hours

by

Michelle S. M. Momo 


\section{Supervisors}

Prof. Dr. Wim Groot

Dr. Sofie J. Cabus

\section{Assessment Committee}

Prof. Dr. Rolf van der Velden (chair)

Prof. Dr. Louis Volante

Prof. Dr. Carla Haelermans

Prof. Dr. Harry Patrinos (World Bank, USA)

Prof. Dr. Pauline Rose (University of Cambridge, UK) 


\section{Summary}

The aim of this thesis is to increase our knowledge on educational outcomes in low income and lower-middle-income countries by examining the intergenerational correlation of education in multiple dimensions, given the complexity inherent in the concept and the global persistence in the number of early school leavers. We posit that in order to combat the high rate of school dropout among the poor and to increase the intergenerational mobility of education, it is necessary to explore the role played by the reduction in the intergenerational mobility on inequalities that occur early in the lives of children. In other words, gaps that emerge early in life among families that need to be addressed and offset. These are gaps that exist due to inherited limited opportunities from parents and a lack of basic necessities for a comfortable standard of living.

The exploration of the reduction of educational inequalities across generations is on two fronts. First, by increasing opportunities educationally, economically, and socially in society so that the independence of children's education to that of their parents will be enhanced. This may be done through public policies or actions that favour the socioeconomically disadvantaged in the society. Second, by increasing the absolute intergenerational mobility through the easing of deprivations in the households and their consequences, which make that school-aged individuals are more likely to leave school early. More knowledge and insight in these issues may contribute to achieving this goal. We therefore examine whether educational attainment vulnerability in developing countries can be explained by looking at their institutional or contextual characteristics and household deprivation status.

We therefore advance the following hypothesis in Chapter 1:

Hypothesis A: Push, pull, and falling out factors are prominent determinants of early schoolleaving in both Africa and Asia and context-specific

Hypothesis B: Favourable institutional characteristics are able to reduce the intergenerational correlation of education

Hypothesis C: Intergenerational correlation of education significantly increases with household deprivation

Chapter 2 presents the evidence on early school leaving in the literature using findings from low income and lower-middle-income countries. This is done by a systematic literature review on the causes of early school leaving in Africa and Asia. It comprises of studies published from 2001 to 2018, which are either quantitative, mixed, or qualitative. We review a total of 43 
studies. The studies included applied different analyses including logistic regression, linear regression, descriptive statistics, analysis of variance, probit regression, discrete-time logit model, Cox regression model, and narrative studies.

Based on the findings, pull factors, push factors and falling out factors determine early school leaving. However, the pull factors show a very high prominence across Africa and Asia. These pull factors include gender, religion, ethnicity, house work, wage labor, farming, region of residence, ill health, truancy, disability, pregnancy, marriage, age, no self-esteem, late school entry, pre-marital sex, substance use, family-related factors, and environmental factors. The factors which push students away in these findings are inadequate school facilities and quality, unavailable and unskilled teachers, student-teacher conflict, inadequate student assistance, no leisure activities, unsuitable school time, corporal punishment, exam failure, school distance, absenteeism, grade repetition, poor academic performance, and unofficial enrolment. The falling out factors are lack of interest, and unawareness of importance of education. In addition, in Asia, immigration and ethnicity are important factors. This suggests that multi-perspective targeting is required to prevent school dropout. That is, targets that involve family, school, individual, as well as community focus. The findings confirm our hypothesis that push, pull, and falling out factors are prominent determinants of early school-leaving in both Africa and Asia and contextspecific.

Chapter 3 looks at the institutional factors that contribute to explaining the relationship between parent's education and children's education. Data for 48 countries in total, from multiple harmonized surveys, are utilised. A total of 149 surveys are included. Using multivariate regressions, we first present the correlation coefficients of the relationship between parent's education and children's education. These coefficients then serve as the dependent variable in the regression analysis with the institutional factors at the second stage. To this end, secondary data are obtained from the household Demographic and Health Surveys (DHS), and from the U.S. Agency for International Development (USAID) and the World Bank data catalogue.

The DHS are nationally representative cross-sectional surveys where data on impact evaluation indicators on the population, health, and nutrition in over 90 countries are represented. The primary respondents of the surveys are women of reproductive age, between 15-49 years, who respond to a household questionnaire and a woman's questionnaire (DHS Program, 2020). The man's questionnaire is responded to by men of reproductive age (typically 15 to 49, 54, or 59). In the household questionnaire, the respondent provides information on household membership, 
individual characteristics, household head, health, housing, consumer goods, and living conditions (DHS Program, 2020).

The factors from the USAID and the World Bank data catalogue are part of the world development indicators (WDI) and the worldwide governance indicators (WGI). Corruption estimates, political stability estimates, and voice and accountability estimates are taken from the WGI while the others (GDP, prevalence of HIV, life expectancy at birth, female-male labour force participation, government expenditure on education, pupil-teacher ratio, primary school starting age, primary school duration, secondary school duration, compulsory years of education, fixed telephone subscriptions, and mobile cellular subscriptions) are from the WDI. The WDI is a compilation of high-quality, relevant, and internationally comparable statistics about global development and the fight against poverty (World Bank, 2020b). 1600 time series indicators are contained in the database for 217 countries. These indicators are organized according to six main thematic areas that are poverty and inequality, people, environment, economy, states and markets, global links (World Bank, 2020b).

The WGI are nationally comparable indicators of government selection, monitoring, replacement, effectiveness, and the respect of citizens and the state. The worldwide governance indicators generally report on six broad governance dimensions for over 215 countries and territories. These dimensions are government effectiveness, control of corruption, rule of law, voice and accountability, regulatory quality, and political stability and absence of violence (World Bank, 2019). Specifically, we focus on GDP, the prevalence of HIV, life expectancy at birth, female-male labour force participation, government expenditure on education, pupilteacher ratio, primary school starting age, primary school duration, secondary school duration, compulsory years of education, fixed telephone subscriptions, mobile cellular subscriptions, the extent of corruption, the extent of political stability, and the extent of voice and accountability. The factors used in this chapter are selected based on data availability. The process looks at the correlation between these factors and the intergenerational correlation of education.

The results show that these institutional factors account for $39 \%$ of the explained cross-country variation in the intergenerational correlation of education. The pupil-teacher ratio, primary school duration, and compulsory years of education reduce intergenerational correlation of education by 0.03 years, 0.03 years, and 0.02 years respectively, following a one standard deviation change in the variables. Besides these variables, GDP, female-male labour force participation, and extent of voice and accountability reduce intergenerational correlation of 
education by 0.01 years, 0.03 years, and 0.03 years respectively, following a one standard deviation change in the variables. This confirms our second hypothesis on favourable institutional characteristics being able to reduce intergenerational correlation of education.

Chapter $\mathbf{4}$ is a case study of how changes in institutional factors may be used to offset the effect of parent's education on children's education by improving educational attainment of children. We use the extension of compulsory education in 2004 in Senegal from primary to lower secondary. This involves observing the marginal impact of the increase in the number of years of compulsory education on compulsory school completion (grade 10 completion) and on changes in post-compulsory grades completion (grades 11 to 13 completion). The data used is the 2017 survey on Senegal. The analysis comprises of a treatment group (individuals aged 13 to 15) and a control group (individuals aged 16 to 18). This is because the new school leaving age is 16 , therefore, individuals 16 years and above are not affected by the policy while those 15 years and below are affected by the policy. A logistic regression discontinuity and chi-square tests are applied.

The policy substantially increased grade 10 completion for children aged 13 to 15 as compared to children aged 16-18. This shows that the effect of the change in the compulsory education law on compulsory school completion is highly significant and positive for these marginal learners. Treatment group individuals are $7 \%$ more likely to complete lower secondary education as compared to the control group individuals. In terms of gender, no statistically significant gender differential effect is found of the increase in compulsory education. On the completion of post-compulsory school grades or high school grades (grades 11, 12, and 13), the chi-square tests of association show that the completion of grade 11 and the completion of grade 12 are significantly associated with the education policy for these marginal learners. Therefore, more individuals completed grades 11 and 12 in the treatment group (those aged 13 to 15) as compared to the control group (those aged 16 to 18).

However, completion of grade 13 shows no statistically significant association with the education policy. That is, there is no change in obtaining a high school certificate. Nevertheless, the positive impact of the change in compulsory education years on grades 10 to 12 provides support for the hypothesis that favourable institutional characteristics are some of the channels through which intergenerational correlation of education can be reduced, by means of the improvement of educational attainment of children. This confirms the correlation between the compulsory years of education and the intergenerational correlation of education in Chapter 3. 
Children in countries with a higher number of years of compulsory education face higher intergenerational mobility in education. That is, the higher the compulsory education years the lower the intergenerational correlation of education.

Chapter 5 focuses on the differential relationship between parent's education and children's education in the presence of deprivation. The DHS data are also used in Chapter 5. The analysis is done using ordinary least squares to produce correlation coefficients and interaction terms for these relationships. The indicators used include child mortality, school attendance of schoolaged children, cooking fuel, sanitation, drinking water, housing, electricity, and assets. The DHS data include surveys for twenty-seven developing countries. They were conducted between 2012 and 2018 , the survey years vary between countries.

From our findings, a deprivation index of these variables shows a strong relationship between being deprived and the intergenerational correlation of education of 0.02 years. That is, an additional 0.02 years increase in children's education following a 1-year change in parent's education for the deprived. The result confirms our third hypothesis which said that the: Intergenerational correlation of education significantly increases with household deprivation. Individually, school attendance, cooking fuel, sanitation, drinking water, housing, electricity, and assets have a relationship between being deprived and the intergenerational correlation of education. This relationship ranges between 0.05 years for drinking water and electricity to 0.09 years for housing and assets.

Chapter 6: Most of the institutional and family environment factors in this thesis that correlate with the intergenerational correlation of education are part of the sustainable development goals (SDGs) of the United Nations. The SDGs were designed in 2015 to achieve a better and more sustainable future for all. This thesis shows that a comprehensive achievement on these SDGs has to be mindful of the environmental, social, and economic development aspects of change. The analyses of the intergenerational correlation of education in connection with institutional characteristics and household environment provides an understandable picture of the transmission of education from one generation to the other. Although the correlational coefficients may be quite small, they suggest how equality of opportunity may change in response to increased social mobility.

A policy implication from this thesis is that in an effort to increase educational attainment, and, consequently, to partly reduce the intergenerational correlation of education, institutional 
characteristics and households' circumstances should be taken into consideration. We therefore propose guidelines for the progress towards improving the degree of independence of a child's educational attainment to his/her parent's educational level, and improving the pathway enabling children to exceed the educational level of their most educated parent in developing countries. Efforts should be made to ameliorate economic development, such as promoting more industrialization (or improving manufacturing skills) and training programs, and trade exchange in favour of technology import. Industrial improvement requires labour and education, which may in turn create more opportunities and a more higher education-oriented generation. An increase in GDP is therefore a vital input in improving outcomes like employment, decent work and economic growth, and empowering educational decisions, investment, and actual mobility. In addition, education provision and the quality of education such as more teachers to student ratio, and many years of compulsory education so students spend more time at school obligatorily, contribute to increasing intergenerational mobility in education.

Access to basic education by households is also vital, as cost to school still act as hindrances to higher education. Despite the global acceptance of a free basic education, some basic learning institutions in low- and middle-income countries still operate on fee collection. The governance structure such as voice and accountability should carefully be observed. In other words, the motivation to go to higher education also relates to how governance is handled in terms of freedom and rights to citizens to practice association, expression, and voting. In addition, attention should be paid to household deprivation that may affect school attendance and retention and which may increase the number of out of school children. Besides enabling the availability of basic services, policies could motivate and encourage students for higher education earlier.

It is our recommendation that the analysis of intergenerational correlation of education in low income and lower-middle-income countries should use a multidimensional perspective, and importantly, that these countries also place strategic focus on the SDGs. Because focusing on one of them in isolation would not provide a richer picture of improving educational mobility but a combination of multiple factors as complements to one another is relevant to public policy.

In conclusion, these findings provide insight into some of the situations surrounding households and economies with persistent low intergenerational mobility of education and the way the institutions and household environments can be assessed and ameliorated to further provide comfort and means to higher levels of schooling. They shed light on the multifaceted nature of 
solutions to educational improvement which comprise of both micro level and macro level circumstances surrounding school goers. These circumstances are considered the responsibility of all stakeholders in society ranging from the state to the direct household members on which children rely on for their early childhood development and educational attainment. 


\section{Table of Contents}

Summary

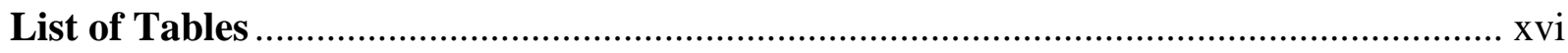

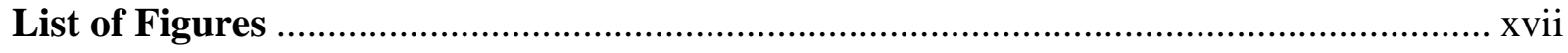

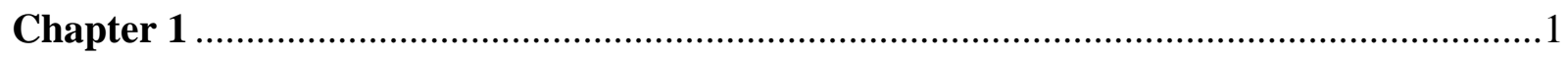

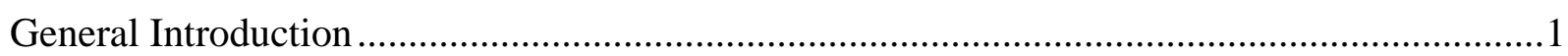

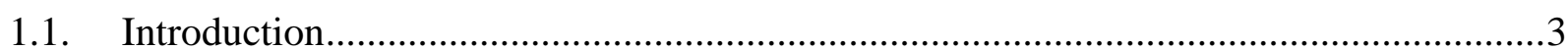

1.2. Relevance, research aim and research questions ..................................................6

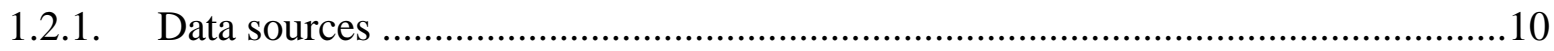

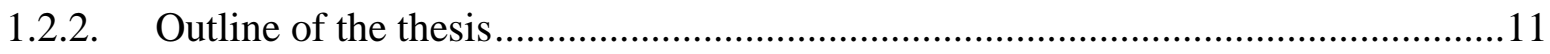

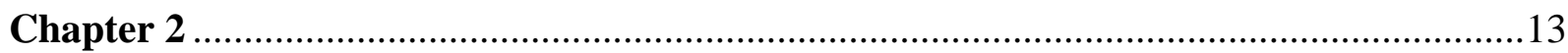

A Systematic Review of the Literature on the Causes of Early School Leaving in Africa and Asia

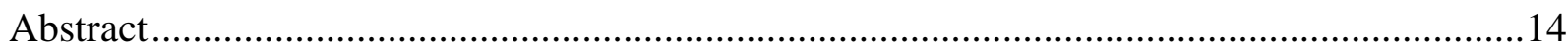

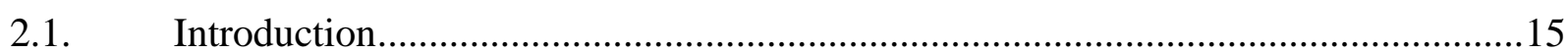

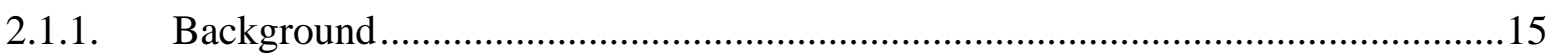

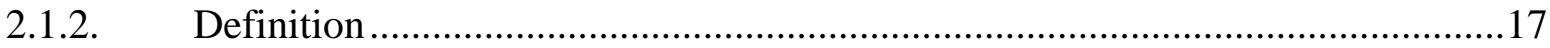

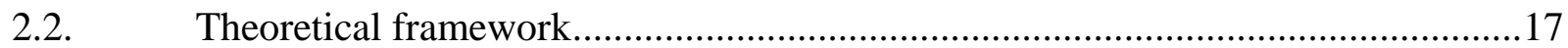

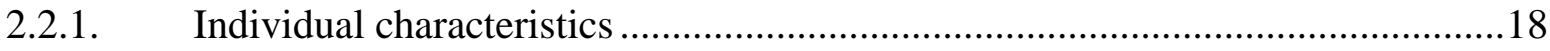

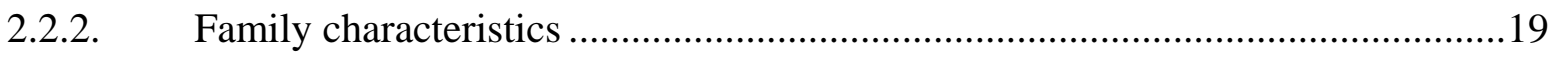

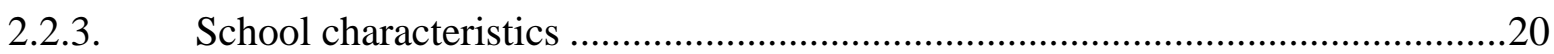

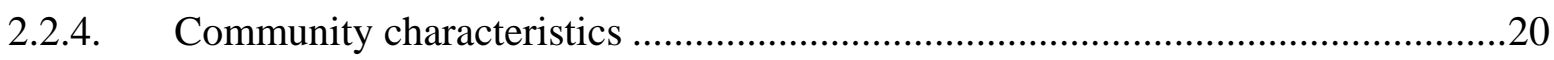

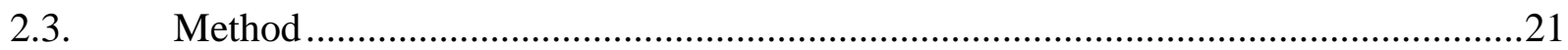

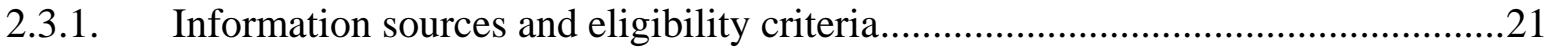

2.3.2. The data types and analyses included in the review .......................................22

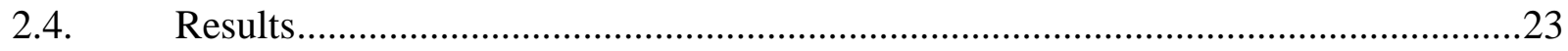

2.4.1. Presentation of results of quantitative, mixed, and qualitative studies................23

2.4.2. Importance of the significant factors relating to early school leaving..................27

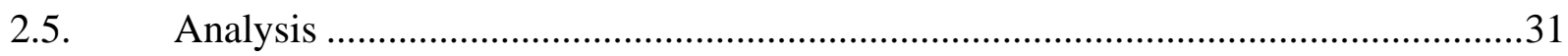

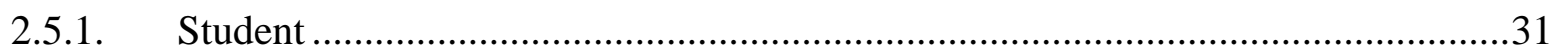

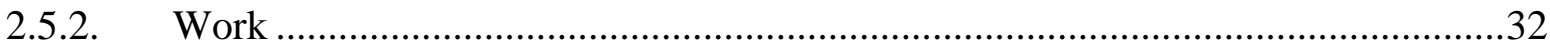

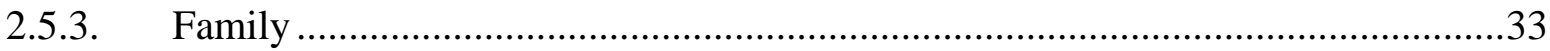

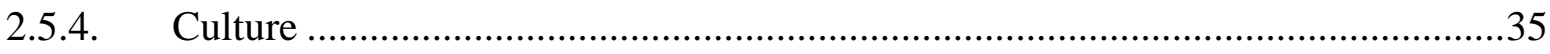

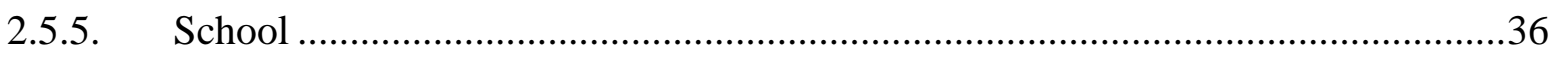

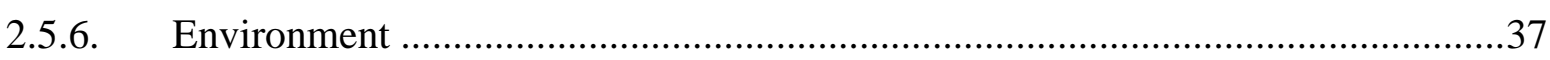

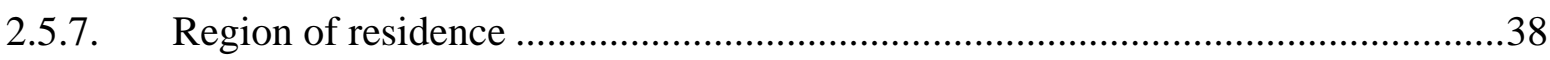

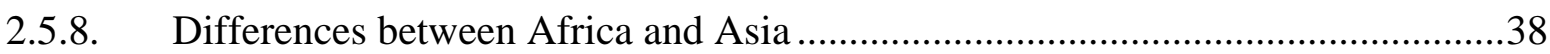




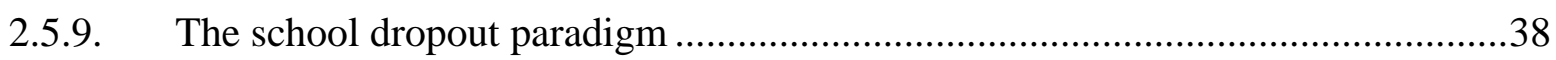

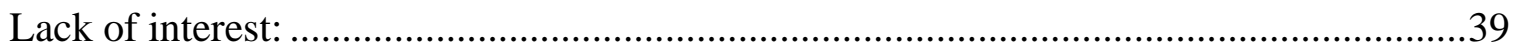

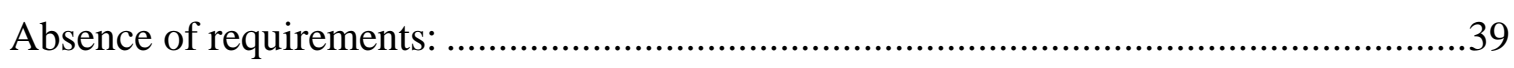

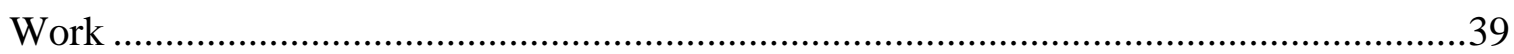

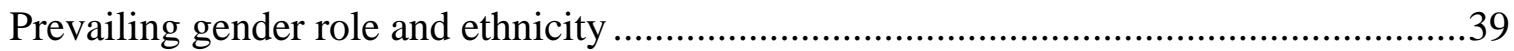

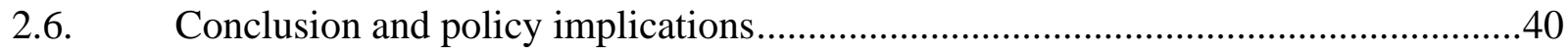

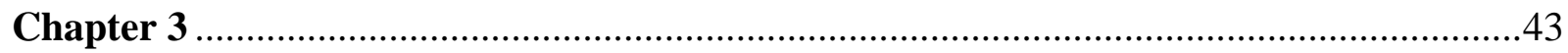

The Relationship between Contextual Characteristics and the Intergenerational Correlation of

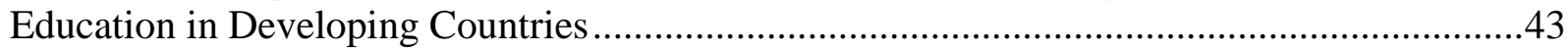

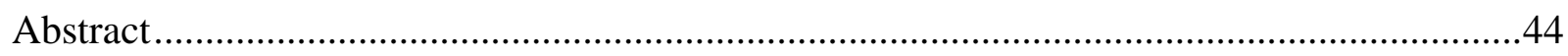

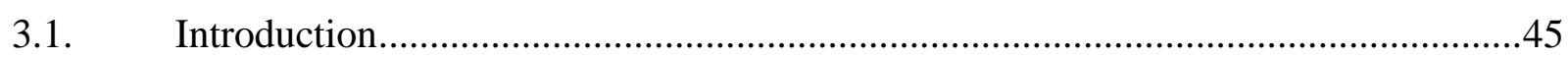

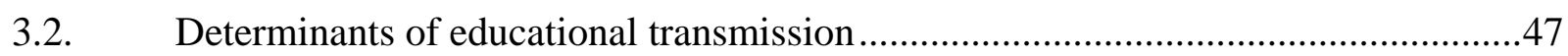

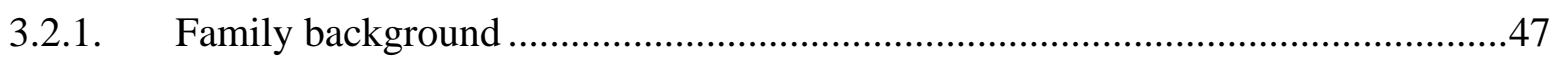

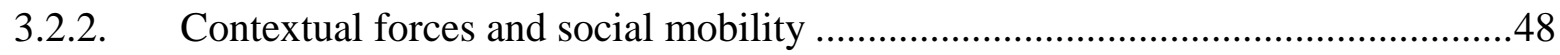

3.2.2.1. Economic modernization driven by technological changes .............................48

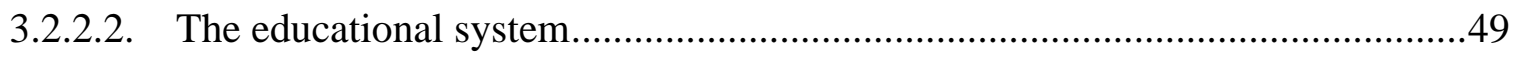

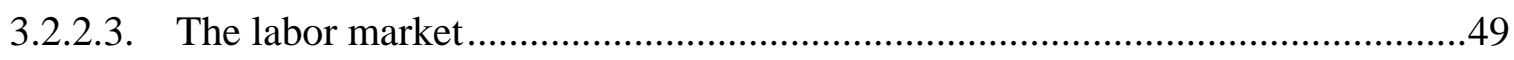

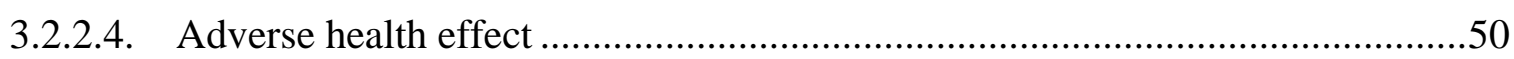

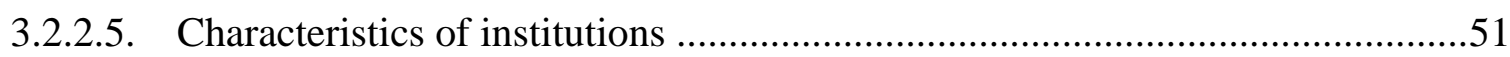

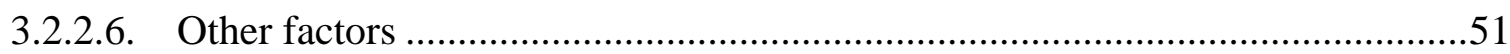

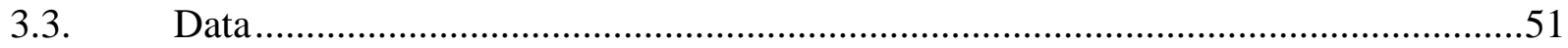

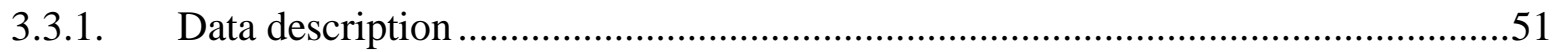

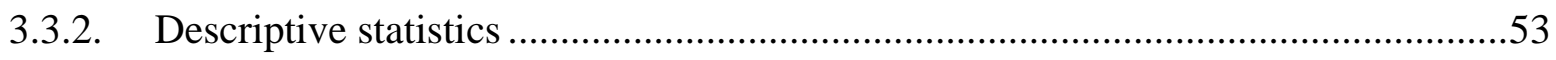

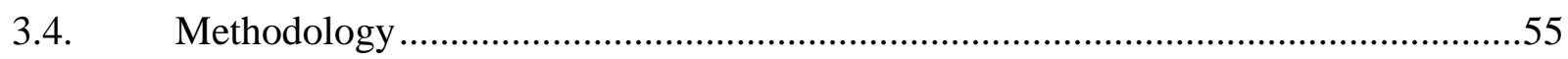

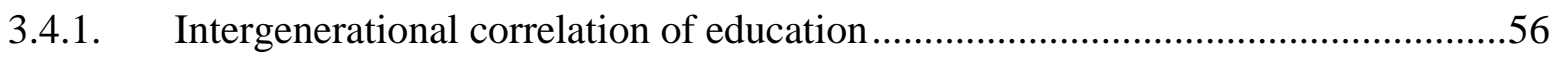

3.4.2. The relationship between contextual characteristics and intergenerational

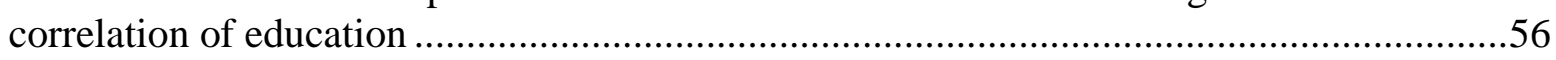

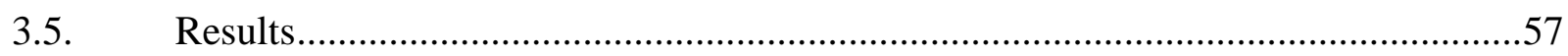

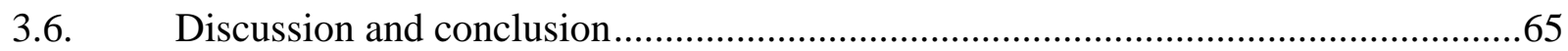

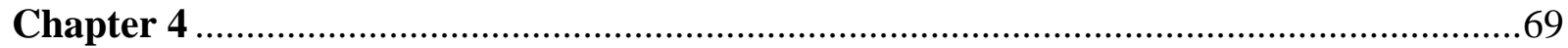

Evidence on the marginal impact of a compulsory secondary education reform in Senegal on years of education and changes in high school decisions .....................................................69

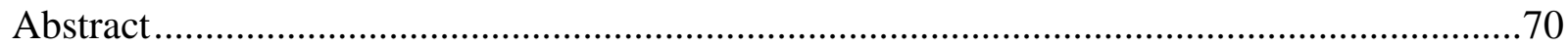

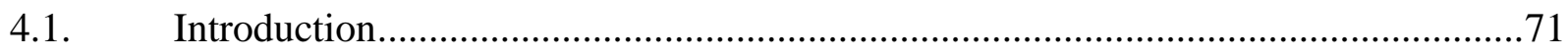

4.2. Compulsory secondary education in low income and lower-middle-income countries

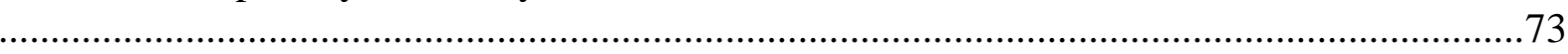

4.3. Education in Senegal and the compulsory school age reform ..................................

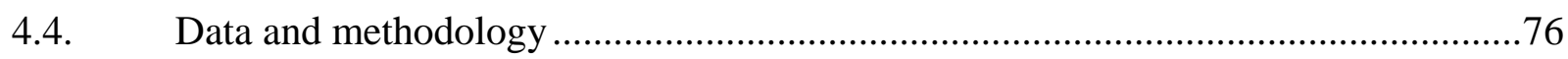




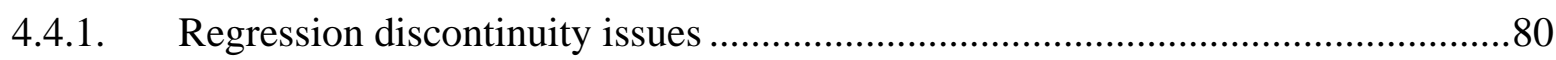

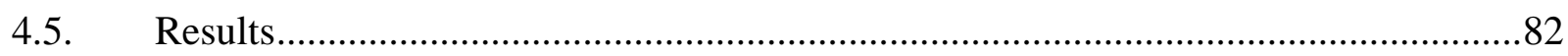

4.5.1. Effect of the compulsory education policy on grade 10 completion ......................82

4.5.2. Gender differential effect of the policy on grade 10 completion................................84

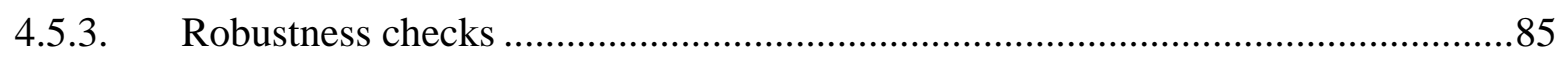

4.5.4. Descriptive trends for post-compulsory grades completion ...............................86

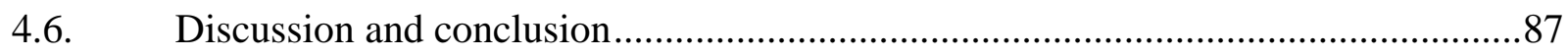

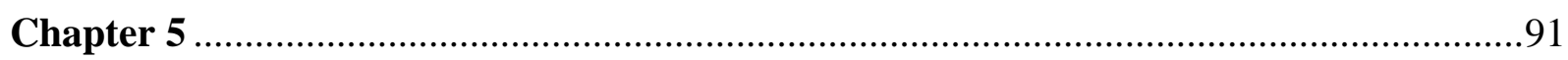

Household deprivation and the intergenerational correlation of education: an analysis of

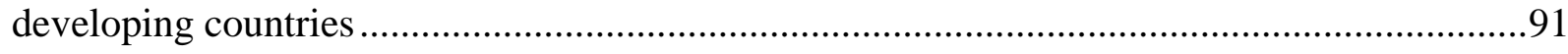

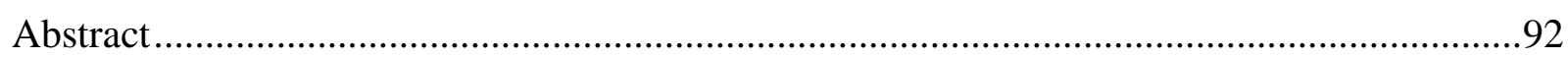

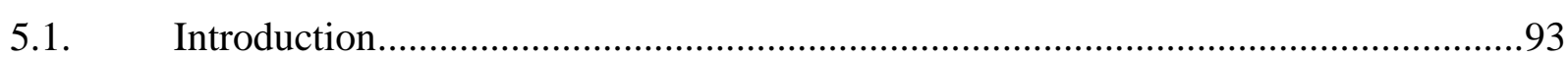

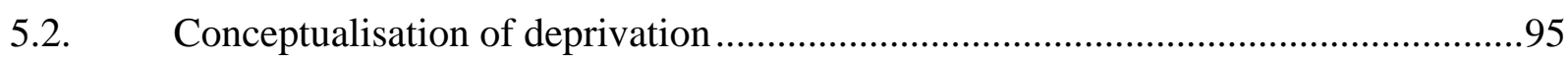

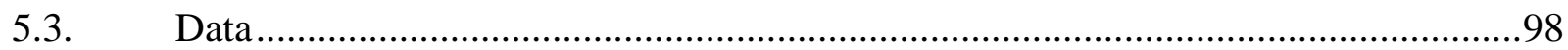

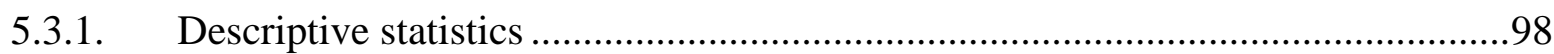

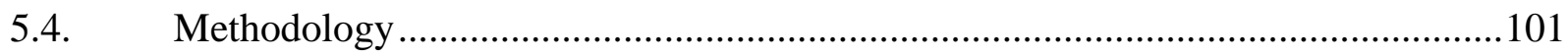

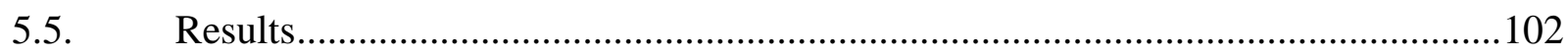

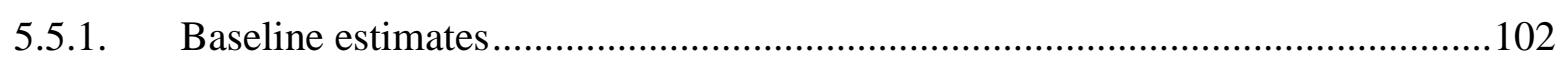

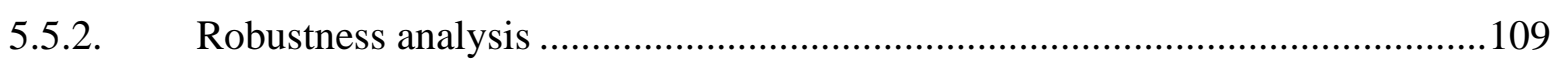

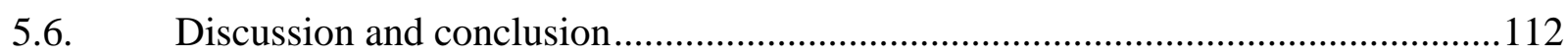

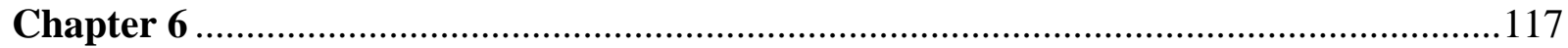

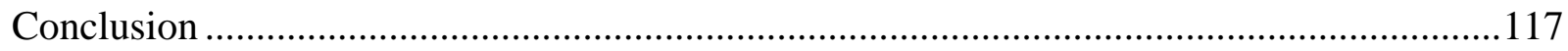

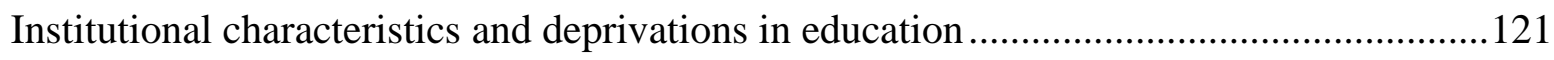

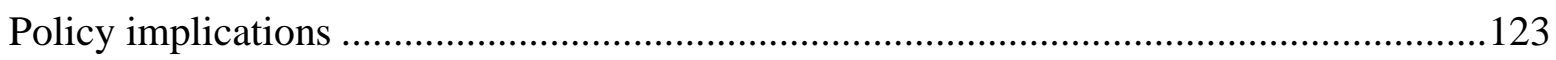

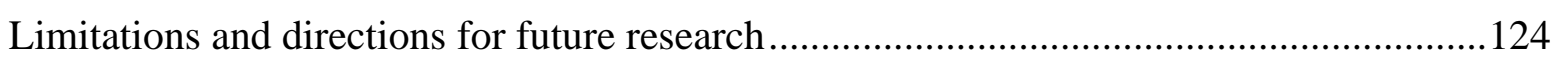

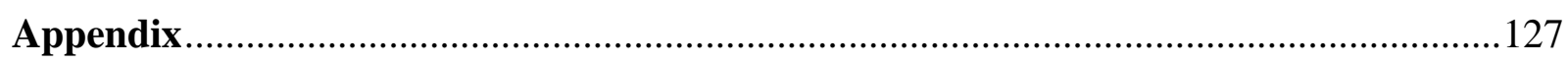

A2.1.: Overview of the School Dropout Determinants Included in the Review: Quantitative

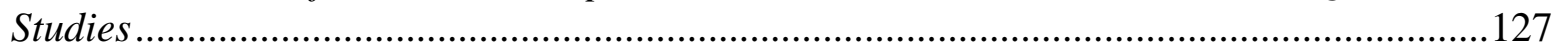

A2.2.: Overview of the School Dropout Determinants Included in the Review: Mixed Studies

A2.3.: Overview of the School Dropout Determinants Included in the Review: Qualitative

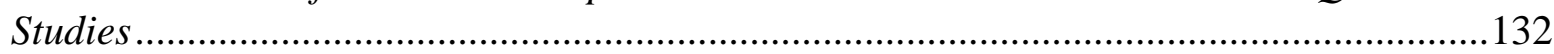

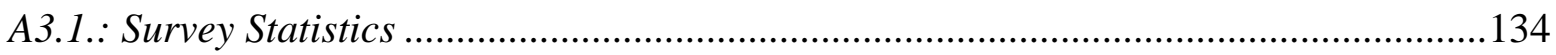

A4.1.: Logistic regression of grade 10 completion with standard error clustered at

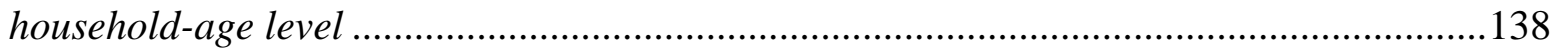

A5.1. : Country-level descriptive statistics of deprivation variables...................................139

A5.2.: Matrix of correlations (pooled sample) ................................................................ 140

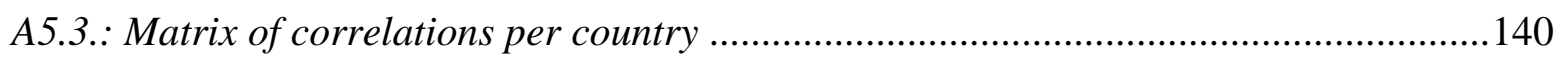




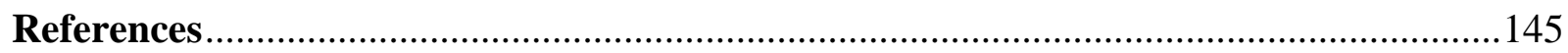

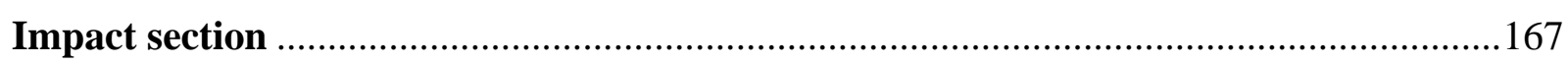

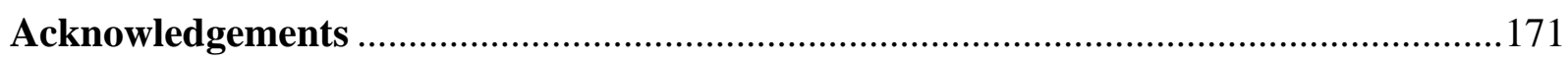

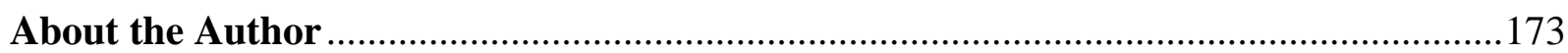

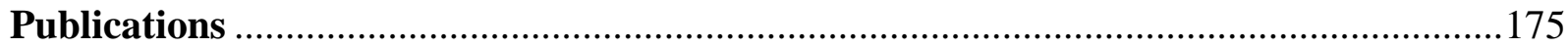




\section{List of Tables}

Table 2.1.: Significant Determinants of Early School Leaving...........................................244

Table 2.2.: Importance of the Significant Factors Relating to Early School Leaving.............288

Table 3.1.: Descriptive statistics of the individual-level characteristics.................................533

Table 3.2.: Descriptive statistics of the macro-level characteristics........................................55

Table 3.3.: Intergenerational education correlation, pooled estimates ...................................577

Table 3.4.: Intergenerational correlation of education coefficients .....................................599

Table 3.5.: The relationship between contextual characteristics and intergenerational correlation of education, stepwise

Table 4.1.: Descriptive statistics: range, mean, standard deviation (in brackets), percentage, and t-test of covariate balance

Table 4.2.: Logistic regression of compulsory education completion (grade 10) for treatment

(13-15) and control group (16-18)

Table 4.3.: Gender differential effect.

Table 4.4.: Logistic regression of grade 10 completion for treatment (16-18) and control (19-

21), and treatment (19-21) and control (22-24) .855

Table 4.5.: Chi-square tests of association for completion of grades 11,12 , and 13 ............866

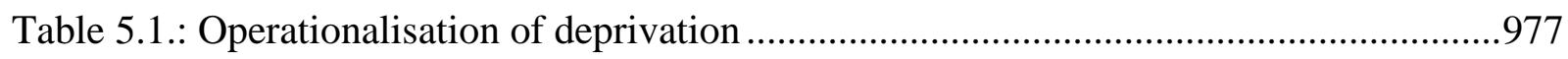

Table 5.2.: Descriptive statistics of the individual-level characteristics................................100

Table 5.3.: OLS regression coefficients of children's education on parents' education (1), deprivation index (2), and interaction of deprivation index and parent's education (3) .......1066 Table 5.4.: Standardized OLS regression coefficients of children's education on parents' education (1), deprivation index (2), and interaction of deprivation index and parent's education (3) 1088

Table 5.5.: Ordered probit coefficient of children's certificate on parents' education (1), deprivation index (2), and marginal effects on the certificate categories 


\section{List of Figures}

Figure 1.1.: A theoretical model of relative and absolute intergenerational mobility in education

Figure 2.1.: Cumulative dropout rate to the last grade of primary education for Africa and Asia

Figure 2.2.: Flowchart of articles reviewed .22

Figure 2.3.: Framework for school dropout .39

Figure 4.1.: Trends in grade 10 completion .78

Figure 4.2.: Density for the forcing variable 81

Figure 5.1.: Composition of the MPI - dimensions and indicators .96

Figure 5.2.: OLS intergenerational correlation coefficients with confidence intervals for the baseline equation without deprivation index (1), and with deprivation index (2) 103 Figure 5.3.: OLS intergenerational correlation coefficients with confidence intervals for the baseline equation (1), and estimated coefficients with one single measure each, of household deprivation

Figure 5.4.: OLS intergenerational correlation coefficients with confidence intervals for the baseline equation without deprivation index (1), and with deprivation index (2), by gender.104 
Chapter 1

General Introduction 


\subsection{Introduction}

Educational vulnerability characterizes education trajectories of millions of children in developing countries. This is evidenced by - among others - the persistent high rate of school dropout and early school leaving. Sub-Saharan Africa had a $42 \%$ dropout rate, South and West Asia 33\%, and Latin America 17\% in 2019 (United Nations Educational, Scientific and Cultural Organization (UNESCO), 2019). Despite numerous efforts and national policies to ameliorate schooling outcomes, the developing world still battles with a learning crisis. Children from poor households are disproportionately affected by this crisis, for they are far more likely to leave school early (UNESCO, 2019; World Bank, 2018a). This is because before they start school, they tend to exhibit learning deficits, which render them ill prepared for education (World Bank, 2018a). The foundational skills or early childhood development required for higher learning trajectories are much more adverse for children from a poor background, which highly undermines their educational attainment as compared to their peers with a wealthier background. These adversities include illness, low parental support, cumulative effects of material deprivation, chronic malnutrition, and violent, chaotic, or unpredictable environments that are associated with poverty (Lupien et al., 2000; McCoy et al., 2016; Walker et al., 2007).

De Hoyos (2016) explained that one of the main reasons why there still is no easy way of fixing the school dropout problem in developing countries is because of the early life and educational trajectories of the dropouts. This is where the root of the problem can be found. These are found in household-level conditions that shape the lack of opportunities in education. It has led to the frequent identification of household wealth and parents' educational attainment as important determinants of educational participation (Abuya et al, 2017; Miller, 2016), largely because they direct the decisions concerning who goes to school and who stays in school in developing countries (Farah and Upadhyay, 2017; Mabika and Shapiro, 2012; Moyi, 2012; Stash and Hannum, 2001). This is in line with the large body of literature which show that the different life prospects of children largely reflect differences in their family background. In other words, the outcomes of children are tied to their parents' achievements earlier in life (Mahler et al., 2018). This is evidenced by the intergenerational correlation of education: the extent to which children's education is determined by that of their parents.

In many parts of the developing world, the persistent inequality in education is associated with what children benefit from their parents, or what is being passed down from one generation to the other. These include culture, values, wisdom, wealth, social status, and legacies (Mahler et 
al., 2018). The education of parents still remains a strong determinant of the education of children in developing countries (Azomahou and Yitbarek, 2016). Parent's education reflected in the education of their children is more than the role they play in the life of their children in terms of inheritance, educational investment and motivation. As mentioned earlier, the effect of parents' education is largely attached to the fact that they direct the decision on school attendance and continuation. This may lead to a similar educational attainment of children to that of the parents (intergenerational transmission of education) (Blanden and Macmillan, 2016), probably as a result of parents' involvement in the school attendance decision of their children and the lack of educational opportunities.

Lack of educational mobility from one generation to the other therefore represents the fact that too often, socioeconomically disadvantaged children struggle to climb up the ladder of education, with fewer than half of adults attaining a level of education higher than their parents' (World Bank, 2018).The consensus is that to reduce the low mobility in education in developing countries, public policies have to affect and offset gaps that emerge early in life representing family and individual differences. This is to improve relative intergenerational mobility and to reduce the degree of independence of a child's educational attainment to his/her parent's educational level (World Bank, 2018). This improvement is supposed to be accomplished by national actions that assist in increasing possibilities and opportunities benefiting the socioeconomically disadvantaged in order to reduce inequality. Examples of such policies include expenditure on education and increasing gross domestic product (Alesina et al., 2019; Neidhofer et al., 2018; Van Doorn et al., 2011). A successful policy that improves possibilities and opportunities is expected to increase the general average educational attainment of a nation (Zhan, 2017). These policies or national actions are described as the contextual characteristics of an institution or a state, which can range from different sectors such as industry, labour, education, health, and governance nature. Institutions are said to comprise of rules and macrostructural forces that not only provide opportunities, but also affect the behaviour of individuals (Zhan, 2017).

The role of institutions has been very much emphasized in the analyses of the intergenerational mobility in educational attainment in developed countries. The literature on this role has contributed to our understanding about some of the elements of a country's institutions that affect educational attainment. For instance, Sieben and De Graaf (2001) established that a modernisation indicator such as better energy consumption per capita is related to educational attainment in the United States, England, Hungary, the Netherlands, Spain, and Scotland. The 
indicator explains the existence of a decrease in the effect of parental education on educational attainment. Pfeffer (2008) showed that institutions with a high quality educational system such as stable student selection into highly differentiated educational pathways reduces the intergenerational persistence of educational opportunities. Besides better education quality and a high level of industrialisation, labour force participation is shown to cause more years of education of children as compared to their parents. Van Doorn et al. (2011) investigated this in 28 European countries using gross domestic product (GDP), female labour force participation, education expenditure, and pupil-teacher ratio. Similarly, a low pupil-teacher ratio as observed by Zhan (2017) in the United States, favours lower intergenerational education mobility.

In addition, achieving high absolute intergenerational mobility (a child exceeds the educational level of his/her most educated parent) requires breaking household poverty and privilege links (or rather the absence of it) across generations such that every child has a fair chance to flourish as well as inherit possibilities for advancement (Mahler et al., 2018). This is to help break the cycle of poverty so that the next generation are able to realize their potential and improving their lives, given that children in poor households are still struggling on a regular basis with school attendance (UNESCO, 2019; Villa, 2018). These actions are educational interventions aimed at building demand for education in order to reduce the rate at which students leave school early (Febrianti Purba, 2018; Ganimian and Murnane, 2016).

Some of these actions include increasing the compulsory education age and providing student grants. The most common are the cash transfers or scholarships to low income households, so that their children can stay in school. Some of these transfers are conditional on school attendance while some are unconditional. Examples of countries that have introduced such policies include Malawi, Columbia, Honduras, Cambodia, Kenya, Ecuador, Mexico (Baird et el., 2011; Barrera-Osorio et al., 2011; Behrman et al., 2009; Ferreira et al., 2017; Galiani and McEwan, 2013; Kremer, 2009; Schady and Araujo, 2008; Schultz, 2004). The evidence on the impact of these cash transfers are mixed, but they generally show that cash transfers increase enrolment. These outcomes are however, dependent most of the times on features like the characteristics of the beneficiaries, the schooling outcome on which the unconditional or conditional cash transfer is being made (outcomes include dropout, retention, enrolment, repetition, attendance, or cognitive skills), the program design, treatment exposure, and families' perceptions of the cash transfers conditionality (Ganimian and Murnane, 2016).

Besides cash transfers implemented to reduce school dropout in developing countries, Loyalka et al. (2013) worked on teachers providing information to students about the benefits of 
schooling and the disadvantage of leaving school early in favour of wage work. In Malawi and Lesotho, a flexible learning approach experiment was carried out in order to help reduce the rate of school dropout. This approach required that students be provided with a package containing pens, textbooks, notebooks, and self-study guides for independent learning; a buddy system for peer support for learning; and youth volunteering catch-up clubs to provide additional learning opportunities (Jere and Tofaris, 2017; Jukes et al., 2014; Reimao, 2019).

However, despite progress made, sustainable increase in educational outcomes still needs to be achieved (Ganimian and Murnane, 2016). Moreover, evidence suggests that according to a multidimensional definition of deprivation that includes education, consumption, and access to basic utilities, the share of the poor is approximately $50 \%$ higher than when relying solely on income poverty (World Bank, 2020a). This implies that the deprivations faced by households are not well captured by monetary poverty. This is motivated by what the poor identify as their problems, priorities, needs, and view of well-being (Biggeri et al., 2006). That is, the concept of household poverty examined using deprivation measures.

To summarize, what we see is that there is a need to evaluate the factors that correlate with the intergenerational transmission of education in a multidimensional perspective both at the macrolevel and at the micro-level. At the macro-level with respect to management of the economy and at the micro-level with respect to the home environment.

\subsection{Relevance, research aim and research questions}

Education is not only a powerful instrument for improving stability, health, peace, and gender equality, it is above all a powerful driver of development (Millennium Development Goals, 2020). An extra year of secondary education is capable of increasing future earnings, especially for girls, by $10 \%$ to $20 \%$. In this light, high educational attainment has the greatest impact on poverty elimination (Millennium Development Goals, 2020). Children who drop out of school mostly become unskilled workers and therefore have a low probability of being employed in non-elementary occupations and a higher probability of becoming poor. This also has lasting macroeconomic effects because a key element of economic development and growth is the formation of a skilled workforce (Mussida, Sciulli and Signorelli, 2018). There is presently an urgent need to address the high numbers of children that leave school before completing secondary education. The rate at which children drop out of school is becoming a stumbling block to completing secondary education in developing countries (UNESCO, 2019). 
The aim of this thesis is to increase our knowledge on educational outcomes in low income and lower-middle-income countries by examining the intergenerational correlation of education in multiple dimensions, given the complexity inherent in the concept and the global persistence in the number of early school leavers. We posit that in order to combat the high rate of school dropout among the poor and to increase the intergenerational mobility of education, it is necessary to explore the role played by the reduction in the intergenerational mobility on inequalities that occur early in the lives of children. In other words, gaps that emerge early in life among families that need to be addressed and offset. These are gaps that exist due to inherited limited opportunities from parents and a lack of basic necessities for a comfortable standard of living. We therefore advance the following hypotheses:

Hypothesis A: Push, pull, and falling out factors are prominent determinants of early schoolleaving in both Africa and Asia and context-specific

The exploration of the reduction of educational inequalities across generations is on two fronts. First, by increasing opportunities educationally, economically, and socially in society so that the independence of children's education to that of their parents will be enhanced. This may be done through public policies or actions that favour the socioeconomically disadvantaged in the society. Second, by increasing absolute intergenerational mobility through the easing of deprivations in the households and their consequences, which make that school-aged individuals are more likely to leave school early. More knowledge and insight in these issues may contribute to achieving this goal. We therefore examine whether educational attainment vulnerability in developing countries can be explained by looking at their institutional or contextual characteristics and household deprivation status.

Hypothesis B: Favourable institutional characteristics are able to reduce the intergenerational correlation of education

When looking at the determinants of increasing relative intergenerational mobility of education, we look at institutional factors because they are said to map onto inequalities in educational attainment at the macro-level by representing the extend of the intergenerational transmission of education (Azomahou and Yitbarek, 2016; Bukodi et al., 2018; Van Doorn et al., 2011). In other words, they explain the variation in the relationship between parents' education and children's education. Institutional factors provide some benefits to citizens. For instance, developing countries often suffer from a lack of communication technology due to poor infrastructure. Students become negatively affected in that they have limited electronic methods 
through which schools can connect with them, limited communication with friends, limited information and message sharing; and non-exposure to information acquisition mediums (Hajli and Lin, 2014). Better standard of living in an economy gives citizens the capacity to obtain access to necessities such as good health, balanced diet, and positive decisions on societal activities including schooling (Popkova et al., 2018; Waziri et al., 2018).

The education system determines the level of exposure of students to school facilities and services. Van Doorn et al (2011), in their analysis of developed countries, found that a low pupilteacher ratio reduces the dependence of children's educational attainment on the education of their parents, as children are more exposed to school services. The governance structure of the country is another factor which policy makers and the society should be concerned about. As explained in Adelowokan et al (2019), it is beneficial to have good governance, for this act as a route to achieving a peaceful and trustworthy environment. High labour force participation, especially for women, increases educational aspirations of parents towards their children and also acts as a push factor for higher educational achievements in households (Van Doorn, 2011). The evidence on the institutional factors' capacity to increase independence of children's education towards their parents' have been observed in developed countries. However, there is lack of cross country evidence for developing nations. Providing more knowledge and insight on this is part of our focus. We therefore observe the correlation of some institutional factors with educational mobility. The institutional factors observed here include measures of standard of living, educational systems, infrastructure, health, labor market efficiency, and nature of governance.

Hypothesis C: Intergenerational correlation of education significantly increases with household deprivation

For absolute intergenerational education mobility, we focus on household deprivation. The measures of household deprivation we consider here are those in the Global Multidimensional Poverty Index (MPI) put forward by Alkire and Foster (Alkire et al., 2015). These deprivation measures are important because they are not just the identification of who is poor, but how they are poor (Alkire et al., 2019). In this situation, people described as poor explained what they face in their daily lives, or what their actual living conditions are. It is relevant to broaden the lens to observe the nature of poverty by using information on the daily living of households. The global MPI is applied because it is the most recent internationally comparable poverty measure available (Alkire and Kanagaratnam, 2018). This comprises indicators like child mortality, school attendance, cooking fuel, sanitation, drinking water, electricity, housing, and 
assets. Figure 1.1. describes the model proposition of targeting high rate of school dropout by improving relative intergenerational mobility and absolute intergenerational mobility.

Figure 1.1.: A theoretical model of relative and absolute intergenerational mobility in education

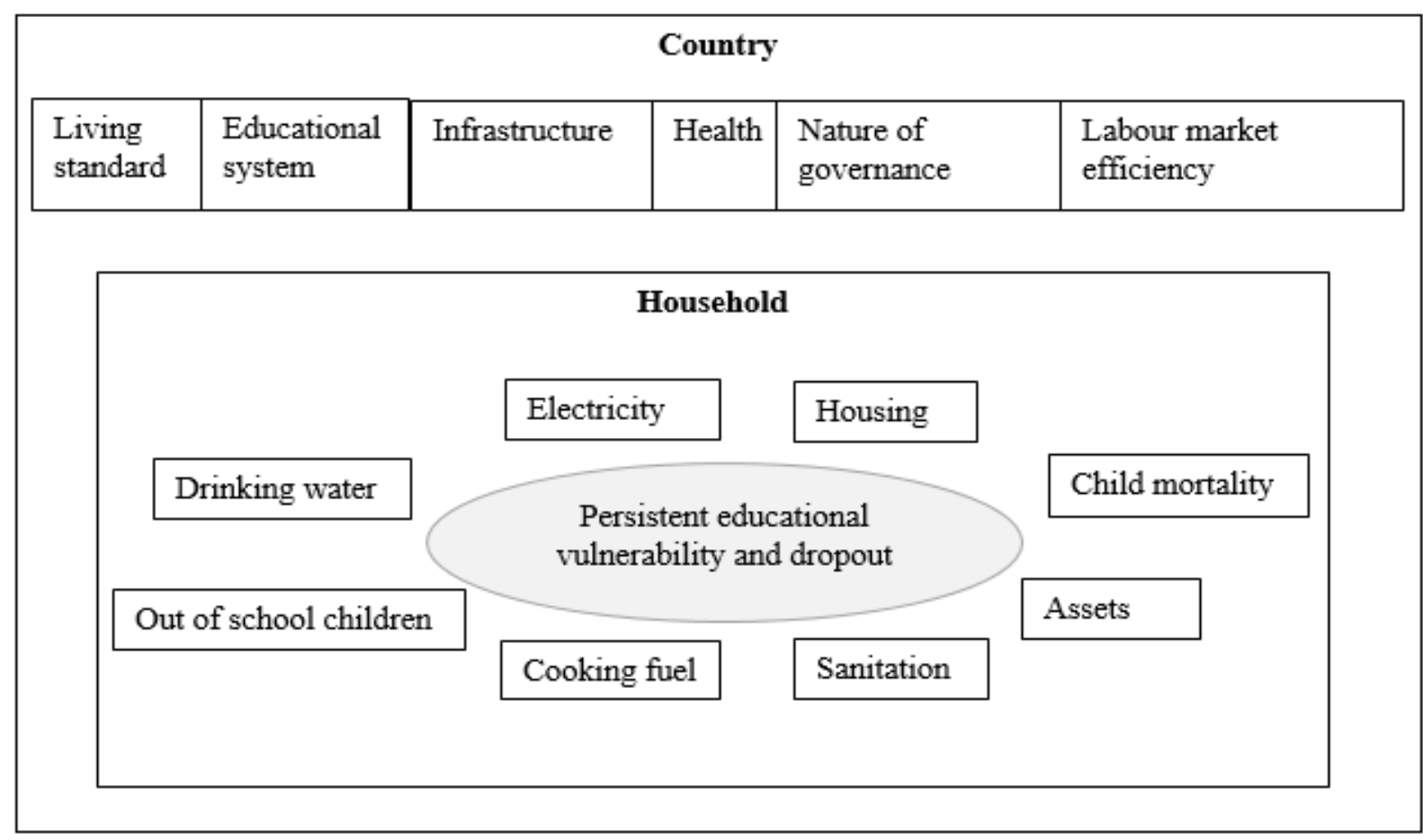

As depicted in Figure 1.1., the focus of this thesis is assessing the educational attainment vulnerability in developing countries by looking at the institutional characteristics and household deprivation. The rationale behind the Figure is that to improve educational attainment in a sustainable manner requires on the one hand, national changes to reflect educational means, good health and diet, improved learning and teaching, good communication and message sharing with school, more exposure to news, increased educational aspiration, peaceful environment, and trust. On the other hand, it refers to household educational and health status, and the possession of basic necessities. In this light, we first of all look at the literature on school dropout in developing countries. This comprises of the reasons why students leave school early, causing the persistent intergenerational transmission of educational attainment. Second, we assess the variation in the intergenerational transmission of education in relation to institutional factors across developing countries, and a developing-country empirical investigation of a change in an institutional characteristic. Third, we assess the variations in the intergenerational correlation of education in relation to household deprivation. Consequently, this thesis addresses the following research questions: 
- What do we know about dropout in developing countries?

- Do institutional factors correlate with educational attainment transmission between parents and their children?

- Does a national policy change bring about a reduction in the intergenerational transmission of education and increase educational attainment of children in developing countries?

- Does the household deprivation contribute to the intergenerational correlation of education?

\subsubsection{Data sources}

In this thesis, we use data from the household Demographic and Health Surveys (DHS), and the U.S. Agency for International Development (USAID) and the World Bank data catalogue. The DHS are nationally representative cross-sectional surveys where data on impact evaluation indicators on the population, health, and nutrition in over 90 countries are represented. On the household questionnaire, the respondent gives information on the household membership, individual characteristics, household head, health, housing, consumer goods, and living conditions (DHS Program, 2020). The factors from the USAID and the World Bank data catalogue are part of the world development indicators (WDI) and the worldwide governance indicators (WGI). Corruption estimates, political stability estimates, and voice and accountability estimates are taken from the WGI while the others (GDP, prevalence of HIV, life expectancy at birth, female-male labour force participation, government expenditure on education, pupil-teacher ratio, primary school starting age, primary school duration, secondary school duration, compulsory years of education, fixed telephone subscriptions, and mobile cellular subscriptions) are from the WDI.

The WDI is a compilation of high-quality, relevant, and internationally comparable statistics about global development and the fight against poverty (World Bank, 2020b). 1600 time series indicators are contained in the database for 217 countries. These indicators are organized according to six main thematic areas that are poverty and inequality, people, environment, economy, states and markets, global links (World Bank, 2020b). The WGI are nationally comparable indicators of government selection, monitoring, replacement, effectiveness, and the respect of citizens and the state. The worldwide governance indicators generally report on six broad governance dimensions for over 215 countries and territories. These dimensions are 
government effectiveness, control of corruption, rule of law, voice and accountability, regulatory quality, and political stability and absence of violence (World Bank, 2019).

\subsubsection{Outline of the thesis}

Chapter 2 presents the evidence on early school leaving in the literature using findings from low income and lower-middle-income countries. This is done by a systematic literature review on the causes of early school leaving in Africa and Asia. It comprises of studies published from 2001 to 2018, which are either quantitative, mixed, or qualitative. We review a total of 43 studies. The studies included applied different analyses including logistic regression, linear regression, descriptive statistics, analysis of variance, probit regression, discrete-time logit model, Cox regression model, and narrative studies.

Chapter 3 looks at the institutional factors that contribute to explaining the intergenerational correlation of education, i.e., the relationship between parent's education and children's education. Data for 48 developing countries in total, from multiple harmonized surveys, are utilised. A total of 149 surveys are included. Using multivariate regressions, we first present the correlation coefficients of the relationship between parent's education and children's education in developing countries. These coefficients then serve as the dependent variable in the regression analysis with institutional factors at the second stage.

Chapter 4 is an empirical investigation of the situation in one country of how changes in institutional reforms may be used to offset the effect of parent's education on children's education by improving educational attainment of children. We use the extension of compulsory education in 2004 in Senegal from primary to lower secondary. This involves observing the marginal impact of the increase in the number of years of compulsory education on compulsory school completion (grade 10 completion) and on changes in post-compulsory grades completion (grades 11 to 13 completion). The data used is the 2017 DHS survey on Senegal. The analysis compares the education outcomes of a treatment group (individuals aged 13 to 15) and a control group (individuals aged 16 to 18). This is because the new school leaving age is 16 , therefore, individuals 16 years and above are not affected by the policy while those 15 years and below are affected by the policy. A logistic regression discontinuity and chi-square tests are applied.

Chapter 5 focuses on the differential relationship between parent's education and children's education in the presence of deprivation. The DHS data we use include surveys for twenty-seven developing countries. They were conducted between 2012 and 2018, the survey years vary 
Chapter 1

between countries. The analysis is done using ordinary least squares to produce correlation coefficients and interaction terms for these relationships.

Chapter 6 concludes this thesis. It summarizes the findings in the previous chapters and highlights what this implies for policy. The limitations of the thesis are acknowledged and discussed and propositions for possible research avenues of improvement in the future are stated. 


\section{Chapter 2}

\section{A Systematic Review of the Literature on the Causes of Early School Leaving in Africa and Asia ${ }^{a}$}

${ }^{a}$ This chapter is based upon: Momo, M. S. M., Cabus, S. J., De Witte, K., \& Groot, W. (2018). A systematic review of the literature on the causes of early school leaving in Africa and Asia. Review of Education, 7(3), 496-522. https://doi.org/10.1002/rev3.3134 


\begin{abstract}
This chapter systematically reviews the literature on the causes of leaving school early in Africa and Asia. Despite the improvement in primary school enrolment in the developing countries by 2015, the persistence of school dropout however, renders this improvement almost insignificant. This leads to the necessity of observing the prolonged specific determinants of dropping out from school together, from several studies, amid the current global development efforts to improve educational attainment in these countries. Pull, push, and falling out notations are included to the framework for understanding school dropout. Pull factors pull students to the point of leaving school, usually in the form of needs and wants external to the school. Push factors are internal to the school, which push students away, and falling out factors neither arise from being pushed out nor owing to wants or needs. For this purpose, we review 43 articles in this study. These articles are peer-reviewed publications on the causes of early school leaving or school dropout in Africa and Asia, from the year 2001 to present. Based on the findings, pull factors, push factors and falling out factors determine early school leaving. However, the pull factors show a very high prominence across Africa and Asia.
\end{abstract}


Systematic Review of the Literature on the Causes of Early School Leaving

\subsection{Introduction}

\subsubsection{Background}

Since the launch of the Millennium Development Goals (MDG), the universal primary school net enrolment ratio has increased from 84\% in 1999 to approximately 93\% in 2015 (EFA Global Monitoring Report, 2015). This indicates a decline in out-of-school children worldwide from 100 million in 2000 to 57 million in 2015. In developing nations, however, more than one in four children entering primary school is likely to drop out (United Nations, 2014). As observed by the United Nations, while children are increasingly obtaining primary education in developing nations, a large number of students drop out of primary and secondary education. Education is a key route to the development of a nation and it is a very vital input in fostering economic growth (Shi et al., 2015). A high dropout rate leaves a good number of people without adequate numeracy, literacy and cognitive skills.

Between 1999 and 2013, there has not been a general improvement in the reduction of the rate of early school leaving. Unfortunately, in primary education the rate was found to be higher in 2013 than in 1999, as illustrated in Figure 2.1. below. It actually ranged between $32 \%$ to $41 \%$ in Africa and $21 \%$ to $28 \%$ in Asia. Precisely, Figure 2.1. suggests that during this period the cumulative dropout rate in Africa was lowest in 2001 (32.8\%) and highest in 2007 (40.1\%). In Asia, it was lowest in 2001 (22.9\%) and highest in 2005 (28.4\%). The cumulative dropout rate is calculated by subtracting the survival rate from 100 at a given grade, while the survival rate is the percentage of a cohort of pupils enrolled in the first grade of a given educational cycle in a given school year (UNESCO Institute for Statistics, 2009). 
Figure 2.1.: Cumulative dropout rate to the last grade of primary education for Africa and Asia

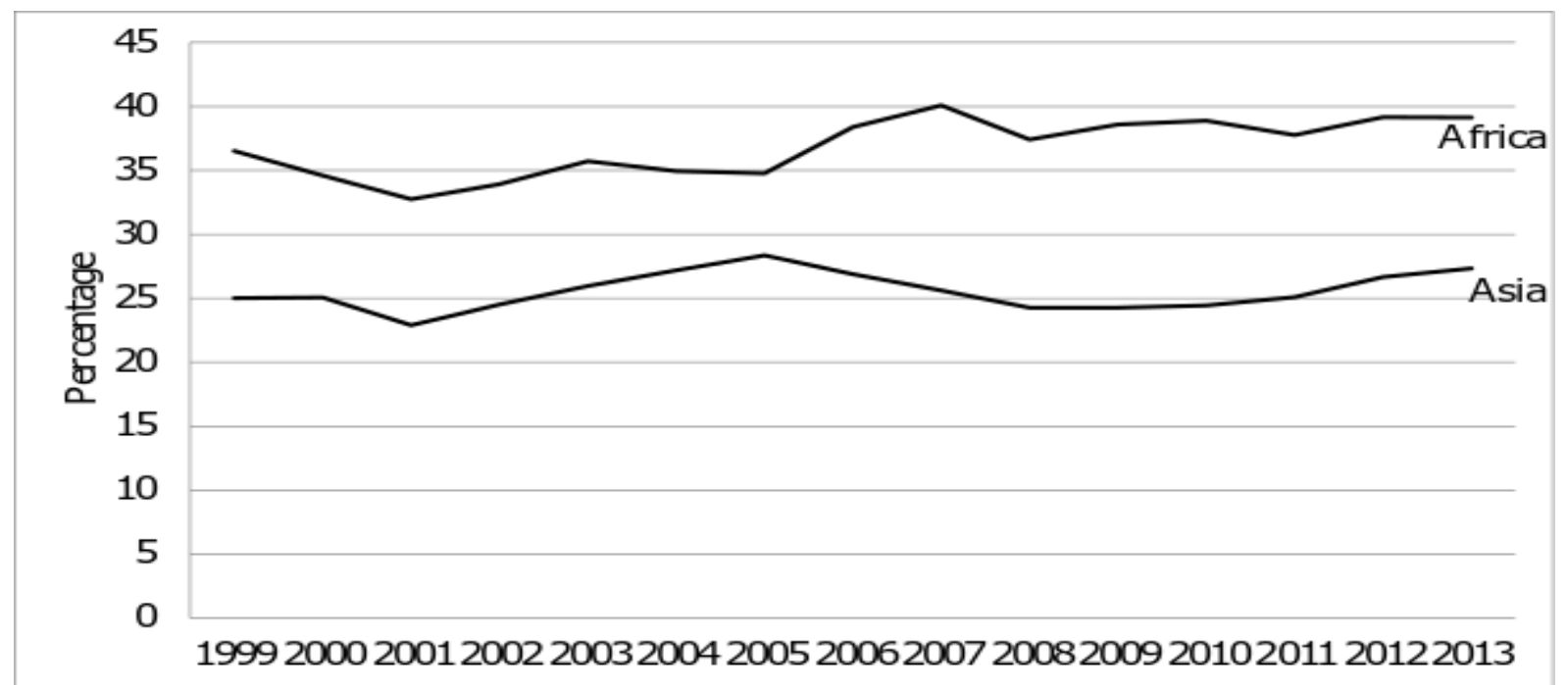

(Source: UNESCO Institute for Statistics, (2017))

This systematic literature review aims to examine the determinants of school dropout in Africa and Asia, to identify why some children are more likely to drop out of school than others, in countries where the economy is less developed. This is important to understand the underlying constraints in improving learning outcomes and grade advancement. That is, the necessity to observe the prolonged specific determinants of dropping out from school together, from several studies, amid the current global development efforts to improve educational attainment in these countries. Furthermore, understanding the specific factors enhancing early school leaving will contribute to the school dropout literature by shedding light on the problems currently pertinent to developing nations. This is critical for formulating and evaluating public and social policies by identifying intervention targets concerning students, families, institutions, environments, and minority or marginalised groups that may have been hidden to policy interventions. Pull, push, and falling out notations are included to the framework for understanding school dropout. As observed in Doll, Eslami and Walters (2013), pull, push, and fall out notations in school dropout are important in that they indicate the agent. While Doll, Eslami and Walters (2013) have investigated the prominence of these in a developed country setting, our study is the first to discern why students drop out such that they can be pulled, pushed, or fall out of school in Africa and Asia. 


\subsubsection{Definition}

'School dropout' or 'early school leaving' is a somewhat ambiguous concept as different countries attribute leaving school early to different years or stages of schooling. Consequently, the term is defined differently by different people (Tukundane, Minnaert, Zeelen \& Kanyandago, 2015). Definitions of school dropout include: a pupil who does not complete the final year of the educational level enrolled in (Braimah \& Oduro-Ofori, 2005); leaving school before completing a given grade in a given school year (Wegner, Flisher, Chikobvu, Lombard \& King, 2008); leaving school before completing primary education, completing primary education but not progressing to secondary grades, and leaving school before completing secondary grades (Biddlecom, Gregory, Lloyd \& Mensch, 2008); a pupil who enrols at the beginning of a school year and leaves before the end of the school year and does not enrol elsewhere (UNESCO Institute for Statistics, 2009); a pupil who starts education being over aged and who is prevented from completing due to repetition (Lewin \& Little, 2011); leaving school before the legal school-leaving age with no formal primary school qualification (Ananga, 2011); a student who is absent from school for at least one month, or who fails to take exams, or who is absent in the next year at the school (Manandhar \& Sthapit, 2012); leaving school before completing at least the final secondary grade (Mahlomaholo, 2012); no transition from primary or secondary school to higher education to obtain formal work qualifications (Tukundane et al., 2015); and a student who enrols into formal school but never completes or graduates with his/her cohort and never re-enrols into another school (Christian, 2015). We therefore acknowledge that there may be differences in the methods of calculation and classifications of early school leavers in the different countries (Lamb \& Markussen, 2011).

\subsection{Theoretical framework}

Early school leaving is considered as the last stage of a process of disengagement from school which occurs over time (Finn, 1989). These young people who leave school early are mostly from a disadvantaged background in society (Land \& Markussen, 2011). The process that results in withdrawal from school encompasses the outcome of the interactions within and between an individual and the surrounding environment (adapted from Bronfenbrenner (1977)'s ecological framework of human development). Bronfenbrenner (1977) assumed that understanding the reasons for leaving school early is equivalent to studying pupils' relations to one another and to their physical environment, thus the appellation 'ecological'. In the school dropout setting, there are three levels of this environment. These are family, school, and the community respectively, 
in terms of their closeness to the student (Abuya, Oketch \& Musyoka, 2013; Rumberger, 1995). Thus, understanding the reasons for leaving school early evolves around the profound understanding of characteristics and relationships of students and their family, school, and community (Abuya et al., 2013). By implication, dropout factors comprise four categories (or "levels"), namely: the student (individual)-level, the family-level, the school-level, and the community-level. Below, each category is discussed in more depth.

\subsubsection{Individual characteristics}

In understanding and explaining the process of dropout, the concepts of emotional, behavioural and cognitive engagement of students are central (Wang \& Fredricks, 2014). This is because they together capture thoughts, words and actions of students that determine their engagement in school. Additionally, the outcome of the interactions of students with their environment can substantially vary with respect to their contexts and characteristics (Bronfenbrenner, 1979). A student is emotionally engaged if he/she has the feeling of being a member of the school, enjoys learning, and sees the success from the learning outcome as valuable in life (Finn, 1989). Behavioural engagement is when a student participates in the academic activities (Fredricks, Blumenfeld \& Paris, 2004). Cognitive engagement, as defined by Pintrich and de Groot (1990), refers to learning out of self-regulation. According to Morrison, Robertson, Laurie and Kelly (2002), school disengagement has numerous elements including negative peer influence, disobedience, truancy and consequent dropout. Newcomb et al. (2002) suggest that illicit drug, alcohol and tobacco use by youths is one of the problem behaviours, and that this has a unique and consistent relationship with dropout.

Other effects like poor school performance, no educational aspirations, and exam failure can stem from the inability to emotionally, behaviourally and cognitively engage in school (Ream \& Rumberger, 2008; Skinner \& Pitzer, 2012). Many other reasons pertaining to pupils and students have been enlisted in the literature, some of which include over age, late school entry, gender, illness, exam failure, preference for wage labour, grade repetition, and poor nutritional status (Aloise-Young, 2002; Brown, 2010; Lloyd, Mensch \& Clark, 2000). Girls have been found to drop out of school more than boys (49\% for boys as compared to $66 \%$ for girls) in Pakistan (Holmes, 2003). In 2010 in Pakistan, the results of Farid-ul-Hasnain and Krantz showed a $51 \%$ dropout rate for girls and $43 \%$ for boys. In Nepal, however, the study of Manandhar and Sthapit (2012) found a 5.87\% dropout rate for girls and 6.14\% dropout rate for boys. 
The study of Smits and Huisman (2013) found dropout rates for 15 year-olds to be $65 \%$ for girls and $26 \%$ for boys in Yemen, 54\% for girls and 43\% for boys in Morocco, 50\% for girls and $49 \%$ for boys in Syria, 33\% for girls and 23\% for boys in Algeria, and 22\% for girls and 18\% for boys in Egypt. Equally in India, Siddhu (2011) found more girls (26\%) than boys (11.5\%) dropping out from school. In the context of the developing countries, the gender effect on school continuity is significant because there is in some areas the prevalence of certain cultural beliefs amongst which is the preference for one group of children, girls in most cases, to stay at home to do household work or get married while boys can go to school.

\subsubsection{Family characteristics}

According to Brown (2010), a greater share of the evidence as to why pupils and students regardless of gender leave school early has to do with difficult economic circumstances and the inability of families to invest in the education of their children. In other words, Diyu (2001) stated that most of the dropouts or children at risk of dropping out in developing countries are from less well-off families. This is a main characteristic of families of dropouts, alongside the size of the family, migration, family crisis, lack of family support and supervision with school work, and the education of the parents (Chernichovsky, 1985; Guryan, 2004; Thomas et al., 2004).

Parents' education and their influence on school discontinuity are rather contextual and different in some cases in the sense that they depend on the parent and gender of the child involved (Holmes, 2003). Other relevant family characteristics are religion and ethnicity. It is believed that in West Africa, most of the dropouts and unenrolled children come from predominantly Islamic groups (Bah-Lalya, 2015). Bah-Lalya (2015) asserted that this can be explained by the fact that traditional Islamic education is more widespread in rural African areas as compared to urban areas, while secular schools are distributed sparsely. Additionally, studies are done in the Arabic or local languages in the Islamic schools but in the secular school, studies are done in French or English. Students find it difficult to continue schooling at a level where the language of instruction is different from their mother tongue. The problems of religion and ethnicity in the realm of education stem from both beliefs and language, especially in areas of concentrated minority subpopulations (Lu et al., 2016). 


\subsubsection{School characteristics}

Some studies highlight school characteristics like school size and school quality, meanwhile others point at the experiences of students in school (Fortin, Marcotte, Diallo, Potvin \& Royer, 2013). In terms of school size, children were found to drop out more in large schools than in small schools (Werblow \& Duesbery, 2009). Quality-wise, students stay longer in high quality schools than in low quality schools (Hanushek, Lavy \& Hitomi, 2008). As suggested in Fortin et al. (2013), the climate of the classroom under which students study and the quality of the relationship they maintain with their teachers and peers are vital for their perseverance and achievement. It also plays an important role in their well-being emotionally and socially (Fredriksen \& Rhodes, 2004).

Therefore, conflicts and negative attitudes of teachers and peers, lack of classroom cooperation and order, and limited academic support are some of the trajectories linked to early school leaving (Anderson, Hamilton \& Hattie, 2004; Dorman, Fraser \& McRobbie, 1997). Apart from the relationship with teachers, teacher absenteeism is another way to demotivate students and develop a negative perception toward the academic environment (Diyu, 2001). Another school characteristic detrimental to school completion is the distance to school (Abuya et al., 2013). Lloyd, Mete and Sathar (2005) found that with the problem of distance, students waste much time commuting to school and therefore become exhausted.

\subsubsection{Community characteristics}

Rural areas are said to harbour more dropouts and unschooled children than urban areas because poverty and hardship are more prevalent in those areas, coupled with longer distances to school (Bah-Lalya, 2015). Other characteristics include the level of community development, and the distance to local economic activities and urban centres (Abuya et al., 2013). Tansel (2002) stated that school dropout is also influenced by the predominant activity carried out in a community. That is, in areas with industrial activities parents tend to educate their children to higher levels than where agriculture is predominant. Communities having low social security experience high dropout rates (Levy, 1971). Similar to insecurity, Staff and Kreager (2008) added that communities with high rates of anti-social behaviour and violence are prone to high dropout rates. There is also the claim that communities that provide employment opportunities help to increase the school incompletion rate (Tansel, 2002). The kind of school in the community plays a role in keeping children in school (Rumberger, 1995). For instance, attending a religious 
school compared to attending a public school. The findings of Rumberger (1995) showed that this was possible with non-Catholic religious schools because there, the students have more transfer alternatives. Rumberger (1995) also mentions the effect on school completion of the relationship maintained by students with their peers.

Generally, dropout causes can be pull, push, or falling out factors as described by Doll, Eslami and Walters (2013). Pull factors pull students to the point of leaving school, usually in the form of needs and wants external to the school. Push factors are internal to the school which push students away, and falling out factors neither arise from being pushed out nor due to wants or needs (Doll, Eslami \& Walters, 2013). For the purpose of discussion in this article, barriers to school discontinuity (school dropout causes) will be identified through the wide range of reasons why students leave school early, from differentiable categories. This is to provide a platform for identifying appropriate intervention strategies against factors that could be altered.

\subsection{Method}

\subsubsection{Information sources and eligibility criteria}

Five electronic databases (ERIC, PsycINFO, EconLit, SocINDEX, and Google Scholar) are searched. The search is limited to peer-reviewed publications from 2001 to 2016 to access most recent articles. It is also limited to work done on African and Asian countries for primary and secondary levels of education. The keywords used during the search include: 'school dropout', 'early school leaving', 'determinants of school dropout', and 'determinants of school attainment'. The initial search of ERIC, limiting the search to 'foreign' articles so as to eliminate articles written about early school leaving in the United States, yields 598 articles. Filtering through to identify non-English articles and those that were not done on Africa and Asia, as well as not focused on why students leave school early leads to the exclusion of 572 articles. Twentysix papers are thus considered. We acknowledge that the elimination of non-English articles may lead to the omission of key reports which could have influenced the conclusions drawn.

From PsycINFO, EconLit and SocINDEX, the initial search of the English academic journals yields a total of 1906 articles. Of these, 25 papers are retained after screening for Africa and Asia nations and causes of leaving school. Screening for article duplication results in 6 papers eligible for consideration. Google Scholar provides 1409 search results which are reduced to 35 after initial screening for criteria, and a total of 11 articles retained after duplicates are removed. This gives a final amount of 43 articles for the study, as indicated in Figure 2.2. that follows; 
Figure 2.2.: Flowchart of articles reviewed

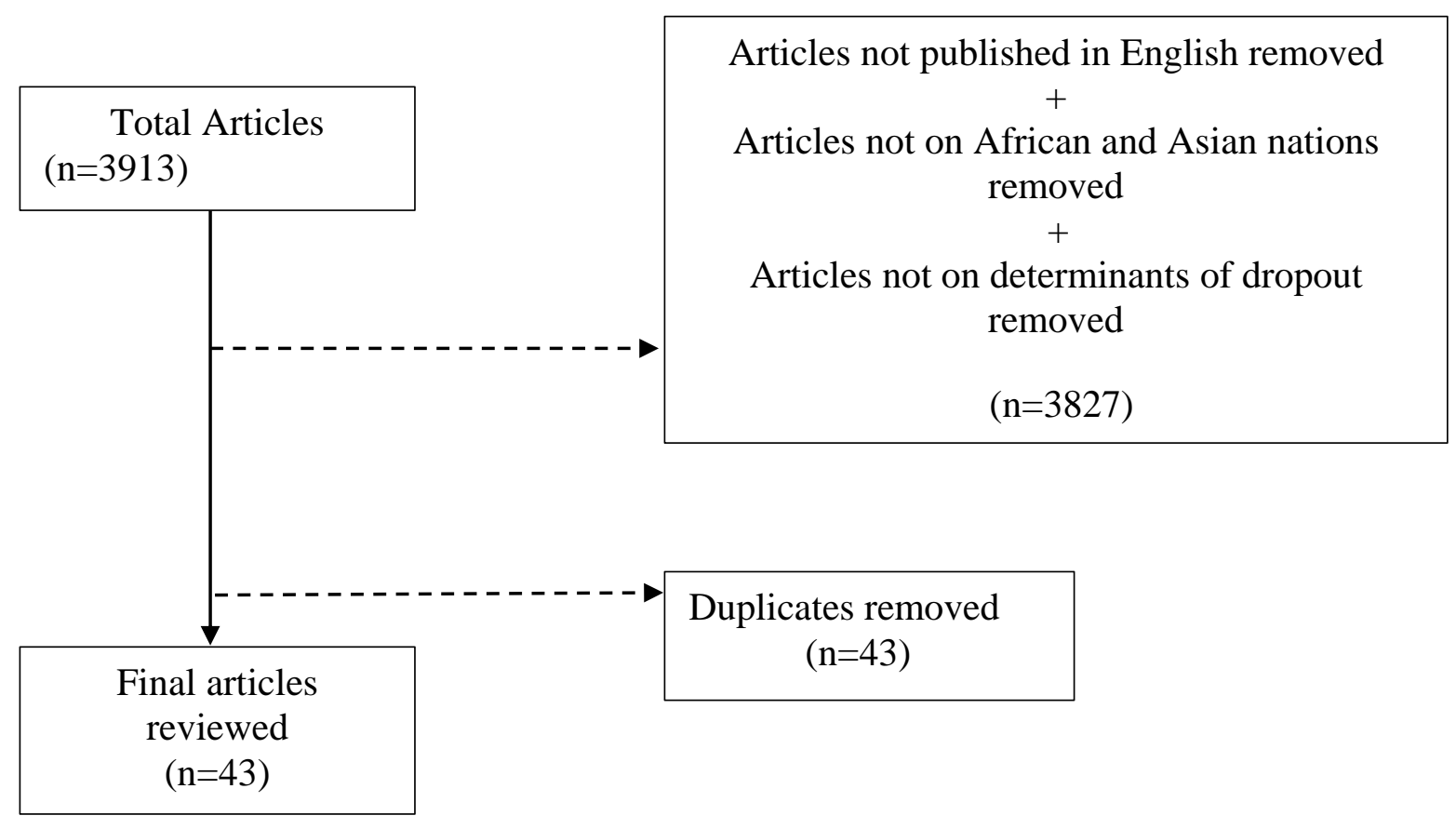

\subsubsection{The data types and analyses included in the review}

The data used in the quantitative and mixed studies include retrospective, two-wave prospective and longitudinal data. These were obtained from school documents, national and international organisations, questionnaires, focus-group discussion, and interviews. The studies with retrospective data applied logistic regression, descriptive statistics, analysis of variance, or linear regression. Two-wave prospective data studies mostly applied a logistic model or probit model. The longitudinal studies used logistic regression, and survival analysis methods such as the discrete-time logit model and the cox regression model. Narratives of participants' responses were used to analyse the data in the qualitative studies. The qualitative studies are important in this work as they enable gathering more in-depth information on the needs, desires, problems and circumstances of the subjects. The quantitative data on the other hand, enable access to a greater sample size and thus get access to much more general, though not in-depth, issues as compared to the qualitative data. The causes of early school leaving are similar in the various types of studies and the effects relate to Asian and African countries similarly. Section 2.4. summarises the results derived from the review. 


\subsection{Results}

\subsubsection{Presentation of results of quantitative, mixed, and qualitative studies}

In Table 2.1. below, the factors that are found to be significant are grouped into 7 main categories (family, environment, school, region of residence, work, culture, student), the influence (with the positive and negative notations indicating correlational relationship), and the articles in which these are observed. This is done for the quantitative and mixed methods studies. A positive notation denotes a positive relationship with dropout, that is higher values of the variable are associated with higher dropout, while a negative notation refers to an inverse relationship with dropout. We also include the authors of the articles where results pertain to. 
Table 2.1.: Significant Determinants of Early School Leaving.

\begin{tabular}{|c|c|c|}
\hline Factor & Influence & Study \\
\hline \multicolumn{3}{|l|}{ Student-related } \\
\hline \multirow[t]{2}{*}{ Advancement in age } & Positive & $\begin{array}{l}\text { Biddlecom et al. (2008); Farid-ul-Hasnain \& Krantz (2010); Flisher et al. (2010); Korinek \& } \\
\text { Punpuing (2012); Sabates et al. (2013); Siddhu (2011); Smits \& Huisman (2013); Yi et al. } \\
\text { (2012); Zuilkowski et al. (2016) }\end{array}$ \\
\hline & Negative & Zhao \& Glewwe (2010) \\
\hline Pre-marital sex & Positive & Biddlecom et al. (2008) \\
\hline Late school entry & Positive & No et al. (2012); No et al. (2016); Sabates et al. (2013) \\
\hline Absenteeism/irregular attendance & Positive & Flisher et al. (2010); No et al. (2016); Sabates et al. (2013); Siddhu (2011) \\
\hline Grade repetition & Positive & No et al. (2016); Sabates et al. (2013) \\
\hline Poor academic performance & Positive & $\begin{array}{l}\text { No et al. (2012); No et al. (2016); Sabates et al. (2013); Ud Din et al. (2011); Yi et al. (2012); } \\
\text { Zuilkowski et al. (2016) }\end{array}$ \\
\hline Exam failure & Positive & Mzuza, Yudong \& Kapute (2014); Wudu (2015); Ud Din et al. (2011); Zuilkowski et al. (2016) \\
\hline Substance use & Positive & Flisher et al. (2010) \\
\hline Lack of better nourishment & Positive & Sabates et al. (2013); Zhao \& Glewwe (2010) \\
\hline Not interested & Positive & No et al. (2016); Siddhu (2011); Wudu (2015); Ud Din et al. (2011) \\
\hline Early marriage & Positive & Farid-ul-Hasnain \& Krantz (2010) \\
\hline Not socializing with other students & Positive & No et al. (2012); No et al. (2016) \\
\hline Lack of self-esteem & Positive & No et al. (2012); No et al. (2016) \\
\hline Preschool or unofficial enrolment & Positive & No et al. (2016) \\
\hline Pregnancy & Positive & Lloyd et al. (2009) \\
\hline Truancy & Positive & Wudu (2015) \\
\hline Disability/ illness & Positive & Sabates et al. (2013); Wudu (2015); Yi et al. (2012) \\
\hline Recently finished primary education & Positive & Huisman \& Smits (2015) \\
\hline \multicolumn{3}{|l|}{ Family-related } \\
\hline Family is an immigrant household & Positive & Cemalcilar \& Goksen (2014); Farid-ul-Hasnain \& Krantz (2010); Korinek \& Punpuing (2012) \\
\hline Unawareness of importance of education & Positive & Banik \& Neogi (2015); Cemalcilar \& Goksen (2014); Ud Din et al. (2011) \\
\hline Family disputes & Positive & Wudu (2015) \\
\hline
\end{tabular}

Note: These factors are significant at $P<.05$, with most of them significant at $P<.001$ 
Table 2.1. (continues)

\begin{tabular}{|c|c|c|}
\hline Factors & Influence & Studies \\
\hline \multicolumn{3}{|l|}{ Family-related } \\
\hline Family member ill/disable/elderly & Positive & Wudu (2015) \\
\hline Father's education & Negative & $\begin{array}{l}\text { Biddlecom et al. (2008); Huisman \& Smits (2015); Korinek \& Punpuing (2012); No et al. } \\
\text { (2012); Shahidul (2013); Siddhu (2011); Smits \& Huisman (2013); Ud Din et al. (2011); Yi et } \\
\text { al. (2012); Zuilkowski et al. (2016) }\end{array}$ \\
\hline Mother's education & Negative & $\begin{array}{l}\text { Biddlecom et al. (2008); Cemalcilar \& Goksen (2014); Huisman \& Smits (2015); Lloyd et al. } \\
\text { (2009); No et al. (2012); Shahidul (2013); Siddhu (2011); Smits \& Huisman (2013); Zhao \& } \\
\text { Glewwe (2010); Ud Din et al. (2011); Zuilkowski et al. (2016) }\end{array}$ \\
\hline Father's employment status & Negative & $\begin{array}{l}\text { Cemalcilar \& Goksen (2014); Huisman \& Smits (2015); Korinek \& Punpuing (2012); Shahidul } \\
\text { (2013); Smits \& Huisman (2013) }\end{array}$ \\
\hline Mother's employment status & Negative & Sabates et al. (2013); Shahidul (2013) \\
\hline Father's age & Positive & Siddhu (2011) \\
\hline Poverty & Positive & $\begin{array}{l}\text { Banik \& Neogi (2015); Biddlecom et al. (2008); Farid-ul-Hasnain \& Krantz (2010); Flisher et } \\
\text { al. (2010); Huisman \& Smits (2015); Korinek \& Punpuing (2012); Lloyd et al. (2009); Sabates } \\
\text { et al. (2013); Shahidul (2013); Siddhu (2011); Smits \& Huisman (2013); Wudu (2015); Ud Din } \\
\text { et al. (2011); Yi et al. (2012); Zhao \& Glewwe (2010); Zuilkowski et al. (2016) }\end{array}$ \\
\hline Mother had first child under age 18 & Positive & Huisman \& Smits (2015); Smits \& Huisman (2013) \\
\hline Single father & Positive & $\begin{array}{l}\text { Biddlecom et al. (2008); Flisher et al. (2010); Huisman \& Smits (2015); Korinek \& Punpuing } \\
\text { (2012); No et al. (2012); No et al. (2016); Smits \& Huisman (2013) }\end{array}$ \\
\hline Single mother & Positive & $\begin{array}{l}\text { Flisher et al. (2010); Huisman \& Smits (2015); No et al. (2012); No et al. (2016); Sabates et al. } \\
\text { (2013); Smits \& Huisman (2013) }\end{array}$ \\
\hline Not biological child & Positive & Smits \& Huisman (2013); Huisman \& Smits (2015) \\
\hline Number of siblings & Positive & $\begin{array}{l}\text { Huisman \& Smits (2015); Korinek \& Punpuing (2012); Siddhu (2011); Smits \& Huisman } \\
\text { (2013); Yi et al. (2012) }\end{array}$ \\
\hline Birth order & Negative & Huisman \& Smits (2015); Smits \& Huisman (2013) \\
\hline Household debt & Negative & Korinek \& Punpuing (2012) \\
\hline Extended household & Positive & Farid-ul-Hasnain \& Krantz (2010) \\
\hline Extended household with grand parents & Negative & Huisman \& Smits (2015) \\
\hline Lack of parental care & Positive & Yi et al. (2012) \\
\hline
\end{tabular}


Table 2.1. (continues)

\begin{tabular}{|c|c|c|}
\hline Factors & Influence & Studies \\
\hline \multicolumn{3}{|l|}{ Work } \\
\hline Domestic and agricultural work & Positive & Banik \& Neogi (2015); Sabates et al. (2013); Wudu (2015) \\
\hline Wage labor & Positive & Cemalcilar \& Goksen (2014); Sabates et al. (2013); Wudu (2015) \\
\hline \multicolumn{3}{|l|}{ Culture } \\
\hline \multirow[t]{2}{*}{ Gender/female } & Positive & $\begin{array}{l}\text { Cemalcilar \& Goksen (2014); Huisman \& Smits (2015); Siddhu (2011); Smits \& Huisman } \\
\text { (2013); Shahidul (2013) }\end{array}$ \\
\hline & Negative & Flisher et al. (2010); Korinek \& Punpuing (2012); Sabates et al. (2013); Shahidul (2013) \\
\hline Religion/Muslim & Positive & Biddlecom et al. (2008); Siddhu (2011) \\
\hline Ethnicity & Positive & Lloyd et al. (2009); No et al. (2012); No et al. (2016) \\
\hline \multicolumn{3}{|l|}{ School-related } \\
\hline Inadequate school facilities/quality & Positive & Cemalcilar \& Goksen (2014); Huisman \& Smits (2015); Zhao \& Glewwe (2010) \\
\hline Unskilled teachers & Positive & No et al. (2012); Zhao \& Glewwe (2010) \\
\hline Unavailability of teachers & Positive & Huisman \& Smits (2015); No et al. (2012); Zhao \& Glewwe (2010) \\
\hline Conflict with teacher & Positive & Sabates et al. (2013); Ud Din et al. (2011) \\
\hline Leisure-boredom & Positive & Wegner et al. (2008) \\
\hline Inadequate assistance to students & Positive & Cemalcilar \& Goksen (2014); Sabates et al. (2013); Ud Din et al. (2011) \\
\hline School time not suitable & Positive & Banik \& Neogi (2015) \\
\hline Corporal punishment & Positive & Ud Din et al. (2011) \\
\hline Government versus private school & Positive & Lloyd et al. (2009) \\
\hline \multicolumn{3}{|l|}{ Environment } \\
\hline Bullying & Positive & Alika (2012) \\
\hline Employed adults with white-collar jobs & Negative & Huisman \& Smits (2015); Korinek \& Punpuing (2012) \\
\hline Average men with higher education & Negative & Smits \& Huisman (2013) \\
\hline Distance to school & Positive & Siddhu (2011); Wudu (2015); Zhao \& Glewwe (2010) \\
\hline Child dependency ratio & Negative & Sabates et al. (2013) \\
\hline Less developed community & Positive & Lloyd et al. (2009) \\
\hline Teacher resides in community & Negative & Lloyd et al. (2009) \\
\hline National GDP per capita & Negative & Huisman \& Smits (2015) \\
\hline \multicolumn{3}{|l|}{ Region of residence: $\mathrm{rural} / \mathrm{urban}$} \\
\hline Rural & Positive & $\begin{array}{l}\text { Biddlecom et al. (2008); Huisman \& Smits (2015); Korinek \& Punpuing (2012); Smits \& } \\
\text { Huisman (2013); Wudu (2015) }\end{array}$ \\
\hline
\end{tabular}


Supplementary Tables are presented separately, in the appendix. The appendices are numbered as A2.1., A2.2., and A2.3., for quantitative studies, mixed studies, and qualitative studies respectively. In these Tables, we include the general determinants (both significant and nonsignificant) of early school leaving in Africa and Asia.

\subsubsection{Importance of the significant factors relating to early school leaving}

We note in Table 2.2. below, the relative importance of the factors with respect to their possible association to early school leaving. This importance describes the negative impact of a factor in the lives of the pupils. The authors of the articles where results pertain to are put in bracket. 
Table 2.2.: Importance of the Significant Factors Relating to Early School Leaving.

\begin{tabular}{|c|c|c|}
\hline Factors & Type & Conditions susceptible to arise \\
\hline Advancement in age & Pull & $\begin{array}{l}\text { Feeling of alienation from a group of students (younger students in this case), attachment to the wrong group of } \\
\text { students (for instance, other older students who also feel detached from school or who may have dropped out from } \\
\text { school) (Flisher et al., 2010) } \\
\text { Social discomfort in being older than classmates (Siddhu, 2011) }\end{array}$ \\
\hline Immigrant household & Pull & $\begin{array}{l}\text { Financial constraints from physical separation of children from parents, limitations in accessing school facilities, } \\
\text { discrimination, cultural adaptation difficulties (Korinek \& Punpuing, 2012) } \\
\text { Difficulties adapting to foreign language (Cemalcilar \& Goksen, 2014) }\end{array}$ \\
\hline Poverty & Pull & $\begin{array}{l}\text { Children pressurised to look for means to contribute to the family income (Banik \& Neogi, 2015; Farid-ul-Hasnain \& } \\
\text { Krantz, 2010) } \\
\text { Males more likely to be pressurised to contribute to family income (Flisher et al., 2010) } \\
\text { Under-nutrition, poor health (Siddhu, 2011) } \\
\text { Irregular school attendance from being sent home for fees (Zuilkowski et al., 2016) } \\
\text { Risk of unwanted pregnancy for girls (Zuilkowski et al., 2016) } \\
\text { Limitation of ability to purchase educational materials (Huisman \& Smits, 2015; Wudu, 2015; Zhao \& Glewwe, 2010) }\end{array}$ \\
\hline Early marriage & Pull & Devote time to household work and childcare due to social and cultural opinions (Flisher et al., 2010) \\
\hline Single parent & Pull & $\begin{array}{l}\text { Financial difficulties (Flisher et al., 2010) } \\
\text { Being required to take up house work in replacement of missing parent (Smits \& Huisman, 2013) } \\
\text { Not open to better schooling opportunities and likely obliged to do wage labour (No et al., 2012) } \\
\text { Spend time helping at home (No et al., 2016) }\end{array}$ \\
\hline Rural residence & Pull & $\begin{array}{l}\text { Lack of schools labour market opportunities (Korinek \& Punpuing, 2012; Smits \& Huisman, 2013) } \\
\text { Weak influence of modern values (Smits \& Huisman, 2013) }\end{array}$ \\
\hline $\begin{array}{l}\text { Few adults with white- } \\
\text { collar jobs }\end{array}$ & Pull & Absence of future employment possibility guarantee (Korinek \& Punpuing, 2012) \\
\hline Grade repetition & Push & $\begin{array}{l}\text { Age-in-grade inappropriateness and over age alienation (Sabates et al., 2013) } \\
\text { Reduction of parental investment on education (No et al., 2016) }\end{array}$ \\
\hline Late school entry & Pull & $\begin{array}{l}\text { Feeling of ge-in-grade inappropriateness and over age alienation (Sabates et al., 2013) } \\
\text { Develops less interest and preference for opportunity cost of schooling (No et al., 2016) }\end{array}$ \\
\hline $\begin{array}{l}\text { Preschool or unofficial } \\
\text { enrolment }\end{array}$ & Push & Self-alienation from officially enrolled students (No et al., 2016) \\
\hline $\begin{array}{l}\text { Parental unawareness of } \\
\text { importance of education }\end{array}$ & Fall & Determines whether children stay in school or not, unable to provide academic support to children \\
\hline
\end{tabular}


Table 2.2. (continues)

\begin{tabular}{|c|c|c|}
\hline Factors & Type & Conditions susceptible to arise \\
\hline Gender/female & Pull & $\begin{array}{l}\text { Social and cultural beliefs that females do not need education, rather marriage (Sabates et al., 2013; Siddhu, } \\
\text { 2011; Smits \& Huisman, 2013) } \\
\text { Face high social risk and limited job opportunities (Cemalcilar \& Goksen, 2014) }\end{array}$ \\
\hline Number of siblings & Pull & $\begin{array}{l}\text { Decision on not educating some school-age children due to financial difficulties (Siddhu, 2011; Smits \& } \\
\text { Huisman, 2013) }\end{array}$ \\
\hline Birth order & Pull & Preference given to older born (Smits \& Huisman, 2013) \\
\hline Religion/Muslim & Pull & More restrictions for females in public (Siddhu, 2011) \\
\hline Poor academic performance & Push & $\begin{array}{l}\text { Feeling deprived, discouraged, alienated from the system of education (Yi et al., 2012) } \\
\text { Corporal punishment (Zuilkowski et al., 2016) } \\
\text { Reduces parental investment on education (No et al., 2012; No et al., 2016) }\end{array}$ \\
\hline Not interested & Fall & Develop preference for wage labour (Sabates et al., 2013) \\
\hline Less educated father & Pull & $\begin{array}{l}\text { Unable to provide assistance to children on school work (Biddlecom et al., 2008; Huisman \& Smits, 2015; } \\
\text { No et al., 2012) }\end{array}$ \\
\hline Less educated mother & Pull & $\begin{array}{l}\text { Unable to provide assistance to children on school work (Biddlecom et al., 2008; Cemalcilar \& Goksen, 2014; } \\
\text { Huisman \& Smits, 2015; No et al., 2012; Zhao \& Glewwe, 2010; Zuilkowski et al., 2016) }\end{array}$ \\
\hline Disability/illness & Pull & $\begin{array}{l}\text { Probability of being excluded from the educational system (Sabates et al., 2013) } \\
\text { Irregular attendance (Wudu, 2015) }\end{array}$ \\
\hline Lack of better nourishment & Pull & May jeopardize educational access and educational attainment (Sabates et al., 2013) \\
\hline Long distance to school & Push & $\begin{array}{l}\text { Insecurity for girls (Siddhu, 2011) } \\
\text { Community places less value on education (Zhao \& Glewwe, 2010) }\end{array}$ \\
\hline Inadequate school facilities/quality & Push & Reduces student learning (Cemalcilar \& Goksen, 2014; Zhao \& Glewwe, 2010) \\
\hline Unskilled teachers & Push & Impact less knowledge in students (Zhao \& Glewwe, 2010) \\
\hline Unavailability of teachers & Push & $\begin{array}{l}\text { Reduces student learning ((No et al., 2012; Zhao \& Glewwe, 2010) } \\
\text { High work load for teachers thereby reducing their quality teaching (No et al., 2012) }\end{array}$ \\
\hline Not socializing with other students & Pull & $\begin{array}{l}\text { Lack of motivated by finding schooling experience boring, not enjoyable and not fear-free (No et al., 2012; } \\
\text { No et al., 2016) }\end{array}$ \\
\hline Lack of self-esteem & Pull & Low academic performance (No et al., 2012; No et al., 2016) \\
\hline Ethnicity & Pull & $\begin{array}{l}\text { Speak local languages, thus have difficulties with official language at school, poor academic performance (No } \\
\text { et al., 2012; No et al., 2016) }\end{array}$ \\
\hline Absenteeism/irregular attendance & Push & Poor performance and achievement ((No et al., 2016; Sabates et al., 2013; Zuilkowski et al., 2016) \\
\hline
\end{tabular}


Table 2.2. (continues)

\begin{tabular}{|c|c|c|}
\hline Factors & Type & Conditions susceptible to arise \\
\hline Domestic and agricultural work & Pull & Irregular attendance (Banik \& Neogi, 2015) \\
\hline $\begin{array}{l}\text { Unawareness of importance of } \\
\text { education }\end{array}$ & Fall & $\begin{array}{l}\text { Parents prefer to send children to do wage labour, farm and domestic work (Banik \& Neogi, 2015) } \\
\text { Negatively affects investment on education (Cemalcilar \& Goksen, 2014) }\end{array}$ \\
\hline School time not suitable & Push & Irregular attendance (Banik \& Neogi, 2015) \\
\hline Pre-marital sex & Pull & Promise of marriage that could hasten school dropout, unwanted pregnancy (Biddlecom et al., 2008) \\
\hline Substance/drug use & Pull & Psychopathology (Flisher et al., 2010) \\
\hline Father's employment status & Pull & Children obliged to work and contribute to family income (Cemalcilar \& Goksen, 2014) \\
\hline Truancy & Pull & Less interested in schooling (Wudu, 2015) \\
\hline Family member disable/ill & Pull & $\begin{array}{l}\text { Obliged to get employment to cater for sick or disabled parent (Yi et al., 2012) } \\
\text { Absenteeism to cater for ill family member (Wudu, 2015) }\end{array}$ \\
\hline Exam failure & Push & Negative attitude towards school (Mzuza, Yudong \& Kapute, 2014; Wudu, 2015; Zuilkowski et al., 2016) \\
\hline $\begin{array}{l}\text { Leisure-boredom (no extracurricular } \\
\text { sport and leisure activities at school) }\end{array}$ & Push & Perceive school as being a boring place (Wegner et al., 2008) \\
\hline Work & Pull & Absenteeism (Sabates et al., 2013) \\
\hline Inadequate assistance to students & Push & $\begin{array}{l}\text { Poor academic performance (Cemalcilar \& Goksen, 2014; Sabates et al., 2013; Yi et al., 2012) } \\
\text { School absenteeism (Sabates et al., 2013) }\end{array}$ \\
\hline
\end{tabular}




\subsection{Analysis}

This section discusses the various factors found to correlate with early school leaving, as well as the studies and the countries concerned.

\subsubsection{Student}

The impact of age is that as children grow older or as they go further in grade, they become more likely to drop out (Ampiah \& Adu-Yeboah, 2009; Biddlecom et al., 2008; Huisman \& Smits, 2015; Smits \& Huisman, 2013; Yi et al., 2012; Zuilkowski, Jukes \& Dubeck, 2016) (Ghana, Burkina Faso, Malawi, Uganda, 30 developing countries (Bolivia, Colombia, Peru, Benin, Cameroon, Ghana, Guinea, Mali, Nigeria, Senegal, Kenya, Rwanda, Uganda, Congo Brazzaville, Madagascar, Malawi, Mozambique, Namibia, South Africa, Tanzania, Zambia, Algeria, Morocco, Syria, Yemen, Bangladesh, India, Indonesia, Nepal, Philippines), Algeria, Egypt, Morocco, Syria, Tunisia, Yemen, China, Kenya). Another effect of age as observed in Manandhar and Sthapit (2012) in Nepal is when a student is 'over age'. Over age students are children older than their classmates of the official age for the grade (Siddhu, 2011). Over age could come as a result of repetition, late school entry, as well as quitting school for some years and return later (Flisher, Townsend, Chikobvu, Lombard \& King, 2010; No, Taniguchi \& Hirakawa, 2016; Zuilkowski et al., 2016) (South Africa, Cambodia, Kenya).

Many school-aged children, as observed by No, Sam and Hirakawa (2012) in Cambodia, start school late because their parents allow them to become old enough to be able to take care of themselves. This means that they do not enrol in school at the official school enrolment age but rather at ages older than the official age, when their parents think it is safe for them to go to school. The negative effect from over age has been shown to increase at higher grade levels (Sabates, Hossain \& Lewin, 2013) (Bangladesh). Completely dropping out of school for over age students may occur because of the influence of other over age dropouts, and school disassociation due to alienation from younger classmates (Flisher et al., 2010) (South Africa).

Underage (unofficial enrolment) is a strong causative factor of dropout (No et al., 2016) (Cambodia). They explain that parents prefer to send their children to school once they are five years old regardless of the official school enrolment age because they are more troublesome when they stay at home. With regards to irregular attendance and absenteeism, the more students are absent from school the higher the odds of leaving school (Flisher et al., 2010; No et al., 2016; Sabates et al., 2013; Tas, Bora, Selvitopu \& Demirkaya, 2013) (South Africa, Cambodia, 
Bangladesh, Turkey). Other reasons for absenting from school is lack of interest in schooling, exam failure, early marriage, pregnancy, illness, truancy, pre-marital sex, lack of self-esteem, not being sociable, poor academic performance, grade repetition, and substance use (Biddlecom et al., 2008; Farid-ul-Hasnain \& Krantz, 2010; Igboanusi, 2014; Lloyd, Mete \& Grant, 2009; No et al., 2016; Polat, 2014; Sabates et al., 2013; Wudu, 2015; Tas et al., 2013; Yi et al., 2012; Zuilkowski et al., 2016) (Ghana, Burkina Faso, Malawi, Uganda, Gambia, Pakistan, Cambodia, Turkey, Bangladesh, Ethiopia, Turkey).

Good student-to-student relationships help students stay in school. Sometimes this relationship is not cultivated because of fear, insecurity, boredom, and intimidation (Abuya et al., 2013; No et al., 2012; Sahin, Arseven \& Kılıç, 2016) (Kenya, Cambodia, Turkey). In some cases, students do not willingly pull out but do so because of their parents. For example, No et al. (2016) (Cambodia) explained that while high ranking students continue to receive investment from their parents because of the prospect of future economic benefits, poor performing students tend to be considered as non-productive and will not obtain significant returns. Thus, their parents do not invest in them. Disability is a disadvantage as disability is linked to educational exclusion because guardians of disabled students perceive them as not having potential (Sabates et al., 2013) (Bangladesh). School dropout is also frequent among students who just completed primary school (Huisman \& Smits, 2015) (30 developing countries). Once children complete primary school some of them decide to leave at that stage and some are withdrawn by their parents, probably because they believe that further learning is not important.

\subsubsection{Work}

During the harvest season, children absent themselves because they have to join their parents in the farms to harvest as well as to sell (Ampiah \& Adu-Yeboah, 2009; Ananga, 2011; Abhisek \& Soumendu, 2014; Sarker \& Davey, 2009; Wudu, 2015) (Ghana, India, Bangladesh, Ethiopia, Bangladesh, Ethiopia). They are also required to work at home sometimes (Abuya, Onsomu \& Moore, 2014; Banik \& Neogi, 2015; Abhisek \& Soumendu, 2014; Mahlomaholo, 2012; Sahin et al., 2016; Smits \& Huisman, 2013; Wudu, 2015) (Kenya, India, South Africa, Turkey, Algeria, Egypt, Morocco, Syria, Tunisia, Yemen, Ethiopia). It is also common for students to be sent to do wage work to support the family financially (Abuya et al., 2013; Farid-ul-Hasnain \& Krantz, 2010; Flisher et al., 2010; Mokibelo, 2014) (Kenya, Pakistan, South Africa, Botswana). Because guardians need to bring up their own children, they sometimes send non- 
biological children to do wage labour to reduce the financial burden (No et al., 2012) (Cambodia).

Students also stay at home to take care of the sick, disabled or elderly family members (Wudu, 2015) (Ethiopia). In some cases, the youths willingly leave school to join the world of work because they have no interest in studying (Mahlomaholo, 2012; Siddhu, 2011; Tukundane, Zeelen, Minnaert \& Kanyandago, 2014) (South Africa, India, Uganda). Sabates et al. (2013) note that students spend more time working rather than learning because their parents are not educated and do not see the leverage in letting children learn more. In this case, they do not receive parental assistance on school work. The pressure to do housework is more felt by the girls (Cemalcilar \& Goken, 2014; Farid-ul-Hasnain \& Krantz, 2010; Manandhar \& Sthapit, 2012) (Turkey, Pakistan, Nepal).

\subsubsection{Family}

Shahidul (2013) demonstrated how parental participation in household decision making affect their child's schooling in Bangladesh. Proxies to participation are education and income level. In other words, the parent with the highest level of education and who earns more money has more of the bargaining power in decision making. Differences lie at the level of the child's gender, where preference is given to the male child. Besides this preference, the effect is more prevalent among self-employed parents than among parents who are in paid employment (Shahidul, 2013). On the other hand, educated mothers show no preference and consider the education of both genders very important (Cemalcilar \& Goken, 2014; Shahidul, 2013) (Turkey, Bangladesh).

Zhao and Glewwe (2010) in China find mother's education significantly impacting the children's years of schooling positively. This finding is consistent with that of Lloyd et al. (2009) in Pakistan. Nevertheless, in most studies, it was found that if the father or the mother did at least have some primary or secondary education, all the children were liable to stay in school, as the parents then better understand the importance of learning (Biddlecom et al., 2008; Huisman \& Smits, 2015; Korinek \& Punpuing, 2012; No et al., 2012; Smits \& Huisman, 2013; Sahin et al., 2016; Siddhu, 2011; Yi et al., 2012; Zuilkowski et al., 2016) (Burkina Faso, Ghana, Malawi, Uganda, Algeria, Egypt, Morocco, Syria, Tunisia, Yemen, 30 developing countries, Thailand, Cambodia, Turkey, India, China, Kenya) . 
In terms of occupation, children from agricultural households tend to leave school more often. But if the father's occupation is not in agriculture and especially if it's upper non-farm (white collar), children tend to stay in school more often (Cemalcilar \& Goken, 2014; Smits \& Huisman, 2013) (Turkey, Algeria, Egypt, Morocco, Syria, Tunisia, Yemen). Similarly, as suggested in Korinek and Punpuing (2012) (Thailand) school attrition is significantly lower for children whose parents are employed in entrepreneurial, clerical, managerial, sales, professional, and service sectors as compared to those with parents employed in agriculture.

Birth order and the number of siblings also have a significant impact on grade enrolment (Abuya et al., 2014; Huisman \& Smits, 2015; Korinek \& Punpuing, 2012; Smits \& Huisman, 2013; Siddhu, 2011; Yi et al., 2012) (Kenya, 30 developing countries, Thailand, Algeria, Egypt, Morocco, Syria, Tunisia, Yemen, India, China). In decisions regarding entering school, preference is given to earlier born children, as shown in the study by Smits and Huisman (2013) (Algeria, Egypt, Morocco, Syria, Tunisia, Yemen). There are nonetheless other family factors such as single parent, non-biological child, no parental care, aged father, parental migration, family dispute, presence of extended family, and when mothers gave birth too young, that facilitate dropout (Ananga, 2011; Biddlecom et al., 2008; Farid-ul-Hasnain \& Krantz, 2010; Huisman \& Smits, 2015; Korinek \& Punpuing, 2012; No et al., 2012; No et al., 2016; Sahin et al., 2016; Siddhu, 2011; Wudu, 2015; Yi et al., 2012). (Ghana, Burkina Faso, Malawi, Uganda, Pakistan, 30 developing countries, Thailand, Cambodia, Turkey, India, Ethiopia, China). Singleparent households or orphans generally have fewer opportunities or chances to study than children with both parents alive and present. This notion is similar for children living with parents who are not their biological parents, as observed in Nepal by Manandhar and Sthapit (2012). For non-biological children in Cambodia, their guardians in most cases have their own children to send to school and to reduce the financial burden may decide to enrol only their own children (No et al., 2012).

African and Asian countries have a higher rate of households with a very low socioeconomic status as opposed to developed countries. For instance, in African and Asian countries it is very common to live in a household without amenities like television, electricity, running water, toilet facilities, computer, telephones, fridge, and vehicle (Farid-ul-Hasnain \& Krantz, 2010; Flisher et al., 2010; Smits \& Huisman, 2013) (Pakistan, South Africa, Algeria, Egypt, Morocco, Syria, Tunisia, Yemen), which may add to a disadvantaged learning environment. Generally, parents may be willing to send their children to school but cannot do so due to the inability to pay school fees, buy school materials or provide for children's safety (Banik \& Neogi, 2015; Biddlecom et 
al., 2008; Flisher et al., 2010; Huisman \& Smits, 2015; Korinek \& Punpuing, 2012; Polat, 2014; Sabates et al., 2013; Shahidul 2013; Siddhu, 2011; Smits \& Huisman, 2013; Yi et al., 2012; Zhao \& Glewwe, 2010; Zuilkowski et al., 2016) (India, Ghana, Burkina Faso, Malawi, Uganda, South Africa, 30 developing countries, Thailand, Turkey, Bangladesh, Algeria, Egypt, Morocco, Syria, Tunisia, Yemen, China, Kenya).

Some parents lack awareness of the importance of education, leading them to withdraw children from school (Banik \& Neogi, 2015; Cemalcilar \& Goksen, 2014; Ud Din, Dad, Iqbal, Ali Shah $\&$ Niazi, 2011) (India, Turkey, Pakistan). The analysis of Banik and Neogi (2015) in India showed that these parents consider education as a waste of money which may make them go hungry. Dropout is also prevalent among immigrant households, as observed in Turkey, Pakistan and Thailand (Cemalcilar \& Goksen, 2014; Farid-ul-Hasnain \& Krantz, 2010; Korinek $\&$ Punpuing, 2012). According to them, difficulties faced by migrants as a result of migration which hamper the children's schooling include difficulty in adapting to a different culture or ethnic background, absence of citizenship rights, discrimination and marginalization, and foreign language communication difficulty.

\subsubsection{Culture}

Cultural restrictions on gender, which are more prevalent in rural areas, show a preference for boys' education than girls (Abuya et al., 2014; Ampiah \& Adu-Yeboah, 2009; Biddlecom et al., 2008; Sahin et al., 2016; Smits \& Huisman, 2013; Tukundane et al., 2014) (Kenya, Ghana, Burkina Faso, Malawi, Uganda, Turkey, Algeria, Egypt, Morocco, Syria, Tunisia, Yemen). Since marriage is the ultimate goal for girls in these societies, high education levels are not deemed necessary, so they are being kept close to home (Sahin et al., 2016; Siddhu, 2011) (Turkey, India). In traditional families, marriage is arranged for the girls by the families. Children born in such new homes with a traditional mother who was married off early are negatively affected in the sense that they risk not going to school too. Boys are reckoned to take care of their parents in old age and thus investment in boys is more substantial (Shahidul, 2013; Smits \& Huisman, 2013) (Bangladesh, Algeria, Egypt, Morocco, Syria, Tunisia, Yemen).

Manandhar and Sthapit (2012) observed another form of gender bias in Nepal where more boys are enrolled in private schools than government schools while girls are rather enrolled in government schools. In a private school parents pay admission and examination fees, while this is free in the government school. But the private school is advantageous in that children get 
more individual care and attention (Manandhar \& Sthapit, 2012). The findings of Korinek and Punpuing (2012) in Thailand revealed that girls are however, more favored than boys because they are deemed reliable in providing greater and more certain returns. This is observed in regions where factory production jobs are dominant.

The problem of ethnicity lies at the level of languages, given that the different ethnic groups may have different local languages. For example, when children study in their local language in the first few years, transitioning to further studies in schools in which the official language is different from what they speak is cumbersome and they tend to perform poorly (Abhisek \& Soumendu, 2014; Igboanusi, 2014; No et al., 2012; No et al., 2016; Sarker \& Davey, 2009) (India, Gambia, Cambodia, Bangladesh). Being part of a disadvantaged minority as observed in India and Bangladesh is also a factor observed in terms of religion (Abhisek \& Soumendu, 2014; Sarker \& Davey, 2009). In two of such studies carried out in Ghana, Burkina Faso, Malawi, Uganda and India, the minority religion that was noted is Islam (Biddlecom et al., 2008; Siddhu, 2011). Muslim children were seen to drop out more than others and this is even more prevalent among girls.

\subsubsection{School}

Wegner et al. (2008) found leisure boredom as one of the quality weakness aspects of schools that make students disconnect themselves to the point of departing in South Africa. Students may feel bored because of lack of recreational, sports and leisure activities for their prosocial development. Other school provisions such as inadequate and low-quality facilities, less qualified teachers, and unavailability of teachers deter students from staying in school (Abhisek \& Soumendu, 2014; Cemalcilar \& Goken, 2014; Chung \& Mason, 2012; Edwards, Zimmermann, Sitha, Williams \& Kitamura, 2014; Huisman \& Smits, 2015; Zhao \& Glewwe, 2010) (India, Turkey, China, Cambodia, 30 developing countries). In Cambodia, No et al. (2012) showed that trained teachers improve their students' experience and performances due to the better and effective methods of teaching they use. This notion is consistent with the conclusions in the study by Zhao and Glewwe (2010) in China.

However, teaching performance is also affected by the shortage of teaching staff. The few available teachers are usually required to teach in both the morning and afternoon shifts which leads to exhaustion. This tends to negatively affect the learning experiences and performance of students, and consequently increases the dropout risk (No et al., 2012) (Cambodia). Evidence 
from Kenya, Turkey, Cambodia and Pakistan also suggests that school work assistance to students tends to enhance their performance (Abuya et al., 2013; Cemalcilar \& Goken, 2014; Edwards et al., 2014; Ud Din et al., 2011). Students who receive feedback on school work from their teachers performed well and stayed in school. In the analyses of Abhisek and Soumendu (2014) and Sabates et al. (2013) in India and Bangladesh respectively, this implies that students may lose interest in school due to the absence of interaction in teaching and learning. Corporal punishment too can initiate early school leaving. Some students leave school for fear of the kind of punishment they are due to receive (Ampiah \& Adu-Yeboah, 2009; Huisman \& Smits, 2015; Makwinja-Morara, 2009; Tukundane et al., 2014) (Ghana, 30 developing countries, Botswana, Uganda). In rural Pakistan, government schools have a higher dropout rate because they are of lesser quality, as compared to private schools (Lloyd et al., 2009).

\subsubsection{Environment}

Huisman and Smits (2015) showed that dropout is less in communities where there are more adults with higher education and white-collar jobs in 30 developing countries. The result is consistent with that of Korinek and Punpuing (2012) in Thailand, who confirmed that the odds of deserting school are relatively lower in areas with a large proportion of adults employed in managerial, professional, and clerical positions, and a relatively smaller proportion engaged in agriculture. In other words, the engagement of the larger population in agriculture in rural regions provides no incentives for investment in children's education given the absence of future employment possibilities (Edwards et al., 2014; Mahlomaholo, 2012; Mokibelo, 2014; Tukundane et al., 2014) (Cambodia, South Africa, Botswana, Uganda). This boils down to the assertion by Chung and Mason (2012) and Lloyd et al. (2009) in China and Pakistan respectively, that development in a community is a statistically significant and important factor in reducing the odds of dropout.

Another aspect is bullying. Students facing the challenges of bullying from others around them are at risk of deserting school. From studies in Nigeria, Alika (2012) reported that the rate of dropout was high among students who were experiencing bullying. According to his explanation, this could be as a result of anxiety, frustration, depression and fear that emerged from bullying. Years of schooling is also reduced by the distance between a child's home and the school (Makwinja-Morara, 2009; Mahlomaholo, 2012; Manandhar \& Sthapit, 2012; Siddhu, 2011; Wudu, 2015; Zhao \& Glewwe, 2010) (Botswana, South Africa, Nepal, India, Ethiopia, China). That is, the further the distance to school, the quicker a learner will leave school. This 
is more pronounced for girls. In research carried out in India and Turkey by Siddhu (2011) and Tas et al. (2013) respectively, results suggested that there is fear for girls' safety generally when they leave home for school. This situation is heightened where school distances are greater.

\subsubsection{Region of residence}

The effect of this factor can be more felt by children living in the rural areas (Biddlecom et al., 2008; Smits \& Huisman, 2013; Wudu, 2015) (Burkina Faso, Ghana, Malawi, Uganda, Algeria, Egypt, Morocco, Syria, Tunisia, Yemen, Ethiopia). In Thailand for example, the urban areas provide certain enrolment advantages such as the household and community structural factors as compared to the rural areas (Korinek \& Punpuing, 2012). This includes differences in the wealth of households, as well as the differences in the labor market structure. Agriculture predominates in the rural economy and school attrition tends to be higher, as observed by (Siddhu, 2011) in India. Coupled with the problem of school unavailability, girls in the study of the 30 developing countries in Huisman and Smits (2015) are less likely to attend school in rural areas in the absence of female teachers. In other words, the presence of more female teachers reduces children's probability to quit school.

\subsubsection{Differences between Africa and Asia}

There are some differences between Africa and Asia in the determinants of dropout. The first determinant of dropout that showed a difference in both the quantitative and qualitative studies is migration. Migration was shown to be a problem mostly in Asia, and was significant in Turkey, Pakistan and Thailand (Cemalcilar \& Goksen, 2014; Farid-ul-Hasnain \& Krantz, 2010; Korinek \& Punpuing, 2012). Secondly, ethnicity was another determinant of dropout that showed a difference. Ethnicity was found to be a significant problem only in Pakistan and Cambodia (Lloyd et al., 2009; No et al., 2012; No et al., 2016).

\subsubsection{The school dropout paradigm}

The preceding examination of school dropout provides some distinguishable characteristics stemming from individuals and surroundings, where early school leaving altogether is the utmost. Dimensions that can be identified can be directly manipulated to facilitate targeted intervention designs, as shown in Figure 2.3. that follows; 
Figure 2.3.: Framework for school dropout

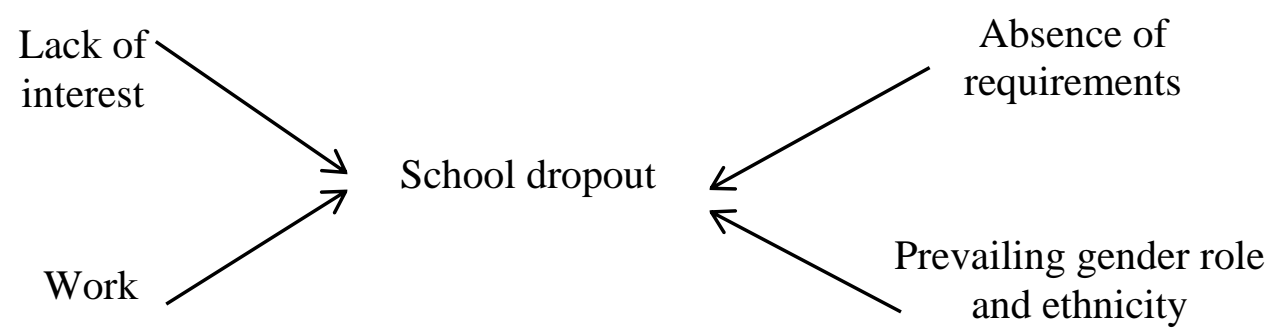

Lack of interest: In normal circumstances, the effects of having less interest in studying is evident as we observe for instance from reasons such as truancy, drug use and preference for wage labour. The need to disengage from school also develops due to lack of self-esteem, early marriage, poor academic performance, examination failure, relationships with opposite sex, age at school, unsociability and conflict at school.

Absence of requirements: It is observed in the majority of the studies that lack of financial means is a huge obstacle to school completion. In detail, this is brought about mostly by limited household wealth. It is also as a result of deteriorated family situations such as illness, disability, parental absence or divorce, migration, death, non-biological household members, and an increase in household members. Besides financial resources, some poorer areas are reported to have no available schools for students, inadequate school facilities and assistance or encouragement from school and family. Additionally, the problem of underdeveloped communities poses threats such as a lack of transportation, very far distance to school, and inappropriate language of instruction and textbook content. For instance, textbooks' contents can be contextualised meaningfully only in the urban environment which has got the facilities and thus, not known to rural pupils. Examples of such facilities include constructions and equipment like playground, supermarket, subway, city centre, park, tower block, and libraries common to mainly urban areas in the community (Chung \& Mason, 2012).

Work: Besides personal preferences for wage labour, students engage themselves in wage labour because of demands from the family, where they work to assist in financial supplies. The demand for labour is also due to farming and housework. These activities keep students away from school, the contexts in which some studies mention irregular attendance and seasonal withdrawal as consequences, and eventual school dropout.

Prevailing gender role and ethnicity: On the one hand, there is the problem of some parents not being inclined to send their girl child to school. On the other hand, gender bias is a form of 
cultural restriction where girls are generally not supposed to go to school, for other options such as housework and early marriage. Furthermore, the existence of numerous ethnic groups can lead to disadvantageous segregation where some groups become disadvantaged minorities as a consequence of their language or religion. To that effect, most of their children drop out of school.

\subsection{Conclusion and policy implications}

Based on the systematic review of the literature, we can conclude that pull factors, push factors and falling out factors determine early school leaving. However, the pull factors show a very high prominence across Africa and Asia. This finding is similar to that of Doll, Eslami and Walters (2013). These pull factors include gender, religion, ethnicity, house work, wage labor, farming, region of residence, ill health, truancy, disability, pregnancy, marriage, age, no selfesteem, late school entry, pre-marital sex, substance use, family-related factors, and environmental factors. The factors which push students away in these findings are inadequate school facilities and quality, unavailable and unskilled teachers, student-teacher conflict, inadequate student assistance, no leisure activities, unsuitable school time, corporal punishment, exam failure, school distance, absenteeism, grade repetition, poor academic performance, and unofficial enrolment. The falling out factors are lack of interest, and unawareness of importance of education.

The results suggest that the problem of dropout is multi-perspective (individual and institutional) in both Asia and Africa, involving a variety of factors which require targeting in order to encourage students to stay in school. The institutional perspective involves dropout determinants associated with the school, community and family. This is in other words, the dimensions - absence of requirements, gender role and ethnicity - previously discussed. There is a need to assess and regulate the financial expenditure faced by households to educate primary, secondary and high school students in areas where financial difficulties seem to be a major challenge. School provisions should be carefully checked to ensure that they, at least, include the basic necessities required for quality learning and skills development. These are provisions like laboratories, libraries, classrooms, trained and sufficient teachers, and sporting as well as leisure activities. It is also essential that schools are available and that students don't find it very difficult to commute to school or switch to another school based, for instance, on the trajectory between their home and school. 
This review shows some similarities with the main dropout factors found in a study for developed countries (western world), carried out by De Witte, Cabus, Thyssen, Groot and van den Brink (2013). In the latter study, results suggested that the school-related factors are similar to the ones identified in this study with the exception of age, which is not prevalent in the western world. The problem of gender, though present in the developed nations, differs with that in the less developed countries in that the effect in the latter nations is more related to cultural beliefs which mostly disfavor girls. Family-wise, the factors that all the countries (i.e. both developed and less developed countries) have in common are socio-economic status, non-biological child, family crisis, single parent, and unsupportive family.

The school factors found in both worlds include school quality, facilities, teacher experience, and support. Community factors such as peer influence, wage labor, and neighborhood influence are also present in all regions. School dropout in Africa and Asia however, is influenced more by community factors including underdevelopment, distance to school, region of residence, religion, and ethnicity. The overall and significant determinants are problems on a seemingly equal scale in both Africa and Asia partly due to the existence of common beliefs in both areas, the high population involvement in less professional activities like agriculture, and the lacking behind of infrastructure and educational provisions as compared to the developed world. 


\section{Chapter 3}

\section{The Relationship between Contextual Characteristics and the Intergenerational Correlation of Education in Developing Countries ${ }^{b}$}

\footnotetext{
b This chapter is based upon: Momo, M. S. M., Rud, I., Cabus, S. J., De Witte, K., \& Groot, W. (2019). The relationship between contextual characteristics and the intergenerational correlation of education in developing countries. International Journal of Educational Development, 66, 173-183. https://doi.org/10.1016/j.ijedudev.2018.10.002
} 
Chapter 3

\begin{abstract}
We investigate the importance of contextual variables in explaining the differences in the correlation of education from parents to children in 48 developing countries. The contextual characteristics are internationally comparable macro-economic and institutional indicators. We use measures on GDP and industrial development, public spending, the education system, infrastructure, health outcomes, political stability and accountability. Our results show that contextual characteristics account for $39 \%$ of the explained cross-country variation in the education correlation across generations. The quality of the education system is the most important explanation of the variation of the intergenerational education correlation in the developing countries.
\end{abstract}




\subsection{Introduction}

Over the last five decades, studies have garnered evidence on the extent and determinants of social mobility, more specifically on the association between occupational class or the educational attainment of the parents and that of their children. In social mobility research, the status attainment model of Blau and Duncan (1967) is considered as a milestone. This model links the inequalities in educational attainment and the subsequent inequalities in occupational status of individuals to inequalities in the background of their families. However, a reduction in the effect of family background on individual status attainment over time due to increased access to better quality education is tenable. Research that has shed light on how macro-structural variables, for instance, gross domestic product per capita (GDP per capita), education expenditure, education expansion, health condition and political ideology shape social mobility, supports the status attainment model (Akbulut-Yuksel and Turan, 2013; Ballarino et al., 2009; Bauer and Riphahn, 2013; Sieben and De Graaf, 2001; Van Doorn et al., 2011). These variables underlie the relationship between parental educational attainment and that of their children. For clarity purposes, educational mobility is the opposite of educational transmission or persistence. While with educational transmission or persistence, the inequalities in educational attainment of parents replicate to their children, educational mobility is the non-replication of parental educational attainment (Hertz et al., 2008).

In this study, we present a comparative analysis of the impact of contextual characteristics, i.e. macro-structural variables, on the intergenerational correlation of education. We do not seek to establish a causal relationship between parents' education and children's education. We focus on the intergenerational association or correlation given that there exist many potential inputs, besides what we consider in this chapter, that causally relates parents' education to children's education (Holmlund et al., 2011). The contextual characteristics referred to here can be broadly defined as the macro-economic factors of countries. The study builds on Van Doorn et al. (2011), which advanced the findings of the effect of contextual characteristics on education transmission. Their comparative analysis suggested that contextual variables play a key role in shaping the patterns of the intergenerational education transmission in different societies. Van Doorn et al. (2011) simultaneously examined the effect of multiple contextual characteristics on the intergenerational transmission of educational attainment using cross-national data for European countries. Hence, their conclusion is drawn from a multi-contextual (utilizing multiple contextual variables) and multi-societal (across multiple countries) perspective. However, their study was carried out within the context of developed countries. To the best of our knowledge, 
our study is the first to analyze the multi-contextual and multi-societal variation of intergenerational correlation of education in developing countries.

We thus extend the cross-national comparative analysis about origin-destination of educational attainment in industrialized contexts to the developing countries. The relevance and importance of this research is the testing of the existence of possible systematic differences across developing countries and the impact of variation in access to education on these differences. Research on the impact of contextual factors on the intergenerational correlation of educational attainment is important as it sheds light on how to strengthen the macroeconomic context by increasing standards of living and strengthening governance and how the institutional context may increase social mobility and weaken the intergenerational correlation of education. It shows how institutions affect social mobility through individual opportunities in education. This is useful given the weak position and large variation in education systems in many less developed countries and their lower levels of economic development. The need to increase educational attainment makes it important to analyze the relationship between the intergenerational correlation of education and social, economic, and demographic variables. It is considered to be the course to obtain more equal opportunities for children and higher productivity levels.

Barro and Lee (2013) suggested that developing countries may acquire advanced technology by investing in the skills levels of workers, by increasing their educational levels. Additional years of schooling provide a high rate of return, which has a positive influence on - among others fertility, reduction of child mortality, and income distribution (Breierova and Duflo, 2004; Gregorio and Lee, 2002). This chapter contributes to this literature by extending it to comparative studies. It does so by utilizing data from 48 developing countries. This enables conclusions about the intergenerational correlation of education for developing countries. The specific research question is: How do contextual characteristics influence the variation in the relationship between education of parents and the educational attainment of their children between countries? To better understand the cross-national variation in the correlation of parental education with children's education, we analyze the impact of macro-economic and institutional indicators. This chapter uses data from the Demographic and Health Surveys (DHS) for 48 developing countries and figures on macro-economic and institutional indicators from the World Bank for these developing countries to answer this question.

We conduct the analysis in two stages. First, we estimate the intergenerational correlation of education in developing countries using micro-data from the DHS. Subsequently, we analyze 
the relationship between contextual characteristics taken from the World Bank and the transfer of education from parents to children by exploring the variation in the correlation coefficient obtained in the first stage. The macro-economic and institutional indicators include indicators of national income and public spending, the system of education, infrastructure, health outcomes, labor market, and governance institutions. The choice of the contextual variables is based on evidence from the existing literature, as well as data availability. It is worth noting that the contextual characteristics used here are macro level characteristics without incongruence in the coding of the data. Thus the same measurement and the same coding apply to all the countries, making it comparable. This is a requirement for carrying out this comparative analysis (Jonsson and Mills, 1993). We acknowledge that due to differences in industrial development, institutions and labor market conditions, country-specific data could contain incongruences that may prevent generalization from a mono-contextual to a multi-contextual perspective.

\subsection{Determinants of educational transmission}

\subsubsection{Family background}

Several studies have analyzed the intergenerational transmission of family background variables such as education and occupation of parents to that of their children (see Carvalho, 2012 and reference therein). The family is the primary source of learning and socialization, which suggests that these qualities transmitted from parents to children are vital (Kovan et al., 2009). The intergenerational transmission of years of education attained by parents and that attained by their children is corroborated by evidence from both developed and developing countries and is explained by a range of potential avenues. From the literature it can be concluded that the persistence or immobility in education caused by family background is explained by two mechanisms, which allow children to inherit some fraction of their parents' human capital. These mechanisms include family wealth (Huang, 2013) and ability (Pfeffer, 2008).

Ability is transmitted from parents to children genetically (nature) or through parental care (nurture) (Plug and Vijverberg, 2003). Becker (2003) and Stocke' (2007) argue that parents rely on their own educational experiences in decisions concerning education. This theory assumes that an important condition for success at all school levels is the strategic knowledge of parents as well as their social know-how, which are crucial sources of information liable to mediate part of the educational association between generations (Deil-Amen and Rosenbaum, 2003). With regards to family wealth, the approach put forward by the rational choice theory is that parents 
and children make decisions on education based on careful consideration of economic resources, weighing the costs and benefits concerning education and their alternatives (Breen and Goldthorpe, 1997).

\subsubsection{Contextual forces and social mobility}

Blau and Duncan (1967) argue that in industrialized countries, individual status attainment is more related to achievement than to ascription (social background). That is, a decrease in social mobility as a result of family conditions from birth (for instance, parent's occupation and education) in favor of social mobility stemming from the influence of industrial and policy situations. In this regard, it is expected that a favorable contextual characteristic weakens the inheritance of educational attainment of the parents by the children.

\subsubsection{Economic modernization driven by technological changes}

The level of industrialization is one of the societal conditions used to examine the development in the resemblance in educational positions between parents and children in modern societies (Sieben and De Graaf, 2001). According to expectation, industrialization reduces the effect of social origin on educational attainment, or reduces the resemblance of educational attainment between generations in favor of inequality reduction and opportunity amelioration (Müller and Karle, 1993). Even though Müller and Karle (1993) found no negative influence of industrialization on the resemblance of educational attainment between generations in developed countries as expected, their finding is not similar to that of Van Doorn et al. (2011). The latter found a weaker relationship between parents' and their children's educational achievements in highly industrialized countries.

The argument for the weakening of origin effect lies in the efficient use of labor, which is higher in more industrialized countries. We use GDP per capita as a measure of industrialization. We also use fixed telephone subscriptions and mobile cellular subscriptions. Just like industrialization, fixed telephone subscriptions and mobile cellular subscriptions are proxies for the level of modernization in the society. The modernization theory stipulates that intergenerational transmission of education is reduced by a higher level of modernization (Sieben and De Graaf, 2001). Here, we derive our hypothesis from the prediction of the modernization theory and we assume that fixed telephone subscriptions and mobile cellular subscriptions are part of the economic processes driven by technological change. In this light 
we advance the hypothesis that the relationship between the parents' education and children's education is weaker at higher levels of modernization (Hypothesis 1).

\subsubsection{The educational system}

Jonsson and Mills (1993) studied the effect of educational expansion in reducing inequalities in educational opportunities. Educational changes created more opportunities, which benefit less privileged children as well as increase their educational attainment and class transition. In other words, these changes lead to a reduction in the intergenerational transmission of education. The study of Kerckhoff (1995) confirms that changes in educational institutions serve as a pathway for the movement from origin to destination in the system of stratification as well as shaping the opportunity structure. The role of educational changes is to provide possible movements from one location (e.g social class status) to another. Kerckkoff (1995) argued that the system of education has the ability to specify the strength of the relationship between family background and educational attainment.

In conclusion, better quality of education and a better educational system reduce the strength between family background and educational attainment. That is, it leads to a reduction of the intergenerational transmission of education. This varies from one country to another depending on the differences in institutional settings (Ballarino et al., 2009). One argument forwarded to support the fact that family background loses its importance on status attainment in more modern societies, is that the expansion of educational systems makes individual educational careers longer, thereby affecting the importance of the family in educational careers negatively (Sieben and De Graaf, 2001). Features of educational institutions considered in this chapter include the pupil-teacher ratio in primary education, primary school starting age, primary school duration, secondary school duration, duration of compulsory education, and government expenditure on education. As a result, we have the following hypothesis: the relationship between parents' educational attainment and their children's educational attainment is weaker in countries with more access to educational infrastructure (Hypothesis 2).

\subsubsection{The labor market}

Labor market institutions serve as a pathway between family and school, and shape the structure of educational mobility (Kerckhoff, 1995). One such labor market circumstance is the female labor force participation rate. Traditionally, we place the effect of female employment as a complement to family background characteristics in influencing the education of children given 
that they, for instance, increase the financial provision for educational decisions. For instance, Kalmijn (1994) concluded that a higher educational achievement of children is positively influenced by higher occupational status of mothers, thereby weakening the effect of father's education. In the case of participation of women in the labor market as a macroeconomic characteristic, the interest is to test whether increasing women's participation in the labor market affects the relative father versus mother transmission rate, with possibly negative impacts on the intergenerational transmission of education through family background (Van Doorn et al., 2011).

The expected negative effect of female participation in the labor force on educational transmission is based on the argument that the labor market provides external incentives that are not related to family background. These incentives are rather to motivate individuals towards attaining better education stemming from new occupational aspirations and female empowerment on becoming breadwinners (Van Doorn et al., 2011). Just like the assumption concerning the system of education, Kerckoff (1995) concluded that labor market institutions have the ability to mediate the intergenerational transmission of education. This mediation is in the direction of a reduction of the effect of family background on educational attainment in case of a favorable system of the labor force. The feature of the labor market system included in this study is the ratio of the female to male labor force participation rate. We therefore expect that in countries with a higher ratio of the female to male labor force participation rate, the relationship between the educational level of the parents and the educational level of the children is weaker (Hypothesis 3).

\subsubsection{Adverse health effect}

Akbulut-Yuksel and Turan (2013) investigated adverse health conditions as one of the potential underlying mechanisms affecting the transfer of status from one generation to the next. They proposed two mechanisms that explain how ill health affects education transmission. First, sick mothers may be unable to educate their children properly. Second, decisions concerning education may change as a result of the increased mortality risk not only for sick or infected parents, but also for non-infected parents in the community. Other studies have also documented the negative impact of, in this case, the HIV/AIDS epidemic on educational attainment for both orphans (Evans and Miguel, 2007) and non-orphans (Fortson, 2011). We use life expectancy at birth and the prevalence of HIV as measures of health. Therefore, our hypothesis is as follows: 
the higher the level of ill-health the stronger the intergenerational correlation of education (Hypothesis 4).

\subsubsection{Characteristics of institutions}

Research has examined how contextual characteristics, including state policies and global forces, shape educational stratification through their effects on the demand for education or the structure and supply of schooling. Sieben and De Graaf (2001) argued that characteristics of the institutions (state) are important factors in explaining cross-country differences in status attainment. It has been established that systems with less corruption, and more voice and accountability as well as good governance for the citizens, build trust and the willingness to contribute and corporate (Bird et al., 2008). We therefore assume that more opportunities and freedom to partake reduces the intergenerational transmission of education. In this sub-section, we also include contextual characteristics that have not been documented in the literature in this field of study. These are the extent of voice and accountability, the extent of corruption, and the extent of political stability. The hypothesis is: More positive state characteristics weaken the correlation of education across generations (Hypothesis 5).

\subsubsection{Other factors}

There are a number of other contextual factors that have been used in research to explain the evolution of the origin-status relationship, which we will not include in this chapter. For instance, Sieben and De Graaf (2001) studied inequalities in family background and inequalities in educational attainment while testing the socialist ideology hypothesis. This is a measure of the political circumstance of a country. Their socialist ideology hypothesis is that socialdemocratic and communist societies reduce the family background effect on educational achievement through social reforms.

\subsection{Data}

\subsubsection{Data description}

We conduct the analysis using the DHS data for 48 developing countries from 149 surveys conducted between the years 1990 and 2014. The countries that are included in this data set are listed in Appendix A3.1.. The surveys are nationally representative, comparable across countries and give information on households including personal, household, and residential characteristics (Rutstein and Rojas, 2006). The data are collected using standard model 
questionnaires, and by identifying eligible respondents of the households for interview. Both variables of interest, parent's education and child's education are provided. For the purpose of this chapter, in households with both parents present, the education of the parent with the highest level of education is considered. When both parents are present and have the same level of education, the head of the household's education is retained.

The distribution is truncated to children aged 20-30 as to ensure that we include a generation that has (relatively) recently completed formal education at the time of survey. There is a potential problem of a downward biased education transmission coefficient that may arise from the lower limit. This is as a result of the exclusion of children who still need to complete their final educational levels and those who take longer time than usual to complete their final studies. With the 20-30 years truncation, we assume the bias from this problem to be fairly small, as ascertained by Hertz et al. (2008). The decision with regards to the upper limit is in consideration of the possibility of an upward bias of the mean level and a downward education transmission coefficient bias for the relatively older children. This possibility arises because education may be correlated with longevity (Hertz et al., 2008).

The educational process is considered in this study as unitary, given that the purpose is to determine how country characteristics influence the relationship between educational achievements of parents and their children. As such, we consider the education completed in single years. Data on 305,416 parents and 406,253 children are included after deleting households with missing values on required variables. Sample sizes range from 337 (for Dominican Republic) to 10,340 (for Indonesia).

The sampling issue we face here is that the sample in the analysis is more representative of the parent-child sub-sample. Besides children, the original data include information on other individuals such as 'other relative, not related, niece/nephew by blood, niece/nephew by marriage, son/daughter-in-law'. The estimated coefficients may be biased if any of these family members have an educational attainment which is significantly different from that of children. We can remedy the situation by including them as children who also lived in the household. However, we did not include them because they could be members who do not normally live in the household. 


\subsubsection{Descriptive statistics}

Table 3.1. presents the descriptive statistics. Survey weights are used in all calculations to make surveys nationally representative. As seen from the table, children tend to be more educated than parents with an average of 8.38 years of education, which is larger than the 5.21 average years of education of parents. The dependent variable captures the number of years of schooling of the children while the major independent variable is the number of years of schooling of the parent. The control variables include individual characteristics, household characteristics, region of residence, and fixed effects for year and country. The individual characteristics are the gender of the parent, gender of the child, and the age of the child. Household characteristics are household wealth and the number of children aged 5 and below. Household wealth is organized into quintiles: richest, richer, middle, poorer, and poorest. The region of residence is split into rural region and urban region.

Table 3.1.: Descriptive statistics of the individual-level characteristics

\begin{tabular}{llccc}
\hline Generation & \multicolumn{1}{c}{ Variable } & Mean & $\begin{array}{c}\text { Standard } \\
\text { deviation }\end{array}$ & Range \\
\hline Parents & Parent education & 5.21 & 4.98 & $0-24$ \\
& Number of children age $\leq 5$ & 0.72 & 1.07 & $0-17$ \\
& Gender: Father(vs Mother) & 0.77 & 0.42 & $0-1$ \\
& Rural region of residence(vs Urban) & 0.55 & 0.50 & $0-1$ \\
& Wealth quintiles & & & \\
& Richest & 0.25 & 0.43 & $0-1$ \\
& Richer & 0.22 & 0.41 & $0-1$ \\
& Middle & 0.20 & 0.40 & $0-1$ \\
& Poorer & 0.18 & 0.38 & $0-1$ \\
& Poorest & 0.16 & 0.36 & $0-1$ \\
\hline Children & Child education & 8.38 & 4.74 & $0-24$ \\
& Child age & 23.46 & 2.96 & $20-30$ \\
& Child gender: Male (vs Female) & 0.61 & 0.49 & $0-1$ \\
\hline
\end{tabular}

Notes: The household sampling weights are used to compute all statistics. $\mathrm{N}_{\text {children }}=406,253 ; \mathrm{N}_{\text {parents }}=$ $305,416$. 
In Table 3.2., the contextual variables and the dependent variable used in the second stage of the analysis are presented. The dependent variable in this table is the correlation coefficient between parents and children's education computed for each survey. Contextual characteristics are computed for each survey per country. We include GDP per capita (measured in constant 2010 US dollars) as an indicator of standard of living. Indicators used to determine the effect of the educational system include pupil-teacher ratio (average number of pupils per teacher), the government expenditure on education (\% of GDP), primary school starting age, primary school duration (years), secondary school duration (years), and the compulsory years of education. We use fixed telephone subscriptions (per 100 people), and mobile cellular subscriptions (per 100 people) as measures of infrastructure. Life expectancy at birth (years) and prevalence of HIV (\% of population ages 15-49) are used as indicators of health.

The ratio of female to male labor force participation rate (\%) is used as an indicator of the efficiency of the labor market. Institutional effects are measured by three different estimates. These are the estimates of the extent of corruption, the extent of political stability, and the extent of voice and accountability for the citizens. They are given in units of distribution ranging from approximately -2.5 to 2.5. All these variables are obtained from the World Bank (2017). One issue with the data collection is the existence of missing values, which are filled using cubic interpolation per country. Where there are no data, such as for Nigeria on government expenditure on education and for Turkey on the prevalence of HIV indicator, the mean values of all countries were imputed for that. 
Table 3.2.: Descriptive statistics of the macro-level characteristics

\begin{tabular}{lccll}
\hline Variable & $N$ & Mean & $\begin{array}{l}\text { Standard } \\
\text { deviation }\end{array}$ & Range \\
\hline Education correlation coefficients (years) & 149 & 0.27 & 0.08 & $0.10-0.50$ \\
Primary school pupil-teacher ratio(average) & 149 & 40.28 & 13.94 & $15-79.27$ \\
Fixed telephone subscriptions (per 100 people) & 149 & 3.36 & 4.96 & $0-28.69$ \\
GDP per capita (constant 2010 US\$) & 149 & 1602.13 & 1738.68 & $196-10137$ \\
Government education expenditure (\% of GDP) & 149 & 4.29 & 4.71 & $1.07-44.33$ \\
Life expectancy at birth (years) & 149 & 59.01 & 8.76 & $28.11-73.75$ \\
Mobile cellular subscriptions (per 100 people) & 149 & 24.67 & 35.91 & $0-156.67$ \\
Prevalence of HIV(\% of population ages 15-49) & 149 & 3.88 & 5.36 & $0.10-23$ \\
Primary education duration (years) & 149 & 5.87 & 0.77 & $3-7$ \\
Primary school starting age (years) & 149 & 6.27 & 0.50 & $5-7$ \\
Female-male labor force participation rate (\%) & 149 & 73.62 & 21.67 & $15.88-108.20$ \\
Secondary education duration (years) & 149 & 6.25 & 0.73 & $4-7$ \\
Compulsory education duration (years) & 149 & 7.81 & 2.37 & $0-15$ \\
Corruption estimate & 149 & -0.68 & 0.44 & $-1.50-0.81$ \\
Political stability estimate & 149 & -0.63 & 0.75 & $-2.26-1.05$ \\
Voice and accountability estimate & 149 & -0.51 & 0.52 & $-1.67-0.50$ \\
\hline & & & & \\
\hline
\end{tabular}

\subsection{Methodology}

Our analysis is conducted in two stages. First, we estimate the intergenerational correlation of education in developing countries by pooling all surveys and countries (406,253 observations), and introducing fixed effects for countries and years (results in Table 3.3.). Second, we examine how contextual characteristics affect the intergenerational correlation of education by running a set of linear regressions on the 149 surveys separately (results in Table 3.4.), which are then used as the dependent variable to carry out linear regressions of the intergenerational education correlation (149 observations) on the contextual variables simultaneously (results in Table 3.5.). We detail those steps next. 
Chapter 3

\subsubsection{Intergenerational correlation of education}

In line with Becker and Tomes (1986), we derive our equation for estimating a linear regression of years of education of children on years of education of parents,

$\mathrm{E}_{\mathrm{it}}=\mathrm{a}_{0}+\mathrm{a}_{1} \mathrm{E}_{\mathrm{it}-1}+\mathrm{f}\left(\right.$ Age $_{\mathrm{it}}$, Gender $_{i t}$, Gender $_{\mathrm{it}-1}, \mathrm{NC}, \mathrm{RR}, \mathrm{WQ}$, Country, Year $)+\mathrm{e}_{\mathrm{it}}$,

where $\mathrm{E}_{\mathrm{it}}$ is the education of the child $i$ in generation $t, \mathrm{E}_{\mathrm{it}-1}$ is the education of the parent $i$ in generation $t-1, \mathrm{f}\left(\mathrm{Age}_{\mathrm{i}}, \ldots\right)$ denote the characteristics of children and parents we control for in the regression analysis. For this purpose, it and $t-1$ simply differentiates the information of the child from the information of the parent. The control variables are age of child, gender of child, gender of parent, number of children aged 5 or less (denoted by NC), region of residence (RR), wealth quintile (WQ), and country and year fixed effects. The latter captures the time-invariant heterogeneity across years and across countries. We control for the gender of the parent because we do not intend to compare the effect of parent education on child education by parent gender. We merely determine the average years of schooling of the child to be achieved following a year increase in the educational attainment of a parent. The econometric specification provides a measure of association indicating how an additional year of education of the parent correlates with the education of the child. $a_{1}$ is the parameter of interest which indicates the association between parent's education and child's education, thus measuring the educational correlation between generations (Table 3.3.).

\subsubsection{The relationship between contextual characteristics and intergenerational correlation of education}

In the second stage of the analysis, we measure the intergenerational correlation coefficient of education for each survey separately in the data, giving a total of 149 intergenerational correlation coefficients. In particular, we estimate for each survey the following regression model:

$\mathrm{E}_{\mathrm{it}}=\mathrm{a}_{0}+\mathrm{a}_{1} \mathrm{E}_{\mathrm{it}-1}+\mathrm{f}\left(\mathrm{Age}_{\mathrm{it}}\right.$, Gender $_{i t}$, Gender $\left._{\mathrm{it}-1}, \mathrm{NC}, \mathrm{RR}, \mathrm{WE}\right)+\mathrm{e}_{\mathrm{it}}$,

We utilize these correlation coefficients (Table 3.4.) as the dependent variable and estimate a linear regression with this dependent variable on the contextual variables,

$\operatorname{ITC}_{\mathrm{y}, \mathrm{c}}=\mathrm{b}_{0}+\mathrm{b}_{1} \mathrm{CV}_{\mathrm{y}, \mathrm{c}}+\mathrm{e}_{\mathrm{y}, \mathrm{c}}$ 
where ITC is the intergenerational education correlation of year $y$ in country $c, b_{1}$ represents the relationship between intergenerational education correlation and contextual characteristics, and $\mathrm{CV}$ is the contextual characteristic of year $y$ in country $c$. The GDP per capita is represented in thousand change by dividing the values by one thousand while the other independent variables are standardized (Table 3.5.).

\subsection{Results}

Table 3.3.: Intergenerational education correlation, pooled estimates

\begin{tabular}{|c|c|c|c|c|c|c|}
\hline \multirow[b]{2}{*}{ Child education } & \multicolumn{3}{|c|}{ (1) } & \multicolumn{3}{|c|}{ (2) } \\
\hline & Coefficient & $\begin{array}{c}\text { Standard } \\
\text { error }\end{array}$ & P-value & Coefficient & $\begin{array}{c}\text { Standard } \\
\text { error }\end{array}$ & $P$-value \\
\hline Parent's education & 0.5262 & 0.0016 & 0.000 & 0.390 & 0.0018 & 0.000 \\
\hline Children age $\leq 5$ & No & & & -0.509 & 0.008 & 0.000 \\
\hline Parent's gender & No & & & & & \\
\hline Father & & & & (base) & & \\
\hline Mother & & & & 0.152 & 0.0189 & 0.000 \\
\hline Region of residence & No & & & & & \\
\hline Urban & & & & (base) & & \\
\hline Rural & & & & -1.369 & 0.020 & 0.000 \\
\hline Wealth quintiles & No & & & & & \\
\hline Poorest & & & & (base) & & \\
\hline Poorer & & & & 0.708 & 0.027 & 0.000 \\
\hline Middle & & & & 1.266 & 0.027 & 0.000 \\
\hline Richer & & & & 1.705 & 0.029 & 0.000 \\
\hline Richest & & & & 2.321 & 0.031 & 0.000 \\
\hline Child's age & No & & & 0.071 & 0.002 & 0.000 \\
\hline Child's gender & No & & & & & \\
\hline Male & & & & (base) & & \\
\hline Female & & & & -0.010 & 0.015 & 0.507 \\
\hline Year & No & & & 0.028 & 0.001 & 0.000 \\
\hline Country & No & & & -0.004 & 0.001 & 0.000 \\
\hline $\mathrm{R}^{2}$ & 0.3095 & & & 0.3897 & & \\
\hline $\mathrm{N}$ & 406,253 & & & 406,253 & & \\
\hline
\end{tabular}

Notes: We report robust standard errors in parentheses, clustered at the family level.

To preview the result on the general association between parents' education and children's education at the micro level in developing economies, we estimate equation (1). The results, as presented in Table 3.3., indicate in column (1) an average association over all 48 countries in our sample of 0.53-year increase in children's years of schooling following an additional year of parent's education. This correlation reduces to 0.39 -year in column (2), when we control for 
Chapter 3

household characteristics and individual characteristics. These characteristics include wealth quintile, number of children aged 5 and below, parent's gender, child's gender and child's age. We also control for the region of residence as well as the fixed effects for year and country. This persistence in educational attainment of 0.39 in absolute terms is of a bit stronger magnitude than the one found by Akbulut-Yuksel and Turan, (2013) for Sub-Saharan Africa (0.20 years), confirming the existence of parent-child educational attainment persistence in developing countries.

Next, we estimate equation (2) for each of the 149 surveys for the 48 countries separately. This is presented in Table 3.4.. 
Table 3.4.: Intergenerational correlation of education coefficients

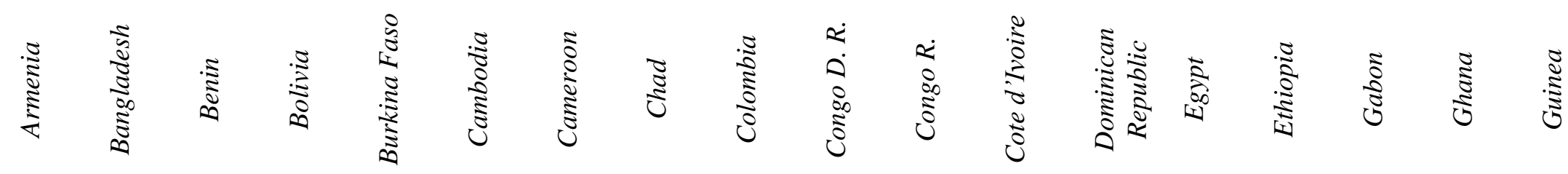

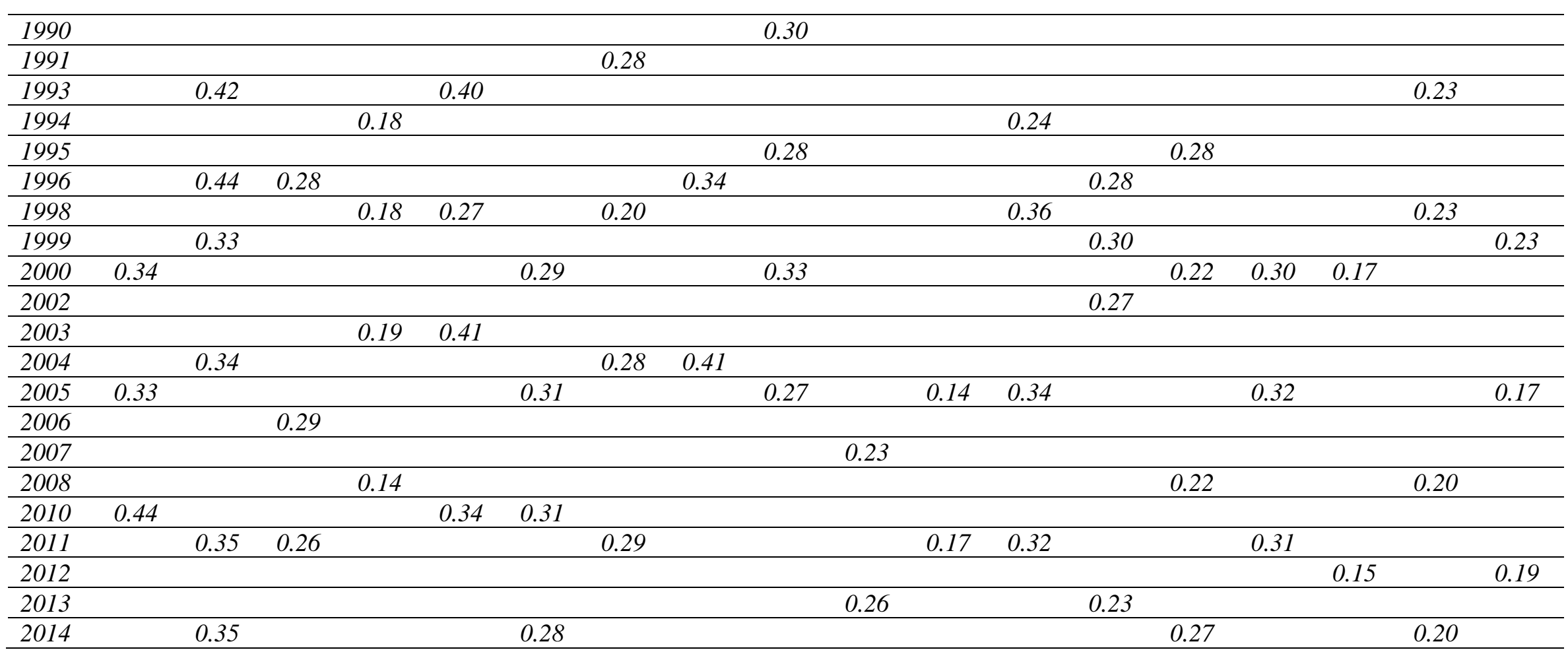

Notes: $\mathrm{D}=$ Democratic; $\mathrm{R}=$ Republic. Gabon (2012) is statistically significant at the 0.005 significance level ( $\mathrm{p}=0.001)$. All other coefficients are statistically significant at the 0.001 significance level $(\mathrm{p}=0.000)$. 
Chapter 3

Table 3.4.: (continued)

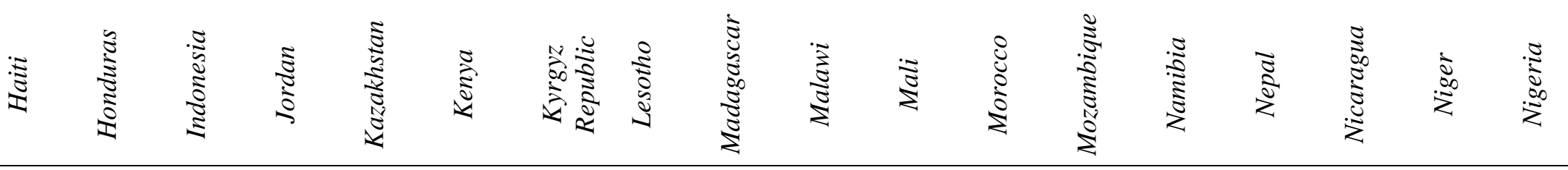

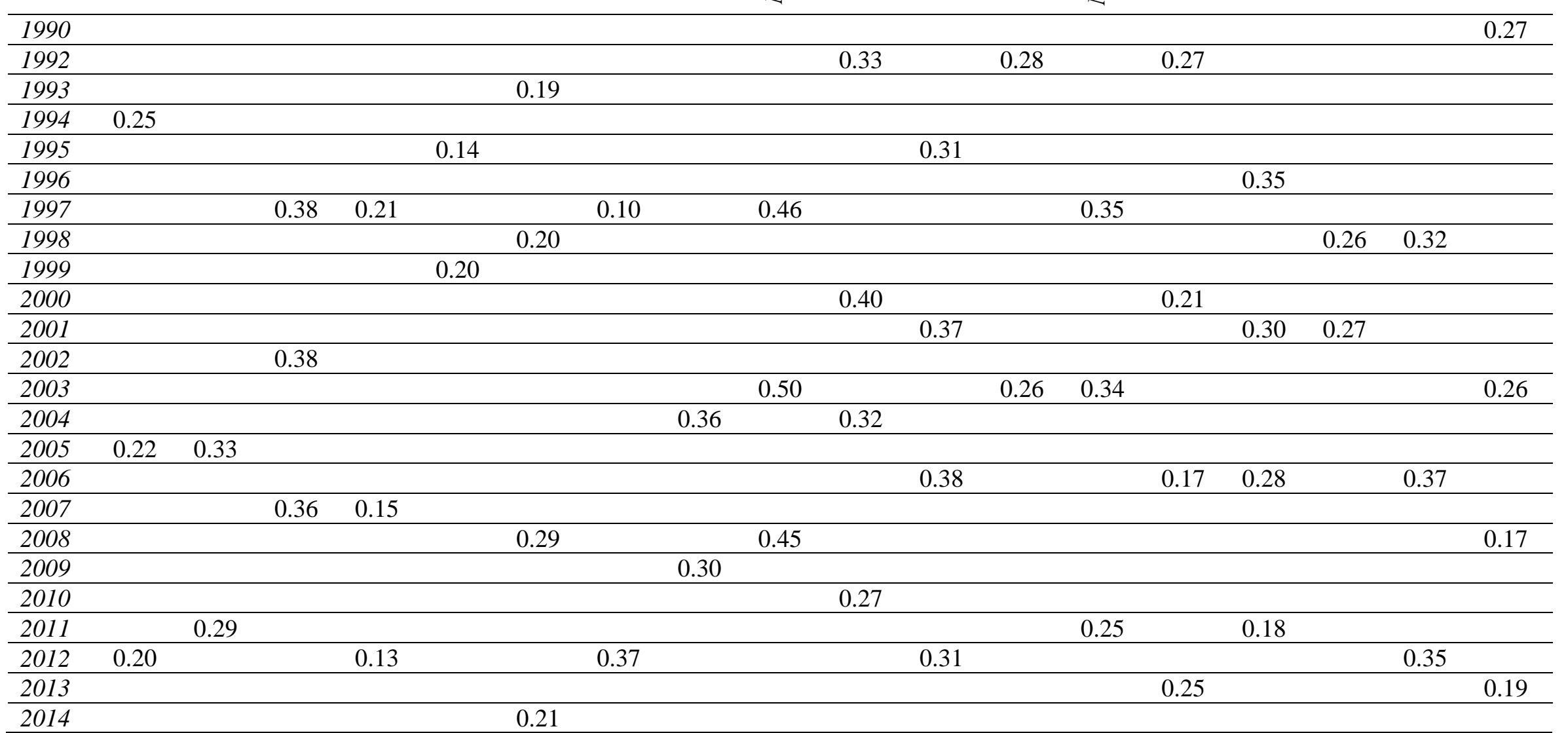

Note: All coefficients are statistically significant at the 0.001 significance level $(\mathrm{p}=0.000)$. 
Table 3.4.: (continued)

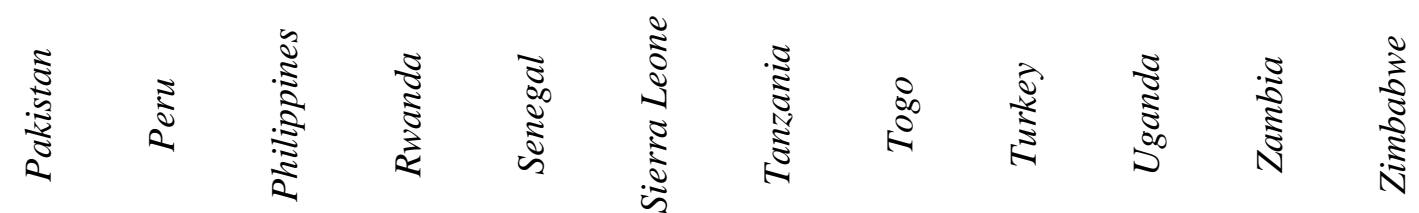

\begin{tabular}{|c|c|c|c|c|c|c|c|c|c|c|}
\hline 1990 & 0.36 & & & & & & & & & \\
\hline 1991 & & 0.16 & & & & & & & & \\
\hline 1992 & & & & 0.32 & & & & & & \\
\hline 1993 & & & & & & & & & & \\
\hline 1994 & & & & & & & & & & 0.22 \\
\hline 1995 & & & & & & & & & & \\
\hline 1996 & & 0.18 & & & & & & & 0.23 & \\
\hline 1998 & & & 0.28 & & & & & 0.17 & & \\
\hline 1999 & & & & & & & 0.19 & & & 0.16 \\
\hline 2000 & & 0.21 & & 0.24 & & & & & & \\
\hline 2001 & & & & & & & & & 0.28 & \\
\hline 2003 & & & 0.29 & & & & & & & \\
\hline 2005 & & & & 0.28 & 0.27 & & & & & 0.16 \\
\hline 2006 & 0.29 & & & & & & & & & \\
\hline 2007 & & & & & & & & & 0.30 & \\
\hline 2008 & & & & & & 0.23 & & & & \\
\hline 2010 & & & & 0.23 & 0.23 & & 0.17 & & & 0.19 \\
\hline 2011 & & & & & & & & & & \\
\hline 2013 & & & & & & 0.19 & & 0.28 & 0.18 & \\
\hline
\end{tabular}

Note: All coefficients are statistically significant at the 0.001 significance level $(\mathrm{p}=0.000)$. 
Chapter 3

Table 3.4. presents the intergenerational correlation coefficients which serve as the dependent variable for the second stage of the analysis. From this parent-child educational association relationship across developing countries, we find an average of 0.27 years of education. The correlation coefficients range from a weak value of 0.10 (Kyrgyz Republic) to a much stronger intergenerational correlation coefficient of 0.50 (Madagascar). The coefficients show irregularities in the within group variation over time, which decrease in the majority of countries. With the exception of Kyrgyz Republic, the within group variations are not substantial. The majority (44\%) lie between $0.20-0.29,29 \%$ is between $0.30-0.39,20 \%$ between $0.10-0.19$ and $7 \%$ between $0.40-0.50$. 
Table 3.5.: The relationship between contextual characteristics and intergenerational correlation of education, stepwise

\begin{tabular}{|c|c|c|c|c|}
\hline Intergenerational correlation of education & (1) & (2) & (3) & (4) \\
\hline Gross domestic product(GDP) & $\begin{array}{l}-0.012 * * \\
(0.004)\end{array}$ & $\begin{array}{l}-0.013 * * \\
(0.004)\end{array}$ & $\begin{array}{l}-0.009 * \\
(0.004)\end{array}$ & $\begin{array}{l}-0.012 * * \\
(0.004)\end{array}$ \\
\hline Prevalence of HIV & & $\begin{array}{l}-0.010 \\
(0.008)\end{array}$ & $\begin{array}{l}0.012 \\
(0.010)\end{array}$ & $\begin{array}{l}0.011 \\
(0.009)\end{array}$ \\
\hline Life expectancy at birth & & $\begin{array}{l}-0.004 \\
(0.009)\end{array}$ & $\begin{array}{l}-0.002 \\
(0.010)\end{array}$ & $\begin{array}{l}-0.012 \\
(0.010)\end{array}$ \\
\hline Female-male labor force participation & & $\begin{array}{l}-0.010 \\
(0.008)\end{array}$ & $\begin{array}{l}-0.025 * * \\
(0.007)\end{array}$ & $\begin{array}{l}-0.026 * * \\
(0.007)\end{array}$ \\
\hline Government expenditure on education & & & $\begin{array}{l}-0.010 \\
(0.007)\end{array}$ & $\begin{array}{l}0.009 \\
(0.006)\end{array}$ \\
\hline Pupil-teacher ratio & & & $\begin{array}{l}0.030^{* *} \\
(0.007)\end{array}$ & $\begin{array}{l}0.034^{* *} \\
(0.007)\end{array}$ \\
\hline Primary school starting age & & & $\begin{array}{l}0.004 \\
(0.005)\end{array}$ & $\begin{array}{l}0.004 \\
(0.006)\end{array}$ \\
\hline Primary school duration & & & $\begin{array}{l}-0.035 * * \\
(0.008)\end{array}$ & $\begin{array}{l}-0.033 * * \\
(0.009)\end{array}$ \\
\hline Secondary school duration & & & $\begin{array}{l}-0.005 \\
(0.008)\end{array}$ & $\begin{array}{l}0.003 \\
(0.007)\end{array}$ \\
\hline Compulsory years of education & & & $\begin{array}{l}-0.012 \\
(0.006)\end{array}$ & $\begin{array}{l}-0.017 * * \\
(0.006)\end{array}$ \\
\hline Fixed telephone subscriptions & & & & $\begin{array}{l}0.013 \\
(0.009)\end{array}$ \\
\hline Mobile cellular subscriptions & & & & $\begin{array}{l}0.007 \\
(0.009)\end{array}$ \\
\hline Extent of corruption & & & & $\begin{array}{l}0.006 \\
(0.007)\end{array}$ \\
\hline Extent of political stability & & & & $\begin{array}{l}-0.013 \\
(0.007)\end{array}$ \\
\hline Extend of voice and accountability & & & & $\begin{array}{l}0.028 * * \\
(0.007)\end{array}$ \\
\hline $\begin{array}{r}\mathrm{N} \\
\text { Adjusted } \mathrm{R}^{2}\end{array}$ & $\begin{array}{l}149 \\
0.0706\end{array}$ & $\begin{array}{l}149 \\
0.0889\end{array}$ & $\begin{array}{l}149 \\
0.3123\end{array}$ & $\begin{array}{l}149 \\
0.3917\end{array}$ \\
\hline
\end{tabular}

$* \mathrm{p}<0.05 ; * * \mathrm{p}<0.01 ;$ Standard errors are presented in parentheses.

The results of the estimation of equation (3) are presented in Table 3.5.. It shows the regression estimates for the relationship between contextual characteristics and the intergenerational correlation coefficient of education. The four model specifications present the step-wise inclusion of the independent variables in the analysis. This is done to observe inconsistencies in 
the magnitude of the relationship when measures of institutions and government policies are held fixed. There is no specific reason for the order of adding the variables. We, however, start with GDP because it underlies measures of health and the state of the economy. In model 1, we start with solely GDP, which shows a statistically significant relationship with the intergenerational correlation coefficient. In model 2, we include the prevalence of HIV, life expectancy at birth, and the ratio of the female to male labor force participation rate and find that there is no change on the significance level of the coefficient of GDP, while the added variables show no statistical significance.

In model 3, we add government expenditure on education, pupil-teacher ratio, primary school starting age, primary school duration, secondary school duration, and compulsory education. The magnitude and statistically significance level of GDP decreases in this model. However, GDP increases in significance level in model 4 with the same results for the other variables after including fixed telephone subscriptions, mobile cellular subscription, extent of corruption, extent of political stability, and extent of voice and accountability. We thus observe that GDP has been more precisely estimated $(\mathrm{p}<0.01)$. In this model, compulsory years of education and the extent of voice and accountability are statistically significant with $\mathrm{p}<0.01$, as are the GDP, female to male labor force participation, pupil-teacher ratio, and primary school duration coefficients. Therefore, by using all variables in model 4, GDP, female to male labor force participation, pupil-teacher ratio, primary school duration, compulsory years of education, and the extent of voice and accountability have a statistically significant correlation with the intergenerational correlation of education. $39 \%$ of the variance in the intergenerational correlation of education can be explained by it.

Looking at the effect sizes, we can conclude that pupil-teacher ratio and primary school duration have the highest association with the intergenerational education correlation. A standard deviation increase in the pupil-teacher ratio leads to a 0.034 years increase in the intergenerational correlation of education. On the other hand, an increase in the primary school duration by one standard deviation leads to a decrease in the intergenerational correlation of education by 0.033 years. The female to male labor force participation rate and the extent of voice and accountability have smaller effect sizes. The intergenerational education correlation decreases by 0.026 years with one standard deviation increase in the female to male labor force participation, and increases by 0.028 years with a standard deviation increase in the extent of voice and accountability. GDP and the compulsory years of education have the smallest effect on the intergenerational education correlation. They decrease the education correlation 
coefficient by 0.012 years and 0.017 years respectively, following a standard deviation increase. The stepwise inclusion of contextual variables does not impact their effect sizes, which suggests that there is no collinearity between the variables.

\subsection{Discussion and conclusion}

We estimated the relationship between contextual characteristics and the intergenerational correlation of education in developing countries. The results show that the relationship between parent's education and the child's education is weaker in countries with a higher level of modernization. This corroborates the industrialization effect hypothesis (hypothesis 1). The negative effect of GDP on the intergenerational education correlation may be due to the benefits of national output trickle down as expected. Our findings further suggest that a higher pupilteacher ratio (more students per teacher) increases intergenerational education correlation, while higher primary school duration years and compulsory years of education reduce the intergenerational education correlation. This is in accordance with our hypothesis on education quality: the relationship between parents' educational attainment on their children's educational attainment is weaker in countries with greater access to education. It confirms hypothesis 2 . More students per teacher may mean that teacher-student interaction, feedback and follow-up reduces, which in turn may relatively increase family involvement in student learning and progression. But increasing years of primary school and compulsory education extends student's interaction with the school and reduces family influence caused by the amount of time spent with the family.

Third, the female to male labor force participation rate is highly negatively related to education correlation across generations. This is in accordance with our hypothesis 3 , which states that in countries with a high ratio of female to male labor force participation rate, the relationship between the educational level of the parents and the educational level of the children will be weaker. Female to male labor force participation in this context can be thought of as the extent at which countries have succeeded in combatting gender inequality, which helps in motivating aspiring youngsters as well as increasing competition. Lastly, voice and accountability for citizens has a positive relationship with the education correlation across generations. This effect contradicts hypothesis 5, which states that a higher positive state characteristic weakens the association of education across generations. This could be the case if voice and accountability for citizens is more to the advantage of parents so much that they tend to influence the decision on the education of their children, from their perception of the state of this variable. 
In comparison with the results for European countries carried out by Van Doorn et al (2011), GDP, female labor force participation, and pupil-teacher ratio are similar in their level of statistically significance, with the GDP having the highest effect size in Europe. However, the effect of the pupil-teacher ratio in Europe is not in accordance with the expected direction of influence. Generally, the effect sizes in the European context are all higher than those in developing countries in our study. This is perhaps partly due to the differences in state efficiency and the effectiveness in utilizing inputs and outputs. Another contribution to this observation is that in developing countries, a high percentage of the population find themselves disadvantaged.

This result confirms our assumption that if contextual characteristics are part of the driving force in shaping the size of the intergenerational correlation of education, this should be portrayed in the decrease or increase of the relationship between the education of parents and the education of their children. The findings in this chapter are in accordance with previous literature on the impact of contextual characteristics on the inheritance of parental educational attainment by their children. In the developing country context, our study establishes that cross-national differences in the intergenerational correlation of education in developing countries are moderated by differences in the contextual characteristics of countries. These characteristics are reflected here by the level of industrialization, quality of education system, structure of the labor force and the nature of the institutions.

Our study has one most obvious policy implication. The quality of the education system is the most important explanation of the variation of the relationship between the educational attainment of parents and the educational attainment of their children across developing countries. This suggests that governmental investment in the quality of education will reduce dependency of children's education on their parents' education and therefore will increase socio-economic equality.

We acknowledge some limitations of the analysis in this chapter. First, there are other characteristics of the family and the community that might contribute to the extent of the educational attainment relationship between parents and children across countries, thereby reducing the intergenerational association between parents' education and children's education. Examples include parents' occupation, parents' age, family income, number of children living in the household, marital status, and community fixed effect. Another limitation is that although we use nationally representative data, the original sample sizes in this study are slightly modified by the elimination of observations due to incomplete required information for the analysis as 
well as truncation by age groups. The estimates of the intergenerational correlation may have limited predictive power to a representative population given the less representative samples and the non-randomness of missing values. Therefore, representativeness of the results needs to be interpreted with caution. We also observe that though the ordinary least square method is useful as it allows controlling for unobserved heterogeneity in the estimated relationship, we do not assume causality because of possible unobserved heterogeneity that can underlie the effects. Future research in this area would further contribute to explaining the role of contextual factors in the correlation of education across generations and mechanisms of these effects. 


\section{Chapter 4}

Evidence on the marginal impact of a compulsory secondary education reform in Senegal on years of education and changes in high school decisions ${ }^{\mathrm{c}}$

' This chapter is based upon: Momo, M. S. M., Cabus, S. J., \& Groot, W. (2021). Evidence on the marginal impact of a compulsory secondary education reform in Senegal on years of education and changes in high school decisions. International Journal of Educational Research Open, 2, 1-10. https://doi.org/10.1016/j.ijedro.2021.100058 
Chapter 4

\begin{abstract}
This chapter analyses the marginal impact of a compulsory secondary education reform in Senegal. The policy increased compulsory education from 6 to 10 years, incorporating lower secondary school to compulsory education. Using data from the Demographic and Health Survey 2017, we investigate the effect of the policy in increasing compulsory education completion and changes in post-compulsory schooling decisions. Our results show that the compulsory education policy significantly increased compulsory education completion, and improved post-compulsory grades completion. However, completion of the last postcompulsory grade in high school to obtain a secondary certificate was not affected.
\end{abstract}




\subsection{Introduction}

There is substantial evidence to suggest that compulsory education improves school attendance (Kirdar et al., 2015; Lleras-Muney, 2002; Rauscher, 2014). Consequently, in the past decades, many countries have made changes in their compulsory education laws in order to improve educational outcomes (Landis and Reschly, 2011; OECD, 2013). These improvements in education may be via increasing years of education completed and/or reducing school dropout (Cabus and De Witte, 2011; Oreopoulos, 2006). These improvements in school attendance started in the 1960s when the U.S. and Europe extended universal primary education to some parts of secondary education, usually the lower part of secondary education. The benefits obtained from additional years of compulsory education have been to universalize (lower) secondary education and increase schooling attainment (Brunello et al., 2009; Diaz-Serrano, 2020). Other benefits aimed at prolonging compulsory education are the improvement of child health, reducing of teenage fertility, and increasing economic returns (Black et al., 2008; Brunello et al., 2009; Kirdar et al., 2015). With the growing consensus that prolonging compulsory education to incorporate lower secondary education is interrelated with students' progression to secondary education, developing countries have typically adopted Western models to overcome the barriers of progression to secondary education.

The impact of prolonged compulsory education on educational attainment has been widely analyzed in advanced economies. Following the scantiness of evidence on the effects from low income and lower-middle-income countries, Diaz-Serrano (2020) is the first study to analyze the impact of lengthening the duration of compulsory education on progression from primary to secondary education in low income and lower-middle-income countries. These countries include Afghanistan, Chad, Georgia, Cape Verde, Morocco, Senegal, Vietnam, and Syria Arab Republic. The study shows that the transition from primary education to secondary education increased following the augmentation of compulsory years of education. One explanation of this finding is that individuals who are compelled to stay in school longer become more interested in schooling and view further studies as less daunting (Oreopoulos, 2009). However, the impact of the inclusion of lower secondary education into compulsory education years on secondary school transition does not provide empirical evidence on the actual completion of lower secondary education. It also does not provide evidence on the changes in schooling decisions after the compulsory education threshold, specifically with regards to higher secondary (high school). To the best of our knowledge, this chapter is the first of such study for a lower-middleincome country. Analyzing the effects on the actual completion of compulsory lower secondary 


\section{Chapter 4}

education and the changes in schooling decisions after the compulsory education age in a lowermiddle-income country is a major extension of the literature on the impact of compulsory education on educational attainment.

The aim of this chapter is to answer the question whether for students close to the margin of treatment, the prolonged compulsory school years law in Senegal contributed to the completion of the last grade of compulsory education and possibly to the completion of secondary school. It is relevant to explore the impact of prolonged compulsory education reforms in developing countries where governance is weak (Lom, 2018). Studies on compulsory education and subsequent secondary school completion are important because if all adults could complete secondary school the global poverty rate would be more than halved (UNESCO, 2017). Also, the intergenerational transmission of education (where children continuously attain the same low education level as their parents) could be reduced, given that intergenerational transmission of education is predominant among the poor (Azomahou and Yitbarek, 2016). It is expected that in countries with weak governance, policies may not always have a great impact and achieve a high educational attainment increase while, at the same time, one additional year of (subsidized) compulsory schooling is costly to the government.

To this end, we explore the impact of the December 2004 compulsory education law amendment in Senegal on years of schooling. This natural experiment stems from the fact that the compulsory education age law obliges children from the age of 6 to stay in school up to the age of 16 before dropping out. As such, the compulsory education years increased from 6 to 10 years in December 2004. We distinguish two groups in this analysis, one group comprises of individuals whose ages are close and lower than the new school leaving age, that is, those aged 13,14 , and 15. This is the treatment group. A second group comprises of those of the new school leaving age or just above, that is, those aged 16, 17, and 18. This is the control group. The age range as the criterion for distinguishing the groups is used because of the fact that school was compulsory up to the age of 12 when students are allowed to leave school, before the policy. After the policy, they could only leave school at the age of 16 . Therefore, those who were 15 and below were no longer eligible for school leaving, thereby making them the affected or intervention group. While the ages 16 and above who were already at/or above the new school leaving age could leave school earlier, thereby making them the non-affected or control group. With this division, we compare the treatment and the control group with respect to the completion of grade 10 (last grade of lower secondary, or the compulsory education threshold). That is, a discontinuity analysis between the treatment and the control group. 
We use a regression discontinuity design because the compulsory education policy is equivalent to an intervention or a treatment that is applied to a set of eligible individuals based on the fact that they are above or below a certain cut-off (in this case, below the age of 16). It is also a national policy, therefore, no part of the nation is excluded, which could have enabled an alternative analytical method such as difference-in-differences design to compare individuals of the same age with different treatment status. The grade 10 completion comparison is also done by gender. This is because, as observed in Chapter 2 , females are more disadvantaged than males in terms of school attendance. In the presence of fee-free education, more parents may send female children to school because of the reduction in school expenses. For instance, the free education policy in junior secondary schools in Tanzania caused a larger increase in female enrolment compared to male enrolment (Lyanga and Chen, 2020). We also describe completion between the treatment group and the control group for the high school grades (grades 11 to 13). We summarize the variables used in the analysis in Table 4.1.. In what follows, we briefly discuss the literature followed by a description of the formal education system in Senegal and the compulsory school reform of 2004. We then describe the methodology and the data, and we finally present the results and discussion.

\subsection{Compulsory secondary education in low income and lower-middle-income countries}

In some low income and lower-middle-income countries, compulsory education has been extended beyond primary education through the incorporation of lower secondary education in the compulsory education system. For instance, in Afghanistan, Syria Arab Republic, Georgia, and Morocco, compulsory education has been increased from 6 to 9 years (grades 1-9 in all). It was increased from 6 to 10 years in Chad, Cape Verde, and Senegal (grades 1-10); 5 to 9 years in Vietnam (grades 1-9) (Diaz-Serrano, 2020). Tanzania increased from 7 to 10 years (grades 110) (Lyanga and Chen, 2020; Mashala, 2019). The elimination of school fees in lower secondary education in these countries accompanied the compulsory education reform. This is a strategy to increase enrollment in school and to contribute to universal primary and secondary education, a move supported by - among others - the World Bank and UNICEF.

The success of these laws requires that necessary conditions such as school provisions and accessibility of schools, as well as compliance are met. This aspect differentiates compulsory schooling reforms in advanced economies from those in low income and lower-middle-income countries because low income and lower-middle-income countries do not usually have the 
necessary infrastructure to ensure that the newly compulsory grade levels ensure universal accessibility. In Senegal for instance, a gradual provision of the necessary requirements was being carried out by the Government. The Government provided grants for some public schools to ensure fees-free primary and lower secondary education (World Bank, 2013). A new basic education curriculum was introduced in 2005, and new primary and lower secondary schools were being constructed progressively which let to about 7487 schools in total by 2007 as compared to 4751 existing schools in 2000 (UNESCO, 2010).

Nevertheless, the number of schools, desks, textbooks, classrooms, and teachers required to universally accommodate children remains insufficient in these countries (Dramani and Ndiaye, 2015; Lom, 2018; Lyanga and Chen, 2020; Mashala, 2019; World Bank, 2013). Besides insufficient capacity in these countries, compulsory education is frequently only free at some government schools (Chapman et al., 2010; Senegal, 2004). Therefore, parents have to pay fees in government schools where it is not free, as well as in private schools. Parents also have to take care of other expenses like school uniforms, school bags, school shoes, feeding, medical services, and accommodation (Chapman et al., 2010; Fute et al., 2019; Lyanga and Chen, 2020; Mashala, 2019).

Compulsory education laws usually involve non-compliance costs, which can be monetary or non-monetary (Kirdar et al., 2015). Countries also carry out improved registration such that parents of children who practice unauthorized absenteeism or who illegally leave school can be identified and, if necessary, fined (Cabus and De Witte, 2011). Developing countries however, do not benefit from such enforcement mechanisms to oblige children to go to school. In Afghanistan for instance, although all pupils must attend secondary education, parents are not asked to send their children to school and neither are out-of-school children nor those who dropped out of school asked to enroll. Families whose children do not attend school face no consequences (Human Rights Watch, 2017). In Senegal, it is left to the will of the parents to enroll their children in an institution, and there is no follow-up to make sure that enrolled children stay in school until the school leaving age (Senegal, 2004).

\subsection{Education in Senegal and the compulsory school age reform}

Senegal has a formal system with 3 years of early childhood education, 6 years of primary education, 4 years of lower secondary education, 3 years of upper secondary education, and 5 years of tertiary education (UNESCO, 2020). The age of school entry is 6, and the school year starts in October. The country comprises of 14 educational (subnational) cities. They include 
Dakar, Ziguinchor, Diourbel, Saint-louis, Tambacounda, Kaolack, Thies, Louga, Fatick, Kolda, Matam, kaffrine, kedougou, Sedhiou (EPDC, 2011). The formal education system comprises government schools and independent private schools (World Bank Group, 2016). More than $80 \%$ of students are enrolled in Government schools at each level from pre-primary to high school (UNESCO, 2010). Besides the formal education system, Senegal has a cultural and religious education system in which children are being instructed in the Muslim faith. This system comprises of Arabic language schools known as Daaras, where the students enroll at the age of seven and study the Koran, in Arabic, rather than the foundational literacy and numeracy that is being taught in the formal education system (World Bank, 2013). Daara students in some areas cannot attend primary school because Daara and primary school are mutually exclusive (World Bank, 2013).

In 2004, Senegal embarked on an education policy known as the Act 2004-37 of 15 December 2004 which modifies the 1991 compulsory education law. The law was implemented because of the increasing number of children excluded from school (Lom, 2018). Lom (2018) explained that because of the increasing number of out-of-school children, the 2004 compulsory education law was implemented as a measure to achieve inclusion. The modification of this law comprises the inclusion of lower secondary education to the compulsory education (Senegal, 2004). This implies that education is now compulsory for children of the age of 6 to the age of 16 when they complete lower secondary (UNESCO, 2006). While 16 year-olds from the 15th of December 2004 could legally leave school as before the policy amendment, 15, 14, and 13-year olds from the 15th of December 2004 are legally required to stay in school for one, two, and three more years respectively, unlike before the policy amendment.

Following the reform, there was an increase in primary school enrolment from 29,216 in 2003 to 45,957 in 2007 . The changes between 2005 and 2011 reduced the primary school repetition rate from $13 \%$ to $3 \%$, and reduced the pupil/teacher ratio (37) through the recruitment of more teachers (World Bank, 2013). The transition rate from primary to lower secondary increased from $48 \%$ in 2005 to $90.5 \%$ in 2011 . The transition rate from lower secondary to high school also increased from $37.4 \%$ in 2006 to $45.2 \%$ in 2007 (UNESCO, 2010).

However, Senegal still faces numerous challenges such as low primary school completion. In total, only $42 \%$ of the children in a cohort complete primary education by 2015 (UNESCO, 2015). Among this $42 \%, 12 \%$ are children from the poorest households. There is also a more than $20 \%$ teacher absenteeism rate in primary education (UNESCO, 2015). There are many 


\section{Chapter 4}

causes of formal school dropout or school exclusion in Senegal. Some of these causes include the lack of learning infrastructure, teenage marriages, poor academic results, and poverty (Lom, 2018).

The existence of religious schools called Daaras, is also considered one of the causes of students' exclusion from school (Lom, 2018). In Daaras, children enroll to study the Koran. In that process, they cannot enroll in formal education because Daaras run parallel to formal primary education. This is also intergenerational, as a higher proportion of children who have never attended school come from households with uneducated household heads or household heads who only attended Koranic schools (Lom, 2018).

\subsection{Data and methodology}

The data used come from the Demographic and Health Surveys (DHS) among households in Senegal. This is a nationally representative cross-sectional survey carried out in 2017 . We use the ages the individuals would be in 2017. For instance, a 13 years old student in 2005 would be 25 years old in 2017. The same approach is taken for the other ages, as shown in Table 4.1.. We thus projected their ages in 2017. The age composition derived from this ranges from 25 to 30 years. Our dependent variable is the completion of compulsory education (grade 10). Table 4.1. below presents the descriptive statistics and t-tests for covariates differences in both groups. 
Table 4.1.: Descriptive statistics: range, mean, standard deviation (in brackets), percentage, and $t$-test of covariate balance

\begin{tabular}{ccc}
\hline Variables & Treatment cohort $(N=859)$ & Control cohort $(N=702)$ \\
\hline Grade 10 completion & $0.29(0.45)$ & $0.23(0.42)$ \\
\hline Parent's education & Range: $0-20$ & Range: $0-19$ \\
Difference: $P r=0.9025$ & $2.39(4.26)$ & $2.42(4.43)$ \\
\hline Number of household members & Range: $1-50$ & Range: $1-50$ \\
Difference: $P r=0.0018$ & $12.28(7.00)$ & $13.45(7.69)$ \\
\hline Gender: Boy (vs Girl) & Range: $0-1$ & Range: $0-1$ \\
Difference: $P r=0.0355$ & $0.64(0.48)$ & $0.70(0.46)$ \\
\hline Region: Rural (vs Urban) & Range: $0-1$ & Range: $0-1$ \\
\hline Difference: $P r=0.2188$ & $0.50(0.50)$ & $0.47(0.50)$ \\
\hline City & $\%$ & $\%$ \\
Dakar & 13.62 & 14.96 \\
Ziguinchor & 6.75 & 6.55 \\
Diourbel & 8.96 & 6.13 \\
Saint-louis & 8.15 & 8.83 \\
Tambacounda & 6.98 & 6.70 \\
Kaolack & 5.59 & 5.84 \\
Thiés & 10.36 & 9.69 \\
Louga & 5.94 & 7.69 \\
Fatick & 6.40 & 5.70 \\
Kolda & 6.64 & 6.41 \\
Matam & 5.36 & 5.56 \\
Kaffrine & 5.36 & 5.70 \\
Kedougou & 2.68 & 2.71 \\
Sedhiou & 7.22 & 7.55 \\
Difference: $P r=0.7261$ & & \\
13 & Age in 2017 & Sample size \\
14 & 25 & 462 \\
15 & 26 & 268 \\
16 & 27 & 129 \\
17 & 28 & 219 \\
18 & 29 & 316 \\
\hline Age in 2005 & 30 &
\end{tabular}

A comparison between variables in both groups using t-tests shows that parent's education, region of residence and city are not statistically different in both groups. Gender and the number of household members are statistically different. However, these variables are not particularly related to age. We include these variables in the analysis to account for any effect from their differences. We also include an interaction term between gender and the treatment variable to observe the gender differential effect of the policy. 
Figure 4.1.: Trends in grade 10 completion

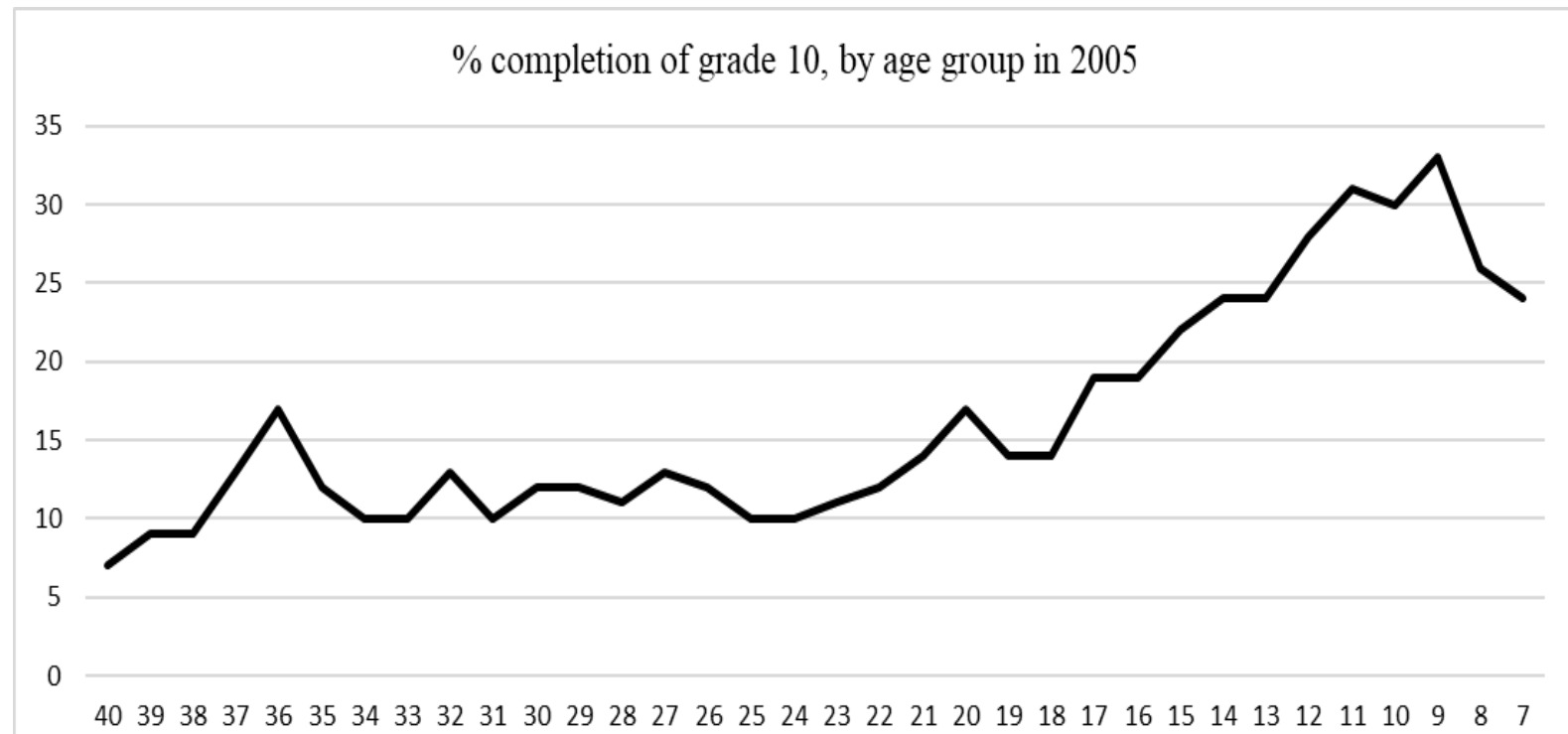

The Y-axis in Figure 4.1. shows the percentages of the individuals in the age cohorts who completed grade 10, while the $\mathrm{X}$-axis (from left to right) represents the corresponding age cohorts from older (age 40) to younger (age 7). These are their ages in 2005. In 2017, this corresponds to age 52 to age 19, respectively. Generally, the younger you are the more likely you will complete grade 10 . The completion of grade ten exhibits a very irregular pattern both before and after it became compulsory. Those aged 40 down to age 37 experienced an increase from about $7 \%$ to $36 \%$ in the completion of grade 10 . This trend went down to $12 \%$ and remained almost unchanged until age 22 . After age 22 , the movement is characterized by an increasing trend where it increased from $14 \%$ to $33 \%$, while for younger cohorts (20-19 years) the completion rate seems lower.

We exploit the December 2004 increase in the compulsory education age from 12 to 16 to estimate the causal impact of the increase in compulsory education on educational attainment. The policy took effect as from the academic year 2005-06. The academic year 2005 together with the ages of the students, serve as the basis for the determination of the treatment group and the control group. The estimation strategy we propose principally relies upon a comparison across age cohorts. The choice of using age cohort is because the data does not have information on the exact date of birth of the individuals. That is, the age information is only available or recorded in the data in years, which renders the treatment variable discrete. We apply a parametric regression discontinuity that estimates the effect of an increase in the years of compulsory education on educational attainment, which indicates the change in the average outcome between those affected and those not affected by the policy change (Meghir and Palme, 
2005). Therefore, instead of computing arbitrarily small neighborhood averages at the cutoff, we choose a functional form relating the treatment variable to the outcome of interest, as explained in Lee and Card (2008).

Because of the binary nature of the outcome, we apply a logistic regression analysis.

Binary values 1 and 0 are used to represent 'completion of grade 10' and 'no completion of grade 10', respectively. As described in Kleinbaum (1994), the probability of completing grade 10 is described by the following regression model:

$P\left(Y=1 \mid X_{1}, X_{2}, \ldots X_{k}\right)=\frac{1}{1+e^{-(b o+b 1 X 1+b 2 X 2+\cdots b k X k)}}$

where $P\left(Y=1 \mid X_{1}, X_{2}, \ldots X_{k}\right)$ is the probability of the dependent variable being 1 . We define the Latent variable $\mathrm{Y}^{*}$ using the age threshold as follows;

$$
\begin{aligned}
& \mathrm{Y}^{*}=0 \text { if control group (ages 16-18) } \\
& \mathrm{Y}^{*}=1 \text { if treatment group (ages 13-15) }
\end{aligned}
$$

We estimate the following model;

$Y^{*}=a o+b 1 D j+b 2 X i j+e i j$

$\mathrm{Dj}$ is a dummy variable indicating 1 for belonging to the treatment group and 0 for belonging to the control group. The parameter of interest is $b 1$ of the variable $D j$ (the difference in grade 10 completion between the treatment group and the control group). $X i j$ is a vector of the observable individual characteristics and family characteristics. These characteristics include gender; number of household members; parent's education; and fixed effects for city and region. eij is an error term. The standard errors are clustered at the household level. The results (coefficients and marginal effects) of this analysis are presented in Table 4.2.. The effect shows the percentage increase in the likelihood of completing grade 10 in the treatment group as compared to the control group.

To address potential specification error concerns regarding the discreteness of our dependent variable, we perform the standard error correction suggested by Lee and Card (2008). They suggested clustering of standard errors at the running variable level. In our case, this variable is age. We therefore constructed a household-age (household + age) variable for clustering. The results show, however, that by doing so coefficients remained unchanged and statistically significant, though the standard errors increased slightly. This output is presented in Appendix A4.1.. 


\section{Chapter 4}

To analyze the changes in schooling decisions after the compulsory education threshold, we perform chi-square tests of the association on the completion of the high school grades. There are three high school grades, which are, grades 11, 12, and 13. The output of these tests are presented in Table 4.5..

\subsubsection{Regression discontinuity issues}

The pros of the regression discontinuity analysis in regards to the evaluation of the education policy is that it reduces biasness in the estimates given that the exact treatment assignment as well as the probability of being assigned to the treatment condition is known (Hausman and Rapson, 2018). Further, regression discontinuity analysis does not have to deal with impractical or unethical issues that may arise in the process of randomization of individuals into control and treatment conditions (Tuckwiller et al., 2010). A regression discontinuity design also has good external validity as it uses natural variation between individuals to assign people to the treatment and control groups. However, the regression discontinuity analysis is not without limitations, even though it is valid for this education policy. Model misspecification from incorrectly specified baseline-outcome functional relation can lead to biased estimates. This could be an issue if the possible variation in the $\mathrm{x}$-values calls for concern or is subject to error (Tuckwiller et al., 2010).

The treatment cohort may possibly have higher educational attainment because of rapid economic growth (Fang et al., 2012). This is also possible in the presence of various contemporaneous policies (Chin, 2005). However, there wasn't a rapid economic growth in Senegal, with an annual average growth rate of 3.3\%, causing an almost constant poverty rate throughout the decade (World Bank, 2013). The rate of employment in Senegal has decreased gradually since 1991 from $50 \%$ to about $43 \%$ in 2019. Moreover, this study's data does not span a long period. The evaluation of this policy is facilitated by the fact that the compulsory education component included elements of exogenous variations, one of which is that only children aged 15 and below were affected. In addition, school improvement programs and grants accompanied the policy, to enable quality and free education (World Bank, 2013).

The interviews were carried out from January to December. It is possible that those who were 15 years old and interviewed before October (the month of school commencement) turned 16 by October thereby creating fuzziness in the data. In the same way, there could be 16 year-olds interviewed in November and December who were 15 in October. To resolve this, these two age cohorts in this analysis are comprised respectively of the 15 year-olds who were interviewed 
between October and December and also the 16 year-olds who were interviewed between January and October.

There is also the problem of bunching or manipulation of the data around the cutoff. The data in this chapter strictly divides age cohorts according to either the treatment group or the control group. However, we run the analysis after eliminating the 15 year-olds and 16 year-olds as explained above in order to cater for possible fuzziness. This led to a reduction of the number of individuals closest to the cutoff on both sides, which may lead to minor change in the size of the coefficient. We provide a graph of the density of the forcing variable age in Figure 4.2. below.

Figure 4.2.: Density for the forcing variable

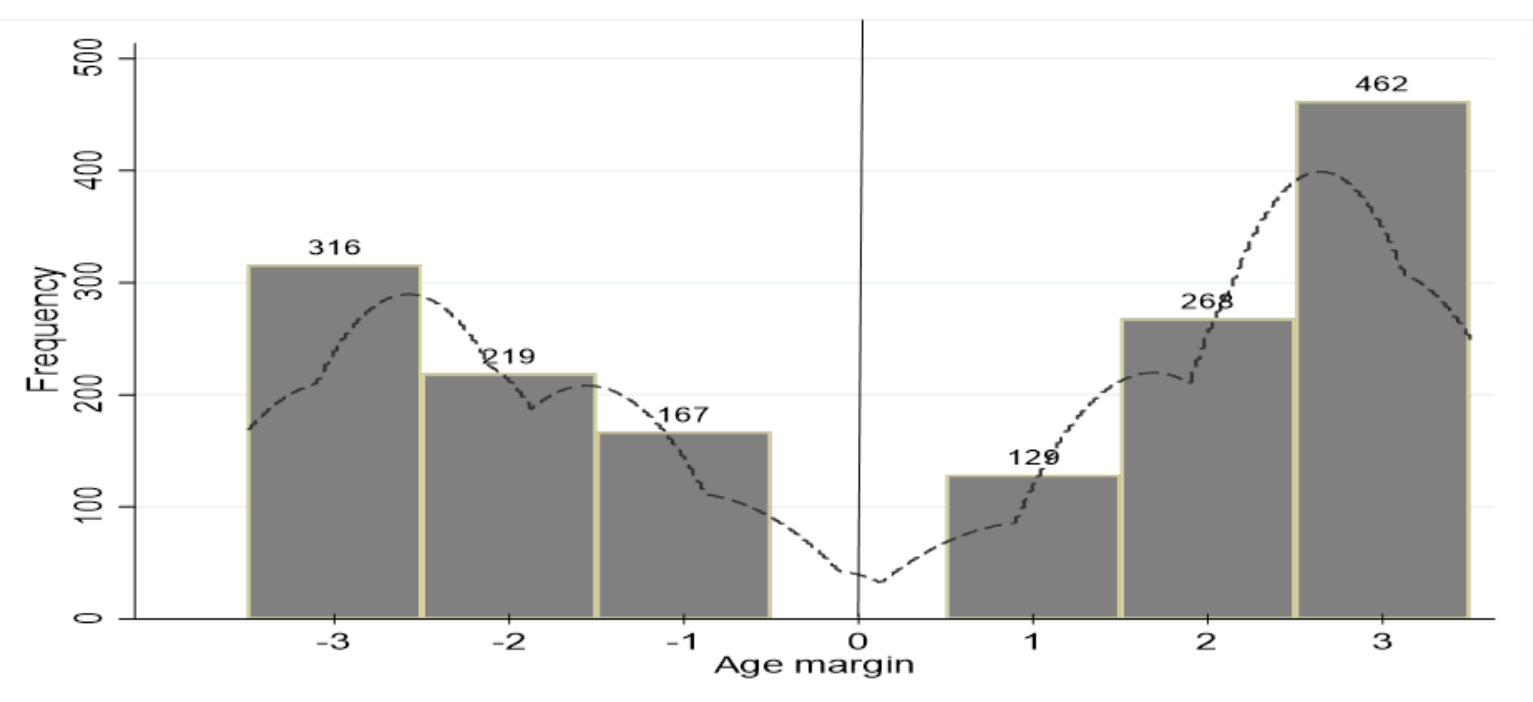

The right side of Figure 4.2. represents the treatment group while the left side represents the control group. Values 1, 2, and 3 are ages 13, 14, and 15, respectively, while values $-1,-2$, and -3 are ages 16,17 , and 18 , respectively. The point ' 0 ' is the cutoff. The density distribution looks continuous to the left as well as to the right.

Covariates that could influence the outcome might also have a discontinuity around the cut-off, which could pose a problem. We verify this by performing the covariate test to see if there is no discontinuity in other covariates around the age cut-off. The t-tests done for this purpose are presented in Table 4.1. above.

Another concern in our identification strategy is the existence of a discontinuity at another arbitrary cut-off before the treatment. There could be discontinuity in case the outcome variable did not evolve similarly before the treatment. We carry out a placebo test by assuming the law 
Chapter 4

took place three years prior to the cutoff to see whether this would significantly change the outcome. That is, 16-18(treatment group) vs 19-21(control group). We do the same procedure again using three years prior to the first placebo test. That is 19-21(treatment group) vs 2224(control group). The results from the two placebo tests do not show significant differences between treatment and control group in the outcome. We present this in Table 4.4..

\subsection{Results}

\subsubsection{Effect of the compulsory education policy on grade 10 completion}

Table 4.2. below presents the results of the logistic regression analysis. This shows the effect of the compulsory education policy on grade 10 completion for the treatment group as compared to the control group. Based on the logistic model in Table 4.2., the positive coefficient $(0.42)$ indicates that the policy significantly impacted grade 10 completion. The marginal effect shows that individuals in the treatment group are $7 \%$ more likely to complete grade 10 as compared to those in the control group. 
Marginal Impact of a Compulsory Education Reform on Secondary Education

Table 4.2.: Logistic regression of compulsory education completion (grade 10) for treatment (13-15) and control group (16-18)

\begin{tabular}{|c|c|c|c|c|c|c|c|c|c|}
\hline & Coefficient & $\begin{array}{l}\text { Standard } \\
\text { Error }\end{array}$ & \multicolumn{2}{|c|}{ t-value } & p-value & $\begin{array}{r}\text { [Confidence } \\
95 \% \\
\end{array}$ & Interval] & \multicolumn{2}{|c|}{ Marginal effect } \\
\hline & & & & & & & & Coef. & Std. Err. \\
\hline \multicolumn{10}{|l|}{ Group (Control) } \\
\hline Treatment & $0.423 * * *$ & 0.161 & 2.64 & & 0.008 & 0.109 & 0.738 & $0.072 * * *$ & 0.027 \\
\hline PE & $0.114 * * *$ & 0.021 & 5.48 & & 0.000 & 0.073 & 0.155 & $0.019 * * *$ & 0.003 \\
\hline \multicolumn{10}{|l|}{ Gender $(\mathrm{F})$} \\
\hline M & 0.043 & 0.168 & 0.26 & & 0.799 & -0.287 & 0.373 & 0.007 & 0.029 \\
\hline $\mathrm{NHH}$ & $-0.042 * * *$ & 0.015 & -2.6 & & 0.007 & -0.072 & -0.011 & $-0.007 * * *$ & 0.003 \\
\hline \multicolumn{10}{|l|}{ City (Dakar) } \\
\hline Ziguinchor & $0.704 * *$ & 0.288 & 2.44 & & 0.014 & 0.140 & 1.268 & $0.145^{* *}$ & 0.059 \\
\hline Diourbel & -0.420 & 0.326 & -1.2 & & 0.197 & -1.058 & 0.218 & -0.076 & 0.058 \\
\hline Saint-louis & $-1.106 * * *$ & 0.343 & -3.2 & & 0.001 & -1.778 & -0.434 & $-0.176 * * *$ & 0.049 \\
\hline Tambacounda & -0.348 & 0.325 & -1.0 & & 0.285 & -0.986 & 0.290 & -0.064 & 0.059 \\
\hline Kaolack & -0.192 & 0.311 & -0.6 & & 0.537 & -0.802 & 0.418 & -0.036 & 0.058 \\
\hline Thiés & -0.022 & 0.254 & -0.0 & & 0.930 & -0.520 & 0.475 & -0.004 & 0.049 \\
\hline Louga & $-1.586^{* * *}$ & 0.409 & -3.8 & & 0.000 & -2.388 & -0.784 & $-0.226 * * *$ & 0.049 \\
\hline Fatick & -0.018 & 0.311 & -0.0 & & 0.954 & -0.628 & 0.592 & -0.003 & 0.060 \\
\hline Kolda & $-0.755^{* *}$ & 0.336 & -2.2 & & 0.025 & -1.415 & -0.096 & $-0.129 * *$ & 0.055 \\
\hline Matam & -0.708 & 0.371 & -1.9 & & 0.056 & -1.436 & 0.019 & $-0.122 * *$ & 0.060 \\
\hline Kaffrine & $-1.379 * * *$ & 0.474 & -2.9 & & 0.004 & -2.307 & -0.451 & $-0.206^{* * *}$ & 0.058 \\
\hline Kedougou & 0.140 & 0.426 & 0.3 & & 0.743 & -0.696 & 0.975 & 0.027 & 0.084 \\
\hline Sedhiou & -0.038 & 0.312 & -0.1 & & 0.903 & -0.649 & 0.573 & -0.007 & 0.060 \\
\hline \multicolumn{10}{|l|}{ Residence (U) } \\
\hline $\mathrm{R}$ & $-0.562 * * *$ & 0.184 & -3.0 & & 0.002 & -0.923 & -0.202 & $-0.097 * * *$ & 0.032 \\
\hline Constant & $-0.630 * *$ & 0.299 & -2.1 & & 0.035 & -1.215 & -0.044 & & \\
\hline \multicolumn{2}{|c|}{ Mean dependent variable } & \multicolumn{2}{|c|}{0.261} & \multicolumn{3}{|c|}{ SD dependent variable } & \multicolumn{2}{|c|}{0.440} & \\
\hline \multicolumn{2}{|c|}{ Pseudo r-squared } & \multicolumn{2}{|c|}{0.161} & \multicolumn{3}{|c|}{ Number of observations } & \multicolumn{2}{|c|}{1561} & \\
\hline \multicolumn{2}{|l|}{ Chi-square } & \multicolumn{2}{|c|}{175.178} & \multicolumn{3}{|c|}{ Prob > chi 2} & \multicolumn{2}{|c|}{0.000} & \\
\hline
\end{tabular}

Note: $\mathrm{PE}=$ Parent's education, $\mathrm{NHH}=$ Number of household members, $\mathrm{U}=$ Urban, $\mathrm{R}=$ Rural, $\mathrm{M}=\mathrm{Male}, \mathrm{F}=\mathrm{Female} ; * * * \mathrm{p}<0.01, * * \mathrm{p}<0.05$ 


\subsubsection{Gender differential effect of the policy on grade 10 completion}

The gender differential is identified by interacting the policy dummy with the gender, as shown below;

$Y i j=a o+b 1 D j+b 2(D j \times G e n d e r i j)+b 3 X i j+e i j$,

$D j \times$ Genderij represents the interaction between the policy dummy and the gender variable.

Xij includes gender, number of household members, parent's education, and fixed effects for city and region.

Table 4.3.: Gender differential effect

\begin{tabular}{|c|c|c|c|c|c|c|}
\hline & Coefficient & $\begin{array}{l}\text { Standard } \\
\text { Error }\end{array}$ & $\mathrm{t}$-value & $\mathrm{p}$-value & $\begin{array}{c}\text { [Confidence } \\
95 \%\end{array}$ & Interval] \\
\hline \multicolumn{7}{|l|}{ Group (Control) } \\
\hline Treatment & $0.563 * *$ & 0.273 & 2.06 & 0.039 & 0.028 & 1.098 \\
\hline $\mathrm{PE}$ & $0.114 * * *$ & 0.021 & 5.47 & 0.000 & 0.073 & 0.155 \\
\hline \multicolumn{7}{|l|}{ Gender $(\mathrm{F})$} \\
\hline M & 0.172 & 0.260 & 0.66 & 0.509 & -0.337 & 0.680 \\
\hline \multicolumn{7}{|l|}{ Group×gender } \\
\hline Treatment/Male & -0.211 & 0.339 & -0.62 & 0.534 & -0.876 & 0.454 \\
\hline $\mathrm{NHH}$ & $-0.042 * * *$ & 0.015 & -2.73 & 0.006 & -0.072 & -0.012 \\
\hline \multicolumn{7}{|l|}{ City (Dakar) } \\
\hline Ziguinchor & $0.712 * *$ & 0.288 & 2.47 & 0.013 & 0.148 & 1.275 \\
\hline Diourbel & -0.420 & 0.325 & -1.29 & 0.197 & -1.058 & 0.218 \\
\hline Saint-louis & $-1.105^{* * *}$ & 0.344 & -3.22 & 0.001 & -1.779 & -0.432 \\
\hline Tambacounda & -0.349 & 0.325 & -1.07 & 0.283 & -0.986 & 0.288 \\
\hline Kaolack & -0.192 & 0.310 & -0.62 & 0.537 & -0.800 & 0.416 \\
\hline Thiés & -0.021 & 0.254 & -0.08 & 0.935 & -0.519 & 0.477 \\
\hline Louga & $-1.585 * * *$ & 0.409 & -3.87 & 0.000 & -2.387 & -0.782 \\
\hline Fatick & -0.011 & 0.311 & -0.04 & 0.971 & -0.622 & 0.599 \\
\hline Kolda & $-0.756 * *$ & 0.336 & -2.25 & 0.024 & -1.414 & -0.097 \\
\hline Matam & -0.705 & 0.372 & -1.90 & 0.058 & -1.435 & 0.024 \\
\hline Kaffrine & $-1.367 * * *$ & 0.474 & -2.88 & 0.004 & -2.295 & -0.438 \\
\hline Kedougou & 0.151 & 0.423 & 0.36 & 0.722 & -0.679 & 0.980 \\
\hline Sedhiou & -0.040 & 0.311 & -0.13 & 0.897 & -0.650 & 0.570 \\
\hline \multicolumn{7}{|l|}{ Residence (U) } \\
\hline $\mathrm{R}$ & $-0.564 * * *$ & 0.184 & -3.07 & 0.002 & -0.924 & -0.204 \\
\hline Constant & $-0.715^{* *}$ & 0.335 & -2.13 & 0.033 & -1.372 & -0.057 \\
\hline \multicolumn{2}{|l|}{ Mean dependent $v$} & 0.261 & \multicolumn{3}{|c|}{ SD dependent variable } & 0.440 \\
\hline \multirow{2}{*}{\multicolumn{2}{|c|}{$\begin{array}{l}\text { Pseudo r-squared } \\
\text { Chi-square }\end{array}$}} & 0.161 & \multirow{2}{*}{\multicolumn{3}{|c|}{ Number of observations }} & 1561.000 \\
\hline & & 175.403 & Prob > & & & 0.000 \\
\hline
\end{tabular}

Note: $\mathrm{PE}=$ Parent's education, $\mathrm{NHH}=$ Number of household members, $\mathrm{U}=$ Urban, $\mathrm{R}=$ Rural, $\mathrm{M}=\mathrm{M}$ ale, $\mathrm{F}=$ Female; $* * * \mathrm{p}<0.01, * * \mathrm{p}<0.05$

The gender differential effect is negative, implying a grade 10 completion gap between men and women. However, this gender differential effect is statistically insignificant, implying that there is no reduction in the grade 10 completion gender gap of the reform. 


\subsubsection{Robustness checks}

Table 4.4.: Logistic regression of grade 10 completion for treatment (16-18) and control (19-21), and treatment (19-21) and control (22-24)

\begin{tabular}{|c|c|c|c|c|c|c|c|c|c|}
\hline \multicolumn{5}{|c|}{ Treatment (16-18) and control (19-21) } & \multicolumn{5}{|c|}{ Treatment (19-21) and control (22-24) } \\
\hline & Coefficient & Standard Error & t-value & p-value & Coefficient & Standard Error & t-value & p-value & \\
\hline \multicolumn{10}{|l|}{ Group (Control) } \\
\hline Treatment & 0.148 & 0.187 & 0.79 & 0.429 & 0.367 & 0.211 & 1.74 & 0.082 & \\
\hline $\mathrm{PE}$ & $0.125 * * *$ & 0.020 & 6.09 & 0.000 & $0.124 * * *$ & 0.027 & 4.67 & 0.000 & \\
\hline \multicolumn{10}{|l|}{ Gender $(F)$} \\
\hline M & 0.337 & 0.206 & 1.64 & 0.102 & 0.214 & 0.248 & 0.86 & 0.388 & \\
\hline $\mathrm{NHH}$ & $-0.041 * *$ & 0.016 & -2.53 & 0.011 & -0.033 & 0.021 & -1.60 & 0.110 & \\
\hline \multicolumn{10}{|l|}{ City (Dakar) } \\
\hline Ziguinchor & $1.101 * * *$ & 0.374 & 2.95 & 0.003 & $1.631 * * *$ & 0.416 & 3.92 & 0.000 & \\
\hline Diourbel & -0.048 & 0.469 & -0.10 & 0.918 & -0.160 & 0.504 & -0.32 & 0.751 & \\
\hline Saint-louis & $-0.687 * *$ & 0.332 & -2.07 & 0.038 & -0.519 & 0.428 & -1.21 & 0.226 & \\
\hline Tambacounda & -0.328 & 0.411 & -0.80 & 0.424 & -1.498 & 0.767 & -1.95 & 0.051 & \\
\hline Kaolack & -0.240 & 0.451 & -0.53 & 0.594 & -0.726 & 0.628 & -1.16 & 0.248 & \\
\hline Thiés & 0.025 & 0.291 & 0.09 & 0.931 & -0.090 & 0.351 & -0.26 & 0.798 & \\
\hline Louga & -0.701 & 0.456 & -1.54 & 0.124 & -0.506 & 0.558 & -0.91 & 0.365 & \\
\hline Fatick & -0.160 & 0.386 & -0.41 & 0.679 & 0.418 & 0.432 & 0.97 & 0.333 & \\
\hline Kolda & -0.580 & 0.452 & -1.28 & 0.199 & -0.063 & 0.466 & -0.14 & 0.893 & \\
\hline Matam & -0.564 & 0.474 & -1.19 & 0.234 & -0.352 & 0.616 & -0.57 & 0.567 & \\
\hline Kaffrine & -1.188 & 0.644 & -1.84 & 0.065 & $-2.115 * *$ & 1.012 & -2.09 & 0.037 & \\
\hline Kedougou & 0.190 & 0.600 & 0.32 & 0.752 & 0.291 & 0.696 & 0.42 & 0.676 & \\
\hline Sedhiou & 0.476 & 0.436 & 1.09 & 0.275 & -0.034 & 0.563 & -0.06 & 0.952 & \\
\hline \multicolumn{10}{|l|}{ Residence (U) } \\
\hline $\mathrm{R}$ & $-0.732 * *$ & 0.288 & -2.55 & 0.011 & $-0.669 * *$ & 0.338 & -1.98 & 0.048 & \\
\hline Constant & $-1.030 * * *$ & 0.326 & -3.16 & 0.002 & $-1.568 * * *$ & 0.397 & -3.94 & 0.000 & \\
\hline \multirow{3}{*}{$\begin{array}{l}\text { Mean dependent varial } \\
\text { Pseudo r-squared } \\
\text { Chi-square }\end{array}$} & ole $\quad 0.225$ & \multicolumn{2}{|c|}{ SD dependent variable } & 0.418 & \multicolumn{2}{|c|}{ Mean dependent variable 0.176} & SD deper & nt variable & 0.381 \\
\hline & 0.156 & Number of ol & servations & 1159 & Pseudo r-sq & 0.141 & Number & bservations & 923 \\
\hline & 136.67 & Prob > chi 2 & & 0.000 & Chi-square & 89.983 & Prob $>\mathrm{cl}$ & & 0.000 \\
\hline
\end{tabular}


A robustness check is carried out by setting a first arbitrary cutoff three years prior the actual date, and a second arbitrary cutoff three years prior the first arbitrary cutoff. That is, (16-18 vs 19-21) and (19-21 vs 22-24), as shown in Table 4.4.. In both Tables, there is no significant difference in the coefficients of the outcome variable. This indicates that the outcome variable evolved in the same manner prior to the treatment.

\subsubsection{Descriptive trends for post-compulsory grades completion}

Completion of the post-compulsory grades are dichotomous variables reflecting whether or not individuals have completed the $11^{\text {th }}, 12^{\text {th }}$, and $13^{\text {th }}$ grade of high school. We examine the proportion that completed grades 11, 12, and 13 by group (treatment group and control group). Chi-square tests of association are used to examine differences between these variables.

Table 4.5.: Chi-square tests of association for completion of grades 11, 12, and 13

\begin{tabular}{|c|c|c|c|c|c|}
\hline \multicolumn{6}{|c|}{ Completed grade 11} \\
\hline & \multicolumn{2}{|c|}{ Yes } & \multicolumn{2}{|c|}{ No } & \\
\hline & $\%$ & $95 \% \mathrm{CI}$ & $\%$ & $95 \% \mathrm{CI}$ & \\
\hline Overall & 22.61 & & 77.39 & & \\
\hline Treatment & 24.91 & $0.55-0.66$ & 75.09 & $0.51-0.56$ & $\operatorname{Pr}=0.016$ \\
\hline Control & 19.80 & $0.34-0.45$ & 80.20 & $0.44-00.49$ & \\
\hline \multicolumn{6}{|c|}{ Completed grade 12} \\
\hline & \multicolumn{2}{|c|}{ Yes } & \multicolumn{2}{|c|}{ No } & \\
\hline & $\%$ & $95 \% \mathrm{CI}$ & $\%$ & $95 \% \mathrm{CI}$ & \\
\hline Overall & 20.63 & & 79.37 & & \\
\hline Treatment & 22.47 & $0.54-0.65$ & 77.53 & $0.51-0.57$ & $\operatorname{Pr}=0.047$ \\
\hline Control & 18.38 & $0.35-0.46$ & 81.62 & $0.43-00.49$ & \\
\hline \multicolumn{6}{|c|}{ Completed grade 13} \\
\hline & \multicolumn{2}{|c|}{ Yes } & \multicolumn{2}{|c|}{ No } & \\
\hline & $\%$ & $95 \% \mathrm{CI}$ & $\%$ & $95 \% \mathrm{CI}$ & \\
\hline Overall & 13.13 & & 86.87 & & $\operatorname{Pr}=0.434$ \\
\hline Treatment & 13.74 & $0.55-0.66$ & 86.26 & $0.51-0.56$ & \\
\hline Control & 12.39 & $0.34-0.45$ & 87.61 & $0.44-0.49$ & \\
\hline
\end{tabular}

Note: $\mathrm{CI}=$ confidence interval, percentages and confidence intervals reflect row percentages. Significance values are associated with chi-square tests of association.

We find that in grades 11,12 , and 13 , more than $70 \%$ of the individuals did not complete this grade $(77.39 \%, 79.37 \%$, and 86.87 , respectively). The compulsory education policy is associated with the completion of grade 11 and grade 12, but not with the completion of grade 13. The treatment group individuals are significantly more likely to complete grade $11(24.91 \%$ for treatment; $19.80 \%$ for control) and grade $12(22.47 \%$ for treatment; $18.38 \%$ for control). 


\subsection{Discussion and conclusion}

The extension of compulsory education in 2004 in Senegal from primary to lower secondary following high rates of exclusion and out of school children - substantially increased grade 10 completion for children aged 13 to 15 as compared to children aged 16-18. This shows that the effect of the change in the compulsory education law on compulsory school completion is highly significant and positive for these marginal learners. Treatment group individuals are $7 \%$ more likely to complete lower secondary education as compared to the control group individuals. Although the likelihood to complete grade 10 has increased, this outcome is not very sizable, given the number of years increase in compulsory education. The probability of completing grade 10 is $26 \%$ in the control group and $33 \%$ in the treatment group. Therefore, the probability of grade 10 completion following the policy increased from $26 \%$ by only 7 percentage points.

This means that among the total population of children, the likelihood of completing compulsory education is still relatively small. This implies that there is still a great challenge in getting children to stay in school until they complete compulsory education. This relatively small effect may be because of the challenges in the implementation of education policy in low-and-middleincome-countries, such as insufficient facilities (e.g. schools, teachers), no enforcement mechanisms of policy changes, and school expenses. It may also be because of the many other significant factors that cause students to drop out of school, as investigated in Chapter 2 of this thesis. For instance, wage labour is a significant deterrent to school attendance, and there is more than $60 \%$ informal employment in these countries. This informal employment is in turn highly correlated with primary to secondary school transition (Diaz-Serrano, 2020).

In terms of gender, no statistically significant gender differential effect is found of the increase in compulsory education. Similarly, in Tanzania, following the elimination of fees for compulsory lower secondary school, Lyanga and Chen (2020) found improvements in pass rates for junior secondary grades, with, however, more females than males being enrolled. On the completion of post-compulsory school grades or high school grades (grades 11, 12, and 13), the chi-square tests of association show that the completion of grade 11 and the completion of grade 12 are significantly associated with the education policy for these marginal learners. Therefore, more individuals completed grades 11 and 12 in the treatment group (those aged 13 to 15) as compared to the control group (those aged 16 to 18). However, completion of grade 13 does not show a statistically significant association with the education policy. And with more than $70 \%$ non-completion of grades 11 and 12, and more than $80 \%$ non-completion of grade 13, many 


\section{Chapter 4}

individuals still leave school without completing secondary education or obtaining secondary school certificate.

The spillover effects of the policy to post-compulsory grades (grades 11 and 12) is an interesting finding. There is not much report in the literature concerning this; an exception is Kirdar et al. (2015) and Oreopoulos (2009). Raising the compulsory education years limit increased high school completion (grades 11 and 12) indicating that would-be dropouts perhaps reconsidered post-compulsory school options after getting close to, or completing, compulsory education. This finding could also arise as a result of high price elasticity of schooling demand accompanied by a high reduction in schooling costs, as observed in Kirdar et al. (2015). Given the financial constraints some households in low income and lower-middle-income countries face, we expect that students who could not complete secondary education because of financial responsibilities in educating younger household members, would be able to go to school following costs reductions for compulsory education household members.

Within a standard framework of compulsory education laws, this finding on the increase in completion of grade 10 can be explained by measures put in place, such as the substantial investment in schooling infrastructure that accompanied the law. As such, this compulsory education policy may be similar to the school construction policies due to the substantial investment in schooling infrastructure. Investment in schooling, grants for some public schools, and new basic curriculum are the concurrent reforms that accompanied the policy. The estimated coefficients might therefore be partially capturing some of these measures. Unfortunately, this information cannot be specifically investigated. However, we assume that these concurrent reforms are embodied in the compulsory education policy. That is, the compulsory education reform is complemented by these concurrent reforms in order to be effective, and create impacts. Grants for instance enable funding and exempt households from paying fees, and the construction of more schools helps to accommodate the expected increase in the number of learners following the elimination of fees.

The improvement in grades completion after the compulsory education law has important implications for policy relevant to lower-middle-income and low income countries to achieve inclusion. First, these countries could extend compulsory education to include lower secondary school and obtain improvements in secondary grades completion and subsequent secondary school certificate obtention. Second, there is reason to believe that this achievement can be optimal especially if the challenges to compulsory education implementation are accommodated. This is because though the compulsory education policy seems to focus on 
making education free from primary to lower secondary, and providing more schools and school facilities, it still does not adequately cater for universal school enrolment. The country still faces insufficient infrastructures and a lack of human resources (Dramani and Ndiaye, 2015). This situation is found in other African countries, for instance, in Tanzania, where scarcity of resources such as schools, classrooms, teachers (to reduce high student-teacher ratios), and learning materials were found to be the most critical factors hindering the efforts to improve free secondary education (Lyanga and Chen, 2020).

Until present, accessing school facilities is part of the explanation of the huge gap between the rural and urban areas, with the rural areas having the larger amount of inaccessibility to school and school incompletion (World Bank Group, 2016). Teaching staff is still limited and there is still a lack of schools and infrastructure that can accommodate the education expansion brought about by the policy. Amongst the available middle schools for instance, up to $40 \%$ are housed in risky outdoor shelters which also limit learning by causing students and teachers to wait until the rainy season ends before commencing studies (World Bank, 2013). Therefore, prolonging compulsory education to incorporate lower secondary school and enabling free enrollment for some does not guarantee inclusion since many children are still out of school and more than $50 \%$ do not obtain secondary certificate.

Third, free education requires that parents no longer spend money on school-related needs to educate their children. Many parents still have to pay school fees where compulsory schooling is not subsidized. It is the task of the government to ensure all compulsory schools get the necessary support to assist free compulsory education. In addition, a follow-up measure to make sure the children involved are enrolled and/or stay in school until at least the school dropout age. Fourth, in low income and lower-middle-income countries, a $1 \%$ increase in employment in the informal sector is associated with a $0.66 \%$ decrease in effective transition of students from primary to secondary education (Diaz-Serrano, 2020). Of the overall employment, the average size of the informal employment is above $80 \%$ in the low income countries, and above $60 \%$ in the lower-middle-income countries. The question to ask is if the opportunity costs of schooling is more significant than the direct costs, and to what extent. Policy should also focus on improving secondary school retention and completion by preparing students earlier in their academic career for the desire and demands of schooling relative to working.

In conclusion, measures that could be introduced to ensure increases in free enrollment and completion rates of secondary education include ensuring that the costs of education in the compulsory grades are eliminated in all schools, and enough schools and teachers (to also 


\section{Chapter 4}

eliminate high pupil-teacher ratio) are provided especially in rural areas. Given that there are many other individual, household, and community-related factors that contribute in low school attendance, for instance, wage labour, parents' education, ethnicity, gender-related cultural beliefs, and lack of knowledge on the importance of school (Momo et al., 2019a), policy makers should device means of communication and sensitization on why schooling should be regarded as a priority.

We however, acknowledge important limitations of the analysis in this chapter, which are that, first, reducing the sample size of the age cohorts closest to the cutoff to cater for possible fuzziness may slightly reduce the effect size of the policy. Second, our analysis is limited to individuals closest to the cutoff, that is, we suggest that the effect of this regression discontinuity be generalized to individuals close to the threshold. We conclude from these results that the 2004 compulsory education amendment in Senegal increased the completion of compulsory education, as well as post-compulsory secondary school grades at the margin of the cutoff. However, we also observe that the final secondary school grade in order to obtain secondary certificate is not affected. This suggests further future policy investigation following the government's planned continuous efforts to ensure all children, including those in private schools and non-formal education schools have the chance to attend primary and lower secondary levels, and in better conditions. 


\section{Chapter 5}

\section{Household deprivation and the intergenerational correlation of education:}

an analysis of developing countries ${ }^{d}$

${ }^{\mathrm{d}}$ This chapter is based upon: Momo, M. S. M., Cabus, S. J., \& Groot, W. (2021). Household deprivation and the intergenerational correlation of education: an analysis of developing countries. International Journal of Educational Research, 109, 1-17.

https://doi.org/10.1016/j.ijer.2021.101797 
Chapter 5

\begin{abstract}
We investigate the relationship between parent's education and children's education in the presence of deprivation in developing countries. The aim is to contribute to the evidence on the important factors in the intergenerational transmission of education. The deprivation index constructed comprises of child mortality, school attendance, cooking fuel, sanitation, drinking water, electricity, housing, and assets. Our findings show a strong relationship between being deprived and the intergenerational correlation of education. This relationship is a little stronger for women as compared to the men.
\end{abstract}




\subsection{Introduction}

Education is a means to exit from poverty, while poverty is often a huge barrier to enroll in education (Engle and Black, 2008). In developing countries, there is persistent inequality in education and consequently, in the intergenerational transmission of education (Mahler et al., 2018; World Bank, 2018). The causes and consequences of the intergenerational correlation of education is one of the most debated topics in economics (Dennison and Swisher., 2018; Neidhofer et al., 2018). The majority of the early school leavers and out-of-school children come from poor households (UNESCO, 2019). The fact that many of the individuals with low attainment in education come from households with parents with low educational attainment like themselves - the intergenerational transmission of education - has been well documented (Azomahou and Yitbarek, 2016).

This has allowed researchers to address important issues in the relative and absolute intergenerational correlation of education and intergenerational mobility of education such as the relationship with infrastructure, income, occupation, educational development and industrialization (Aydemir and Yazici, 2019; Emran et al., 2019; Momo et al., 2019b; Qi and Wu, 2019; Van Doorn et al., 2011). Studies have investigated the association between economic development factors, and institutional characteristics on the one hand and the degree of intergenerational persistence of educational attainment on the other hand, for both advanced and developing economies (Aydemir and Yazici, 2019; Momo et al., 2019b; Van Doorn et el., 2011). In Chapter 3, we have been able to investigate the correlation between the characteristics of the institution and intergenerational correlation. We showed how characteristics such as GDP, female to male labour force participation, pupil-teacher ratio, primary school duration, compulsory years of education, and extent of voice and accountability can weaken the correlation between parents' education and children's education. A favourable characteristic favours educational attainment for the children such that they attain more education as compared to their parents.

For instance, in Chapter 4, the compulsory education policy amendment in Senegal was meant to increase the number of years of compulsory and free education such that children get to spend more time at school than before. This policy actually increased significantly the number of students who completed grade 10 (the new compulsory grade) and the post-compulsory secondary grades, for the marginal students. However, these macro-level economic variables are able to explain only a part of the relationship between parents' education and the children's 


\section{Chapter 5}

education. At the micro-level in developing countries, school dropout is closely associated with the poor and with children from households with low educated parents. It is not clear, however, what determines the non-financial gaps that occur early in the lives between children from advantaged families (high parental education) and disadvantaged families (low parental education). That is, household inequalities that represent inherited limited opportunities from parents and the lack of basic necessities for a comfortable standard of living for the children. In an advanced economy study, Aydemir and Yazici termed this as the home environment.

For instance, given the importance of the home environment in determining the outcomes in children, Aydemir and Yazici (2019) suggested some home environment factors that may contribute to high correlations across generations with regards to educational outcomes. They thus investigated the importance of four home-based deprivations or home environment variables on the intergenerational mobility of education in Turkey. These home variables include the presence of an encyclopedia, musical instrument, the number of siblings, and the ability to watch movies or go to theatres while growing up. Encyclopedia, musical instrument, and the ability to watch cultural events significantly interacted with parent's education to vary the educational attainment of children.

However, this relationship between household environment and the intergenerational correlation of education has not been identified in the literature for developing countries yet. This emphasizes the need to broaden our knowledge on the relevant household characteristics that are associated with the intergenerational correlation of education through their relationship with one's life trajectory (Alkire, 2008; Biggeri et al., 2006; Mohaqeqi Kamal et al., 2019). In this chapter, we are thus interested in how household environment is associated with the intergenerational correlation of education in developing countries, thus extending the investigation of Aydemir and Yazici (2019) to developing countries. Given that this study takes a developing country perspective, the household factors used here are factors that reflect conditions in that region.

We rely on internationally comparable indicators such as those of the global Multidimensional Poverty Index (MPI). They include the most recent internationally comparable deprivation factors of acute poverty of households (Global Multidimensional Poverty Index, 2018). These originated from the explanations of individuals considered poor, with regard to their living conditions or what their daily lives look like. These indicators are taken because they represent the views of the poor with regards to their well-being, priorities and problems (Biggeri et al., 
2006). They are the deprivations mentioned in their day-to-day lives. This means that we look at basic utilities that are relevant, and sometimes lacking, for individuals in developing countries. This can provide important information for policy action regarding the intergenerational correlation of education.

This chapter thus contributes to the existing knowledge by investigating the interaction between deprivation and the intergenerational correlation of education. We therefore answer the following research question: Does household deprivation or the home environment contribute to the intergenerational correlation of education? Our main hypothesis is that the intergenerational correlation of education significantly increases with household deprivation. We do not identify a causal relationship between deprivation and intergenerational correlation of education, we rather look at the interaction between parent's education and deprivation in explaining educational attainment variation of children. This is because our estimations do not include all potential independent variables that affect educational attainment (Holmlund et al., 2011). Besides omitted variable bias, it is not feasible to methodologically correct for endogeneity bias due to the difficulty in satisfying the exclusion restrictions required for valid instruments. Section 5.2 of this study reviews the internationally comparable approaches applied to define the quality of living of individuals thereby determining their deprivation status. Section 5.3 describes the data. Section 5.4 describes the analytical method to examine the association between educational attainment and deprivation. Section 5.5 presents the results of the analysis, and section 5.6 discusses the results and concludes.

\subsection{Conceptualisation of deprivation}

The most frequently used internationally comparable indicators of deprivation in the developing regions are the Bristol, and the Alkire and Foster approaches of poverty measurement (PinillaRoncancio and Silva, 2018). For the Bristol approach, Gordon et al. (2003) puts forward a conceptual foundation providing an explanation of the measurement of child poverty and its dimensions. It is aimed at highlighting the extent and severity of child poverty in developing countries. It puts forward internationally agreed standards and conventions of threshold measures of severe deprivation of basic human needs. In other words, Gordon et al. conceptualised deprivation as a continuum ranging from no deprivation, through mild deprivation, moderate deprivation, and severe deprivation to extreme deprivation. The basic human needs used to analyse the severity level of deprivation of a child include food, drinking water, sanitation, health, shelter, education, information, and services (Gordon et al., 2003). The 
operationalisation of these measures lies in the deviation of height and weight for age, access to sufficient drinking water, access to toilet facilities, access to medical care, overcrowding of dwelling, learning adequacy, access to communication services, and access to health and education facilities.

Alkire and Foster look at deprivations experienced by poor people, derived from the lack they regularly describe when explaining their disadvantages (Alkire et al., 2015). The family of measures developed by Alkire and Foster was used to construct the global MPI in 2010 (PinillaRoncancio and Silva, 2018), which was revised in 2018 and 2019 (Global Multidimensional Poverty Index, 2019). The United Nations Development Programme and the Oxford Poverty and Human Development Initiative jointly developed the global MPI. They used health, education, and living standards to measure child poverty across countries. Within these dimensions, they developed ten indicators including nutrition, child mortality, years of schooling, school attendance, cooking fuel, sanitation, drinking water, electricity, housing and assets. They used household-level microeconomic data to identify the numerous deprivations at the individual and household levels. Alkire and Foster's division of the categories into the various indicators and the operationalisation of deprivation are shown in Figure 5.1. and Table 5.1. below respectively:

Figure 5.1.: Composition of the MPI-dimensions and indicators

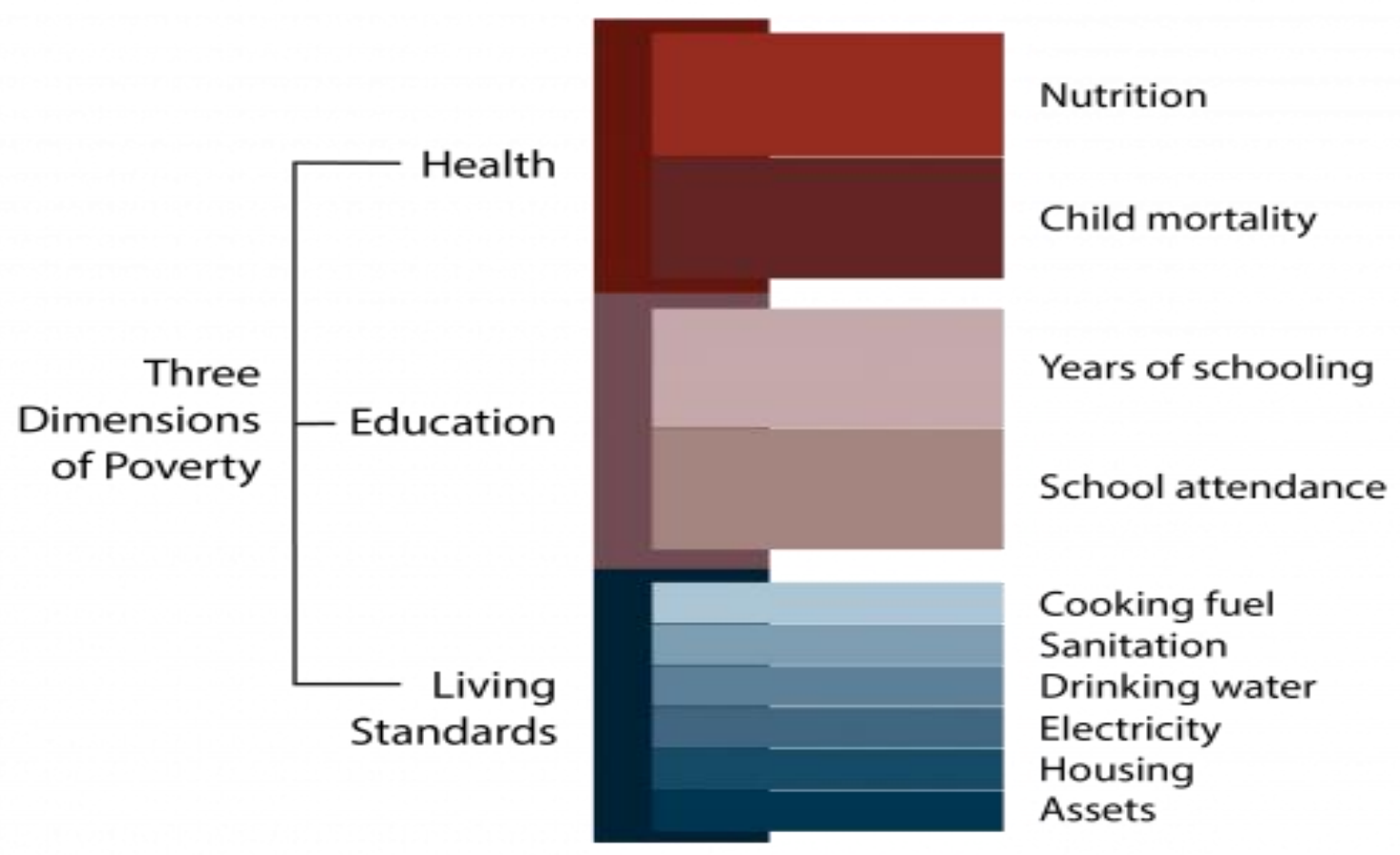

Source: Global Multidimensional Poverty Index (2018) 
Table 5.1.: Operationalisation of deprivation

\begin{tabular}{|c|c|}
\hline Indicators & Households considered deprived \\
\hline Nutrition & $\begin{array}{l}\text { Households have malnourished individual if they: } \\
\text {-Have adults } 20 \text { to } 70 \text { years whose Body Mass Index (BMI) is below } \\
18.5 \mathrm{~m} / \mathrm{kg} 2 \text {. } \\
\text {-Have } 5 \text { to } 20 \text { years individuals whose age-specific BMI cutoff is } \\
\text { below minus two standard deviations. } \\
\text {-Have children under } 5 \text { years whose z-score of either height-for-age } \\
\text { (stunting) or weight-for-age (underweight) is below minus two } \\
\text { standard deviations from the median of the World Health } \\
\text { Organisation } 2006 \text { reference population. }\end{array}$ \\
\hline Child mortality & $\begin{array}{l}\text { Any child has died in the family in the five-year period preceding the } \\
\text { survey. }\end{array}$ \\
\hline Years of schooling & $\begin{array}{l}\text { No household member aged ten years or older has completed six } \\
\text { years of schooling. }\end{array}$ \\
\hline School attendance & $\begin{array}{l}\text { Any school-aged child is not attending school up to the age at which } \\
\text { he/she would complete class } 8 \text {. }\end{array}$ \\
\hline Cooking fuel & The household cooks with dung, wood or charcoal. \\
\hline Sanitation & $\begin{array}{l}\text { The household's sanitation facility is not improved or it is improved } \\
\text { but shared with other households. } \\
\text { (A household is considered to have access to improved sanitation if } \\
\text { it has some type of flush toilet or latrine, or ventilated improved pit } \\
\text { or composting toilet, if they are not shared). }\end{array}$ \\
\hline Drinking water & $\begin{array}{l}\text { The household does not have access to improved drinking water or } \\
\text { safe drinking water is at least a } 30 \text {-minute walk from home, roundtrip. } \\
\text { (A household has access to clean drinking water if the water source } \\
\text { is any of the following types: piped water, public tap, borehole or } \\
\text { pump, protected well, protected spring or rainwater). }\end{array}$ \\
\hline Electricity & The household has no electricity. \\
\hline Housing & $\begin{array}{l}\text {-Floor is made of mud/clay/earth, sand or dung; } \\
\text {-Or if dwelling has no roof or walls; } \\
\text {-Or if either the roof or walls are constructed using natural materials } \\
\text { such as cane, palm/trunks, sod/mud, dirt, grass/reeds, thatch, } \\
\text { bamboo, sticks, or rudimentary materials such as carton, plastic/ } \\
\text { polythene sheeting, bamboo with mud/stone with mud, loosely } \\
\text { packed stones, uncovered adobe, raw/reused wood, plywood, } \\
\text { cardboard, unburnt brick or canvas/tent. }\end{array}$ \\
\hline Assets & $\begin{array}{l}\text { The household does not own more than one of these assets: radio, } \\
\text { television, telephone, computer, animal cart, bicycle, motorbike or } \\
\text { refrigerator, and does not own a car or truck. }\end{array}$ \\
\hline
\end{tabular}

Source: Global Multidimensional Poverty Index (2018) 


\subsection{Data}

The data used in this chapter to operationalise household deprivation are the Demographic and Health Surveys (DHS). These are nationally representative household survey data available for many developing countries. Information on the household was reported through face-to-face interviews of eligible respondents of the households. This study uses DHS data for twentyseven developing countries with surveys that were conducted between 2012 and 2018, the survey years vary between countries. The surveys cover a broad range of household, individual and residential characteristics such as education, family dynamics, health, housing, amenities, cities, and regions. The individuals for whom we analyse educational attainment are those aged 20 to 30 and are children of the head of the household. This truncation was in order to include information for those who have relatively recently finished formal education at the time of the survey which enables us to capture mostly the current situations of the households.

As ascertained by Hertz et al. (2008), we assume that the bias that may arise because of the age truncation is small. There could be downward bias from the lower limit for excluding individuals still to complete final education and those who take longer to finish, or an upward mean level bias and downward coefficient bias from the upper limit possibly, because longevity may be correlated with education. The education of the highest educated parent is taken to represent the variable 'parent's education'. Therefore, households included are households with individuals aged 20-30 (who are considered as the children in the analysis), and for who we have information on their parent(s). This is regardless of whether there are other children in the household or not. So, some households may have more children while some may not. The data include 27 countries with sample sizes ranging from 1,305 (for Zimbabwe) to 10,763 (for Indonesia). The countries include Bangladesh, Benin, Cameroon, Chad, Dominican Republic, Ethiopia, Ghana, Guinea, Haiti, Indonesia, Kenya, Lesotho, Malawi, Mali, Namibia, Nepal, Nigeria, Pakistan, Peru, Philippines, Rwanda, Senegal, Sierra Leone, Tanzania, Uganda, Zambia, and Zimbabwe. All the households included in the countries are those living in their usual residence, since we expect that where they grew up may be more relevant. Survey weights are used in statistical representations to make the surveys nationally representative.

\subsubsection{Descriptive statistics}

In this chapter, the Alkire and Foster's deprivation indicators are utilized. We construct an index by summing these indicators, after first creating dummy variables with them indicating ' 1 ' for being deprived and ' 0 ' for being non-deprived. The index is then entered as a continuous 
variable in the analysis. The outcome variable 'educational attainment' is represented by the number of years of education completed. In total, eight indicators of the three dimensions of deprivation are used as explanatory variables. This include child mortality, school attendance, cooking fuel, sanitation, drinking water, electricity, housing, and assets. Nutrition and years of schooling were left out due to incomplete data and multicollinearity with parent's education respectively, leaving eight indicators or dummy variables in total.

For the variable 'school attendance', we compute the age of class 8 completion depending on the primary school starting age of the various countries. Primary school starting ages are 6, 7, or 8 , for the different countries. This gives different ages of class 8 completion, which are 13, 14 , and 15 , respectively. Parent's education is the education of the single parent in a singleparent household or the education of the parent having the highest level of education in households with both parents. In Table 5.2., we present the descriptive statistics of the dependent and independent variables. The dependent variable is educational attainment. The independent variables are the deprivation indicators (child mortality, school attendance, cooking fuel, sanitation, drinking water, electricity, housing, and assets), age, gender, parent's education, number of household members, and region of residence (rural or urban). We also present the correlation coefficients between parents' education and the deprivation index within each country and across countries. Results show that they are not highly correlated. In Appendix A5.1., we present per country sample size, educational attainment, parent's education, and the percentage deprived in each deprivation indicator. 


\section{Chapter 5}

Table 5.2.: Descriptive statistics of the individual-level characteristics

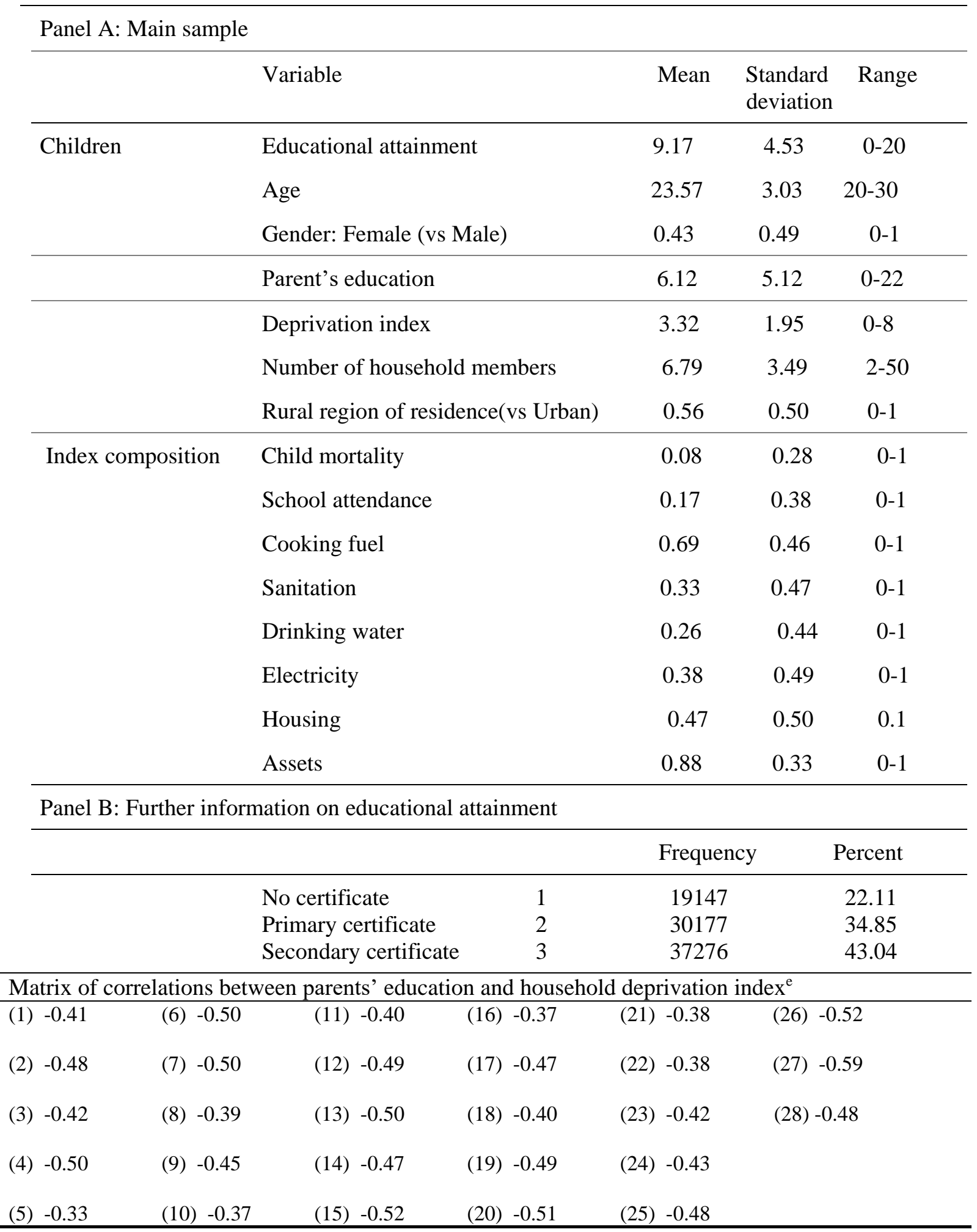

Notes: The household sampling weights are used to compute all statistics. $\mathrm{N}=86,600$.

e (1) Bangladesh, (2) Benin, (3) Chad, (4) Cameroon, (5) Dominican Republic, (6) Ethiopia, (7) Ghana, (8) Guinea, (9) Haiti, (10) Indonesia, (11) Kenya, (12) Lesotho, (13) Malawi, (14) Mali, (15) Namibia, (16) Nepal, (17) Nigeria, (18) Pakistan, (19) Peru, (20) Philippines, (21) Rwanda, (22) Senegal, (23) Sierra Leone, (24) Tanzania, (25) Uganda, (26) Zambia, (27) Zimbabwe, (28) Pooled sample 


\subsection{Methodology}

A check for collinearity in the data per country shows that the indicators are not highly correlated with each other, with the highest correlation being lower than 0.7. Country-level check however, show a high correlation of 0.8 between fuel and electricity in Zimbabwe. The pooled regression with the eight indicators is therefore conducted with all the countries, and then, with the removal of Zimbabwe. However, both regression analyses produce similar results. Therefore, we present the pooled data regression with Zimbabwe included. The correlation matrices, for the pooled data and country-wise data, are presented in Appendix A5.2. and Appendix A5.3. respectively. Educational attainment can be operationalized by different measures, including the highest degree completed and completed years of schooling. One limitation with cross-country data on education is that the distribution of education varies across countries. Also, educational attainment might be biased because individuals might have dropped out of school before they have completed a degree, while in developing countries it is not uncommon that individuals drop out of school in the course of a grade level in primary or secondary education.

A finer measure of educational attainment is therefore that which also captures any additional grade(s) completed after the highest degree attained (Aydemir and Yazici, 2019). Therefore, an individual with additional completed years of schooling after the highest degree attained will differ from an individual who dropped out right after completing his/her highest degree. We therefore use completed years of education because it is a more precise measure to capture this. Given its continuous nature, it allows for an analysis by means of ordinary least squares (OLS) regression, which is what we apply in this chapter. We measure the intergenerational correlation of education using the regression coefficient and the standardized coefficient. While the regression coefficient uses the years of schooling in the data, the standardized coefficient uses the standardized years of schooling, for both parents and children. We standardize the years of schooling to obtain a distribution with mean zero and standard deviation of one. This divides the years of schooling variable by its standard deviation, for children and parents respectively. We also look at the heterogeneity by conducting the regressions for females and males separately. The standardized coefficient ( $\left.\mathrm{a}_{1 \mathrm{~s}}\right)$ relates to the regression coefficient ( $\left.\mathrm{a}_{1}\right)$ by:

$$
\mathrm{a}_{1 \mathrm{~s}}=\mathrm{a}_{1} \frac{\partial p}{\partial c}
$$

representing a standard deviation increase in children's education following a standard deviation increase in parents' education. $\partial p$ and $\partial c$ are the standard deviations of parents' and children's 
years of schooling, respectively. The baseline analysis involves the intergenerational correlation of education with the pooled data using the following linear equation;

$\mathrm{E}_{\mathrm{ij}}=\mathrm{a} 0+\mathrm{a}_{1}(\text { parent's education })_{\mathrm{ij}}+\mathrm{g}(\text { control variables })_{\mathrm{ij}}+$ error $_{\mathrm{ij}}$

where $E_{\mathrm{ij}}$ represents educational attainment of individual ' $\mathrm{i}$ ' of country ' $\mathrm{j}$ '.

The control variables in the analysis are the number of household members, age, gender, urban/rural residence, city and year fixed effects for the pooled data. The standard errors are clustered at household level and country level. Household level clustering is used because although the children sample may be representative, with each child treated as a separate observation, the parental sample is not representative. This is because parents with more than one child in our data are over-represented. The variable for the standard error clustering is therefore created to have household-country paired values. In the second analysis, we look at the correlation between the deprivation index and educational attainment, thereby adding the deprivation index to equation (1), as shown below;

$\mathrm{E}_{\mathrm{ij}}=\mathrm{b}_{0}+\mathrm{b}_{1}(\text { parent's education })_{\mathrm{ij}}+\mathrm{b}_{2}(\text { deprivation index })_{\mathrm{ij}}+\mathrm{f}(\text { control variables })_{\mathrm{ij}}+$ error $_{\mathrm{ij}}$

Thirdly, we include an interaction term between parent's education and the deprivation index, as follows;

$\mathrm{E}_{\mathrm{ij}}=\mathrm{c}_{0}+\mathrm{c}_{1}(\text { parent's education } \times \text { deprivation index })_{\mathrm{ij}}+\mathrm{c}_{2}(\text { parent's education })_{\mathrm{ij}}+\mathrm{c}_{3}($ deprivation index $)_{i j}+h(\text { control variables })_{i j}+$ error $_{i j}$

Table 5.3. below presents the results of equation (1), (2), and (3), for all individuals, female, and male. Standardized results are presented in Table 5.4.. We however, take a step in confirming the direction of our results by applying an ordered Probit model as well. This estimation groups the individuals into certificate obtained (no certificate, primary certificate, and secondary certificate).

\subsection{Results}

\subsubsection{Baseline estimates}

We present the baseline intergenerational correlation of education for the entire sample without controlling for the deprivation index (1), and with the controls for deprivation index (2). This is to show that the intergenerational correlation after controlling for the deprivation index is lower than the one without the deprivation index control. Figure 5.2. below plots this outcome. 
Figure 5.2.: OLS intergenerational correlation coefficients with confidence intervals for the baseline equation without deprivation index (1), and with deprivation index (2)

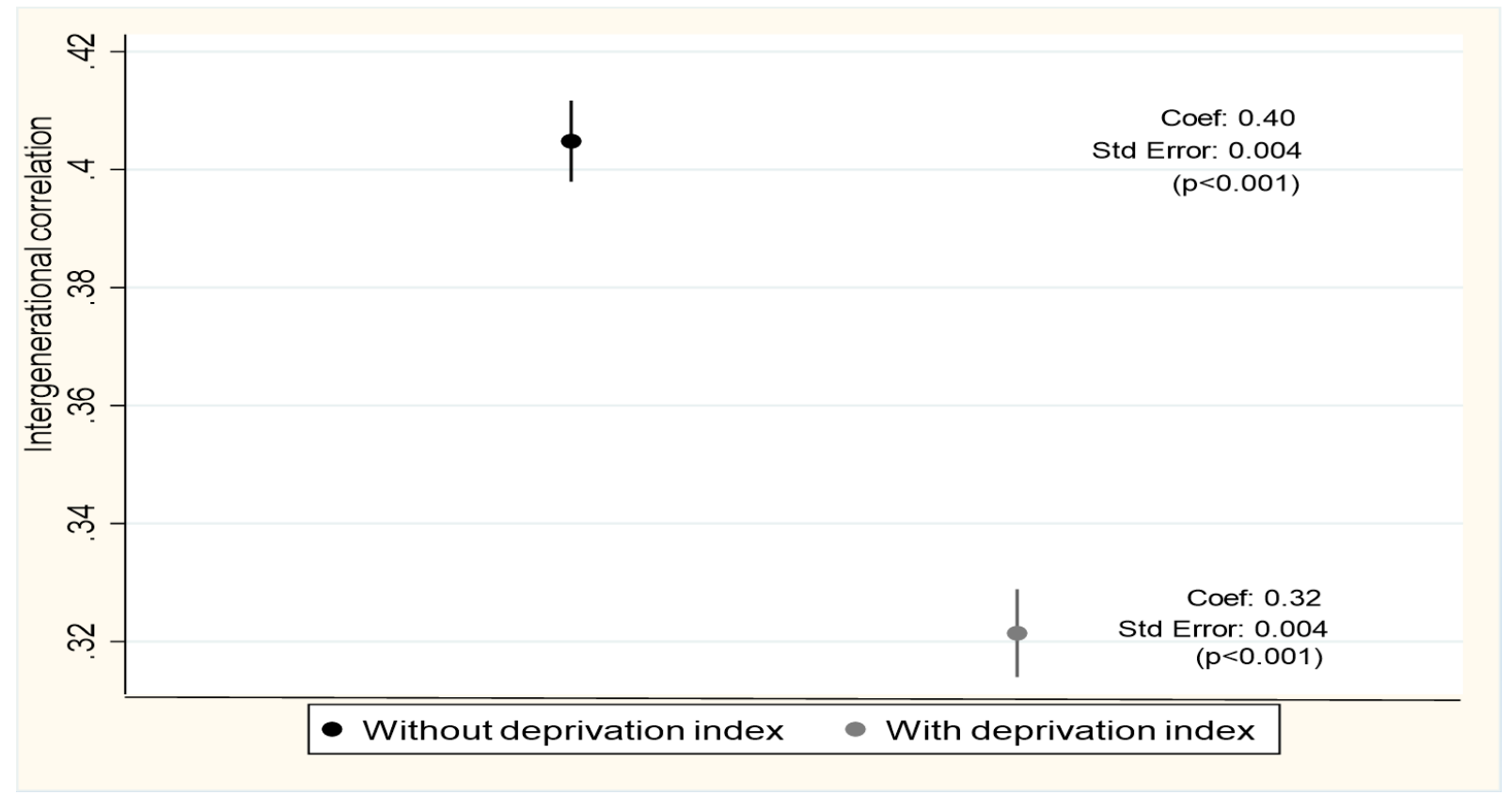

The analysis on intergenerational correlation of education (1) in Figure 5.2. shows that the correlation coefficient between children's and parent's years of education range is 0.40 , that is, the increase in years of education following a one year increase in parent's education. This is similar to what was found in a previous study on developing countries presented in Chapter 3 of this dissertation (Momo et al., 2019b), 0.39, and a bit higher than what Akbulut-Yuksel and Turan (2013) found for Sub-Saharan Africa, 0.20. After controlling for the deprivation index, the intergenerational correlation reduces to 0.32. this implies that when parents' education increase by one years, children's education increase by 0.32 years. 
Figure 5.3.: OLS intergenerational correlation coefficients with confidence intervals for the baseline equation (1), and estimated coefficients with one single measure each, of household deprivation

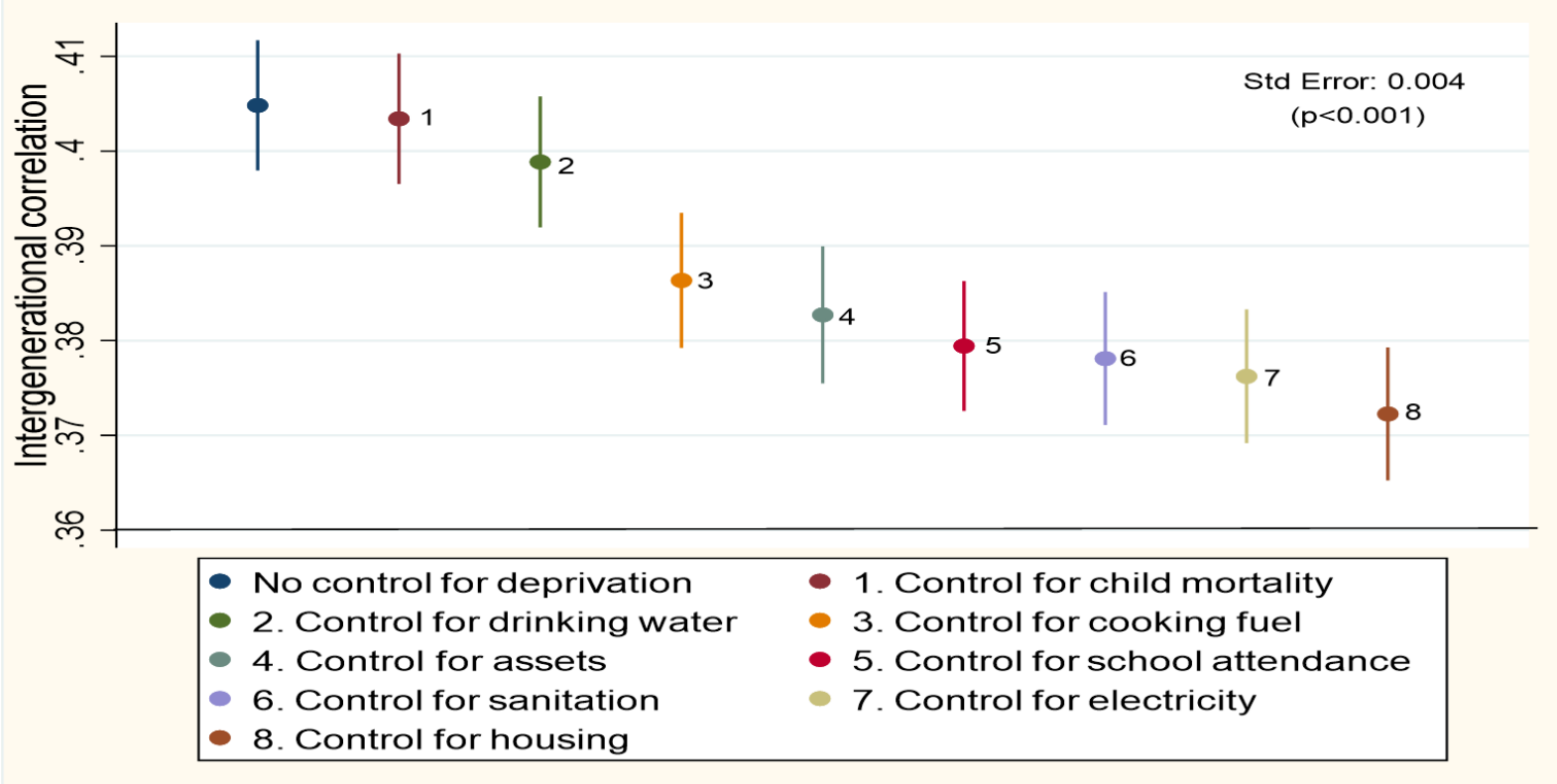

Figure 5.3. presents the results after controlling for separate items in the deprivation index. The results show that each coefficient with a measure of deprivation is lower than the baseline estimate (0.404). They range from child mortality (0.403) through water (0.399), fuel (0.386), assets (0.383), school attendance (0.379), sanitation (0.378), electricity (0.376), and housing (0.372).

Figure 5.4.: OLS intergenerational correlation coefficients with confidence intervals for the baseline equation without deprivation index (1), and with deprivation index (2), by gender

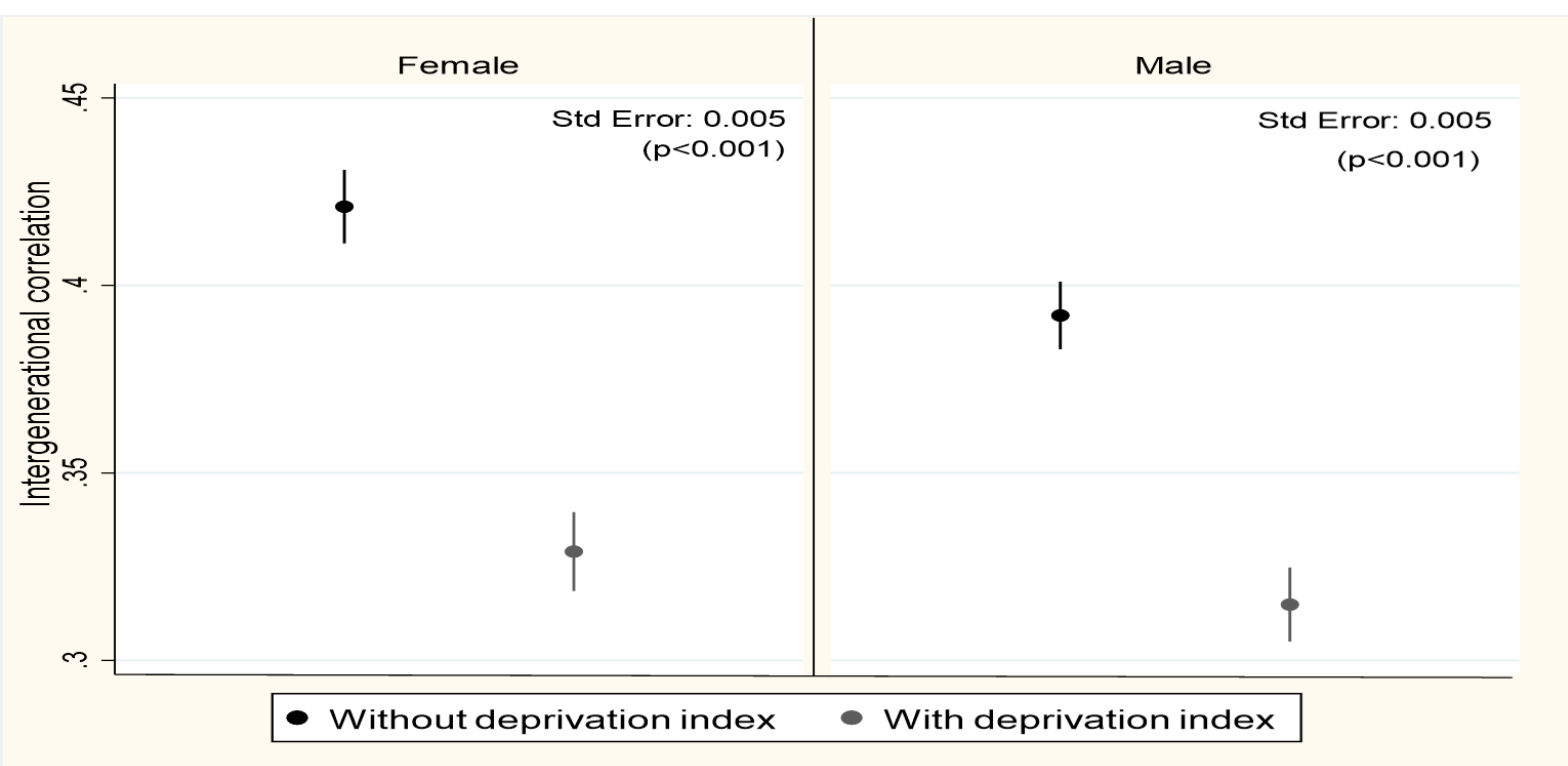


Figure 5.4. summarizes results for female and male. The heterogeneous intergenerational correlation shows the same pattern for both female and male. That is, the baseline estimates without deprivation index are higher than the estimates with controls for the deprivation index. However, the male estimates are lower than those for female. They are 0.39 (compared to 0.42 for females) in the uncontrolled baseline estimate and 0.32 (compared to 0.33 for females) in the deprivation-controlled estimate. Table 5.3. below presents the OLS regression results of equations (1), (2), and (3) for the pooled data, and by gender. The standardized results are presented in Table 5.4.. 


\section{Chapter 5}

Table 5.3.: OLS regression coefficients of children's education on parents' education (1), deprivation index (2), and interaction of deprivation index and parent's education (3)

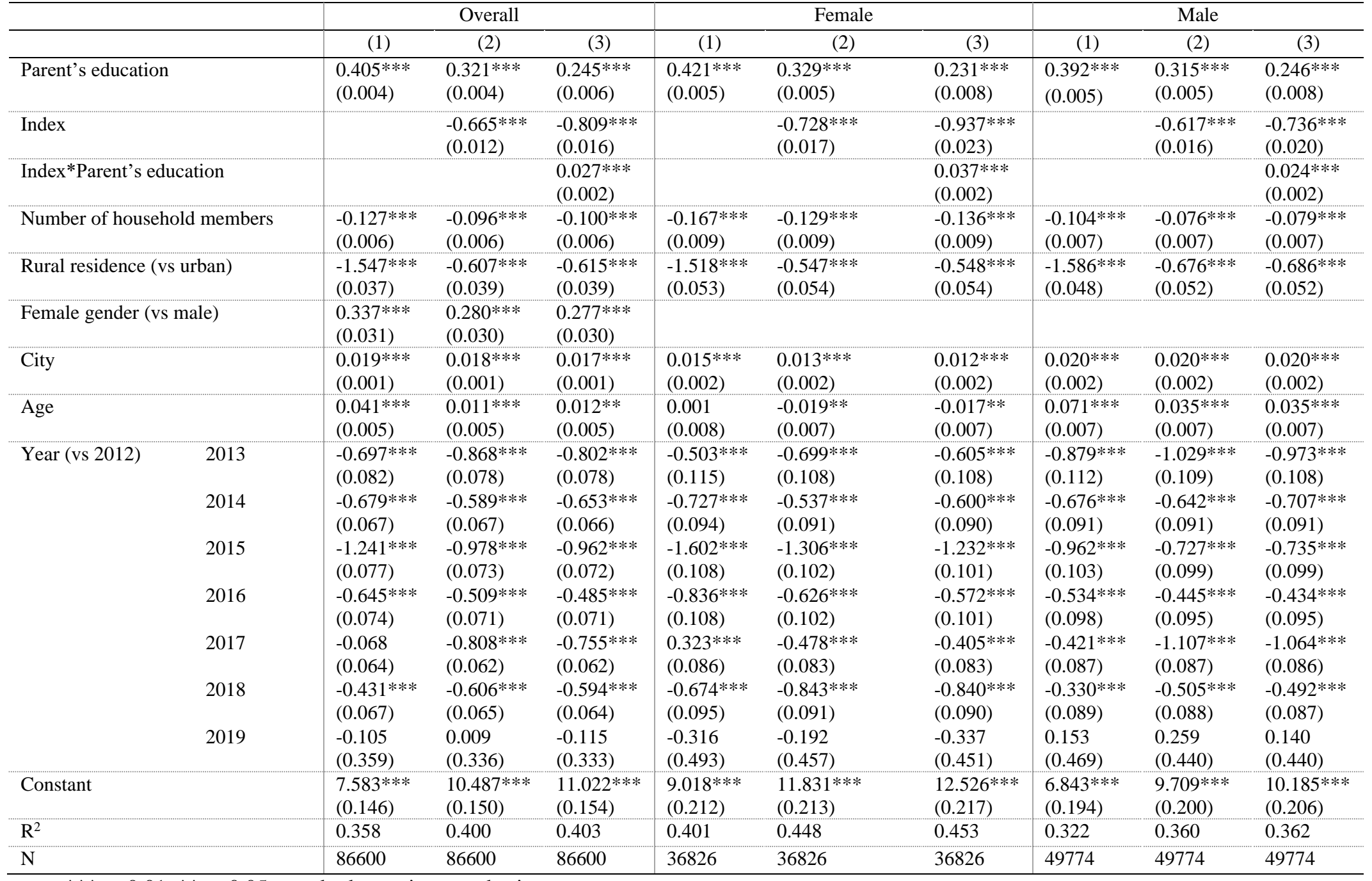

$* * * \mathrm{p}<0.01, * * \mathrm{p}<0.05$, standard error in parenthesis 
Our coefficient of interest, the interaction term in the third row of the results of (3) on Table 5.3., indicates the relationship of home environments with the intergenerational transmission of education. The interaction terms of parent's education and the deprivation index on the overall, the female and the male outcomes show a significantly positive correlation coefficient. This indicates a stronger relationship between parents' years of schooling and children's years of schooling when the number of deprivations are higher, or, the educational attainment of children who grew up in more deprived households depend more on their parents' education. Overall, a one year increase in parent's education leads to an additional 0.02 years increase in children's education for one unit increase in the deprivation index. This relationship is a little bit stronger for women (0.03) as compared to men (0.02). As expected, the impact of parent's education is still positive and almost unchanged, while the deprivation index is still quite large and negative. The outcome on the interaction term confirms our main hypothesis that the intergenerational correlation of education significantly increases with household deprivation.

The coefficient of (2) on Table 5.3. on the correlation between the deprivation index and educational attainment reveals that deprivation seems to weaken educational attainment. This relationship is statistically significant, with 0.67 years decrease in educational attainment following an additional deprivation in the household. This decrease in years of educational attainment after controlling for deprivation is slightly higher for women (-0.72) than for men (0.61). Table 5.4. reports the standardized correlation coefficients between parents' and children's years of schooling. The standardized coefficient without controlling for deprivation is 0.45 and the coefficient with controls for deprivation is 0.35 . Thus a one standard deviation increase in parent's education leads to a 0.45 standard deviation increase in children's education. This deviation in children's education reduces to 0.35 with the inclusion of the deprivation index. These standardized values show a strong association of parent's education with educational attainment. In terms of intergenerational persistence by gender, the standardized coefficients with and without controlling for deprivation indicates that for both women $(0.47$ and 0.36$)$ and men (0.43 and 0.35) there is a strong and similar association between parent's education and educational attainment. 
Table 5.4.: Standardized OLS regression coefficients of children's education on parents' education (1), deprivation index (2), and interaction of deprivation index and parent's education (3)

\begin{tabular}{|c|c|c|c|c|c|c|c|c|c|c|}
\hline & \multicolumn{3}{|c|}{ Overall } & \multicolumn{3}{|c|}{ Female } & \multicolumn{3}{|c|}{ Male } \\
\hline & & (1) & (2) & (3) & (1) & (2) & (3) & (1) & (2) & (3) \\
\hline \multicolumn{2}{|c|}{ Parent's education } & $\begin{array}{l}0.453 * * * \\
(0.004)\end{array}$ & $\begin{array}{l}0.359 * * * \\
(0.004)\end{array}$ & $\begin{array}{l}0.377 * * * \\
(0.004)\end{array}$ & $\begin{array}{l}0.471^{* * *} * \\
(0.006)\end{array}$ & $\begin{array}{l}0.368 * * * \\
(0.006)\end{array}$ & $\begin{array}{l}-0.294 * * * \\
(0.007)\end{array}$ & $\begin{array}{l}0.438 * * * \\
(0.005)\end{array}$ & $\begin{array}{l}0.352 * * * \\
(0.006)\end{array}$ & $\begin{array}{l}-0.245^{* * *} \\
(0.006)\end{array}$ \\
\hline \multicolumn{2}{|l|}{ Index } & & $\begin{array}{l}-0.275 * * * \\
(0.005)\end{array}$ & $\begin{array}{l}-0.266^{* * *} \\
(0.005)\end{array}$ & & $\begin{array}{l}-0.301 * * * \\
(0.007)\end{array}$ & $\begin{array}{l}0.398 * * * \\
(0.006)\end{array}$ & & $\begin{array}{l}-0.256 * * * \\
(0.006)\end{array}$ & $\begin{array}{l}0.365 * * * \\
(0.006)\end{array}$ \\
\hline \multicolumn{2}{|c|}{ Index*Parent's education } & & & $\begin{array}{l}0.058 * * * \\
(0.003)\end{array}$ & & & $\begin{array}{l}0.079 * * * \\
(0.005)\end{array}$ & & & $\begin{array}{l}0.050 * * * \\
(0.005)\end{array}$ \\
\hline \multicolumn{2}{|c|}{ Number of household members } & $\begin{array}{l}-0.028^{* * *} \\
(0.001)\end{array}$ & $\begin{array}{l}-0.021 * * * \\
(0.001)\end{array}$ & $\begin{array}{l}-0.022 * * * \\
(0.001)\end{array}$ & $\begin{array}{l}-0.037 * * * \\
(0.002)\end{array}$ & $\begin{array}{l}-0.028^{* * * *} \\
(0.002)\end{array}$ & $\begin{array}{l}-0.030 * * * \\
(0.002)\end{array}$ & $\begin{array}{l}-0.023^{* * *} \\
(0.002)\end{array}$ & $\begin{array}{l}-0.017 * * * \\
(0.002)\end{array}$ & $\begin{array}{l}-0.017 * * * \\
(0.002)\end{array}$ \\
\hline \multicolumn{2}{|c|}{ Rural residence (vs urban) } & $\begin{array}{l}-0.339 * * * \\
(0.008)\end{array}$ & $\begin{array}{l}-0.133 * * * \\
(0.008)\end{array}$ & $\begin{array}{l}-0.134 * * * \\
(0.008)\end{array}$ & $\begin{array}{l}-0.332 * * * \\
(0.012)\end{array}$ & $\begin{array}{l}-0.120 * * * \\
(0.012)\end{array}$ & $\begin{array}{l}-0.120 * * * \\
(0.012)\end{array}$ & $\begin{array}{l}-0.347 * * * \\
(0.011)\end{array}$ & $\begin{array}{l}-0.148 * * * \\
(0.011)\end{array}$ & $\begin{array}{l}-0.150 * * * \\
(0.011)\end{array}$ \\
\hline \multicolumn{2}{|c|}{ Female gender (vs male) } & $\begin{array}{l}0.074 * * * \\
(0.007)\end{array}$ & $\begin{array}{l}0.061 * * * \\
(0.007)\end{array}$ & $\begin{array}{l}0.061 * * * \\
(0.007)\end{array}$ & & & & & & \\
\hline \multicolumn{2}{|l|}{ City } & $\begin{array}{l}0.004 * * * \\
(0.000)\end{array}$ & $\begin{array}{l}0.004 * * * \\
(0.000)\end{array}$ & $\begin{array}{l}0.004 * * * \\
(0.000)\end{array}$ & $\begin{array}{l}0.003^{* * *} \\
(0.000)\end{array}$ & $\begin{array}{l}0.003 * * * \\
(0.000)\end{array}$ & $\begin{array}{l}0.003 * * * \\
(0.000)\end{array}$ & $\begin{array}{l}0.004 * * * \\
(0.000)\end{array}$ & $\begin{array}{l}0.004 * * * \\
(0.000)\end{array}$ & $\begin{array}{l}0.004 * * * \\
(0.000)\end{array}$ \\
\hline \multicolumn{2}{|l|}{ Age } & $\begin{array}{l}0.009 * * * \\
(0.001)\end{array}$ & $\begin{array}{l}0.002 * * \\
(0.001)\end{array}$ & $\begin{array}{l}0.003 * * \\
(0.001)\end{array}$ & $\begin{array}{l}0.000 \\
(0.002)\end{array}$ & $\begin{array}{l}-0.004 * * \\
(0.002)\end{array}$ & $\begin{array}{l}-0.004 * * \\
(0.002)\end{array}$ & $\begin{array}{l}0.015 * * * \\
(0.002)\end{array}$ & $\begin{array}{l}0.008 * * * \\
(0.002)\end{array}$ & $\begin{array}{l}0.008 * * * \\
(0.002)\end{array}$ \\
\hline Year (vs 2012) & $\begin{array}{l}2013 \\
2014 \\
2015 \\
2016 \\
2017 \\
2018 \\
2019\end{array}$ & $\begin{array}{l}-0.153 * * * \\
(0.018) \\
-0.149 * * * \\
(0.015) \\
-0.272 * * * \\
(0.017) \\
-0.141 * * * \\
(0.016) \\
-0.015 \\
(0.014) \\
-0.094 * * * \\
(0.015) \\
-0.023 \\
(0.079)\end{array}$ & $\begin{array}{l}-0.190 * * * \\
(0.017) \\
-0.129 * * * \\
(0.015) \\
-0.214 * * * \\
(0.016) \\
-0.111 * * * \\
(0.016) \\
-0.177 * * * \\
(0.014) \\
-0.133 * * * \\
(0.014) \\
0.002 \\
(0.073)\end{array}$ & $\begin{array}{l}-0.176^{* * *} \\
(0.017) \\
-0.143^{* * *} \\
(0.015) \\
-0.211^{* * *} \\
(0.016) \\
-0.106^{* * *} \\
(0.015) \\
-0.165^{* * *} \\
(0.014) \\
-0.130^{* * *} \\
(0.014) \\
-0.025 \\
(0.073)\end{array}$ & $\begin{array}{l}-0.110^{* * * *} \\
(0.025) \\
-0.159 * * * \\
(0.021) \\
-0.351 * * * \\
(0.024) \\
-0.183 * * * \\
(0.024) \\
0.071 * * * \\
(0.019) \\
-0.147 * * * \\
(0.021) \\
-0.069 \\
(0.108)\end{array}$ & $\begin{array}{l}-0.153^{* * *} \\
(0.024) \\
-0.117^{* * *} \\
(0.020) \\
-0.286^{* * *} \\
(0.022) \\
-0.137 * * * \\
(0.022) \\
-0.105^{* * *} \\
(0.018) \\
-0.184 * * * \\
(0.020) \\
-0.042 \\
(0.100)\end{array}$ & $\begin{array}{l}-0.132 * * * \\
(0.024) \\
-0.131 * * * \\
(0.020) \\
-0.269 * * * \\
(0.022) \\
-0.125 * * * \\
(0.022) \\
-0.089 * * * \\
(0.018) \\
-0.184 * * * \\
(0.020) \\
-0.074 \\
(0.099)\end{array}$ & $\begin{array}{l}-0.192^{* * * *} \\
(0.025) \\
-0.148 * * * \\
(0.020) \\
-0.211^{* * *} \\
(0.023) \\
-0.117 * * * \\
(0.021) \\
-0.092^{* * *} \\
(0.019) \\
-0.072^{* * *} \\
(0.019) \\
0.033 \\
(0.103)\end{array}$ & $\begin{array}{l}-0.225 * * * \\
(0.024) \\
-0.140 * * * \\
(0.020) \\
-0.159 * * * \\
(0.022) \\
-0.097 * * * \\
(0.021) \\
-0.242 * * * \\
(0.019) \\
-0.110 * * * \\
(0.019) \\
0.057 \\
(0.096)\end{array}$ & $\begin{array}{l}-0.213 * * * \\
(0.024) \\
-0.155^{* * *} \\
(0.020) \\
-0.161 * * * \\
(0.022) \\
-0.095 * * * \\
(0.021) \\
-0.233 * * * \\
(0.019) \\
-0.108 * * * \\
(0.019) \\
0.031 \\
(0.096)\end{array}$ \\
\hline \multicolumn{2}{|l|}{ Constant } & $\begin{array}{l}0.198 * * * \\
(0.031)\end{array}$ & $\begin{array}{l}0.232 * * * \\
(0.030)\end{array}$ & $\begin{array}{l}0.264 * * * \\
(0.030)\end{array}$ & $\begin{array}{l}0.533 * * * \\
(0.045)\end{array}$ & $\begin{array}{l}0.490^{* * *} \\
(0.043)\end{array}$ & $\begin{array}{l}0.524 * * * \\
(0.043)\end{array}$ & $\begin{array}{l}0.019 \\
(0.041)\end{array}$ & $\begin{array}{l}0.089 * * \\
(0.041)\end{array}$ & $\begin{array}{l}0.120^{* * *} \\
(0.041)\end{array}$ \\
\hline \multicolumn{2}{|l|}{$\mathrm{R}^{2}$} & 0.358 & 0.400 & 0.403 & 0.401 & 0.448 & 0.453 & 0.322 & 0.360 & 0.362 \\
\hline \multicolumn{2}{|l|}{$\mathrm{N}$} & 86600 & 86600 & 86600 & 36826 & 36826 & 36826 & 49774 & 49774 & 49774 \\
\hline
\end{tabular}




\subsubsection{Robustness analysis}

We provide further support for the correlation between intergenerational transmission of education and deprivation in this section. The method we apply here is the ordered Probit analysis where educational attainment is the certificate obtained. $\mathrm{Y}^{*}$ is the latent variable that indexes the certificate obtained, with a vector of parameters $\mathrm{Xij}$, and an error term;

$$
\mathrm{Y}^{*}=\beta \mathrm{Xij}+\mathrm{eij}
$$

The latent variable is displayed in ordered categories coded 1,2,3, and the following respective responses;

$$
\begin{aligned}
& \mathrm{Y}^{*}=1 \text { if } \mathrm{Y}^{*} \leq \alpha 1 \\
& \mathrm{Y}^{*}=2 \text { if } \alpha 1<\mathrm{Y}^{*} \leq \alpha 2 \\
& \mathrm{Y}^{*}=3 \text { if } \alpha 2<\mathrm{Y}^{*} \leq \alpha 3
\end{aligned}
$$

These are three categories of the dependent variable; no certificate (1), primary certificate (2), and secondary certificate (3). The variables of the parameters in Xij are the ones defined in the OLS equations above. For interpretation purposes, we present the marginal effect of the explanatory variables parent education and deprivation index from the baseline without deprivation control and the baseline with deprivation control. The result of this analysis is reported in Table 5.5.. Based on the Probit model, parent's education significantly correlates with obtaining a certificate in the model without the deprivation index. The positive sign of the coefficient (0.12) indicates that obtaining a certificate increases with parent's education. In the model, the marginal effects show that a one year increase in parent's education correlates significantly and makes it $3 \%(-0.027)$ less likely to have no certificate, $0.7 \%(-0.007)$ less likely to have primary certificate, and $3 \%(0.034)$ more likely to have a secondary certificate.

When the deprivation index is included in the analysis, the coefficient of the correlation of parent's education is reduced to 0.09 . This coefficient is however, still statistically significant. The marginal effects of parent's education reduce slightly to $-0.021,-0.005$, and 0.026 , respectively. The deprivation index also correlates significantly with certificate in the model. Its negative coefficient (-0.226) implies that obtaining a certificate reduces with a unit increase in deprivation. The marginal effects of the deprivation index show that a one unit increase in deprivation is significantly associated and makes it 5\% (0.050) more likely to have no certificate, $1 \%$ (0.013) more likely to have primary certificate, and 6\% (-0.062) less likely to have secondary certificate. In general, parent's education mostly correlates with no certificate and secondary certificate in both equations, as their marginal effects are of a similar higher magnitude. This 
Chapter 5

might be an explanation of the fact that school dropout is prevalent among the poor, who are also mostly children from households with parents with a low educational attainment. Overall, this result is consistent with the finding of the OLS estimate that deprivation reduces the magnitude of the correlation between parent's educational attainment and that of the children. 
Table 5.5.: Ordered probit coefficient of children's certificate on parents' education (1), deprivation index (2), and marginal effects on the certificate categories

\begin{tabular}{|c|c|c|c|c|c|c|c|c|c|}
\hline & & \multicolumn{4}{|c|}{ Without deprivation index } & \multicolumn{4}{|c|}{ With deprivation index } \\
\hline & & \multirow[t]{2}{*}{ Coefficient } & \multicolumn{3}{|c|}{ Marginal effects on categories } & \multirow[t]{2}{*}{ Coefficient } & \multicolumn{3}{|c|}{ Marginal effects on categories } \\
\hline & & & $(1)$ & $(2)$ & (3) & & $(1)$ & $(2)$ & (3) \\
\hline \multicolumn{2}{|c|}{ Parent's education } & $\begin{array}{l}0.118 * * * \\
(0.001)\end{array}$ & $\begin{array}{l}-0.027 * * * \\
(0.000)\end{array}$ & $\begin{array}{c}-0.007 * * * \\
(0.000)\end{array}$ & $\begin{array}{l}0.034 * * * \\
(0.000)\end{array}$ & $\begin{array}{l}0.094 * * * \\
(0.001)\end{array}$ & $\begin{array}{l}-0.021 * * * \\
(0.000)\end{array}$ & $\begin{array}{l}-0.005 * * * \\
(0.000)\end{array}$ & $\begin{array}{l}0.026 * * * \\
(0.000)\end{array}$ \\
\hline \multicolumn{2}{|l|}{ Index } & & & & & $\begin{array}{l}-0.226^{* * *} \\
(0.004)\end{array}$ & $\begin{array}{l}0.050 * * * \\
(0.001)\end{array}$ & $\begin{array}{l}0.013 * * * \\
(0.000)\end{array}$ & $\begin{array}{l}-0.062 * * * \\
(0.001)\end{array}$ \\
\hline \multicolumn{2}{|c|}{ Number of household members } & $\begin{array}{l}-0.043 * * * \\
(0.002)\end{array}$ & $\begin{array}{l}0.010 * * * \\
(0.000)\end{array}$ & $\begin{array}{l}0.002 * * * \\
(0.000)\end{array}$ & $\begin{array}{l}-0.012 * * * \\
(0.001)\end{array}$ & $\begin{array}{l}-0.034 * * * \\
(0.002)\end{array}$ & $\begin{array}{l}0.007 * * * \\
(0.000)\end{array}$ & $\begin{array}{l}0.002 * * * * \\
(0.000)\end{array}$ & $\begin{array}{l}-0.009 * * * \\
(0.000)\end{array}$ \\
\hline \multicolumn{2}{|c|}{ Rural residence (vs urban) } & $\begin{array}{l}-0.467 * * * \\
(0.012)\end{array}$ & $\begin{array}{l}0.107 * * * \\
(0.003)\end{array}$ & $\begin{array}{l}0.036 * * * \\
(0.001)\end{array}$ & $\begin{array}{l}-0.144 * * * \\
(0.004)\end{array}$ & $\begin{array}{l}-0.151 * * * \\
(0.013)\end{array}$ & $\begin{array}{l}0.033 * * * \\
(0.003)\end{array}$ & $\begin{array}{l}0.009 * * * \\
(0.001)\end{array}$ & $\begin{array}{l}-0.043 * * * \\
(0.004)\end{array}$ \\
\hline \multicolumn{2}{|c|}{ Female gender (vs male) } & $\begin{array}{l}0.072 * * * \\
(0.011)\end{array}$ & $\begin{array}{l}-0.017 * * * \\
(0.002)\end{array}$ & $\begin{array}{l}-0.004 * * * \\
(0.001)\end{array}$ & $\begin{array}{l}0.021 * * * \\
(0.003)\end{array}$ & $\begin{array}{l}0.057 * * * \\
(0.011)\end{array}$ & $\begin{array}{l}-0.012 * * * \\
(0.002)\end{array}$ & $\begin{array}{l}-0.003 * * * \\
(0.001)\end{array}$ & $\begin{array}{l}0.016 * * * \\
(0.003)\end{array}$ \\
\hline \multicolumn{2}{|l|}{ City } & $\begin{array}{l}0.007 * * * \\
(0.000)\end{array}$ & $\begin{array}{l}-0.002^{* * *} \\
(0.000)\end{array}$ & $\begin{array}{l}-0.000 * * * \\
(0.000)\end{array}$ & $\begin{array}{l}0.002 * * * \\
(0.000)\end{array}$ & $\begin{array}{l}0.006^{* * * *} \\
(0.000)\end{array}$ & $\begin{array}{l}-0.001^{* * * *} \\
(0.000)\end{array}$ & $\begin{array}{l}-0.000^{* * *} \\
(0.000)\end{array}$ & $\begin{array}{l}0.002^{* * * *} \\
(0.000)\end{array}$ \\
\hline \multicolumn{2}{|l|}{ Age } & $\begin{array}{l}0.011 * * * \\
(0.002)\end{array}$ & $\begin{array}{l}-0.003 * * * \\
(0.000)\end{array}$ & $\begin{array}{l}-0.001 * * * \\
(0.000)\end{array}$ & $\begin{array}{l}0.003 * * * \\
(0.000)\end{array}$ & $\begin{array}{l}0.001 \\
(0.002)\end{array}$ & $\begin{array}{l}-0.000 \\
(0.000)\end{array}$ & $\begin{array}{l}-0.000 \\
(0.000)\end{array}$ & $\begin{array}{l}0.000 \\
(0.000)\end{array}$ \\
\hline Year (vs 2012) & $\begin{array}{l}2013 \\
2014 \\
2015 \\
2016 \\
2017 \\
2018 \\
2019\end{array}$ & $\begin{array}{l}-0.744 * * * \\
(0.036) \\
-0.704 * * * \\
(0.033) \\
-0.999 * * \\
(0.034) \\
-0.848 * * * \\
(0.034) \\
-0.480 * * * \\
(0.033) \\
-0.559 * * * \\
(0.033) \\
-0.722 * * * \\
(0.140)\end{array}$ & $\begin{array}{l}0.147 * * * \\
(0.006) \\
0.137 * * * \\
(0.005) \\
0.214 * * * \\
(0.006) \\
0.173 * * * \\
(0.006) \\
0.085 * * * \\
(0.005) \\
0.102 * * * \\
(0.005) \\
0.141 * * * \\
(0.034)\end{array}$ & $\begin{array}{l}0.081 * * * \\
(0.005) \\
0.079 * * * \\
(0.005) \\
0.086 * * * \\
(0.005) \\
0.085 * * * \\
(0.005) \\
0.063 * * * \\
(0.005) \\
0.069 * * * \\
(0.005) \\
0.080 * * * \\
(0.008)\end{array}$ & $\begin{array}{l}-0.228^{* * * *} \\
(0.011) \\
-0.216^{* * *} \\
(0.10) \\
-0.301^{* * *} \\
(0.10) \\
-0.258^{* * *} \\
(0.10) \\
-0.148^{* * *} \\
(0.10) \\
-0.172^{* * *} \\
(0.10) \\
-0.221^{* * *} \\
(0.042)\end{array}$ & $\begin{array}{l}-0.824 * * * \\
(0.037) \\
-0.702^{* * *} \\
(0.034) \\
-0.945 * * * \\
(0.035) \\
-0.834 * * * \\
(0.035) \\
-0.753 * * * \\
(0.033) \\
-0.643 * * * \\
(0.034) \\
-0.701 * * * \\
(0.140)\end{array}$ & $\begin{array}{l}0.150 * * * \\
(0.006) \\
0.122 * * * \\
(0.005) \\
0.179 * * * \\
(0.006) \\
0.152 * * * \\
(0.005) \\
0.134 * * * \\
(0.005) \\
0.110 * * * \\
(0.005) \\
0.122 * * * \\
(0.030)\end{array}$ & $\begin{array}{l}0.086^{* * * *} \\
(0.005) \\
0.079 * * * \\
(0.005) \\
0.090 * * * \\
(0.005) \\
0.086^{* * * *} \\
(0.005) \\
0.082^{* * *} \\
(0.005) \\
0.075^{* * *} \\
(0.005) \\
0.079 * * * \\
(0.010)\end{array}$ & $\begin{array}{l}-0.236 * * * \\
(0.010) \\
-0.201 * * * \\
(0.009) \\
-0.269 * * * \\
(0.010) \\
-0.238^{* * * *} \\
(0.010) \\
-0.216^{* * *} \\
(0.009) \\
-0.184 * * * \\
(0.009) \\
-0.201 * * * \\
(0.040)\end{array}$ \\
\hline \multicolumn{2}{|l|}{ cut1 } & $\begin{array}{l}-1.135 \\
(0.054)\end{array}$ & & & & $\begin{array}{l}-2.175 \\
(0.058)\end{array}$ & & & \\
\hline \multicolumn{2}{|l|}{ cut 2} & $\begin{array}{l}0.109 \\
(0.053)\end{array}$ & & & & $\begin{array}{l}-0.862 \\
(0.057)\end{array}$ & & & \\
\hline \multicolumn{2}{|l|}{ Wald Chi2 } & \multicolumn{4}{|l|}{15696.523} & \multicolumn{4}{|l|}{18839.841} \\
\hline \multicolumn{2}{|l|}{ Prob > chi 2} & \multicolumn{4}{|l|}{0.000} & \multicolumn{4}{|l|}{0.000} \\
\hline \multicolumn{2}{|l|}{ Pseudo R2 } & \multicolumn{4}{|l|}{0.195} & \multicolumn{4}{|l|}{0.227} \\
\hline \multicolumn{2}{|l|}{$\mathrm{N}$} & \multicolumn{4}{|l|}{86600} & \multicolumn{4}{|l|}{86600} \\
\hline
\end{tabular}




\subsection{Discussion and conclusion}

In this chapter, we set out to establish the contribution of deprivation measured by characteristics of the home environment to the intergenerational correlation of education. Evidence on the contribution of home environment is scarce in developing countries. We combine different deprivations in a developing country setting, representing the home environment in a multidimensional manner. Deprivation was analyzed as an index from the combination of dummy variables of deprivation indicators in a pooled data of 27 countries. The analyses were based on interactions with parent's education in an intergenerational transmission of education regression to assess the contribution of deprivation index.

First, there is generally a strong relationship between being deprived and the intergenerational correlation of education. This relationship represents an additional 0.02 years increase in children's education following a 1 year change in parent's education for a one unit increase in the deprivation index. So, deprivation strengthens the intergenerational transmission of education and reduces social mobility. This finding is in line with that of Aydemir and Yazici (2019) who find that educational attainment of children in a favourable home environment or higher level of home resources depend less on the educational attainment of their parents. However, their finding holds true for women (0.05 and 0.09 in relation with father's years of schooling and mother's years of schooling, respectively) but is insignificant for men.

Deprivation in school attendance is found in households where there is a school-aged child of up to the age of class 8 completion that is not attending school. Children may not attend school as their parents because of less priority attributed to school and limited school facilities, transmitted from generation to generation. The majority of children not attending school are found in Africa, a good amount of these live in Nigeria (Odeyemi et al., 2016). For this country, there are many other reasons for staying out of school besides income, in societies of consistent educational underachievement. Parents as well as children are eager to do business, while there is limited support to encourage learning and career prospects (Okwaraji et al, 2018). Other major hindrances include distance to school, with lack of infrastructures for transport; and cultural practices of parents who do not believe in the importance of formal education and prefer keeping children at home or send them to religious schools and early marriage (Bello and Hakimi, 2017).

Given that the influence of parent's education on children's education also extends to material provisions (cooking fuel, sanitation, drinking water, electricity, housing and assets), inequalities 
from intergenerational correlation of education may arise from social isolation and the living circumstances that shaped the behavior of parents. As explained in (d'Addio, 2007), this affects childhood care from parents and the educational prospects of the children. He emphasizes on the importance of services that help shape children's upbringing. In other words, parents from poor families may become affected in their behaviors, aspirations, standards and values, that develop in them a culture of poverty. This culture affects the later outcomes of children.

Several other channels may explain the effect of deprivation on the intergenerational education correlation. The home environment may be characterized by lower educational opportunities due to, for instance, health problems arising from waterborne diseases due to inadequate or unimproved drinking water and sanitation. Besides the health effects on children and the welfare of households, children and household members may spend valuable leisure and school time meeting their water and sanitation needs. As affirmed by Ortiz-Correa et al. (2016), these demands on time use negatively affect educational attainment. Unclean cooking fuel is another critical living standard factor because of its negative impact on human health and features. Another downside is that children and other household members may spend a lot of energy and time trekking long distances to fetch cooking wood, charcoal, or dung (Njoh et al., 2018). Until recently, access to clean cooking fuel was very low in Africa (Armah et al., 2019).

Education also significantly depends on electricity in developing countries, besides water, sanitation, and cooking fuel. The explanation lies on the fact that basic service like electricity is required for studying. In the absence of electricity and other basic assets, the execution of domestic chores, communication, information, and learning cannot be facilitated (Njoh et al., 2018). Housing conditions are one of the socio-economic conditions expected to impact on literacy. The survey of Pillay (2017) in South Africa confirms the fact that children living in good housing conditions performed better than their peers in exams. A downside of poor housing is that children are faced with issues like overcrowdedness and more home duties.

One possible measure through which deprivation correlates with the intergenerational transmission of education is the genetic endowments that affect both children's ability to attain higher education and parent's ability to acquire basic home resources. Parents with lower ability accumulate less resources and have children who are unable to obtain more schooling (Huang, 2013). Another mechanism that could give rise to the significantly positive association between educational persistence and deprivation might be that in households with more home and time- 


\section{Chapter 5}

consuming duties, educational aspirations may be low, and parental opinions and decisions regarding children's education may be shaped negatively.

The findings in this chapter are in accordance with the literature on the importance of looking to the actual home environment or deprivations of households in the intergenerational transmission of education of students from poor families. While these findings cannot establish causal relationships, they provide useful hints about the underlying causal mechanisms that lead to the association between poverty and the intergenerational correlation of education. In the context of the developing countries, these findings establish that the intergenerational correlation of education differs by the deprivation status of households. These include having school-aged children that are not attending school; cooking fuel of dung, wood or charcoal; unimproved or shared sanitation facilities; unsafe or shared drinking water; no electricity; unimproved housing; and absence of assets. The deprivations thus suggest that although both financial and non-financial availability are likely to be important in the intergenerational transmission of education, the latter is likely to facilitate the task of ensuring that young people have equal opportunities to succeed.

In our view, these findings are useful for policy. School-aged children's school enrolment, as well as the household living standard indicators play an important role in achieving early and sustained development required for higher educational attainment. Deprivation hampers social mobility. Where a culture of poverty - a consequence of parents from poor or uninspired family background - has shaped parental values and aspirations, income provision such as one dollar a day may not impact on educational attainment. Policies that might contribute to improving intergenerational mobility of education could include the modification of parental values through the creation of incentives and basic services for a convenient living condition. This would also help to reduce any predominance of informal and household-based social and economic activities that negatively affect school attendance and retention. Policy should also focus on improving college retention and completion by preparing students earlier in their academic career for the desire and demands of higher level of schooling.

A few limitations in these analyses should be noted. First, although the data are nationally representative, we have slightly modified the actual sample sizes by some eliminations due to requirements and truncation. This is a limitation which may affect predictive power to a representative population. Second, there may be other characteristics that influence the relationship between parent's education and children's education, thereby influencing the 
magnitude of the correlation coefficients of the intergenerational correlation of education. Third, our data are cross-sectional, not longitudinal. Therefore, we do not control for possible change in deprivation status of the household while the individual was growing up. Therefore, future research focusing on identifying causal relations, and control for possible changes in deprivation status in this area would help in providing more insight into the moderating effect of household deprivation in the study of intergenerational correlation of education. 
Chapter 6

Conclusion 
This thesis contributes by evaluating the intergenerational correlation of education and its relations to both macro-level opportunities and micro-level environments that correlate with the transmission of education from parents to children. We first establish that push, pull, and falling out factors are prominent determinants of early school-leaving in both Africa and Asia and context-specific, through a systematic review of 43 articles on the determinants of school dropout in Africa and Asia (Chapter 2). The high rate of school dropouts in primary and secondary schools in developing countries contributes to the persistence of educational attainment of children that is similar to that of their parents, that is, the persistence of the intergenerational correlation of education.

The systematic literature review, which consists of studies from 2001 to 2018 shows that pull factors, push factors and falling out factors determine early school leaving, with the pull factors showing a very high prominence across Africa and Asia. These pull factors include gender, religion, ethnicity, house work, wage labor, farming, region of residence, ill health, truancy, disability, pregnancy, marriage, age, no self-esteem, late school entry, pre-marital sex, substance use, familyrelated factors, and environmental factors. The factors which push students away in these findings are inadequate school facilities and quality, unavailable and unskilled teachers, student-teacher conflict, inadequate student assistance, no leisure activities, unsuitable school time, corporal punishment, exam failure, school distance, absenteeism, grade repetition, poor academic performance, and unofficial enrolment. The falling out factors are lack of interest, and unawareness of importance of education. In addition, in Asia, immigration and ethnicity are important factors. This suggests that multi-perspective targeting is required to prevent school dropout. That is, targets that involve family, school, individual, as well as community focus.

We then proceed with the multidimensional analysis of the intergenerational transmission of education including on the one hand, macro-level institutional factors that represent socioeconomic and political opportunities, such as industrialization, government expenditure, quality of the education system, infrastructure, health outcomes of the economy, and political stability and accountability (Chapter 3). Specifically, we focused on economic development (GDP), the prevalence of HIV, life expectancy at birth, female-male labour force participation, government expenditure on education, pupil-teacher ratio, primary school starting age, primary school duration, secondary school duration, compulsory years of education, fixed telephone subscriptions, mobile cellular subscriptions, the extent of corruption, the extent of political stability, and the extent of 
voice and accountability. We looked at the correlation between these factors and the intergenerational correlation of education. We discuss these institutional factors because we argue that institutional factors in general are informative about the transmission of education from parents to children. We therefore formulated the second hypothesis, that: Favourable institutional characteristics are a channel to reduce the intergenerational correlation of education.

The results show that these institutional factors account for $39 \%$ of the explained cross-country variation in the intergenerational correlation of education. The most important explanation of this variation is the quality of the education system. The higher the quality of education, the lower the persistence of similar educational attainment from parents to children. The pupil-teacher ratio, primary school duration, and compulsory years of education are the education quality variables that reduce intergenerational correlation of education by 0.03 years, 0.03 years, and 0.02 years respectively, following a one standard deviation change in the variables. Besides the quality of education, important factors are the GDP, female-male labour force participation, and extent of voice and accountability with 0.01 years, 0.03 years, and 0.03 years change in the intergenerational correlation of education respectively, following a one standard deviation change in the variables. This confirms our second hypothesis on favourable institutional characteristics being able to reduce intergenerational correlation of education.

For an empirical investigation of the situation in one country, the change in compulsory education years in Senegal in 2004 is analysed, to observe the marginal impact on compulsory and postcompulsory grades completion (Chapter 4). The compulsory years of education was increased from 6 to 10 in 2004. The policy substantially increased grade 10 completion for children aged 13 to 15 (treatment group) as compared to children aged 16-18 (control group). This shows that the effect of the change in the compulsory education law on compulsory school completion is highly significant and positive for these marginal learners. Treatment group individuals are $7 \%$ more likely to complete lower secondary education as compared to the control group individuals. In terms of gender, no statistically significant gender differential effect is found of the increase in compulsory education. On the completion of post-compulsory school grades or high school grades (grades 11, 12, and 13), the chi-square tests of association show that the completion of grade 11 and the completion of grade 12 are significantly associated with the education policy for these marginal learners. Therefore, more individuals completed grades 11 and 12 in the treatment group (those aged 13 to 15 ) as compared to the control group (those aged 16 to 18 ). 
However, completion of grade 13 shows no statistically significant association with the education policy. That is, there is no change in obtaining a high school certificate. Nevertheless, the positive impact of the change in compulsory education years on grades 10 to 12 provides support for the hypothesis that favourable institutional characteristics are some of the channels through which intergenerational correlation of education can be reduced, by means of the improvement of educational attainment of children. This confirms the correlation between the compulsory years of education and the intergenerational correlation of education in Chapter 3. Children in countries with a higher number of years of compulsory education face higher intergenerational mobility in education. That is, the higher the compulsory education years the lower the intergenerational correlation of education.

On the other hand, the approach includes micro-level or household valuable aspects of life (Chapter 5). Given that there are internationally comparable indicators of household disadvantageous conditions for developing countries, which are the indicators of poverty, we focused on the most recent of these internationally comparable deprivation factors of acute poverty of households. These variables are based on deprivations or valuable aspects of life mentioned by the poor in their explanation of their day-to-day living situations. They include child mortality, school attendance of school-aged children, cooking fuel, sanitation, drinking water, housing, electricity, and assets. From our findings, a deprivation index of these variables show a strong relationship between being deprived and the intergenerational correlation of education of 0.02 years. That is, an additional 0.02 years increase in children's education following a 1-year change in parent's education for the deprived. The result confirms our third hypothesis which said that: Intergenerational correlation of education significantly increases with household deprivation. Individually, school attendance, cooking fuel, sanitation, drinking water, housing, electricity, and assets show that there is a relationship between being deprived and the relationship between parent's education and children's education. This relationship ranges between 0.05 years for drinking water and electricity to 0.09 years for housing and assets.

\section{Institutional characteristics and deprivations in education}

Most of the institutional and family environment factors in this thesis that correlate with the intergenerational correlation of education are part of the sustainable development goals (SDGs) of the United Nations. The SDGs were designed in 2015 to achieve a better and more sustainable 
future for all. This thesis shows that a comprehensive achievement on these SDGs has to be mindful of the environmental, social, and economic development aspects of change. The development indices (GDP, female-male labour force participation, pupil-teacher ratio, primary school duration, and compulsory years of education) lead to the pursuit of the SDG 8 of 'decent work and economic growth' achievement, SDG 5 of 'gender equality', as well as SDG 4 of 'quality education'. The results of the development indices imply that the benefits of industrial productivity (GDP) are experienced at a lower scale in the countries with low GDP (Coscieme, 2020), besides genderrelated labour inequality and low quality educational systems. These may be among others the required level of labour for industrial productivity; employment opportunities; high schooling levels; and financial benefits from interest rates, less indebtedness, trade openness, material prices, exchange rates (Tacchella et al., 2018).

The governance factors such as voice and accountability, and their management not only describe the level of social interaction and respect of citizens and the state but play an important role in achieving a desirable level of human development (Keser and Gokmen, 2018). A low level of human development may be reflected through low income, low education, poor health, communication and knowledge deprivation, low self-esteem, low dignity and confidence, and deprivation in human and political rights practice. Therefore, as part of the motivation to enrol in higher education, practices such as freedom of association, expression, the media, and the ability to participate in selecting the government are essential. This corresponds to the SDG 16 of the need to have an inclusive society and an accountable institution.

Household deprivation (with indicators such as school attendance, cooking fuel, sanitation, drinking water, housing, electricity, and assets) refers to important basic human needs whose access are deemed important in the fight against poverty. The SDGs 6 and 7 emphasized on water, sanitation, and energy in their strategies to fight poverty and end deprivation. School attendance may create encouragement to other students and a culture of education, to the detriment of variables negatively correlated with educational success such as child labour, wage work, religious beliefs, and early marriages. The importance of living standard indicators such as clean cooking fuel, suitable housing, safe and easily accessible drinking water, electricity, improved sanitation, and basic assets is traced to the right for all people to have access to basic needs. 
Deprivations in these basic needs have serious implications for living, ranging from food and energy security, environmental sustainability, health, economic development in terms of economic opportunities and jobs, better education, protection and climate change resilience, and household gender and youth empowerment (Sustainable Development Goal, 2020a,b). A couple of examples of the necessity of these basic needs to engage in education include the fact that electricity makes it safer on the roads to travel to school when there is light on the streets; children can only make homework at home when they have light enough in the house; and traveling far for water may limit a child's potential to have time enough to enrol in school.

The analyses of the intergenerational correlation of education in connection with institutional characteristics and household environment provides an understandable picture of the transmission of education from one generation to the other. Although the correlational coefficients may be quite small, they suggest how equality of opportunity may change in response to increased social mobility.

\section{Policy implications}

A policy implication from this thesis is that in an effort to increase educational attainment, and, consequently, to partly reduce the intergenerational correlation of education, institutional characteristics and households' circumstances should be taken into consideration. We therefore propose guidelines for the progress towards improving the degree of independence of a child's educational attainment to his/her parent's educational level, and improving the pathway enabling children to exceed the educational level of their most educated parent in developing countries. Efforts should be made to ameliorate economic development, such as promoting more industrialization (or improving manufacturing skills) and training programs, and trade exchange in favour of technology import. Industrial improvement requires labour and education, which may in turn create more opportunities and a more higher education-oriented generation. An increase in GDP is therefore a vital input in improving outcomes like employment, decent work and economic growth, and empowering educational decisions, investment, and actual mobility. In addition, education provision and the quality of education such as more teachers to student ratio, and many years of compulsory education so students spend more time at school obligatorily, contribute to increasing intergenerational mobility in education. 
Access to basic education by households is also vital, as cost to school still act as hindrances to higher education. Despite the global acceptance of a free basic education, some basic learning institutions in low- and middle-income countries still operate on fee collection. The governance structure such as voice and accountability should carefully be observed. In other words, the motivation to go to higher education also relates to how governance is handled in terms of freedom and rights to citizens to practice association, expression, and voting. In addition, attention should be paid to household deprivation that may affect school attendance and retention and which may increase the number of out of school children. Besides enabling the availability of basic services, policies could motivate and encourage students for higher education earlier.

It is our recommendation that the analysis of the intergenerational correlation of education in lowand middle-income countries should use a multidimensional perspective, and importantly, that these countries also place strategic focus on the SDGs. Because focusing on one of them in isolation would not provide a richer picture of improving educational mobility but a combination of multiple factors as complements to one another is relevant to public policy.

\section{Limitations and directions for future research}

We acknowledge the fact that first, most of our research is based on correlational relationships, therefore, we cannot assume causality. Second, the sample sizes of the nationally representative surveys used in this thesis are modified by elimination and truncation, thereby possibly limiting the predictive power of the estimates to a representative population. Third, the data we use are crosssectional, not longitudinal. Therefore, changes over time cannot be observed.

We therefore suggest observing overall macro-level and micro-level factors that children can or cannot be held responsible for. For instance, other family background like age, siblings, and occupation; individual ability; genetics; community; and other measures of governance, communication and infrastructure. Due to the potential endogeneity for the deprivation variables, suitable instruments can be used to explore their moderating effects. Also, future research involving a more in-depth exploration in this area by controlling for possible changes over time using longitudinal data, as well as a focus on specific social context, would further contribute to explaining the moderating effect of institutional factors and household deprivations in the correlation of education across generations. In addition, there is need to further assess the 
educational challenges faced by households in the primary, secondary and high school process of children in areas where the deprivation indicators seem to be a challenge.

In conclusion, these findings provide insight into some of the situations surrounding households and economies with persistent low intergenerational mobility of education and the way the institutions and household environments can be assessed and ameliorated to further provide comfort and means to higher levels of schooling. They shed light on the multifaceted nature of solutions to educational improvement which comprise of both micro level and macro level circumstances surrounding school goers. These circumstances are considered the responsibility of all stakeholders in society ranging from the state to the direct household members on which children rely on for their early childhood development and educational attainment. 


\section{Appendix}

Tables A2.1., A2.2. and A2.3. below present the 43 studies included in this review. These studies are grouped by study type, that is, quantitative studies in A2.1., mixed studies (consisting of both a quantitative phase and a qualitative phase of data collection) in A2.2., and qualitative studies in A2.3. The determinants column reports the outcomes (factors that cause school dropout) in these studies.

A2.1.: Overview of the School Dropout Determinants Included in the Review: Quantitative Studies

\begin{tabular}{|c|c|c|c|c|c|}
\hline $\begin{array}{l}\text { Author(s) } \\
\text { and Year }\end{array}$ & Country & Methodology & Study Focus & $\begin{array}{l}\text { Year of Data/ } \\
\text { Sample }\end{array}$ & Determinants \\
\hline $\begin{array}{l}\text { Christian } \\
(2015)\end{array}$ & Nigeria & $\begin{array}{l}\text { Quantitative, school documents, } \\
\text { regression analysis. }(N=48)\end{array}$ & $\begin{array}{l}\text { Gender, school } \\
\text { location and school } \\
\text { section as predictors } \\
\text { of dropout }\end{array}$ & $\begin{array}{l}2009,2012 / \\
\text { Secondary school } \\
\text { students }\end{array}$ & $\begin{array}{l}\text { School location, student gender, school } \\
\text { section }\end{array}$ \\
\hline $\begin{array}{l}\text { Shahidul } \\
(2013)\end{array}$ & Bangladesh & $\begin{array}{l}\text { Quantitative, questionnaires, } \\
\text { logistic regression. }(N=268)\end{array}$ & $\begin{array}{l}\text { Effects of parents' } \\
\text { household decision } \\
\text { making on girls' } \\
\text { attrition }\end{array}$ & $\begin{array}{l}2010 / \\
\text { Parents }\end{array}$ & $\begin{array}{l}\text { Father's participation in decision process, } \\
\text { self-employed father and/or housewife } \\
\text { mother }\end{array}$ \\
\hline $\begin{array}{l}\text { Lloyd et } \\
\text { al. (2009) }\end{array}$ & Pakistan & $\begin{array}{l}\text { Quantitative, school documents, } \\
\text { questionnaire, discrete time } \\
\text { logistic regression. }(N=731)\end{array}$ & $\begin{array}{l}\text { Assessing factors } \\
\text { increasing primary } \\
\text { and middle school } \\
\text { dropout }\end{array}$ & $\begin{array}{l}\text { 1997-2004/ } \\
\text { Married women } \\
\text { aged 20-45 }\end{array}$ & $\begin{array}{l}\text { Unwanted pregnancy, enrolment in } \\
\text { government school, lack of post-primary } \\
\text { school, uneducated mother, poverty, } \\
\text { unavailable teachers, underdeveloped } \\
\text { community }\end{array}$ \\
\hline $\begin{array}{l}\text { Smits \& } \\
\text { Huisman } \\
(2013)\end{array}$ & $\begin{array}{l}\text { Six }^{\mathrm{f}} \text { Arab } \\
\text { countries }\end{array}$ & $\begin{array}{l}\text { Quantitative, Demographic and } \\
\text { Health Survey, Pan Arab Project } \\
\text { for Family Health data, } \\
\text { questionnaire, logistic regression. } \\
(N=79,846)\end{array}$ & $\begin{array}{l}\text { Factors influencing } \\
\text { educational } \\
\text { discontinuity }\end{array}$ & $\begin{array}{l}2001-2005 / \\
\text { Children aged 18- } \\
15 \text { years, } \\
\text { households }\end{array}$ & $\begin{array}{l}\text { Age, number of siblings, birth order, } \\
\text { biological child, agricultural father, } \\
\text { parents' education, unemployed mother, } \\
\text { poverty, rural area, gender, parental } \\
\text { absence, degree of modernisation, extended } \\
\text { family presence, no school facilities }\end{array}$ \\
\hline
\end{tabular}

\footnotetext{
${ }^{f}$ Algeria, Egypt, Morocco, Syria, Tunisia, Yemen
} 
A2.1. (continues)

\begin{tabular}{|c|c|c|c|c|c|}
\hline $\begin{array}{l}\text { Author(s) } \\
\text { and Year }\end{array}$ & Country & Methodology & Study Focus & Year of Data/ Sample & Determinants \\
\hline $\begin{array}{l}\text { Sabates et al. } \\
(2013)\end{array}$ & Bangladesh & $\begin{array}{l}\text { Quantitative, questionnaire, } \\
\text { multivariate logit model. } \\
(N=9046)\end{array}$ & $\begin{array}{l}\text { Factors associated } \\
\text { with abandoning } \\
\text { primary education }\end{array}$ & $\begin{array}{l}2007,2009 / \\
\text { Households of leaners } \\
\text { and dropouts aged } 4- \\
15\end{array}$ & $\begin{array}{l}\text { Age, gender, financial difficulty, school } \\
\text { absenteeism, lack of parental support for } \\
\text { school work }\end{array}$ \\
\hline $\begin{array}{l}\text { Korinek \& } \\
\text { Punpuing } \\
(2012)\end{array}$ & Thailand & $\begin{array}{l}\text { Quantitative, questionnaire, } \\
\text { discrete-time multinomial } \\
\text { logit regression. }(N=3,202)\end{array}$ & $\begin{array}{l}\text { Obstacles to } \\
\text { achieving } \\
\text { secondary } \\
\text { schooling }\end{array}$ & $\begin{array}{l}\text { 2001,2002,2003,2004/ } \\
\text { Children aged between } \\
11-14\end{array}$ & $\begin{array}{l}\text { Migration, financial difficulty, work } \\
\text { unavailability on the labour market }\end{array}$ \\
\hline $\begin{array}{l}\text { Huisman \& } \\
\text { Smits }(2015)\end{array}$ & $\begin{array}{l}30^{\mathrm{g}} \\
\text { developing } \\
\text { countries }\end{array}$ & $\begin{array}{l}\text { Quantitative, Demographic } \\
\text { and Health } \\
\text { Surveys and the Pan Arab } \\
\text { Project for Family Health } \\
\text { data, logistic regression. } \\
(N=134608)\end{array}$ & $\begin{array}{l}\text { Household and } \\
\text { context } \\
\text { determinants of } \\
\text { school dropout }\end{array}$ & $\begin{array}{l}\text { 1998-2006/ } \\
\text { Children aged 12-15 } \\
\text { and their households }\end{array}$ & $\begin{array}{l}\text { Parental education, father's occupation, } \\
\text { unemployed mother, financial hardship, } \\
\text { farming, gender, number and type of } \\
\text { siblings, birth order, mother gave birth } \\
\text { under age 18, non-biological child, parental } \\
\text { absence, no schools, no teachers, no school } \\
\text { quality, no job market, rural area }\end{array}$ \\
\hline $\begin{array}{l}\text { Zhao \& } \\
\text { Glewwe } \\
(2010)\end{array}$ & China & $\begin{array}{l}\text { Quantitative, Gansu Survey } \\
\text { of Children and Families } \\
\text { data, censored ordered } \\
\text { probit regression. }(N=2000)\end{array}$ & $\begin{array}{l}\text { Determinants of } \\
\text { basic school } \\
\text { attainment }\end{array}$ & $\begin{array}{l}\text { 2000, 2004/ Children } \\
\text { aged 9-12, 13-17 }\end{array}$ & $\begin{array}{l}\text { Nutritional deficiency, parental ignorance, } \\
\text { mother's education, age, poverty, no school } \\
\text { facilities, no interest, inexperienced } \\
\text { teachers, academic failure, school distance }\end{array}$ \\
\hline $\begin{array}{l}\text { Farid-ul- } \\
\text { Hasnain \& } \\
\text { Krantz } \\
(2010)\end{array}$ & Pakistan & $\begin{array}{l}\text { Quantitative, questionnaire, } \\
\text { logistic regression. } \\
(\mathrm{N}=1650)\end{array}$ & $\begin{array}{l}\text { Reasons for } \\
\text { involuntary college } \\
\text { dropout }\end{array}$ & $\begin{array}{l}2006 / \\
\text { Adolescence aged } 17- \\
21 \text { years }\end{array}$ & $\begin{array}{l}\text { Migration, extended family presence, } \\
\text { poverty, parental ignorance, early marriage, } \\
\text { illness, exam failure, religion, household } \\
\text { work, school distance, wage labour desire }\end{array}$ \\
\hline $\begin{array}{l}\text { Manandhar } \\
\text { \& Sthapit } \\
(2012)\end{array}$ & Nepal & $\begin{array}{l}\text { Quantitative, questionnaire, } \\
\text { descriptive statistics. } \\
(N=83)\end{array}$ & $\begin{array}{l}\text { Determinants of } \\
\text { primary school } \\
\text { dropout }\end{array}$ & Dropped out children & $\begin{array}{l}\text { Wage labour desire, irregular attendance, } \\
\text { failure, poverty, migration, household } \\
\text { chores, parental ignorance }\end{array}$ \\
\hline
\end{tabular}

${ }^{\mathrm{g}}$ Bolivia, Colombia, Peru, Benin, Cameroon, Ghana, Guinea, Mali, Nigeria, Senegal, Kenya, Rwanda, Uganda, Congo Brazzaville, Madagascar, Malawi, Mozambique, Namibia, South Africa, Tanzania, Zambia, Algeria, Morocco, Syria, Yemen, Bangladesh, India, Indonesia, Nepal, Philippines 
A2.1. (continues)

\begin{tabular}{|c|c|c|c|c|c|}
\hline $\begin{array}{l}\text { Author(s) } \\
\text { and Year }\end{array}$ & Country & Methodology & Study Focus & $\begin{array}{l}\text { Year of Data/ } \\
\text { Sample }\end{array}$ & Determinants \\
\hline $\begin{array}{l}\text { Basu \& } \\
\text { Chatterjee } \\
(2014)\end{array}$ & India & $\begin{array}{l}\text { Quantitative, } \\
\text { questionnaires, } \\
\text { descriptive statistics. } \\
(N=\text { N/A })\end{array}$ & $\begin{array}{l}\text { Why dropout rate is } \\
\text { very high for the } \\
\text { tribal students }\end{array}$ & $\begin{array}{l}\text { Tribal students, } \\
\text { parents, school } \\
\text { authorities }\end{array}$ & $\begin{array}{l}\text { Poor school facilities, inadequate school facilities, } \\
\text { poor toilets and lavatories, distance to school, farm } \\
\text { work, lack of schools, irregular attendance, } \\
\text { unfriendly teachers }\end{array}$ \\
\hline $\begin{array}{l}\text { Braimah \& } \\
\text { Oduro-Ofori } \\
(2005)\end{array}$ & Ghana & $\begin{array}{l}\text { Quantitative, } \\
\text { questionnaire, school } \\
\text { documents, descriptive } \\
\text { statistics. }(N=72)\end{array}$ & $\begin{array}{l}\text { Main causes of } \\
\text { school dropout }\end{array}$ & $\begin{array}{l}\text { 1998/1999, } \\
\text { 2000/2001,2001 } \\
\text { /2002 / Parents } \\
\text { and school } \\
\text { leavers }\end{array}$ & $\begin{array}{l}\text { Exam failure, no parental care, parent ignorance, } \\
\text { poverty, inadequate school facilities, absent } \\
\text { teachers, fear of teachers, corporal punishment, } \\
\text { death or divorce of parent, housework, absenteeism, } \\
\text { truancy, bad influence, no interest, bullying, }\end{array}$ \\
\hline $\begin{array}{l}\text { Shadreck } \\
(2013)\end{array}$ & Zimbabwe & $\begin{array}{l}\text { Quantitative, } \\
\text { questionnaires, school } \\
\text { documents, descriptive } \\
\text { statistics. }(N=20)\end{array}$ & $\begin{array}{l}\text { School factors and } \\
\text { circumstances } \\
\text { leading to dropout }\end{array}$ & 2012 / Dropouts & $\begin{array}{l}\text { Financial constraints, inadequate teacher assistance, } \\
\text { teachers unqualified, discrimination, punishment, no } \\
\text { future jobs, school distance, irrelevant curriculum, } \\
\text { inadequate facilities }\end{array}$ \\
\hline $\begin{array}{l}\text { Banik \& } \\
\text { Neogi } \\
(2015)\end{array}$ & India & $\begin{array}{l}\text { Quantitative, } \\
\text { questionnaire, binomial } \\
\text { logit model. }(N=320)\end{array}$ & $\begin{array}{l}\text { Determinants of } \\
\text { school dropout }\end{array}$ & $\begin{array}{l}\text { 2010, 2011/ } \\
\text { Households }\end{array}$ & $\begin{array}{l}\text { Housework, school distance, poverty, unsuitable } \\
\text { school time, migration, lack of interest, failure, } \\
\text { absenteeism, early marriage, lack of teachers and } \\
\text { quality, uninterested and ignorant parents, no school } \\
\text { sanitation facilities, insecurity }\end{array}$ \\
\hline $\begin{array}{l}\text { Mzuza et al. } \\
(2014)\end{array}$ & Malawi & $\begin{array}{l}\text { Quantitative, } \\
\text { questionnaire, school } \\
\text { documents, analysis of } \\
\text { variance. }(N=965)\end{array}$ & $\begin{array}{l}\text { Factors causing } \\
\text { high dropout rates }\end{array}$ & $\begin{array}{l}2013 / \\
\text { Primary school } \\
\text { students and } \\
\text { teachers }\end{array}$ & $\begin{array}{l}\text { Exam failure, marriage, no interest, over-age, } \\
\text { learning time, parental absence, unmotivated } \\
\text { parents and teachers, no counselling, absenteeism, } \\
\text { fear of teacher, housework, peer influence, } \\
\text { pregnancy, inadequate teachers, truancy, } \\
\text { inappropriate syllabus, sickness, school distance, } \\
\text { poverty }\end{array}$ \\
\hline $\begin{array}{l}\text { No et al. } \\
(2016)\end{array}$ & Cambodia & $\begin{array}{l}\text { Quantitative, } \\
\text { questionnaire, Cox } \\
\text { regression analysis. } \\
(N=905)\end{array}$ & $\begin{array}{l}\text { Causes of school } \\
\text { dropout }\end{array}$ & $\begin{array}{l}2007,2008 \\
2009,2010 / \\
\text { Students }\end{array}$ & $\begin{array}{l}\text { Parents' divorce, late enrolment, grade repetition, } \\
\text { work, poverty, parental ignorance, siblings' number, } \\
\text { parent's death, absenteeism, no academic support, } \\
\text { conflict with teacher, ethnicity, distance, parental } \\
\text { education, friends }\end{array}$ \\
\hline
\end{tabular}




\section{A2.1. (continues)}

\begin{tabular}{|c|c|c|c|c|c|}
\hline $\begin{array}{l}\text { Author(s) } \\
\text { and Year }\end{array}$ & Country & Methodology & Study Focus & Year of Data/ Sample & Determinants \\
\hline $\begin{array}{l}\text { Yi et al. } \\
(2012)\end{array}$ & China & $\begin{array}{l}\text { Quantitative, school } \\
\text { documents, survey, linear } \\
\text { regression. }(N=7811)\end{array}$ & $\begin{array}{l}\text { Examined factors that } \\
\text { correlate with dropout }\end{array}$ & $\begin{array}{l}\text { 2009-2011/Grade 7-9 } \\
\text { students }\end{array}$ & $\begin{array}{l}\text { Rising opportunity cost, poor } \\
\text { academic performance, financial } \\
\text { constraints }\end{array}$ \\
\hline $\begin{array}{l}\text { Biddlecom } \\
\text { et al. } \\
(2008)\end{array}$ & $\begin{array}{l}\text { Four }^{\mathrm{h}} \mathrm{SSA} \\
\text { countries }\end{array}$ & $\begin{array}{l}\text { Quantitative, school } \\
\text { documents, logistic } \\
\text { regression. }(N=19528)\end{array}$ & $\begin{array}{l}\text { Links between } \\
\text { premarital sex and } \\
\text { early school leaving }\end{array}$ & $\begin{array}{l}\text { 2004/ } \\
12-19 \text { years old students }\end{array}$ & Premarital sex, gender \\
\hline $\begin{array}{l}\text { Wegner et } \\
\text { al. (2008) }\end{array}$ & South Africa & $\begin{array}{l}\text { Quantitative, questionnaires, } \\
\text { descriptive statistics, logistic } \\
\text { regression. }(N=303)\end{array}$ & $\begin{array}{l}\text { To determine whether } \\
\text { leisure boredom } \\
\text { predicts high school } \\
\text { dropout }\end{array}$ & Grade 8 students & Leisure boredom \\
\hline $\begin{array}{l}\text { Ud Din et } \\
\text { al. (2011) }\end{array}$ & Pakistan & $\begin{array}{l}\text { Quantitative, questionnaires, } \\
\text { descriptive statistics. } \\
\left(N=\mathrm{N} / \mathrm{A}^{\mathrm{i}}\right)\end{array}$ & $\begin{array}{l}\text { Determining the } \\
\text { causes of male } \\
\text { students' dropouts in } \\
\text { the } 5 \text { th grade }\end{array}$ & $\begin{array}{l}\text { Students, teachers, } \\
\text { parents }\end{array}$ & $\begin{array}{l}\text { Fear of teachers, corporal } \\
\text { punishment, poor performance, no } \\
\text { teacher supervision, examination } \\
\text { failure, illness, poverty, illiterate } \\
\text { parents, parents' ignorance on } \\
\text { education importance }\end{array}$ \\
\hline $\begin{array}{l}\text { Flisher et } \\
\text { al. } \quad(2010)\end{array}$ & South Africa & $\begin{array}{l}\text { Quantitative, questionnaires, } \\
\text { logistic regression. }(N=1470)\end{array}$ & $\begin{array}{l}\text { examined dropout } \\
\text { predictors }\end{array}$ & $\begin{array}{l}\text { 1997, 1999, 2001/ } \\
\text { Grade } 8 \text { students }\end{array}$ & $\begin{array}{l}\text { Cigarette use, poverty, absenteeism, } \\
\text { repetition, non-biological child, } \\
\text { age, gender }\end{array}$ \\
\hline $\begin{array}{l}\text { Alika } \\
(2012)\end{array}$ & Nigeria & $\begin{array}{l}\text { Quantitative, questionnaires, } \\
\text { regression analysis. }(N=200)\end{array}$ & $\begin{array}{l}\text { Effect of bullying on } \\
\text { school leaving }\end{array}$ & High school students & $\begin{array}{l}\text { Bullying significantly determines } \\
\text { dropout }\end{array}$ \\
\hline
\end{tabular}

\footnotetext{
${ }^{\text {h }}$ Burkina Faso, Ghana, Malawi, Uganda
}

${ }^{\mathrm{i}} \mathrm{N} / \mathrm{A}$ means that the information is not specified. 
A2.2.: Overview of the School Dropout Determinants Included in the Review: Mixed Studies

\begin{tabular}{|c|c|c|c|c|c|}
\hline $\begin{array}{l}\text { Author(s) and } \\
\text { Year }\end{array}$ & Country & Methodology & Study Focus & $\begin{array}{l}\text { Year of Data/ } \\
\text { Sample }\end{array}$ & Determinants \\
\hline $\begin{array}{l}\text { Zuilkowski et } \\
\text { al. (2016) }\end{array}$ & Kenya & $\begin{array}{l}\text { Qualitative, interview, } \\
\text { quantitative, randomized } \\
\text { control trial, logistic } \\
\text { regression. }(N=2707)\end{array}$ & $\begin{array}{l}\text { Why students drop } \\
\text { out }\end{array}$ & $\begin{array}{l}\text { 2010, 2011, 2012/ } \\
\text { Dropouts, } \\
\text { students, parents }\end{array}$ & $\begin{array}{l}\text { Poor performance, age, gender, pregnancy, } \\
\text { poor school and teaching quality, poverty, } \\
\text { uneducated parents, no interest in school, } \\
\text { disobedience, truancy, conflict with teachers }\end{array}$ \\
\hline Wudu (2015) & Ethiopia & $\begin{array}{l}\text { Qualitative, interviews, } \\
\text { quantitative, } \\
\text { questionnaires, descriptive } \\
\text { statistics, Chi-square test. } \\
(N=3648)\end{array}$ & $\begin{array}{l}\text { Problems that make } \\
\text { students to totally } \\
\text { drop out from school }\end{array}$ & $\begin{array}{l}\text { Grade } 9 \text { students, } \\
\text { teachers, } \\
\text { principals }\end{array}$ & $\begin{array}{l}\text { Poverty, distance, insecurity, truancy, failure, } \\
\text { poor education quality, no school sanitation, } \\
\text { bullying, peers' abuse, future jobs need no } \\
\text { schooling, housework, agriculture, marriage, } \\
\text { illness, disability, family issues, stigma, } \\
\text { discrimination, seasonal absence, no health } \\
\text { facilities, gender }\end{array}$ \\
\hline $\begin{array}{l}\text { Cemalcilar \& } \\
\text { Goksen (2014) }\end{array}$ & Turkey & $\begin{array}{l}\text { Qualitative, interview, } \\
\text { focus group discussions, } \\
\text { quantitative, } \\
\text { questionnaire, logistic } \\
\text { regression. }(N=764)\end{array}$ & $\begin{array}{l}\text { Determine social risk } \\
\text { factors that increase } \\
\text { early school leaving }\end{array}$ & $\begin{array}{l}\text { Dropouts, parents, } \\
\text { students, teachers, } \\
\text { principles }\end{array}$ & $\begin{array}{l}\text { Gender, work, mother's education, father's } \\
\text { employment, migration during school age, } \\
\text { mother with no social security, lack of } \\
\text { school-related social capital }\end{array}$ \\
\hline $\begin{array}{l}\text { No et al. } \\
(2012)\end{array}$ & Cambodia & $\begin{array}{l}\text { Qualitative, interviews, } \\
\text { quantitative, } \\
\text { questionnaires, logistic } \\
\text { regression. }(N=1224)\end{array}$ & $\begin{array}{l}\text { To gain insight on } \\
\text { the influential factors } \\
\text { of dropout }\end{array}$ & $\begin{array}{l}2008,2009 / \\
\text { Pupils, teachers, } \\
\text { principals }\end{array}$ & $\begin{array}{l}\text { Late school entry, ethnic status, gender, } \\
\text { parental education, parental attitudes towards } \\
\text { education }\end{array}$ \\
\hline Siddhu (2011) & India & $\begin{array}{l}\text { Quantitative, } \\
\text { questionnaire, qualitative, } \\
\text { interview, logistic } \\
\text { regression. }(N=701)\end{array}$ & $\begin{array}{l}\text { Causes of secondary } \\
\text { school non-transition }\end{array}$ & $\begin{array}{l}\text { 2009/ } \\
\text { Students, parents }\end{array}$ & $\begin{array}{l}\text { Costs, gender, distance, traditionally } \\
\text { marginalised society }\end{array}$ \\
\hline
\end{tabular}


A2.3.: Overview of the School Dropout Determinants Included in the Review: Qualitative Studies

\begin{tabular}{|c|c|c|c|c|c|}
\hline $\begin{array}{l}\text { Author(s) and } \\
\text { Year }\end{array}$ & Country & Methodology & Study Focus & $\begin{array}{r}\text { Year of Data/ } \\
\text { Sample } \\
\end{array}$ & Determinants \\
\hline Ananga (2011) & Ghana & $\begin{array}{l}\text { Qualitative, } \\
\text { interviews, identifying } \\
\text { themes. }(N=30)\end{array}$ & $\begin{array}{l}\text { Investigate reasons } \\
\text { for school dropout }\end{array}$ & $\begin{array}{l}2008-2010 / \\
\text { Dropouts, teachers, } \\
\text { parents }\end{array}$ & $\begin{array}{l}\text { Seasonal withdrawal, conflict with teacher, } \\
\text { poverty, death of parent, no value of } \\
\text { education, migration }\end{array}$ \\
\hline $\begin{array}{l}\text { Ampiah \& } \\
\text { Adu-Yeboah } \\
(2009)\end{array}$ & Ghana & $\begin{array}{l}\text { Qualitative, semi- } \\
\text { structured interview. } \\
(N=89)\end{array}$ & $\begin{array}{l}\text { Why children leave } \\
\text { school } \\
\text { Before the age of } \\
16\end{array}$ & $\begin{array}{l}\text { Young dropouts } \\
7-16 \text { years }\end{array}$ & $\begin{array}{l}\text { Seasonal withdrawal, repetition, over- } \\
\text { age/under-age, corporal punishment, } \\
\text { disability, teacher absenteeism, poverty, poor } \\
\text { performance, pregnancy, uninterested } \\
\text { parents, illness, death, religion }\end{array}$ \\
\hline $\begin{array}{l}\text { Abuya et al. } \\
(2013)\end{array}$ & Kenya & $\begin{array}{l}\text { Qualitative, } \\
\text { interviews, focus- } \\
\text { group discussions, } \\
\text { identifying themes, } \\
\text { comparisons and } \\
\text { clustering. }(N=40)\end{array}$ & $\begin{array}{l}\text { Why children } \\
\text { dropout given that } \\
\text { education is free }\end{array}$ & $\begin{array}{l}2008 / \\
\text { Dropouts, teachers, } \\
\text { parents, community } \\
\text { leaders }\end{array}$ & $\begin{array}{l}\text { Unstable home, poor performance, no } \\
\text { support, wage labour, truancy, insecurity, } \\
\text { peer influence, drugs and alcohol use, illness, } \\
\text { disability, poverty, child neglect, pregnancy, } \\
\text { no sanitation }\end{array}$ \\
\hline $\begin{array}{l}\text { Edwards et al. } \\
\text { (2014) }\end{array}$ & Cambodia & $\begin{array}{l}\text { Qualitative, } \\
\text { interviews, narratives. } \\
(N=10)\end{array}$ & $\begin{array}{l}\text { Factors that prevent } \\
\text { school transitioning }\end{array}$ & $\begin{array}{l}\text { 2011/ } \\
\text { Students, family }\end{array}$ & $\begin{array}{l}\text { No job market, few and poor schools, no } \\
\text { counselling, migration, family size, birth } \\
\text { order, poverty, farming }\end{array}$ \\
\hline $\begin{array}{l}\text { Sahin et al. } \\
(2016)\end{array}$ & Turkey & $\begin{array}{l}\text { Qualitative, } \\
\text { interviews, content } \\
\text { analysis. }(N=64)\end{array}$ & $\begin{array}{l}\text { Causes of school } \\
\text { dropout }\end{array}$ & $\begin{array}{l}\text { 2014-2015/ } \\
\text { School principals }\end{array}$ & $\begin{array}{l}\text { Neglect and oppression, no school assistance, } \\
\text { no discipline, divorce, violence, death of } \\
\text { parents, housework, low educated parents, } \\
\text { religion, early marriage, poverty }\end{array}$ \\
\hline $\begin{array}{l}\text { Mokibelo } \\
(2014)\end{array}$ & Botswana & $\begin{array}{l}\text { Qualitative, } \\
\text { interviews. }(N=20)\end{array}$ & $\begin{array}{l}\text { Why learners leave } \\
\text { school early }\end{array}$ & School dropouts & Cattle rearing, wage labour \\
\hline $\begin{array}{l}\text { Makwinja- } \\
\text { Morara (2009) }\end{array}$ & Botswana & $\begin{array}{l}\text { Qualitative, } \\
\text { interviews, } \\
\text { observations, school } \\
\text { files, emerging } \\
\text { themes. }(N=24)\end{array}$ & $\begin{array}{l}\text { Reasons for female } \\
\text { junior secondary } \\
\text { school leaving }\end{array}$ & $\begin{array}{l}\text { 2006/ Dropouts, } \\
\text { students, teachers, } \\
\text { school administrator }\end{array}$ & $\begin{array}{l}\text { Pregnancy, illness, exam failure, crime, } \\
\text { truancy, corporal punishment, poverty, } \\
\text { distance from school }\end{array}$ \\
\hline
\end{tabular}


A2.3. (continues)

\begin{tabular}{|c|c|c|c|c|c|}
\hline $\begin{array}{l}\text { Author(s) and } \\
\text { Year }\end{array}$ & Country & Methodology & Study Focus & $\begin{array}{r}\text { Year of Data/ } \\
\text { Sample } \\
\end{array}$ & Determinants \\
\hline $\begin{array}{l}\text { Igboanusi } \\
(2014)\end{array}$ & Gambia & $\begin{array}{l}\text { Qualitative, observation. } \\
(N=\mathrm{N} / \mathrm{A})\end{array}$ & $\begin{array}{l}\text { Effect of the English-only } \\
\text { language policy in } \\
\text { education }\end{array}$ & $\begin{array}{l}2010 / \\
\text { Pupils and teachers }\end{array}$ & Language, poor school performances \\
\hline $\begin{array}{l}\text { Tas et al. } \\
(2013)\end{array}$ & Turkey & $\begin{array}{l}\text { Qualitative, interviews, } \\
\text { content analysis. }(N=19)\end{array}$ & $\begin{array}{l}\text { Reasons for leaving } \\
\text { vocational high school }\end{array}$ & School leavers & $\begin{array}{l}\text { Absenteeism, grade repetition, socio- } \\
\text { economic status, low income, insecurity } \\
\text { for females }\end{array}$ \\
\hline $\begin{array}{l}\text { Sarker \& } \\
\text { Davey (2009) }\end{array}$ & Bangladesh & $\begin{array}{l}\text { Qualitative, school } \\
\text { records, interviews. } \\
(N=139,833)\end{array}$ & $\begin{array}{l}\text { Why a high rate of } \\
\text { indigenous children leave } \\
\text { primary school }\end{array}$ & $\begin{array}{l}\text { 2005, 2006/ } \\
\text { Parents, teachers, } \\
\text { local leaders }\end{array}$ & $\begin{array}{l}\text { Child labour, poverty, language, } \\
\text { ignorance towards education, migration, } \\
\text { cultural alienation }\end{array}$ \\
\hline Polat (2014) & Turkey & $\begin{array}{l}\text { Qualitative, interview, } \\
\text { identifying themes. } \\
(N=19)\end{array}$ & $\begin{array}{l}\text { Reasons for high school } \\
\text { dropout }\end{array}$ & $\begin{array}{l}\text { Young dropouts } \\
15-24 \text { years }\end{array}$ & $\begin{array}{l}\text { Academic failure, bad friends, no } \\
\text { interest, truancy, lack of finance }\end{array}$ \\
\hline $\begin{array}{l}\text { Chung \& } \\
\text { Mason } \\
(2012)\end{array}$ & China & $\begin{array}{l}\text { Qualitative, interview. } \\
(N=\mathrm{N} / \mathrm{A})\end{array}$ & $\begin{array}{l}\text { Why more students in poor } \\
\text { and rural regions are } \\
\text { dropping out of school }\end{array}$ & $\begin{array}{l}2009,2010 / \\
\text { Students, parent, } \\
\text { teachers, officials }\end{array}$ & $\begin{array}{l}\text { No interest, uneducated parents, } \\
\text { poverty, underdeveloped community, } \\
\text { unqualified teachers, lack of school } \\
\text { facilities and teachers }\end{array}$ \\
\hline $\begin{array}{l}\text { Abuya et al. } \\
(2014)\end{array}$ & Kenya & $\begin{array}{l}\text { Qualitative, interview, } \\
\text { noting themes; making } \\
\text { contrasts; clusters and } \\
\text { counting. }(N=44)\end{array}$ & $\begin{array}{l}\text { The role of social } \\
\text { construction among out of } \\
\text { school girls }\end{array}$ & $\begin{array}{l}2009 \text { / In-school } \\
\text { and dropout } \\
\text { secondary girls, } \\
\text { teachers }\end{array}$ & $\begin{array}{l}\text { Girls are socially constructed as second- } \\
\text { class citizens, household work, little } \\
\text { time to read, drop out to make room for } \\
\text { their male siblings to be educated }\end{array}$ \\
\hline $\begin{array}{l}\text { Tukundane et } \\
\text { al. (2014) }\end{array}$ & Uganda & $\begin{array}{l}\text { Qualitative, interviews, } \\
\text { narratives, identifying } \\
\text { themes. }(N=16)\end{array}$ & $\begin{array}{l}\text { Reasons for dropping out } \\
\text { of school }\end{array}$ & $\begin{array}{l}2010-2011 / \\
\text { Dropouts aged } \\
\text { between } 16-24\end{array}$ & $\begin{array}{l}\text { Costs, wage work, farming, future jobs } \\
\text { need no schooling, peer influence, no } \\
\text { interest, gender, exam failure, truancy, } \\
\text { teacher abuse, corporal punishment }\end{array}$ \\
\hline $\begin{array}{l}\text { Mahlomaholo } \\
(2012)\end{array}$ & $\begin{array}{l}\text { South } \\
\text { Africa }\end{array}$ & $\begin{array}{l}\text { Qualitative, school files, } \\
\text { focus group, identifying } \\
\text { themes. }(\mathrm{N}=15,695)\end{array}$ & $\begin{array}{l}\text { Reasons for leaving school } \\
\text { early }\end{array}$ & $\begin{array}{l}2010 / \\
\text { School leavers }\end{array}$ & $\begin{array}{l}\text { Failure, no motivation, truancy, death, } \\
\text { poverty, long distance, pregnancy, } \\
\text { abuse, resettlement, sickness, early } \\
\text { marriage, criminality, transfers, } \\
\text { housework, job preference, farming }\end{array}$ \\
\hline
\end{tabular}


Appendix

\section{A3.1.: Survey Statistics}

\begin{tabular}{|c|c|c|c|c|c|c|c|c|c|c|c|c|c|}
\hline \multirow[t]{3}{*}{ Country } & \multirow{3}{*}{$\begin{array}{l}\text { Survey } \\
\text { year }\end{array}$} & \multirow{3}{*}{$\begin{array}{l}\text { Sample } \\
\text { size }\end{array}$} & \multicolumn{4}{|c|}{ Years of Education } & \multirow[t]{3}{*}{ Country } & \multirow{3}{*}{$\begin{array}{l}\text { Survey } \\
\text { year }\end{array}$} & \multirow{3}{*}{$\begin{array}{l}\text { Sample } \\
\text { size }\end{array}$} & \multicolumn{4}{|c|}{ Years of Education } \\
\hline & & & \multicolumn{2}{|c|}{ Parents } & \multicolumn{2}{|c|}{ Children } & & & & \multicolumn{2}{|c|}{ Parents } & \multicolumn{2}{|c|}{ Children } \\
\hline & & & Min & $\operatorname{Max}$ & & $\operatorname{Max}$ & & & & Min & $\operatorname{Max}$ & Min & $\operatorname{Max}$ \\
\hline \multirow[t]{4}{*}{ Armenia } & 2000 & 1,987 & 0 & 19 & 0 & 19 & Cameroon & 1991 & 651 & 0 & 18 & 0 & 20 \\
\hline & 2005 & 2,064 & 0 & 21 & 0 & 20 & & 1998 & 951 & 0 & 18 & 0 & 18 \\
\hline & 2010 & 2,082 & 4 & 23 & 0 & 20 & & 2004 & 1,806 & 0 & 17 & 0 & 17 \\
\hline & & & & & & & & 2011 & 2,899 & 0 & 17 & 0 & 17 \\
\hline \multirow[t]{6}{*}{ Bangladesh } & 1993 & 2,437 & 0 & 16 & 0 & 17 & Chad & 1996 & 975 & 0 & 17 & 0 & 17 \\
\hline & 1996 & 2,344 & 0 & 16 & 0 & 16 & & 2004 & 917 & 0 & 17 & 0 & 17 \\
\hline & 1999 & 2,909 & 0 & 17 & 0 & 18 & & & & & & & \\
\hline & 2004 & 2,888 & 0 & 17 & 0 & 17 & & & & & & & \\
\hline & 2011 & 4,553 & 0 & 17 & 0 & 18 & & & & & & & \\
\hline & 2014 & 4,449 & 0 & 18 & 0 & 18 & & & & & & & \\
\hline \multirow[t]{4}{*}{ Benin } & 1996 & 804 & 0 & 17 & 0 & 19 & Colombia & 1990 & 2,369 & 0 & 20 & 0 & 20 \\
\hline & 2006 & 2,707 & 0 & 20 & 0 & 19 & & 1995 & 2,942 & 0 & 21 & 0 & 21 \\
\hline & 2011 & 2,775 & 0 & 21 & 0 & 20 & & 2000 & 3,209 & 0 & 20 & 0 & 20 \\
\hline & & & & & & & & 2005 & 9,840 & 0 & 23 & 0 & 23 \\
\hline \multirow[t]{4}{*}{ Bolivia } & 1994 & 1,867 & 0 & 19 & 0 & 19 & Congo Democratic & 2007 & 2,054 & 0 & 18 & 0 & 18 \\
\hline & 1998 & 2,393 & 0 & 20 & 0 & 19 & Republic & 2013 & 3,292 & 0 & 18 & 0 & 18 \\
\hline & 2003 & 3,960 & 0 & 17 & 0 & 17 & & & & & & & \\
\hline & 2008 & 3,880 & 0 & 17 & 0 & 17 & & & & & & & \\
\hline \multirow[t]{4}{*}{ Burkina Faso } & 1993 & 915 & 0 & 16 & 0 & 16 & Congo Republic & 2005 & 1,505 & 0 & 17 & 0 & 17 \\
\hline & 1998 & 742 & 0 & 18 & 0 & 18 & & 2011 & 1,306 & 0 & 17 & 0 & 17 \\
\hline & 2003 & 1,886 & 0 & 18 & 0 & 18 & & & & & & & \\
\hline & 2010 & 2,122 & 0 & 18 & 0 & 18 & & & & & & & \\
\hline \multirow[t]{4}{*}{ Cambodia } & 2000 & 3,119 & 0 & 16 & 0 & 16 & Cote d'Ivoire & 1994 & 1,188 & 0 & 19 & 0 & 20 \\
\hline & 2005 & 4,240 & 0 & 16 & 0 & 16 & & 1998 & 486 & 0 & 18 & 0 & 17 \\
\hline & 2010 & 6,012 & 0 & 20 & 0 & 20 & & 2005 & 896 & 0 & 17 & 0 & 17 \\
\hline & 2014 & 5,564 & 0 & 20 & 0 & 20 & & 2011 & 1,826 & 0 & 18 & 0 & 18 \\
\hline
\end{tabular}


A3.1. (continues)

\begin{tabular}{|c|c|c|c|c|c|c|c|c|c|c|c|c|c|}
\hline \multirow[t]{2}{*}{ Country } & \multirow{2}{*}{$\begin{array}{l}\text { Survey } \\
\text { year }\end{array}$} & \multirow{2}{*}{$\begin{array}{l}\text { Sample } \\
\text { size }\end{array}$} & \multicolumn{4}{|c|}{ Years of Education } & \multirow[t]{2}{*}{ Country } & \multirow{2}{*}{$\begin{array}{l}\text { Survey } \\
\text { year }\end{array}$} & \multirow{2}{*}{$\begin{array}{l}\text { Sample } \\
\text { size }\end{array}$} & \multicolumn{4}{|c|}{ Years of Education } \\
\hline & & & \multicolumn{2}{|c|}{ Parents } & \multicolumn{2}{|c|}{$\begin{array}{l}\text { Children } \\
\text { Min Max }\end{array}$} & & & & \multicolumn{2}{|c|}{ Parents } & \multicolumn{2}{|c|}{ Children } \\
\hline \multirow[t]{3}{*}{ Dominican Republic } & 1996 & 1,985 & 0 & 18 & 0 & 19 & Haiti & 1994 & 1,049 & 0 & 17 & 0 & 17 \\
\hline & 2002 & 5,508 & 0 & 22 & 0 & 21 & & 2012 & 3,060 & 0 & 17 & 0 & 17 \\
\hline & 2013 & 2,288 & 0 & 23 & 0 & 20 & & & & & & & \\
\hline \multirow[t]{3}{*}{ Egypt } & 1995 & 6,281 & 0 & 24 & 0 & 24 & Honduras & 2005 & 4,843 & 0 & 24 & 0 & 24 \\
\hline & 2008 & 7,864 & 0 & 22 & 0 & 20 & & & & & & & \\
\hline & 2014 & 9,082 & 0 & 21 & 0 & 20 & & & & & & & \\
\hline \multirow[t]{3}{*}{ Ethiopia } & 2000 & 2,878 & 0 & 18 & 0 & 18 & Indonesia & 1997 & 8,223 & 0 & 18 & 0 & 18 \\
\hline & 2005 & 3,087 & 0 & 18 & 0 & 18 & & 2002 & 9,015 & 0 & 17 & 0 & 18 \\
\hline & 2011 & 3,087 & 0 & 18 & 0 & 18 & & 2007 & 10,340 & 0 & 17 & 0 & 18 \\
\hline Gabon & 2000 & 1,247 & 0 & 21 & 0 & 17 & Jordan & 1997 & 4,076 & 0 & 21 & 0 & 20 \\
\hline \multirow{3}{*}{ Ghana } & 1998 & 798 & 0 & 20 & 0 & 20 & & 1999 & 1,124 & 0 & 17 & 0 & 16 \\
\hline & 2008 & 1,905 & 0 & 20 & 0 & 19 & & & & & & & \\
\hline & 2014 & 1,671 & 0 & 20 & 0 & 18 & & & & & & & \\
\hline \multirow[t]{4}{*}{ Guinea } & 1999 & 1,018 & 0 & 20 & 0 & 19 & Kenya & 1993 & 1,533 & 0 & 20 & 0 & 19 \\
\hline & 2005 & 1,143 & 0 & 20 & 0 & 18 & & 1998 & 1,495 & 0 & 19 & 0 & 19 \\
\hline & 2012 & 1,697 & 0 & 19 & 0 & 19 & & 2008 & 1,468 & 0 & 23 & 0 & 21 \\
\hline & & & & & & & & 2014 & 5,810 & 0 & 22 & 0 & 20 \\
\hline
\end{tabular}


Appendix

A3.1. (continues)

\begin{tabular}{|c|c|c|c|c|c|c|c|c|c|c|c|c|c|}
\hline \multirow[t]{3}{*}{ Country } & \multirow{3}{*}{$\begin{array}{l}\text { Survey } \\
\text { year }\end{array}$} & \multirow{3}{*}{$\begin{array}{l}\text { Sample } \\
\text { size }\end{array}$} & \multicolumn{4}{|c|}{ Years of Education } & \multirow[t]{3}{*}{ Country } & \multirow{3}{*}{$\begin{array}{l}\text { Survey } \\
\text { year }\end{array}$} & \multirow{3}{*}{$\begin{array}{l}\text { Sample } \\
\text { size }\end{array}$} & \multicolumn{4}{|c|}{ Years of Education } \\
\hline & & & \multirow{2}{*}{\multicolumn{2}{|c|}{$\begin{array}{l}\text { Parents } \\
\text { Min Max }\end{array}$}} & \multirow{2}{*}{\multicolumn{2}{|c|}{$\begin{array}{l}\text { Children } \\
\text { Min Max }\end{array}$}} & & & & \multicolumn{2}{|c|}{ Parents } & \multicolumn{2}{|c|}{ Children } \\
\hline & & & & & & & & & & Min & $\operatorname{Max}$ & Min & $\operatorname{Max}$ \\
\hline \multirow[t]{3}{*}{ Kyrgyz Republic } & 1997 & 940 & 0 & 16 & 0 & 16 & Mozambique & 1997 & 1,205 & 0 & 14 & 0 & 17 \\
\hline & 2012 & 2,331 & 0 & 24 & 0 & 21 & & 2003 & 2,345 & 0 & 17 & 0 & 17 \\
\hline & & & & & & & & 2011 & 1,756 & 0 & 19 & 0 & 19 \\
\hline \multirow[t]{4}{*}{ Lesotho } & 2004 & 2,892 & 0 & 21 & 0 & 20 & Namibia & 1992 & 991 & 0 & 18 & 0 & 19 \\
\hline & 2009 & 3,180 & 0 & 18 & 0 & 18 & & 2000 & 1,107 & 0 & 18 & 0 & 18 \\
\hline & & & & & & & & 2006 & 1,543 & 0 & 19 & 0 & 18 \\
\hline & & & & & & & & 2013 & 1,446 & 0 & 20 & 0 & 16 \\
\hline \multirow[t]{4}{*}{ Madagascar } & 1997 & 1,334 & 0 & 17 & 0 & 19 & Nepal & 1996 & 1,990 & 0 & 14 & 0 & 14 \\
\hline & 2003 & 1,610 & 0 & 17 & 0 & 17 & & 2001 & 1,999 & 0 & 14 & 0 & 14 \\
\hline & 2008 & 2,864 & 0 & 17 & 0 & 17 & & 2006 & 1,840 & 0 & 14 & 0 & 14 \\
\hline & & & & & & & & 2011 & 2,216 & 0 & 11 & 0 & 11 \\
\hline \multirow[t]{4}{*}{ Malawi } & 1992 & 646 & 0 & 19 & 0 & 14 & Nicaragua & 1998 & 3,473 & 0 & 17 & 0 & 17 \\
\hline & 2000 & 1,710 & 0 & 16 & 0 & 16 & & 2001 & 3,730 & 0 & 19 & 0 & 19 \\
\hline & 2004 & 1,355 & 0 & 21 & 0 & 16 & & & & & & & \\
\hline & 2010 & 2,846 & 0 & 18 & 0 & 17 & & & & & & & \\
\hline \multirow[t]{4}{*}{ Mali } & 1995 & 1,226 & 0 & 16 & 0 & 16 & Niger & 1998 & 1,088 & 0 & 15 & 0 & 18 \\
\hline & 2001 & 1,451 & 0 & 19 & 0 & 19 & & 2006 & 1,464 & 0 & 21 & 0 & 19 \\
\hline & 2006 & 2,190 & 0 & 17 & 0 & 17 & & 2012 & 1,399 & 0 & 21 & 0 & 20 \\
\hline & 2012 & 1,662 & 0 & 23 & 0 & 20 & & & & & & & \\
\hline \multirow[t]{4}{*}{ Morocco } & 1992 & 2,891 & 0 & 19 & 0 & 19 & Nigeria & 1990 & 1,739 & 0 & 19 & 0 & 17 \\
\hline & 2003 & 5,742 & 0 & 20 & 0 & 22 & & 2003 & 1,681 & 0 & 20 & 0 & 18 \\
\hline & & & & & & & & 2008 & 5,484 & 0 & 21 & 0 & 18 \\
\hline & & & & & & & & 2013 & 6,475 & 0 & 20 & 0 & 20 \\
\hline
\end{tabular}


A3.1. (continues)

\begin{tabular}{|c|c|c|c|c|c|c|c|c|c|c|c|c|c|}
\hline \multirow[t]{3}{*}{ Country } & \multirow{3}{*}{$\begin{array}{l}\text { Survey } \\
\text { year }\end{array}$} & \multirow{3}{*}{$\begin{array}{l}\text { Sample } \\
\text { size }\end{array}$} & \multicolumn{4}{|c|}{ Years of Education } & \multirow[t]{3}{*}{ Country } & \multirow{3}{*}{$\begin{array}{l}\text { Survey } \\
\text { year }\end{array}$} & \multirow{3}{*}{$\begin{array}{l}\text { Sample } \\
\text { size }\end{array}$} & \multicolumn{4}{|c|}{ Years of Education } \\
\hline & & & \multicolumn{2}{|c|}{ Parents } & \multicolumn{2}{|c|}{ Children } & & & & Par & $n t s$ & Chil & dren \\
\hline & & & Min & $\operatorname{Max}$ & Min & $\operatorname{Max}$ & & & & Min & $\operatorname{Max}$ & Min & $\operatorname{Max}$ \\
\hline \multirow[t]{2}{*}{ Pakistan } & 1990 & 2,916 & 0 & 20 & 0 & 20 & Tanzania & 1999 & 649 & 0 & 15 & 0 & 15 \\
\hline & 2006 & 7,115 & 0 & 16 & 0 & 16 & & 2010 & 1,776 & 0 & 20 & 0 & 16 \\
\hline \multirow[t]{3}{*}{ Peru } & 1991 & 4,515 & 0 & 16 & 0 & 16 & Togo & 1998 & 1,497 & 0 & 24 & 0 & 23 \\
\hline & 1996 & 7,781 & 0 & 16 & 0 & 16 & & 2013 & 1,675 & 0 & 17 & 0 & 17 \\
\hline & 2000 & 7,864 & 0 & 17 & 0 & 17 & & & & & & & \\
\hline \multirow[t]{2}{*}{ Philippines } & 1998 & 3,649 & 0 & 16 & 0 & 16 & Turkey & 1993 & 2,648 & 0 & 17 & 0 & 17 \\
\hline & 2003 & 3,545 & 0 & 17 & 0 & 17 & & 2003 & 3,508 & 0 & 19 & 0 & 19 \\
\hline \multirow[t]{4}{*}{ Rwanda } & 1992 & 1,399 & 0 & 15 & 0 & 17 & Uganda & 1995 & 765 & 0 & 18 & 0 & 18 \\
\hline & 2000 & 1,459 & 0 & 18 & 0 & 17 & & 2000 & 891 & 0 & 20 & 0 & 19 \\
\hline & 2005 & 2,129 & 0 & 18 & 0 & 19 & & 2006 & 1,183 & 0 & 18 & 0 & 18 \\
\hline & 2010 & 2,779 & 0 & 18 & 0 & 18 & & 2011 & 1,175 & 0 & 18 & 0 & 18 \\
\hline \multirow[t]{4}{*}{ Senegal } & 2005 & 2,737 & 0 & 20 & 0 & 20 & Zambia & 1996 & 1,465 & 0 & 20 & 0 & 17 \\
\hline & 2010 & 3,130 & 0 & 21 & 0 & 21 & & 2001 & 1,256 & 0 & 17 & 0 & 17 \\
\hline & & & & & & & & 2007 & 972 & 0 & 18 & 0 & 18 \\
\hline & & & & & & & & 2013 & 2,520 & 0 & 19 & 0 & 17 \\
\hline \multirow[t]{4}{*}{ Sierra Leone } & 2008 & 1,239 & 0 & 18 & 0 & 18 & Zimbabwe & 1994 & 989 & 0 & 17 & 0 & 19 \\
\hline & 2013 & 2,410 & 0 & 19 & 0 & 19 & & 1999 & 951 & 0 & 18 & 0 & 17 \\
\hline & & & & & & & & 2005 & 1,531 & 0 & 19 & 0 & 16 \\
\hline & & & & & & & & 2010 & 1,352 & 0 & 21 & 0 & 20 \\
\hline
\end{tabular}


Appendix

A4.1.: Logistic regression of grade 10 completion with standard error clustered at household-age level

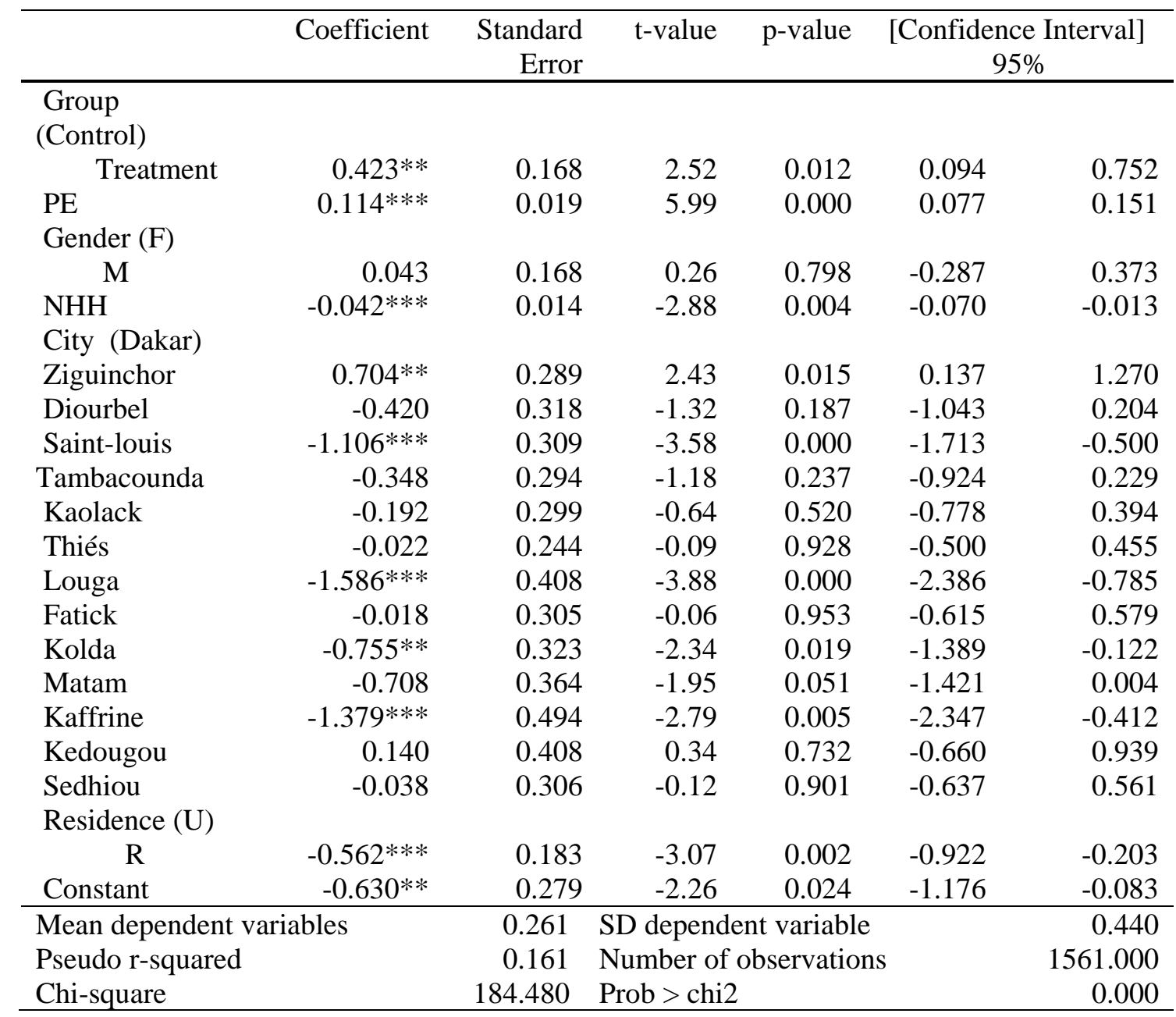

Note: $P E=$ Parent's education, $N H H=$ Number of household members, $U=$ Urban, $R=$ Rural, $M=$ Male, $F=$ Female; $* * * p<0.01, * * p<0.05$ 
A5.1. : Country-level descriptive statistics of deprivation variables

\begin{tabular}{|c|c|c|c|c|c|c|c|c|c|c|c|c|c|}
\hline \multirow{3}{*}{ Country(survey year) } & \multirow{3}{*}{$\begin{array}{l}\text { Sample } \\
\text { size }\end{array}$} & \multirow{2}{*}{\multicolumn{2}{|c|}{$\begin{array}{c}\text { Educational } \\
\text { attainment }\end{array}$}} & \multirow{2}{*}{\multicolumn{2}{|c|}{$\begin{array}{l}\text { Parent's } \\
\text { education }\end{array}$}} & \multicolumn{8}{|c|}{ Percentage deprived in each indicator } \\
\hline & & & & & & \multirow{2}{*}{$\begin{array}{c}\text { Child } \\
\text { mortality }\end{array}$} & \multirow{2}{*}{$\begin{array}{c}\text { School } \\
\text { attendance }\end{array}$} & \multirow{2}{*}{$\begin{array}{l}\text { Cooking } \\
\text { fuel }\end{array}$} & \multirow[b]{2}{*}{ Sanitation } & \multirow{2}{*}{$\begin{array}{l}\text { Drinking } \\
\text { water }\end{array}$} & \multirow{2}{*}{ Electricity } & \multirow{2}{*}{ Housing } & \multirow[b]{2}{*}{ Assets } \\
\hline & & Min & Max & Min & $\operatorname{Max}$ & & & & & & & & \\
\hline Bangladesh(2014) & 3,492 & 0 & 18 & 0 & 18 & 9.8 & 6.6 & 84.7 & 24.8 & 2.0 & 31.2 & 63.9 & 98.9 \\
\hline $\operatorname{Benin}(2017 / 2018)$ & 2,394 & 0 & 17 & 0 & 17 & 9.1 & 33.8 & 95.9 & 67.4 & 31.1 & 61.4 & 48.9 & 92.6 \\
\hline Cameroon(2018/2019) & 2,585 & 0 & 17 & 0 & 17 & 9.3 & 12.5 & 83.0 & 36.6 & 20.6 & 33.7 & 46.5 & 89.7 \\
\hline Chad(2014/2015) & 2,191 & 0 & 18 & 0 & 20 & 18.5 & 45.1 & 94.6 & 77.4 & 36.5 & 83.9 & 89.8 & 92.5 \\
\hline Dominican Republic(2013) & 1,796 & 0 & 20 & 0 & 22 & 45.2 & 1.4 & 10.6 & 5.1 & 1.9 & 1.7 & 8.7 & 81.2 \\
\hline Ethiopia(2016) & 2,951 & 0 & 18 & 0 & 22 & 6.5 & 19.9 & 86.7 & 70.6 & 26.2 & 59.0 & 85.4 & 97.5 \\
\hline Ghana(2014) & 1,518 & 0 & 18 & 0 & 20 & 8.0 & 16.5 & 85.1 & 34.3 & 26.2 & 28.7 & 32.5 & 86.1 \\
\hline Guinea(2018) & 1,621 & 0 & 19 & 0 & 19 & 7.5 & 34.2 & 97.1 & 37.8 & 15.7 & 43.9 & 33.6 & 85.8 \\
\hline Haiti(2016/2017) & 3,643 & 0 & 16 & 0 & 16 & 5.5 & 5.2 & 97.6 & 50.0 & 28.5 & 67.3 & 45.9 & 96.0 \\
\hline Indonesia(2017) & 10,763 & 0 & 18 & 0 & 18 & 4.2 & 2.6 & 31.1 & 22.2 & 36.3 & 2.3 & 9.9 & 79.0 \\
\hline Kenya(2014) & 5,197 & 0 & 20 & 0 & 19 & 6.4 & 5.7 & 96.3 & 55.9 & 37.5 & 79.7 & 98.4 & 93.8 \\
\hline Lesotho(2014) & 1,356 & 0 & 18 & 0 & 18 & 6.0 & 4.0 & 68.4 & 27.4 & 14.6 & 70.5 & 39.9 & 88.5 \\
\hline Malawi(2015/2016) & 3,122 & 0 & 17 & 0 & 20 & 10.5 & 4.7 & 97.9 & 13.2 & 11.6 & 79.7 & 62.2 & 9.37 \\
\hline $\operatorname{Mali}(2018)$ & 1,497 & 0 & 17 & 0 & 17 & 10.4 & 42.3 & 97.9 & 36.6 & 20.2 & 39.9 & 63.9 & 78.0 \\
\hline Namibia(2013) & 1,457 & 0 & 16 & 0 & 20 & 12.3 & 5.5 & 64.6 & 55.3 & 15.4 & 53.1 & 47.9 & 73.5 \\
\hline $\operatorname{Nepal(2016)}$ & 2,016 & 0 & 11 & 0 & 11 & 3.8 & 2.2 & 70.5 & 10.6 & 4.3 & 6.7 & 66.2 & 93.0 \\
\hline Nigeria(2018) & 6,344 & 0 & 20 & 0 & 20 & 13.1 & 18.9 & 90.3 & 42.6 & 30.4 & 39.6 & 36.8 & 83.3 \\
\hline Pakistan(2017/2018) & 5,775 & 0 & 16 & 0 & 16 & 9.0 & 17.6 & 48.2 & 11.9 & 10.3 & 5.0 & 50.9 & 81.5 \\
\hline Peru(2012) & 4,963 & 0 & 17 & 0 & 17 & 4.0 & 78.2 & 28.6 & 24.5 & 5.8 & 7.1 & 48.6 & 84.9 \\
\hline Philippines(2017) & 6,372 & 0 & 19 & 0 & 19 & 2.0 & 3.1 & 58.9 & 8.8 & 5.3 & 5.2 & 31.2 & 86.6 \\
\hline Rwanda(2014/2015) & 2,513 & 0 & 18 & 0 & 20 & 8.8 & 8.6 & 99.6 & 28.7 & 27.2 & 78 & 80.8 & 98.8 \\
\hline Senegal(2017) & 3,125 & 0 & 20 & 0 & 21 & 7.5 & 38.1 & 79.8 & 30.8 & 21.4 & 38 & 40.6 & 94.3 \\
\hline Sierra Leone(2013) & 2,463 & 0 & 19 & 0 & 19 & 15.0 & 23.1 & 99.9 & 42.6 & 34.3 & 81.3 & 53.8 & 96.9 \\
\hline Tanzania(2015/2016) & 2,149 & 0 & 17 & 0 & 21 & 8.5 & 23.5 & 99.5 & 60.4 & 29.2 & 74.3 & 58.7 & 92.6 \\
\hline Uganda(2016) & 2,380 & 0 & 20 & 0 & 21 & 10.0 & 13.2 & 99.3 & 65.5 & 19.4 & 74.4 & 70.3 & 94.3 \\
\hline Zambia(2018/2019) & 2,643 & 0 & 18 & 0 & 22 & 7.3 & 16.1 & 91.9 & 42.1 & 26.2 & 61.8 & 50.3 & 88.9 \\
\hline Zimbabwe(2015) & 1,305 & 0 & 19 & 0 & 21 & 3.2 & 4.8 & 62.3 & 27.9 & 16.0 & 57.7 & 30.8 & 78.5 \\
\hline
\end{tabular}


Appendix

A5.2.: Matrix of correlations (pooled sample)

\begin{tabular}{lrrrrrrrrr}
\hline Variables & $(1)$ & $(2)$ & $(3)$ & $(4)$ & $(5)$ & $(6)$ & (7) & (8) & (9) \\
\hline (1) Child mortality & 1.000 & & & & & & & & \\
(2) School attendance & 0.054 & 0.054 & 0.054 & & & & & & \\
(3) Cooking fuel & 0.041 & 0.041 & 0.041 & 0.041 & & & & & \\
(4) Sanitation & 0.059 & 0.059 & 0.059 & 0.059 & 0.059 & & & & \\
(5) Drinking water & 0.025 & 0.025 & 0.025 & 0.025 & 0.025 & 0.025 & & & \\
(6) Electricity & 0.069 & 0.069 & 0.069 & 0.069 & 0.069 & 0.069 & 0.069 & & \\
(7) Housing & 0.060 & 0.060 & 0.060 & 0.060 & 0.060 & 0.060 & 0.060 & 0.060 & \\
(8) Assets & 0.031 & 0.031 & 0.031 & 0.031 & 0.031 & 0.031 & 0.031 & 0.031 & 0.031
\end{tabular}

\section{A5.3.: Matrix of correlations per country}

\begin{tabular}{|c|c|c|c|c|c|c|c|c|c|}
\hline Bangladesh & $(1)$ & (2) & (3) & (4) & $(5)$ & (6) & (7) & (8) & (9) \\
\hline (1) Child mortality & 1.000 & & & & & & & & \\
\hline (2) School attendance & 0.037 & 0.100 & 1.000 & & & & & & \\
\hline (3) Cooking fuel & 0.068 & 0.233 & 0.013 & 1.000 & & & & & \\
\hline (4) Sanitation & 0.045 & 0.214 & 0.075 & 0.187 & 1.000 & & & & \\
\hline (5) Drinking water & -0.012 & 0.028 & 0.013 & 0.054 & 0.120 & 1.000 & & & \\
\hline (6) Electricity & 0.071 & 0.224 & 0.114 & 0.284 & 0.280 & 0.156 & 1.000 & & \\
\hline (7) Housing & 0.105 & 0.339 & 0.045 & 0.509 & 0.321 & 0.084 & 0.394 & 1.000 & \\
\hline (8) Assets & -0.020 & 0.085 & 0.006 & 0.046 & 0.036 & 0.015 & 0.048 & 0.045 & 1.000 \\
\hline Benin & $(1)$ & $(2)$ & (3) & (4) & $(5)$ & $(6)$ & $(7)$ & $(8)$ & $(9)$ \\
\hline (1) Child mortality & 1.000 & & & & & & & & \\
\hline (2) School attendance & 0.078 & 0.223 & 1.000 & & & & & & \\
\hline (3) Cooking fuel & 0.044 & 0.301 & 0.073 & 1.000 & & & & & \\
\hline (4) Sanitation & 0.087 & 0.327 & 0.252 & 0.249 & 1.000 & & & & \\
\hline (5) Drinking water & 0.026 & 0.094 & 0.205 & 0.085 & 0.230 & 1.000 & & & \\
\hline (6) Electricity & 0.099 & 0.312 & 0.233 & 0.240 & 0.462 & 0.162 & 1.000 & & \\
\hline (7) Housing & 0.097 & 0.261 & 0.207 & 0.161 & 0.406 & 0.116 & 0.452 & 1.000 & \\
\hline (8) Assets & 0.062 & 0.241 & 0.067 & 0.318 & 0.270 & 0.100 & 0.277 & 0.190 & 1.000 \\
\hline Cameroon & $(1)$ & $(2)$ & (3) & (4) & $(5)$ & $(6)$ & $(7)$ & $(8)$ & $(9)$ \\
\hline (1) Child mortality & 1.000 & & & & & & & & \\
\hline (2) School attendance & 0.073 & 0.073 & 0.073 & & & & & & \\
\hline (3) Cooking fuel & 0.078 & 0.078 & 0.078 & 0.078 & & & & & \\
\hline (4) Sanitation & 0.100 & 0.100 & 0.100 & 0.100 & 0.100 & & & & \\
\hline (5) Drinking water & 0.084 & 0.084 & 0.084 & 0.084 & 0.084 & 0.084 & & & \\
\hline (6) Electricity & 0.125 & 0.125 & 0.125 & 0.125 & 0.125 & 0.125 & 0.125 & & \\
\hline (7) Housing & 0.100 & 0.100 & 0.100 & 0.100 & 0.100 & 0.100 & 0.100 & 0.100 & \\
\hline (8) Assets & 0.025 & 0.025 & 0.025 & 0.025 & 0.025 & 0.025 & 0.025 & 0.025 & 0.025 \\
\hline Chad & $(1)$ & $(2)$ & (3) & (4) & $(5)$ & $(6)$ & $(7)$ & $(8)$ & (9) \\
\hline (1) Child mortality & 1.000 & & & & & & & & \\
\hline (2) School attendance & 0.020 & 0.264 & 1.000 & & & & & & \\
\hline (3) Cooking fuel & 0.062 & 0.221 & 0.155 & 1.000 & & & & & \\
\hline (4) Sanitation & 0.038 & 0.274 & 0.227 & 0.320 & 1.000 & & & & \\
\hline (5) Drinking water & 0.009 & 0.103 & 0.065 & 0.172 & 0.294 & 1.000 & & & \\
\hline (6) Electricity & 0.090 & 0.221 & 0.189 & 0.408 & 0.482 & 0.233 & 1.000 & & \\
\hline (7) Housing & 0.033 & 0.254 & 0.151 & 0.360 & 0.455 & 0.187 & 0.464 & 1.000 & \\
\hline (8) Assets & 0.015 & 0.152 & 0.118 & 0.332 & 0.327 & 0.104 & 0.381 & 0.345 & 1.000 \\
\hline
\end{tabular}


Appendix

\begin{tabular}{|c|c|c|c|c|c|c|c|c|c|}
\hline Dominican Republic & $(1)$ & $(2)$ & (3) & $(4)$ & $(5)$ & (6) & $(7)$ & $(8)$ & (9) \\
\hline (1) Child mortality & 1.000 & & & & & & & & \\
\hline (2) School attendance & -0.012 & 0.080 & 1.000 & & & & & & \\
\hline (3) Cooking fuel & 0.015 & 0.248 & 0.067 & 1.000 & & & & & \\
\hline (4) Sanitation & 0.035 & 0.080 & 0.038 & 0.185 & 1.000 & & & & \\
\hline (5) Drinking water & -0.019 & 0.072 & -0.017 & 0.138 & 0.061 & 1.000 & & & \\
\hline (6) Electricity & 0.009 & 0.037 & -0.016 & 0.149 & 0.067 & 0.264 & 1.000 & & \\
\hline (7) Housing & 0.032 & 0.143 & -0.003 & 0.240 & 0.153 & 0.087 & 0.080 & 1.000 & \\
\hline (8) Assets & 0.022 & 0.191 & -0.004 & 0.142 & 0.079 & 0.046 & 0.064 & 0.109 & 1.000 \\
\hline Ethiopia & $(1)$ & $(2)$ & (3) & $(4)$ & $(5)$ & (6) & $(7)$ & $(8)$ & (9) \\
\hline (1) Child mortality & 1.000 & & & & & & & & \\
\hline (2) School attendance & 0.069 & 0.153 & 1.000 & & & & & & \\
\hline (3) Cooking fuel & 0.067 & 0.384 & 0.130 & 1.000 & & & & & \\
\hline (4) Sanitation & 0.070 & 0.341 & 0.165 & 0.427 & 1.000 & & & & \\
\hline (5) Drinking water & 0.082 & 0.216 & 0.181 & 0.229 & 0.307 & 1.000 & & & \\
\hline (6) Electricity & 0.088 & 0.413 & 0.237 & 0.462 & 0.606 & 0.413 & 1.000 & & \\
\hline (7) Housing & 0.046 & 0.293 & 0.100 & 0.341 & 0.528 & 0.224 & 0.470 & 1.000 & \\
\hline (8) Assets & 0.025 & 0.186 & 0.043 & 0.209 & 0.198 & 0.096 & 0.172 & 0.251 & 1.000 \\
\hline Ghana & $(1)$ & $(2)$ & (3) & $(4)$ & $(5)$ & (6) & (7) & $(8)$ & (9) \\
\hline (1) Child mortality & 1.000 & & & & & & & & \\
\hline (2) School attendance & 0.077 & 0.090 & 1.000 & & & & & & \\
\hline (3) Cooking fuel & 0.062 & 0.315 & -0.033 & 1.000 & & & & & \\
\hline (4) Sanitation & 0.031 & 0.362 & 0.033 & 0.271 & 1.000 & & & & \\
\hline (5) Drinking water & -0.055 & -0.118 & 0.022 & -0.181 & -0.137 & 1.000 & & & \\
\hline (6) Electricity & 0.053 & 0.349 & 0.051 & 0.253 & 0.384 & -0.027 & 1.000 & & \\
\hline (7) Housing & 0.090 & 0.339 & 0.017 & 0.266 & 0.361 & -0.061 & 0.471 & 1.000 & \\
\hline (8) Assets & -0.014 & 0.191 & -0.103 & 0.329 & 0.190 & -0.060 & 0.226 & 0.173 & 1.000 \\
\hline Guinea & $(1)$ & $(2)$ & (3) & (4) & $(5)$ & $(6)$ & (7) & $(8)$ & (9) \\
\hline (1) Child mortality & 1.000 & & & & & & & & \\
\hline (2) School attendance & 0.124 & 0.154 & 1.000 & & & & & & \\
\hline (3) Cooking fuel & 0.035 & 0.065 & 0.055 & 1.000 & & & & & \\
\hline (4) Sanitation & 0.087 & 0.221 & 0.184 & 0.081 & 1.000 & & & & \\
\hline (5) Drinking water & 0.044 & 0.166 & 0.131 & 0.075 & 0.317 & 1.000 & & & \\
\hline (6) Electricity & 0.101 & 0.260 & 0.202 & 0.153 & 0.465 & 0.290 & 1.000 & & \\
\hline (7) Housing & 0.109 & 0.225 & 0.227 & 0.115 & 0.440 & 0.245 & 0.502 & 1.000 & \\
\hline (8) Assets & 0.062 & 0.265 & 0.085 & 0.119 & 0.222 & 0.142 & 0.310 & 0.241 & 1.000 \\
\hline Haiti & $(1)$ & $(2)$ & (3) & $(4)$ & $(5)$ & (6) & (7) & $(8)$ & $(9)$ \\
\hline (1) Child mortality & 1.000 & & & & & & & & \\
\hline (2) School attendance & 0.041 & 0.106 & 1.000 & & & & & & \\
\hline (3) Cooking fuel & 0.014 & 0.159 & 0.037 & 1.000 & & & & & \\
\hline (4) Sanitation & 0.055 & 0.248 & 0.124 & 0.139 & 1.000 & & & & \\
\hline (5) Drinking water & 0.048 & 0.193 & 0.138 & 0.079 & 0.330 & 1.000 & & & \\
\hline (6) Electricity & 0.004 & 0.292 & 0.083 & 0.207 & 0.403 & 0.371 & 1.000 & & \\
\hline (7) Housing & 0.032 & 0.283 & 0.127 & 0.120 & 0.413 & 0.339 & 0.412 & 1.000 & \\
\hline (8) Assets & -0.013 & 0.208 & 0.010 & 0.224 & 0.159 & 0.119 & 0.211 & 0.151 & 1.000 \\
\hline Indonesia & (1) & $(2)$ & (3) & $(4)$ & $(5)$ & (6) & $(7)$ & $(8)$ & (9) \\
\hline (1) Child mortality & 1.000 & & & & & & & & \\
\hline (2) School attendance & 0.033 & 0.041 & 1.000 & & & & & & \\
\hline (3) Cooking fuel & 0.070 & 0.169 & 0.062 & 1.000 & & & & & \\
\hline (4) Sanitation & 0.059 & 0.153 & 0.067 & 0.221 & 1.000 & & & & \\
\hline (5) Drinking water & 0.000 & 0.012 & 0.017 & -0.063 & 0.051 & 1.000 & & & \\
\hline (6) Electricity & 0.024 & 0.100 & 0.052 & 0.183 & 0.146 & 0.029 & 1.000 & & \\
\hline (7) Housing & 0.033 & 0.108 & 0.052 & 0.200 & 0.159 & 0.005 & 0.179 & 1.000 & \\
\hline (8) Assets & 0.056 & 0.169 & 0.042 & 0.239 & 0.170 & -0.013 & 0.076 & 0.136 & 1.000 \\
\hline
\end{tabular}




\begin{tabular}{|c|c|c|c|c|c|c|c|c|c|}
\hline Kenya & $(1)$ & $(2)$ & (3) & (4) & $(5)$ & $(6)$ & (7) & $(8)$ & (9) \\
\hline (1) Child mortality & 1.000 & & & & & & & & \\
\hline (2) School attendance & 0.031 & 0.234 & 1.000 & & & & & & \\
\hline (3) Cooking fuel & 0.022 & 0.137 & 0.044 & 1.000 & & & & & \\
\hline (4) Sanitation & 0.029 & 0.154 & 0.092 & 0.188 & 1.000 & & & & \\
\hline (5) Drinking water & 0.025 & 0.135 & 0.071 & 0.145 & 0.197 & 1.000 & & & \\
\hline (6) Electricity & 0.061 & 0.137 & 0.016 & 0.366 & 0.349 & 0.285 & 1.000 & & \\
\hline (7) Housing & 0.009 & 0.046 & 0.019 & 0.280 & 0.145 & 0.094 & 0.222 & 1.000 & \\
\hline (8) Assets & 0.008 & 0.124 & 0.021 & 0.314 & 0.199 & 0.151 & 0.330 & 0.213 & 1.000 \\
\hline Lesotho & $(1)$ & (2) & (3) & (4) & $(5)$ & $(6)$ & (7) & (8) & (9) \\
\hline (1) Child mortality & 1.000 & & & & & & & & \\
\hline (2) School attendance & -0.035 & 0.125 & 1.000 & & & & & & \\
\hline (3) Cooking fuel & 0.058 & 0.221 & 0.098 & 1.000 & & & & & \\
\hline (4) Sanitation & -0.015 & 0.260 & 0.163 & 0.350 & 1.000 & & & & \\
\hline (5) Drinking water & 0.019 & 0.151 & 0.129 & 0.214 & 0.271 & 1.000 & & & \\
\hline (6) Electricity & 0.033 & 0.265 & 0.090 & 0.537 & 0.299 & 0.226 & 1.000 & & \\
\hline (7) Housing & -0.034 & 0.272 & 0.142 & 0.457 & 0.486 & 0.213 & 0.352 & 1.000 & \\
\hline (8) Assets & 0.023 & 0.196 & 0.073 & 0.262 & 0.164 & 0.064 & 0.223 & 0.228 & 1.000 \\
\hline Malawi & $(1)$ & $(2)$ & (3) & (4) & $(5)$ & (6) & $(7)$ & $(8)$ & $(9)$ \\
\hline (1) Child mortality & 1.000 & & & & & & & & \\
\hline (2) School attendance & 0.032 & 0.118 & 1.000 & & & & & & \\
\hline (3) Cooking fuel & 0.043 & 0.121 & 0.033 & 1.000 & & & & & \\
\hline (4) Sanitation & 0.002 & 0.155 & 0.024 & 0.038 & 1.000 & & & & \\
\hline (5) Drinking water & 0.033 & 0.123 & 0.056 & 0.053 & 0.072 & 1.000 & & & \\
\hline (6) Electricity & 0.071 & 0.298 & 0.090 & 0.291 & 0.150 & 0.170 & 1.000 & & \\
\hline (7) Housing & 0.071 & 0.336 & 0.109 & 0.184 & 0.154 & 0.183 & 0.562 & 1.000 & \\
\hline (8) Assets & 0.042 & 0.165 & 0.052 & 0.373 & 0.078 & 0.086 & 0.375 & 0.250 & 1.000 \\
\hline Mali & (1) & (2) & (3) & (4) & (5) & (6) & (7) & (8) & (9) \\
\hline (1) Child mortality & 1.000 & & & & & & & & \\
\hline (2) School attendance & 0.146 & 0.222 & 1.000 & & & & & & \\
\hline (3) Cooking fuel & 0.020 & -0.031 & 0.033 & 1.000 & & & & & \\
\hline (4) Sanitation & 0.104 & 0.289 & 0.248 & 0.045 & 1.000 & & & & \\
\hline (5) Drinking water & 0.145 & 0.205 & 0.200 & 0.051 & 0.309 & 1.000 & & & \\
\hline (6) Electricity & 0.124 & 0.339 & 0.265 & 0.083 & 0.487 & 0.324 & 1.000 & & \\
\hline (7) Housing & 0.120 & 0.405 & 0.309 & 0.004 & 0.474 & 0.337 & 0.500 & 1.000 & \\
\hline (8) Assets & 0.060 & 0.239 & 0.015 & 0.066 & 0.217 & 0.147 & 0.266 & 0.278 & 1.000 \\
\hline Namibia & $(1)$ & $(2)$ & (3) & (4) & $(5)$ & $(6)$ & $(7)$ & $(8)$ & $(9)$ \\
\hline (1) Child mortality & 1.000 & & & & & & & & \\
\hline (2) School attendance & 0.021 & 0.133 & 1.000 & & & & & & \\
\hline (3) Cooking fuel & 0.028 & 0.430 & 0.146 & 1.000 & & & & & \\
\hline (4) Sanitation & 0.026 & 0.396 & 0.124 & 0.667 & 1.000 & & & & \\
\hline (5) Drinking water & -0.031 & 0.156 & -0.018 & 0.303 & 0.314 & 1.000 & & & \\
\hline (6) Electricity & 0.004 & 0.334 & 0.092 & 0.684 & 0.636 & 0.335 & 1.000 & & \\
\hline (7) Housing & 0.014 & 0.311 & 0.104 & 0.566 & 0.574 & 0.326 & 0.551 & 1.000 & \\
\hline (8) Assets & 0.016 & 0.228 & 0.068 & 0.281 & 0.342 & 0.182 & 0.277 & 0.363 & 1.000 \\
\hline Nepal & $(1)$ & $(2)$ & (3) & (4) & $(5)$ & (6) & $(7)$ & $(8)$ & (9) \\
\hline (1) Child mortality & 1.000 & & & & & & & & \\
\hline (2) School attendance & 0.075 & 0.053 & 1.000 & & & & & & \\
\hline (3) Cooking fuel & 0.061 & 0.271 & 0.054 & 1.000 & & & & & \\
\hline (4) Sanitation & 0.058 & 0.056 & 0.101 & 0.173 & 1.000 & & & & \\
\hline (5) Drinking water & -0.004 & 0.061 & -0.032 & 0.120 & 0.023 & 1.000 & & & \\
\hline (6) Electricity & 0.050 & 0.134 & 0.054 & 0.169 & 0.076 & 0.071 & 1.000 & & \\
\hline (7) Housing & 0.049 & 0.311 & 0.058 & 0.552 & 0.170 & 0.104 & 0.183 & 1.000 & \\
\hline (8) Assets & 0.014 & 0.181 & 0.028 & 0.211 & 0.075 & 0.048 & 0.073 & 0.228 & 1.000 \\
\hline
\end{tabular}


Appendix

\begin{tabular}{|c|c|c|c|c|c|c|c|c|c|}
\hline Nigeria & (1) & (2) & (3) & (4) & (5) & (6) & (7) & (8) & (9) \\
\hline (1) Child mortality & 1.000 & & & & & & & & \\
\hline (2) School attendance & 0.195 & 0.270 & 1.000 & & & & & & \\
\hline (3) Cooking fuel & 0.107 & 0.204 & 0.140 & 1.000 & & & & & \\
\hline (4) Sanitation & 0.095 & 0.239 & 0.144 & 0.240 & 1.000 & & & & \\
\hline (5) Drinking water & 0.035 & 0.105 & 0.155 & 0.029 & 0.216 & 1.000 & & & \\
\hline (6) Electricity & 0.092 & 0.241 & 0.233 & 0.233 & 0.445 & 0.279 & 1.000 & & \\
\hline (7) Housing & 0.166 & 0.319 & 0.316 & 0.227 & 0.346 & 0.216 & 0.435 & 1.000 & \\
\hline (8) Assets & 0.059 & 0.203 & 0.065 & 0.228 & 0.194 & 0.087 & 0.237 & 0.233 & 1.000 \\
\hline Pakistan & $(1)$ & (2) & (3) & (4) & $(5)$ & (6) & (7) & (8) & (9) \\
\hline (1) Child mortality & 1.000 & & & & & & & & \\
\hline (2) School attendance & 0.045 & 0.211 & 1.000 & & & & & & \\
\hline (3) Cooking fuel & 0.035 & 0.315 & 0.206 & 1.000 & & & & & \\
\hline (4) Sanitation & 0.068 & 0.195 & 0.220 & 0.264 & 1.000 & & & & \\
\hline (5) Drinking water & -0.003 & 0.014 & 0.045 & 0.109 & 0.111 & 1.000 & & & \\
\hline (6) Electricity & -0.019 & 0.145 & 0.182 & 0.217 & 0.336 & 0.129 & 1.000 & & \\
\hline (7) Housing & 0.058 & 0.178 & 0.189 & 0.361 & 0.266 & 0.063 & 0.199 & 1.000 & \\
\hline (8) Assets & 0.069 & 0.208 & 0.031 & 0.151 & 0.130 & 0.035 & 0.083 & 0.028 & 1.000 \\
\hline Peru & $(1)$ & (2) & (3) & (4) & $(5)$ & (6) & $(7)$ & $(8)$ & (9) \\
\hline (1) Child mortality & 1.000 & & & & & & & & \\
\hline (2) School attendance & 0.040 & -0.090 & 1.000 & & & & & & \\
\hline (3) Cooking fuel & 0.085 & 0.434 & -0.041 & 1.000 & & & & & \\
\hline (4) Sanitation & 0.087 & 0.354 & -0.024 & 0.524 & 1.000 & & & & \\
\hline (5) Drinking water & 0.047 & 0.126 & -0.030 & 0.181 & 0.289 & 1.000 & & & \\
\hline (6) Electricity & 0.056 & 0.244 & -0.025 & 0.381 & 0.367 & 0.214 & 1.000 & & \\
\hline (7) Housing & 0.072 & 0.356 & -0.014 & 0.537 & 0.469 & 0.179 & 0.262 & 1.000 & \\
\hline (8) Assets & 0.025 & 0.154 & 0.001 & 0.156 & 0.159 & 0.068 & 0.090 & 0.166 & 1.000 \\
\hline Philippines & (1) & (2) & (3) & (4) & (5) & (6) & (7) & (8) & (9) \\
\hline (1) Child mortality & 1.000 & & & & & & & & \\
\hline (2) School attendance & 0.013 & 0.101 & 1.000 & & & & & & \\
\hline (3) Cooking fuel & 0.053 & 0.243 & 0.087 & 1.000 & & & & & \\
\hline (4) Sanitation & 0.026 & 0.288 & 0.128 & 0.212 & 1.000 & & & & \\
\hline (5) Drinking water & 0.025 & 0.196 & 0.059 & 0.161 & 0.245 & 1.000 & & & \\
\hline (6) Electricity & 0.051 & 0.218 & 0.053 & 0.165 & 0.239 & 0.212 & 1.000 & & \\
\hline (7) Housing & 0.039 & 0.195 & 0.048 & 0.370 & 0.190 & 0.102 & 0.247 & 1.000 & \\
\hline (8) Assets & 0.015 & 0.130 & 0.038 & 0.309 & 0.108 & 0.077 & 0.088 & 0.212 & 1.000 \\
\hline Rwanda & $(1)$ & (2) & (3) & $(4)$ & $(5)$ & (6) & (7) & $(8)$ & (9) \\
\hline (1) Child mortality & 1.000 & & & & & & & & \\
\hline (2) School attendance & 0.071 & 0.048 & 1.000 & & & & & & \\
\hline (3) Cooking fuel & 0.019 & 0.082 & -0.003 & 1.000 & & & & & \\
\hline (4) Sanitation & 0.047 & 0.105 & 0.018 & 0.040 & 1.000 & & & & \\
\hline (5) Drinking water & 0.014 & 0.083 & 0.022 & 0.039 & 0.100 & 1.000 & & & \\
\hline (6) Electricity & 0.019 & 0.258 & 0.061 & 0.119 & 0.190 & 0.191 & 1.000 & & \\
\hline (7) Housing & 0.054 & 0.262 & 0.038 & 0.130 & 0.201 & 0.152 & 0.578 & 1.000 & \\
\hline (8) Assets & 0.020 & 0.122 & 0.009 & 0.337 & 0.071 & 0.068 & 0.202 & 0.220 & 1.000 \\
\hline Senegal & $(1)$ & (2) & (3) & (4) & $(5)$ & $(6)$ & $(7)$ & $(8)$ & (9) \\
\hline (1) Child mortality & 1.000 & & & & & & & & \\
\hline (2) School attendance & 0.096 & 0.244 & 1.000 & & & & & & \\
\hline (3) Cooking fuel & 0.077 & 0.287 & 0.237 & 1.000 & & & & & \\
\hline (4) Sanitation & 0.102 & 0.216 & 0.216 & 0.301 & 1.000 & & & & \\
\hline (5) Drinking water & 0.055 & 0.104 & 0.046 & 0.237 & 0.242 & 1.000 & & & \\
\hline (6) Electricity & 0.094 & 0.262 & 0.215 & 0.349 & 0.512 & 0.315 & 1.000 & & \\
\hline (7) Housing & 0.098 & 0.159 & 0.161 & 0.305 & 0.446 & 0.290 & 0.489 & 1.000 & \\
\hline (8) Assets & 0.012 & 0.057 & -0.030 & -0.027 & 0.061 & 0.023 & 0.143 & 0.064 & 1.000 \\
\hline
\end{tabular}




\begin{tabular}{|c|c|c|c|c|c|c|c|c|c|}
\hline Sierra Leone & (1) & (2) & (3) & (4) & $(5)$ & (6) & (7) & $(8)$ & (9) \\
\hline (1) Child mortality & 1.000 & & & & & & & & \\
\hline (2) School attendance & 0.059 & 0.161 & 1.000 & & & & & & \\
\hline (3) Cooking fuel & 0.015 & 0.054 & 0.019 & 1.000 & & & & & \\
\hline (4) Sanitation & 0.078 & 0.258 & 0.131 & 0.030 & 1.000 & & & & \\
\hline (5) Drinking water & 0.049 & 0.267 & 0.194 & 0.025 & 0.357 & 1.000 & & & \\
\hline (6) Electricity & 0.108 & 0.322 & 0.137 & 0.073 & 0.316 & 0.316 & 1.000 & & \\
\hline (7) Housing & 0.083 & 0.323 & 0.143 & 0.038 & 0.374 & 0.422 & 0.402 & 1.000 & \\
\hline (8) Assets & 0.023 & 0.189 & 0.087 & 0.061 & 0.131 & 0.130 & 0.321 & 0.175 & 1.000 \\
\hline Tanzania & (1) & (2) & (3) & (4) & $(5)$ & (6) & $(7)$ & (8) & (9) \\
\hline (1) Child mortality & 1.000 & & & & & & & & \\
\hline (2) School attendance & 0.051 & 0.151 & 1.000 & & & & & & \\
\hline (3) Cooking fuel & -0.053 & 0.050 & 0.038 & 1.000 & & & & & \\
\hline (4) Sanitation & 0.070 & 0.239 & 0.253 & 0.056 & 1.000 & & & & \\
\hline (5) Drinking water & 0.094 & 0.083 & 0.253 & 0.014 & 0.407 & 1.000 & & & \\
\hline (6) Electricity & 0.088 & 0.231 & 0.213 & 0.116 & 0.572 & 0.317 & 1.000 & & \\
\hline (7) Housing & 0.080 & 0.269 & 0.228 & 0.054 & 0.602 & 0.323 & 0.585 & 1.000 & \\
\hline (8) Assets & 0.042 & 0.134 & 0.115 & 0.007 & 0.291 & 0.135 & 0.399 & 0.301 & 1.000 \\
\hline Uganda & $(1)$ & (2) & (3) & (4) & $(5)$ & (6) & $(7)$ & $(8)$ & $(9)$ \\
\hline (1) Child mortality & 1.000 & & & & & & & & \\
\hline (2) School attendance & 0.019 & 0.147 & 1.000 & & & & & & \\
\hline (3) Cooking fuel & 0.012 & 0.069 & 0.033 & 1.000 & & & & & \\
\hline (4) Sanitation & 0.024 & 0.235 & 0.068 & 0.117 & 1.000 & & & & \\
\hline (5) Drinking water & 0.003 & 0.123 & 0.007 & 0.042 & 0.125 & 1.000 & & & \\
\hline (6) Electricity & 0.048 & 0.237 & 0.080 & 0.144 & 0.417 & 0.022 & 1.000 & & \\
\hline (7) Housing & 0.045 & 0.285 & 0.130 & 0.131 & 0.480 & 0.132 & 0.502 & 1.000 & \\
\hline (8) Assets & -0.014 & 0.165 & 0.042 & 0.173 & 0.294 & 0.084 & 0.312 & 0.304 & 1.000 \\
\hline Zambia & $(1)$ & (2) & (3) & (4) & (5) & (6) & (7) & (8) & (9) \\
\hline (1) Child mortality & 1.000 & & & & & & & & \\
\hline (2) School attendance & 0.066 & 0.185 & 1.000 & & & & & & \\
\hline (3) Cooking fuel & 0.066 & 0.191 & 0.119 & 1.000 & & & & & \\
\hline (4) Sanitation & 0.085 & 0.195 & 0.147 & 0.331 & 1.000 & & & & \\
\hline (5) Drinking water & 0.118 & 0.135 & 0.151 & 0.228 & 0.341 & 1.000 & & & \\
\hline (6) Electricity & 0.108 & 0.280 & 0.194 & 0.521 & 0.511 & 0.356 & 1.000 & & \\
\hline (7) Housing & 0.126 & 0.283 & 0.192 & 0.366 & 0.509 & 0.365 & 0.656 & 1.000 & \\
\hline (8) Assets & 0.034 & 0.165 & 0.083 & 0.393 & 0.242 & 0.164 & 0.341 & 0.321 & 1.000 \\
\hline Zimbabwe & $(1)$ & $(2)$ & (3) & (4) & $(5)$ & $(6)$ & $(7)$ & $(8)$ & $(9)$ \\
\hline (1) Child mortality & 1.000 & & & & & & & & \\
\hline (2) School attendance & 0.000 & 0.102 & 1.000 & & & & & & \\
\hline (3) Cooking fuel & 0.052 & 0.363 & 0.144 & 1.000 & & & & & \\
\hline (4) Sanitation & 0.022 & 0.329 & 0.118 & 0.445 & 1.000 & & & & \\
\hline (5) Drinking water & 0.051 & 0.187 & 0.079 & 0.314 & 0.292 & 1.000 & & & \\
\hline (6) Electricity & 0.051 & 0.360 & 0.147 & 0.841 & 0.484 & 0.327 & 1.000 & & \\
\hline (7) Housing & 0.029 & 0.324 & 0.124 & 0.492 & 0.540 & 0.311 & 0.531 & 1.000 & \\
\hline (8) Assets & 0.042 & 0.245 & 0.082 & 0.472 & 0.271 & 0.182 & 0.463 & 0.292 & 1.000 \\
\hline
\end{tabular}




\section{References}

Abhisek, B., \& Soumendu, C. (2014). Status of educational performance of tribal students: A study in Paschim Medinipur District, West Bengal. Educational Research and Reviews, 9(20), 925-937.

Abuya, B. A., Elungata, P., Mutisya, M., \& Kabiru, C. W. (2017). Parental education and high school completion in the urban informal settlements in Kenya. Cogent Education, 4(1), 1-13.

Abuya, B., Oketch, M., \& Musyoka, P. (2013). Why do pupils dropout when education is "free"?" Explaining school dropout among the urban poor in Nairobi. Compare: A Journal of Comparative and International Education, 43(6), 740-762.

Abuya, B. A., Onsomu, E. O., \& Moore, D. (2014). Determinants of educational exclusion: Poor urban girls' experiences in-and out-of-school in Kenya. Prospects, 44(3), 381-394.

Adelowokan, A. O., Tella, A. S., Adekunle, A. I., \& Alabi, O. M. (2019). Roles of age and gender in the attainment of sustainable governance in Africa. African Research Review, 13(2), 26-37.

Akbulut-Yuksel, M., \& Turan, B. (2013). Left behind: intergenerational transmission of human capital in the midst of HIV/AIDS. Journal of Population Economics, 26(4), $1523-1547$.

Alesina, A., Hohmann, S., Michalopoulos, S., \& Papaioannou, E. (2019). Intergenerational Mobility in Africa. NBER Working Paper. Retrieved from doi:10.3386/w25534

Alika, H. I. (2012). Bullying as a correlate of dropout from school among adolescents in Delta State: Implication for counselling. Education, 132(3), 523-531. Retrieved from http://go.galegroup.com/ps/anonymous?id=GALE\%7CA283945587\&sid=googleScho lar $\& v=2.1 \& i t=r \&$ linkaccess $=$ fulltext $\& i s s n=00131172 \& p=A O N E \& s w=w \&$ authCount $=1 \&$ isAnonymousEntry $=$ true

Alkire, S. (2008). Choosing dimensions: The capability approach and multidimensional poverty. In N. Kakwani \& J. Silber (Eds.), The many dimensions of poverty (pp. 89119). New York: Palgrave-Macmillan. Retrieved from doi:10.1057/9780230592407_6 
Alkire, S., Conceicao, P., Barham, A., Calderon, C., Conconi, A., Dirksen, J., Espinal, F.C. et al. (2019). Global multidimensional poverty index 2019: illuminating inequalities. Retrieved from http://hdr.undp.org/sites/default/files/mpi_2019_publication.pdf

Alkire, S., Foster, J., Seth, S., Santos, M. E., Roche, J. M., \& Ballón, P. (2015). Multidimensional poverty measurement and analysis. Retrieved from https://www.ophi.org.uk/wp-content/uploads/OPHIWP086_Ch5.pdf

Alkire, S., \& Kanagaratnam, U. (2018). The most detailed picture to date of the world's poorest people. Retrieved from https://ophi.org.uk/wp-content/uploads/GMPI_2018_2ed_web.pdf

Aloise-Young, P. A. (2002). Cigarette smoking and perceived health in school dropouts: A comparison of Mexican American and non-Hispanic white adolescents. Journal of Pediatric Psychology, 27(6), 497-507.

Ampiah, J. G., \& Adu-Yeboah, C. (2009). Mapping the incidence of school dropouts: A case study of communities in Northern Ghana. Comparative Education, 45(2), 219232.

Ananga, E. D. (2011). Typology of school dropout: The dimensions and dynamics of dropout in Ghana. International Journal of Educational Development, 31(4), 374-381.

Anderson, A., Hamilton, R. J., \& Hattie, J. (2004). Classroom climate and motivated behaviour in secondary schools. Learning Environments Research, 7(3), 211-225.

Armah, F. A., Ekumah, B., Yawson, D. O., Odoi, J. O., Afitiri, A.-R., \& Nyieku, F. E. (2019). Predictive Probabilities of Access to Clean Cooking: Evidence from the Demographic and Health Surveys in 31 Countries in Sub-Saharan Africa. Environmental Justice, 12(3), 118-131.

Ayad, M. S., \& El-Aziz, A. A. (2018). The Impact of Remittances on Children's Educational Attainment: Evidence from Egypt. SocioEconomic Challenges, 2(2), 4959.

Aydemir, A. B., \& Yazici, H. (2019). Intergenerational education mobility and the level of development. European Economic Review, 116, 160-185. 
Azomahou, T. T., \& Yitbarek, E. A. (2016). Intergenerational education mobility in Africa: has progress been inclusive? Policy Research Working Papers. Retrieved from doi:10.1596/1813-9450-7843

Bah-Lalya, I. (2015). Koranic education centres: A viable educational alternative for the disadvantaged learner in Sahel Africa? International Review of Education, 61(4), 465479.

Baird, S., McIntosh, C., \& Ozler, B. (2011). Cash or condition? Evidence from a cash transfer experiment. The Quarterly Journal of Economics, 126(4), 1709-1753.

Ballarino, G., Bernardi, F., Requena, M., \& Schadee, H. (2009). Persistent Inequalities? Expansion of Education and Class Inequality in Italy and Spain. European Sociological Review, 25(1), 123-138.

Banik, A., \& Neogi, D. (2015). Poverty and earning compulsions for the family have pushed children out of schools. International Journal of Social Economics, 42(10), 946-958.

Barrera-Osorio, F., Bertrand, M., Linden, L. L., \& Perez-Calle, F. (2011). Improving the design of conditional transfer programs: evidence from a randomized education experiment in Colombia. American Economic Journal: Applied Economics, 3(2), 167195.

Barro, R. J., \& Lee, J. W. (2013). A new data set of educational attainment in the world, 1950-2010. Journal of Development Economics, 104,184-198.

Bauer, P. C., \& Riphahn, R. T. (2013). Institutional determinants of intergenerational education transmission - Comparing alternative mechanisms for natives and immigrants. Labour Economics, 25, 110-122.

Becker, G. S., \& Tomes, N. (1986). Human Capital and the Rise and Fall of Families. Journal of Labor Economics, 4(3), 257-298.

Becker, R. (2003). Educational expansion and persistent inequalities of education: utilizing subjective expected utility theory to explain increasing participation rates in upper secondary school in the Federal Republic of Germany. European Sociological Review, 19(1), 1-24. 
Behrman, J. R., Parker, S. W., \& Todd, P. E. (2009). Schooling impacts of conditional cash transfers on young children: evidence from Mexico. Economic Development and Cultural Change, 57(3), 439-477.

Bello, M., \& Hakimi, M. W. (2017). Revitalizing education for national development: Issues and challenges of out of school children in Sokoto State, Nigeria. International Journal of Topical Educational Issues, 1(2), 375 - 383. Retrieved from http://oer.udusok.edu.ng:8080/xmlui/bitstream/handle/123456789/823/1509985944.p df? sequence $=1 \&$ is Allowed $=\mathrm{y}$

Biddlecom, A., Gregory, R., Lloyd, C. B., \& Mensch, B. S. (2008). Associations between premarital sex and leaving school in four Sub-Saharan African countries. Studies in Family Planning, 39(4), 337-350.

Biggeri, M., Libanora, R., Mariani, S., \& Menchini, L. (2006). Children conceptualizing their capabilities: results of a survey conducted during the first children's world congress on child labour. Journal of Human Development, 7(1), 59-83.

Bird, R. M., Martinez-Vazquez, J., \& Torgler, B. (2008). Tax Effort in Developing Countries and High Income Countries: The Impact of Corruption, Voice and Accountability. Economic Analysis and Policy, 38(1), 55-71.

Black, S. E., Devereux, P. J., \& Salvanes, K. G. (2008). Staying in the Classroom and Out of the Maternity Ward? The Effect of Compulsory Schooling Laws on Teenage Births. The Economic Journal, 118(530), 1025-1054.

Blanden, J., \& Macmillan, L. (2016). Educational inequality, educational expansion and intergenerational mobility. Journal of Social Policy, 45(4), 589-614.

Blau, P., \& Duncan, O. D. (1967). The American Occupational Structure. New York, NY: John Wiley \& Sons.

Braimah, I., \& Oduro-Ofori, E. (2005). Basic school dropout in Ghana: A case study of the Amansie West district. Journal of Science and Technology, 25(1), 67-76.

Breen, R., \& Goldthorpe, J. H. (1997). Explaining educational differentials: Towards a formal rational action theory. Rationality and society, 9(3), 275-305. 
Breierova, L., \& Duflo, E. (2004). The Impact of Education on Fertility and Child Mortality: Do Fathers Really Matter Less Than Mothers? National bureau of economic research. Retrieved from doi:10.3386/w10513

Bronfenbrenner, U. (1979). The ecology of human development: Experiments by nature and design. Cambridge, MA: Harvard University Press.

Bronfenbrenner, U. (1977). Toward an experimental ecology of human development. American Psychologist, 32(7), 513-531.

Brown, B. A. (2010). Social hostility and the "dropout" syndrome: Leadership assisting youths' re-entry into school? Educational Review, 62(1), 53-67.

Brunello, G., Fort, M., \& Weber, G. (2009). Changes in Compulsory Schooling, Education and the Distribution of Wages in Europe. The Economic Journal, 119(536), 516-539.

Bukodi, E., Eibl, F., Buchholz, S., Marzadro, S., Minello, A., Wahler, S., Blossfeld, H., Erikson, R., \& Schizzerotto, A. (2018). Linking the macro to the micro: a multidimensional approach to educational inequalities in four European countries. European Societies, 20(1), 26-64.

Cabus, S. J., \& De Witte, K. (2011). Does school time matter? - On the impact of compulsory education age on school dropout. Economics of Education Review, 30(6), 1384-1398.

Carvalho, L. (2012). Childhood Circumstances and the Intergenerational Transmission of Socioeconomic Status. Demography, 49(3), 913-938.

Cemalcilar, Z., \& Gokşen, F. (2014). Inequality in social capital: Social capital, social risk and drop-out in the Turkish education system. British Journal of Sociology of Education, 35(1), 94-114.

Chapman, D. W., Burton, L., \& Werner, J. (2010). Universal secondary education in Uganda: The head teachers' dilemma. International Journal of Educational Development, 30(1), 77-82.

Chernichovsky, D. (1985). Socioeconomic and demographic aspects of school enrollment and attendance in rural Botswana. Economic Development and Cultural Change, 33(2), 319-332. 
Chin, A. (2005). Can redistributing teachers across schools raise educational attainment? Evidence from Operation Blackboard in India. Journal of Development Economics, $78(2), 384-405$.

Christian, M. (2015). School location, school section and students' gender as predictors to secondary school dropout rate in Rivers State, Nigeria." Journal of Education and Practice, 6(28), 113-118. Retrieved from

https://files.eric.ed.gov/fulltext/EJ1081234.pdf

Chung, C., \& Mason, M. (2012). Why do primary school students drop out in poor, rural China? A portrait sketched in a remote mountain village. International Journal of Educational Development, 32(4), 537-545.

Coscieme, L., Mortensen, L. F., Anderson, S., Ward, J., Donohue, I., \& Sutton, P. C. (2020). Going beyond Gross Domestic Product as an indicator to bring coherence to the Sustainable Development Goals. Journal of Cleaner Production, 248, 1-8.

d'Addio, A. C. (2007). Intergenerational transmission of disadvantage: mobility or immobility across generations. OECD Social, Employment and Migration Working Papers. Retrieved from doi:10.1787/217730505550

De Hoyos, R. (2016). There is no easy fix to the dropout problem. Retrieved from https://blogs.worldbank.org/education/there-no-easy-fix-dropout-problem

Deil-Amen, R., \& Rosenbaum, J. E. (2003). The social prerequisites of success: can college structure reduce the need for social know-how? The ANNALS of the American Academy of Political and Social Science, 586(1), 120-143.

Dennison, C. R., \& Swisher, R. R. (2018). Postsecondary Education, Neighborhood Disadvantage, and Crime: An Examination of Life Course Relative Deprivation. Crime and Delinquency, 65(2), 215-238.

De Witte, K., Cabus, S., Thyssen, G., Groot, W., \& van den Brink, H. M. (2013). A critical review of the literature on school dropout. Educational Research Review, 10, 13-28.

DHS Program (2020). Guide to DHS Statistics. Retrieved from https://www.dhsprogram.com/pubs/pdf/DHSG1/Guide_to_DHS_Statistics_DHS7_v2.pdf 
Diaz-Serrano, L. (2020). The duration of compulsory education and the transition to secondary education: Panel data evidence from low-income countries. International Journal of Educational Development, 75, 1-27.

Diyu, X. (2001). Investigation and discussion on the problem of primary and secondary school dropouts in poor areas. Chinese Education and Society, 34(5), 49-58.

Doll, J. J., Eslami, Z., \& Walters, L. (2013). Understanding why students drop out of high school, according to their own reports: Are they pushed or pulled, or do they fall out? A Comparative Analysis of Seven Nationally Representative Studies. SAGE Open, $3(4), 1-5$.

Dorman, J. P., Fraser, B. J., \& McRobbie, C. J. (1997). Relationship between school-level and classroom-level environments in secondary schools. Journal of Educational Administration, 35(1), 74-91.

Dramani, L., \& Ndiaye, F. (2015). Learning quality in Senegal: children performance determinants. British Journal of Education, Society and Behavioural Science, 6(4), $313-334$.

Edwards, D. B., Zimmermann, T., Sitha, C., Williams, J. H., \& Kitamura, Y. (2014). Student transition from primary to lower secondary school in Cambodia: Narrative insights into complex systems. Prospects, 44(3), 367-380.

EFA Global Monitoring Report (2015). Education For All 2000-2015: achievements and challenges. $\quad$ Retrieved from http://unesdoc.unesco.org/images/0023/002322/232205e.pdf/

Emran, M. S., Ferreira, F. H. G., Jiang, Y., \& Sun, Y. (2019). Intergenerational Educational Mobility in Rural Economy: Evidence from China and India. SSRN Electronic Journal.

Engle, P. L., \& Black, M. M. (2008). The effect of poverty on child development and educational outcomes. Annals of the New York Academy of Sciences, 1136(1), 243-256.

EPDC (2011). Senegal: Out of school children of the population ages 7-14. Retrieved from https://www.epdc.org/sites/default/files/documents/Senegal_OOSC_Profile_2.pdf

Evans, D. K., \& Miguel, E. (2007). Orphans and Schooling in Africa: A Longitudinal Analysis. Demography, 44(1), 35-57. 
Fang, H., Eggleston, K., Rizzo, J., Rozelle, S., \& Zeckhauser, R. (2012). The returns to education in China: Evidence from the 1986 compulsory education law. National Bureau of Economic Research. Retrieved from doi:10.3386/w18189

Farah, N., \& Upadhyay, M. P. (2017). How are school dropouts related to household characteristics? Analysis of survey data from Bangladesh. Cogent Economics and Finance, 5(1), 1-18.

Farid-ul-Hasnain, S., \& Krantz, G. (2010). Assessing reasons for school/college dropout among young adults and implications for awareness about STDs and HIV/AIDS: Findings from a population-based study in Karachi, Pakistan. International Journal of Behavioral Medicine, 18(2), 122-130.

Febrianti Purba, R. H. (2018). Impact evaluation of Indonesia conditional cash transfer program (BSM) on student achievement. European Journal of Economics and Business Studies, 4(1), 98-109.

Ferreira, F. H. G., Filmer, D., \& Schady, N. (2017). Own and sibling effects of conditional cash transfer programs: theory and evidence from Cambodia. Research on Economic Inequality, 25, 259-298.

Finn, J. D. (1989). Withdrawing from school. Review of Educational Research, 59(2), 117.

Flisher, A. J., Townsend, L., Chikobvu, P., Lombard, C. F., \& King, G. (2010). Substance use and psychosocial predictors of high school dropout in Cape Town, South Africa. Journal of Research on Adolescence, 20(1), 237-255.

Fortin, L., Marcotte, D., Diallo, T., Potvin, P., \& Royer, É. (2013). A multidimensional model of school dropout from an 8-year longitudinal study in a general high school population. European Journal of Psychology of Education, 28(2), 563-583.

Fortson, J. G. (2011). Mortality Risk and Human Capital Investment: The Impact of HIV/AIDS in Sub-Saharan Africa. Review of Economics and Statistics, 93(1), 1-15.

Fredricks, J. A., Blumenfeld, P. C., \& Paris, A. H. (2004). School engagement: Potential of the concept, state of the evidence. Review of Educational Research, 74(1), 59-109.

Fredriksen, K., \& Rhodes, J. (2004). The role of teacher relationships in the lives of students. New Directions for Youth Development, 2004(103), 45-54. 
Fute, A. Z., Massawe, B. F., Sele, E. E., \& Richard, M. B. (2019). Free and compulsory primary education in Tanzania: Challenges to a girl child in rural areas. Research on Humanities and Social Sciences, 9(6), 36-73.

Galiani, S., \& McEwan, P. J. (2013). The heterogeneous impact of conditional cash transfers. Journal of Public Economics, 103, 85-96.

Ganimian, A., \& Murnane, R. (2014). Improving educational outcomes in developing countries: lessons from rigorous impact evaluations. Review of Educational Research, 86(3), 719-755.

Global Multidimensional Poverty Index (2019). Illuminating inequalities. Retrieved from http://hdr.undp.org/sites/default/files/mpi_2019_publication.pdf

Global Multidimensional Poverty Index (2018). The most detailed picture to date of the world's poorest people. Retrieved from https://ophi.org.uk/wp-content/uploads/GMPI_2018_2ed_web.pdf

Gordon, D., Nandy, S., Pantazis, C., Townsend, P., \& Pemberton, S. (2003). Child poverty in the developing world. Bristol: Policy Press.

Gregorio, J. D., \& Lee, J.-W. (2002). Education and income inequality: new evidence from cross-country data. Review of Income and Wealth, 48(3), 395-416.

Guryan, J. (2004). Desegregation and black dropout rates. American Economic Review, 94(4), 919-943.

Hajli, M. N., \& Lin, X. (2014). Developing tourism education through social media. Tourism Planning \& Development, 11(4), 405-414.

Hanushek, E. A., Lavy, V., \& Hitomi, K. (2008). Do students care about school quality? Determinants of dropout behavior in developing countries. Journal of Human Capital, 2(1), 69-105.

Hausman, C., \& Rapson, D. S. (2018). Regression discontinuity in time: Considerations for empirical applications. Annual Review of Resource Economics, 10(1), 533-552.

Hertz, T., Jayasundera, T., Piraino, P., Selcuk, S., Smith, N., \& Verashchagina, A. (2008). The inheritance of educational inequality: International comparisons and fifty-year trends. The B.E. Journal of Economic Analysis and Policy, 7(2), 1-46. 
Holmes, J. (2003). Measuring the determinants of school completion in Pakistan: Analysis of censoring and selection bias. Economics of Education Review, 22(3), 249-264.

Holmlund, H., Lindahl, M., \& Plug, E. (2011). The causal effect of parents' schooling on children's schooling: A comparison of estimation methods. Journal of Economic Literature, 49(3), 615-651.

Huang, J. (2013). Intergenerational transmission of educational attainment: The role of household assets. Economics of Education Review, 33, 112-123.

Huisman, J., \& Smits, J. (2015). Keeping children in school: Effects of household and context characteristics on school dropout in 363 districts of 30 developing Countries." SAGE Open, 5(4): 1-16.

Human Rights Watch (2017). "I won't be a doctor, and one day you'll be sick": Girls' access to education in Afghanistan. Retrieved from https://www.hrw.org/sites/default/files/report_pdf/afghanistan1017_web.pdf

Igboanusi, H. (2014). The English-only language education policy in The Gambia and low literacy rates. International Journal of Bilingual Education and Bilingualism, 17(5), $558-569$.

Jere, C., \& Tofaris, E. (2017). Reducing school dropout in Malawi and Lesotho. Retrieved from

https://ueaeprints.uea.ac.uk/id/eprint/65896/1/REDUCING_SCHOOL_DROPOUT_R ATES_IN_MALAWI.pdf

Jonsson, J. O., \& Mills, C. (1993). Social Class and Educational Attainment in Historical Perspective: A Swedish-English Comparison Part I. The British Journal of Sociology, 44(2), 213-247.

Jukes, M. C. H., Jere, C. M., \& Pridmore, P. (2014). Evaluating the provision of flexible learning for children at risk of primary school dropout in Malawi. International Journal of Educational Development, 39, 181-192.

Kalmijn, M. (1994). Mother's occupational status and children's schooling. American Sociological Review, 59(2), 257-275.

Kerckhoff, A. C. (1995). Institutional Arrangements and Stratification Processes of Industrial Societies. Annual Review of Sociology, 21(1), 323-347. 
Keser, A., \& Gokmen, Y. (2018). Governance and Human Development: The Impacts of Governance Indicators on Human Development. Journal of Public Administration and Governance, 8(1), 26-39.

Kirdar, M. G., Dayioglu, M., \& Koc, I. (2015). Does longer compulsory education equalize schooling by gender and rural/urban residence? The World Bank Economic Review, 30(3), 549-579.

Kleinbaum, D. G. (1994). Logistic regression: A self-learning text. New York: Springer.

Korinek, K., \& Punpuing, S. (2012). The effect of household and community on school attrition: An analysis of Thai Youth. Comparative Education Review, 56(3), 474-510.

Kovan, N. M., Chung, A. L., \& Sroufe, L. A. (2009). The intergenerational continuity of observed early parenting: A prospective, longitudinal study. Developmental Psychology, 45(5), 1205-1213.

Kremer, M., Miguel, E., \& Thornton, R. (2009). Incentives to learn. Review of Economics and Statistics, 91(3), 437-456.

Lamb, S., \& Markussen, E. (2011). School dropout and completion: an international perspective, in: S. Lamb, E. Markussen, R. Teese, N. Sandberg \& J. Polesel (Eds). School dropout and completion, Pp. 1-18 (Springer, Dordrecht). Retrieved from doi:10.1007/978-90-481-9763-7_1

Landis, R. N., \& Reschly, A. L. (2011). An examination of compulsory school attendance ages and high school dropout and completion. Educational Policy, 25(5), 719-761.

Lee, D. S., \& Card, D. (2008). Regression discontinuity inference with specification error. Journal of Econometrics, 142(2), 655-674.

Levy, M. B. (1971). Determinants of primary school dropouts in developing Countries. Comparative Education Review, 15(1), 44-58.

Lewin, K. M., \& Little, A. W. (2011). Access to education revisited: Equity, drop out and transitions to secondary school in South Asia and Sub-Saharan Africa. International Journal of Educational Development, 31(4), 333-337.

Lleras-Muney, A. (2002). Were compulsory attendance and child labor laws effective? An analysis from 1915 to 1939. The Journal of Law and Economics, 45(2), 401-435. 
Lloyd, C. B., Mensch, B. S., \& Clark, W. H. (2000). The effects of primary school quality on school dropout among Kenyan girls and boys. Comparative Education Review, 44(2), 113-147.

Lloyd, C. B., Mete, C., \& Grant, M. J. (2009). The implications of changing educational and family circumstances for children's grade progression in rural Pakistan: 1997-2004. Economics of Education Review, 28(1), 152-160.

Lloyd, C. B., Mete, C., \& Sathar, Z. A. (2005). The effect of gender differences in primary school access, type, and quality on the decision to enroll in rural Pakistan. Economic Development and Cultural Change, 53(3), 685-710.

Lom, M. M. (2018). The excluded from education: the extent of the phenomenon. Retrieved from https://palnetwork.org/wp-content/uploads/2018/02/MondeEduc_N\%c2\%b020_Spe\%cc\%81cial-LARTES_ANG-OK.pdf

Loyalka, P., Liu, C., Song, Y., Yi, H., Huang, X., Wei, J., Zhang, L., Shi, Y., Chu, J., \& Rozelle, S. (2013). Can information and counseling help students from poor rural areas go to high school? Evidence from China. Journal of Comparative Economics, 41(4), 1012-1025.

Lu, M., Cui, M., Shi, Y., Chang, F., Mo, D., Rozelle, S., \& Johnson, N. (2016). Who drops out from primary schools in China? Evidence from minority-concentrated rural areas. Asia Pacific Education Review, 17(2), 235-252.

Lupien, S. J., King, S., Meaney, M. J., \& McEwen, B. S. (2000). Child's stress hormone levels correlate with mother's socioeconomic status and depressive state. Biological Psychiatry, 48(10), 976-980.

Lyanga, A. A., \& Chen, M.-K. (2020). The Impacts of Fee - Free Education Policy in Junior Secondary Schools in Tanzania. Asian Journal of Education and Social Studies, 13(3), $36-47$.

Mabika, C. M., \& Shapiro, D. (2012). School enrollment in the Democratic Republic of the Congo: family economic well-being, gender, andplace of residence. African Population Studies, 26(2), 197-220.

Mahler, D. G., Lakner, C., Van Der Weide, R., \& Narayan, A. (2018). Remember to call your grandparents: multigenerational mobility in the developing world. Retrieved from 
https://blogs.worldbank.org/developmenttalk/remember-call-your-grandparentsmultigenerational-mobility-developing-world

Mahlomaholo, S. M. (2012). Early school leavers and sustainable learning environments in rural contexts. Perspectives in Education, 30(1), 101-110. Retrieved from

http://scholar.ufs.ac.za:8080/xmlui/bitstream/handle/11660/3009/persed_v30_n1_a12. pdf? sequence $=1$

Makwinja-Morara, V. (2009). Female dropouts in Botswana junior secondary Schools. Educational Studies, 45(5), 440-462.

Manandhar, N., \& Sthapit, A. (2012). Determinants of primary school dropout in Nawalparasi District. Journal of College of Medical Sciences, 6(4), 14-18.

1. Mashala, Y. L. (2019). The impact of the implementation of free education policy on secondary education in Tanzania. International Journal of Academic Multidisciplinary Research, 3(1), 6-14.

McCoy, D. C., Peet, E. D., Ezzati, M., Danaei, G., Black, M. M., Sudfeld, C. R., Fawzi, W., \& Fink, G. (2016). Early childhood developmental status in low- and middleincome countries: national, regional, and global prevalence estimates using predictive modeling. PLOS Medicine, 13(6), 1-18.

Meghir, C., \& Palme, M. (2005). Educational reform, ability, and family background. American Economic Review, 95(1), 414-424.

Millennium Development Goals (2020). Achieve universal primary education by 2015. Retrieved from http://www5.worldbank.org/mdgs/education.html

Miller, K. E. (2016). Putting the challenge of achieving international education goals into context: an examination of the institutional determinants of educational attainment. Comparative Education Review, 60(4), 673-702.

Mohaqeqi Kamal, S. H., Ghaedamini Harouni, G., Basakha, M., \& Makki Alamdari, S. (2019). Multidimensional child poverty index in Iran: Distribution of deprivation across provinces. Journal of Poverty, 23(4), 353-364.

Mokibelo, E. B. (2014). Why we drop out of school: Voices of San School dropouts in Botswana. The Australian Journal of Indigenous Education, 43(2), 185-194. 
Momo, M. S. M., Cabus, S. J., De Witte, K., \& Groot, W. (2019a). A systematic review of the literature on the causes of early school leaving in Africa and Asia. Review of Education, 7(3), 496-522.

Momo, M. S. M., Rud, I., Cabus, S. J., De Witte, K., \& Groot, W. (2019b). The relationship between contextual characteristics and the intergenerational correlation of education in developing countries. International Journal of Educational Development, 66, 173-183.

Morrison, G. M., Robertson, L., Laurie, B., \& Kelly, J. (2002). Protective factors related to antisocial behavior trajectories. Journal of Clinical Psychology, 58(3), 277-290.

Moyi, P. (2012). Who goes to school? School enrollment patterns in Somalia. International Journal of Educational Development, 32(1), 163-171.

Müller, W., \& Karle, W. (1993). Social Selection in Educational Systems in Europe. European Sociological Review, 9(1), 1-23.

Mussida, C., Sciulli, D., \& Signorelli, M. (2019). Secondary school dropout and work outcomes in ten developing countries. Journal of Policy Modeling, 41(4), 547-567.

Mzuza, M. K., Yudong, Y., \& Kapute, F. (2014). Analysis of factors causing poor passing rates and high dropout rates among primary school girls in Malawi. World Journal of Education, 4(1), 48-61.

Neidhofer, G., Serrano, J., \& Gasparini, L. (2018). Educational inequality and intergenerational mobility in Latin America: A new database. Journal of Development Economics, 134, 329-349.

Newcomb, M. D., Abbott, R. D., Catalano, R. F., Hawkins, J. D., Battin-Pearson, S., \& Hill, K. (2002). Mediational and deviance theories of late high school failure: Process roles of structural strains, academic competence, and general versus specific problem behavior. Journal of Counseling Psychology, 49(2), 172-186.

Njoh, A. J., Ananga, E. O., Ngyah-Etchutambe, I. B., Deba, L. E., Asah, F. J., Ayuk-Etang, E. N., \& Akiwumi, F. A. (2018). Electricity supply, and access to water and improved sanitation as determinants of gender-based inequality in educational attainment in Africa. Social Indicators Research, 135(2), 533-548.

No, F., Sam, C., \& Hirakawa, Y. (2012). Revisiting primary school dropout in rural Cambodia. Asia Pacific Education Review, 13(4), 573-581. 
No, F., Taniguchi, K., \& Hirakawa, Y. (2016). School dropout at the basic education level in rural Cambodia: Identifying its causes through longitudinal survival analysis. International Journal of Educational Development, 49, 215-224.

Odeyemi, K., Olufunlayo, T., Ogunnowo, B., \& Onajole, A. (2016). Sexual violence among out-of-school female adolescents in Lagos, Nigeria. SAGE Open, 6(4), 1-6.

OECD (2013). Education policy outlook: Turkey. Retrieved from http://www.oecd.org/education/EDUCATION\%20POLICY\%20OUTLOOK\%20TUR KEY_EN.pdf

Okwaraji, F. E., Obiechina, K. I., Onyebueke, G. C., Udegbunam, O. N., \& Nnadum, G. S. (2018). Loneliness, life satisfaction and psychological distress among out-of-school adolescents in a Nigerian urban city. Psychology, Health and Medicine, 23(9), 11061112.

Oreopoulos, P. (2006). The compelling effects of compulsory schooling: Evidence from Canada. Canadian Journal of Economics, 39(1), 22-52.

Oreopoulos, P. (2009). Would more compulsory schooling help disadvantaged youth? Evidence from recent changes to school-leaving laws. In The problems of disadvantaged youth: An economic perspective (pp. 85-112). University of Chicago Press. Retrieved from doi:10.7208/chicago/9780226309477.003.0004

Ortiz-Correa, J. S., Resende Filho, M., \& Dinar, A. (2016). Impact of access to water and sanitation services on educational attainment. Water Resources and Economics, 14, 3143.

Paul Schultz, T. (2004). School subsidies for the poor: evaluating the Mexican Progresa poverty program. Journal of Development Economics, 74(1), 199-250.

Pfeffer, F. T. (2008). Persistent inequality in educational attainment and its institutional context. European Sociological Review, 24(5), 543-565.

Pillay, J. (2017). The relationship between housing and children's literacy achievement: Implications for supporting vulnerable children. South African Journal of Education, $37(2), 1-10$. 
References

Pintrich, P. R., \& de Groot, E. V. (1990). Motivational and self-regulated learning components of classroom academic performance. Journal of Educational Psychology, 82(1), 33-40.

Pinilla-Roncancio, M., \& Silva, R. (2018). Children in Angola: Poverty, deprivation and child labour. Child Indicators Research, 11(3), 981-1005.

Plug, E., \& Vijverberg, W. (2003). Schooling, Family Background, and Adoption: Is It Nature or Is It Nurture? Journal of Political Economy, 111(3), 611-641.

Polat, S. (2014). Reasons for school dropout in vocational high school. Educational Research and Reviews, 9(18), 711-718.

Popkova, E. G., Bogoviz, A. V., Pozdnyakova, U. A., \& Przhedetskaya, N. V. (2018). Specifics of economic growth of developing countries. In Management of Changes in Socio-Economic Systems (pp. 139-146). Retrieved from doi:10.1007/978-3-319-726137

Qi, D., \& Wu, Y. (2019). Comparing the Extent and Levels of Child Poverty by the Income and Multidimensional Deprivation Approach in China. Child Indicators Research, 12(2), 627-645.

Rauscher, E. (2014). Hidden gains: Effects of early US compulsory schooling laws on attendance and attainment by social background. Educational Evaluation and Policy Analysis, 36(4), 501-518.

Ream, R. K., \& Rumberger, R. W. (2008). Student engagement, peer social capital, and school dropout among Mexican American and non-Latino white students. Sociology of Education, 81(2), 109-139.

Reimao, M. E. (2019). Cash and change: a replication study of a cash transfer experiment in Malawi. Retrieved from doi:10.23846/rps0021

Rumberger, R. W. (1995). Dropping out of middle school: A multilevel analysis of students and schools. American Educational Research Journal, 32(3), 583-625.

Rutstein, S. O., \& Rojas, G. (2006). Guide to DHS statistics. Calverton, MD: ORC Macro. Retrieved from http://www.ophi.org.uk/wp-content/uploads/OPHI-HDCA-SS2012Guide_DHS_Statistics.pdf 
Sabates, R., Hossain, A., \& Lewin, K. M. (2013). School drop out in Bangladesh: Insights using panel data. International Journal of Educational Development, 33(3), 225-232.

Şahin, Ş., Arseven, Z., \& Kılıç, A. (2016). Causes of student absenteeism and school dropouts. International Journal of Instruction, 9(1), 195-210.

Sarker, P., \& Davey, G. (2009). Exclusion of indigenous children from primary education in the Rajshahi Division of northwestern Bangladesh. International Journal of Inclusive Education, 13(1), 1-11.

Schady, N., \& Araujo, M. C. (2008). Cash transfers, conditions, and school enrollment in Ecuador. Economía, 8(2), 43-70.

Senegal (2004). Law 2004-37 of 15 December 2004 amending and supplementing the National Education Guidance Law No. 91-22 of 16 February 1991. Retrieved from http://www.axl.cefan.ulaval.ca/afrique/senegal-loi2004.htm

Shahidul, S. M. (2013). Household decision-making process: It's effect on school dropout behavior for girls in the secondary school level in Bangladesh. International Education Studies, 6(1), 132-141.

Shi, Y., Zhang, L., Ma, Y., Yi, H., Liu, C., Johnson, N., Chu, J., Loyalka, P. \& Rozelle, S. (2015). Dropping out of rural China's secondary schools: A mixed-methods analysis." The China Quarterly, 224, 1048-1069.

Siddhu, G. (2011). Who makes it to secondary school? Determinants of transition to secondary schools in rural India. International Journal of Educational Development, 31(4), 394-401.

Sieben, I., \& De Graaf, P. M. (2001). Testing the modernization hypothesis and the socialist ideology hypothesis: a comparative sibling analysis of educational attainment and occupational status. British Journal of Sociology, 52(3), 441-467.

Skinner, E. A., \& Pitzer. J. (Eds.). (2012). Developmental dynamics of engagement, coping, and everyday resilience. New York, NY: Springer Science.

Smits, J., \& Huisman, J. (2013). Determinants of educational participation and gender differences in education in six Arab countries. Acta Sociologica, 56(4), 325-346. 
Staff, J., \& Kreager, D. A. (2008). Too cool for school? Violence, peer status and high school dropout. Social Forces, 87(1), 445-471.

Stash, S., \& Hannum, E. (2001). Who goes to school? Educational stratification by gender, caste, and ethnicity in Nepal. Comparative Education Review, 45(3), 354-378.

Stocké, V. (2007). Explaining educational decision and effects of families' social class position: an empirical test of the Breen-Goldthorpe model of educational attainment. European Sociological Review, 23(4), 505-519.

Sustainable Development Goal (2020a). Water and sanitation. Retrieved from https://sustainabledevelopment.un.org/topics/waterandsanitation

Sustainable Development Goal (2020b). Energy. Retrieved from https://sustainabledevelopment.un.org/topics/energy

Tacchella, A., Mazzilli, D., \& Pietronero, L. (2018). A dynamical systems approach to gross domestic product forecasting. Nature Physics, 14(8), 861-865.

Tansel, A. (2002). Determinants of school attainment of boys and girls in Turkey: Individual, household and community factors. Economics of Education Review, 21(5), $455-470$.

Tas, A., Bora, V., Selvitopu, A., \& Demirkaya, Y. (2013). "Reasons for dropout for vocational high school students." Educational Sciences: Theory and Practice, 13(3), 1561-1565.

Thomas, D., Beegle, K., Frankenberg, E., Sikoki, B., Strauss, J., \& Teruel, G. (2004). Education in a Crisis. Journal of Development economics, 74(1), 53-85. Retrieved from http://escholarship.org/uc/item/1gh9r6rr\#page-5

Tuckwiller, E. D., Pullen, P. C., \& Coyne, M. D. (2010). The Use of the Regression Discontinuity Design in Tiered Intervention Research: A Pilot Study Exploring Vocabulary Instruction for At-Risk Kindergarteners. Learning Disabilities Research and Practice, 25(3), 137-150.

Tukundane, C., Minnaert, A., Zeelen, J., \& Kanyandago, P. (2015). A review of enabling factors in support intervention programmes for early school leavers: What are the implications for Sub-Saharan Africa? Children and Youth Services Review, 52, 54-62. 
Tukundane, C., Zeelen, J., Minnaert, A., \& Kanyandago, P. (2014). "I felt very bad, I had self-rejection": narratives of exclusion and marginalisation among early school leavers in Uganda. Journal of Youth Studies, 17(4), 475-491.

Ud Din, M. N., Dad, H., Iqbal, J., Ali Shah, S. S., \& Niazi, M. I. (2011). Causes of male dropout rate in Pakistan. Journal of College Teaching and Learning, 8(4), 37-42.

UNESCO (2015). Achieving Education for All by 2015: Mixed results in Senegal. Retrieved from http://www.unesco.org/new/en/media-services/singleview/news/achieving_education_for_all_by_2015_mixed_results_in_senega/

UNESCO Institute for Statistics (2009) Education Indicators: technical guidelines. Retrieved from http://www.uis.unesco.org/Library/Documents/eiguide09-en.pdf/

UNESCO Institute for Statistics (2017) Education. Retrieved from http://data.uis.unesco.org/Index.aspx?DataSetCode=EDULIT_DS\#/

UNESCO (2017). Reducing global poverty through universal primary and secondary education. Retrieved from http://uis.unesco.org/sites/default/files/documents/reducingglobal-poverty-through-universal-primary-secondary-education.pdf

UNESCO (2006). Senegal: early childhood care and education (ECCE) programmes. Retrieved from https://unesdoc.unesco.org/ark:/48223/pf0000148045

UNESCO (2020). Senegal: Education and literacy. Retrieved from http://uis.unesco.org/country/SN

UNESCO (2019). Stumbling blocks to universal primary education: Repetition rates decline but dropout rates remain high. Retrieved from https://en.unesco.org/news/stumbling-blocks-universal-primary-education-repetitionrates-decline-dropout-rates-remain-high

UNESCO (2010). World data on education. Retrieved from http://www.ibe.unesco.org/fileadmin/user_upload/Publications/WDE/2010/pdfversions/Senegal.pdf

United Nations (2014) The millennium development goals 2014. Retrieved from http://www.un.org/millenniumgoals/2014\%20MDG\%20report/MDG\%202014\%20En glish\%20web.pdf/ 
Van Doorn, M., Pop, I., \& Wolbers, M. H. J. (2011). Intergenerational transmission of education across European countries and cohorts. European Societies, 13(1), 93-117.

Villa, J. M. (2018). The continuous treatment effect of an antipoverty program on children's educational attainment: Colombia's Familias en Accion. Review of Development Economics, 22(3), 1239-1262.

Walker, S. P., Wachs, T. D., Meeks Gardner, J., Lozoff, B., Wasserman, G. A., Pollitt, E., \& Carter, J. A. (2007). Child development: risk factors for adverse outcomes in developing countries. The Lancet, 369(9556), 145-157.

Wang, M.-T., \& Fredricks, J. A. (2014). The reciprocal links between school engagement, youth problem behaviors, and school dropout during adolescence. Child Development, 85(2), 722-737.

Wegner, L., Flisher, A. J., Chikobvu, P., Lombard, C., \& King, G. (2008). Leisure boredom and high school dropout in Cape Town, South Africa. Journal of Adolescence, 31(3), $421-431$.

Werblow, J., \& Duesbery, L. (2009). The impact of high school size on Math achievement and dropout rate. The High School Journal, 92(3), 14-23.

World Bank (2018). A lack of mobility undermines the aspirations of millions and may threaten stability and growth Retrieved from https://www.worldbank.org/en/news/feature/2018/11/28/a-lack-of-mobilityundermines-the-aspirations-of-millions-and-may-threaten-stability-and-growth

World Bank (2018a). Learning to realize education's promise. Retrieved from https://elibrary.worldbank.org/doi/pdf/10.1596/978-1-4648-1096-1

World Bank (2020a). Poverty: overview. Retrieved from https://www.worldbank.org/en/topic/poverty/overview

World Bank (2020b). About world development indicators. Retrieved from https://datatopics.worldbank.org/world-development-indicators/about-worlddevelopment-indicators.html

World Bank Group (2016). Senegal engaging the private sector in education: SABER country report 2016. Systems approach for better education results. Retrieved from https://openknowledge.worldbank.org/handle/10986/26523 
References

World Bank (2013). Senegal - Quality improvement and equity of basic education project. Retrieved

from

http://documents.worldbank.org/curated/en/160831468307457305/pdf/757520PAD0P

133010Box377300B00OUO090.pdf

World Bank (2017): World development indicators. Retrieved from http://databank.worldbank.org/data/reports.aspx?Id=664ca34a\&Report_Name=Data

World Bank (2019). Worldwide governance indicators. Retrieved from https://datacatalog.worldbank.org/dataset/worldwide-governance-indicators

Wudu, M. T. (2015). Challenges students face in their transition from primary to secondary school and the interventions schools take to ease the transition. Educational Research and Reviews, 10(5), 622-633.

Yi, H., Zhang, L., Luo, R., Shi, Y., Mo, D., Chen, X., Brinton, C. \& Rozelle, S. (2012). Dropping out: Why are students leaving junior high in China's poor rural areas?" International Journal of Educational Development, 32(4), 555-563.

Zhan, C. (2017). Institutions, social norms, and educational attainment. Education Economics, 25(1), 22-44.

Zhang, J. (2018). The impact of 9-year compulsory education: quasi-experimental evidence from Taiwan. Applied Economics, 50(45), 4866-4878.

Zhao, M., \& Glewwe, P. (2010). What determines basic school attainment in developing countries? Evidence from rural China. Economics of Education Review, 29(3), 451460.

Zuilkowski, S. S., Jukes, M. C. H., \& Dubeck, M. M. (2016). "I failed, no matter how hard I tried": A mixed-methods study of the role of achievement in primary school dropout in rural Kenya. International Journal of Educational Development, 50, 100-107. 


\section{Impact section}

Intergenerational education persistence in low income and lower-middle-income countries exhibited a declining trend following their independence, in particularly, after the 1960s. The mobility in education was made possible due to the huge changes in systems of education and investment in the accumulation of human capital. However, the intergenerational transmission of education remains one of the most debated topics in the literature given that the education of parents remains a strong determinant in the education of children in developing countries, coupled with the persistent school dropout. Some countries succeed in overcoming the poor educational attainment among children, while other countries still lag behind in doing so. This observed difference may arise from institutional barriers and system characteristics that are not easy to alter by the individuals themselves but calls for policy action.

The conception of this thesis originates from the growing need for policies that are more redistributive and targeted. Also, educational success of students being affected by their early life journey highlights the need for exploring household environments that potentially determines children's educational success. We therefore look at institutional factors and the deprivations faced by households. In this light, we first explore the causes of school dropout in developing countries to explore the most common factors. The factors found include lack of income, parents' education and employment status, living in a single-parent household, being an illegitimate child, age, region of residence and school performance.

We then investigate institutional characteristics and their association with intergenerational correlation of education to observe factors that can inform policy concerning measures aimed at educational attainment improvement. The sample includes 48 developing countries. This finding confirms the strong link between institutional factors and intergenerational correlation of education. Gross domestic product, female-male labour force participation, pupil-teacher ratio, primary school duration, compulsory years of education, and extent of voice and accountability are the factors that associate with intergenerational transmission of education. In addition, we empirically investigate a situation of one of these factors in one country, namely, the compulsory education law modification in Senegal in 2004. This law increased compulsory education from 6 years to 10 years. The analysis looks at the impact of the law on compulsory grades completion, as well as on post-compulsory secondary grades completion. The results show that the compulsory education policy significantly increased compulsory 
Impact section

education completion, and improved post-compulsory grades completion. However, completion of the last post-compulsory grade in high school to obtain a secondary certificate is not affected.

Regarding household environment, we look at household deprivations for 27 developing countries. These deprivations include, child mortality, school attendance, cooking fuel, sanitation, drinking water, electricity, housing, and assets. An index is created with the deprivations. Our findings show a strong relationship between being deprived and the intergenerational correlation of education. This relationship is a little stronger for women as compared to the men.

A policy implication from this thesis is that in an effort to reduce school dropout and consequently to reduce the intergenerational correlation of education, institutional characteristics and households' circumstances should be taken into consideration. We therefore propose guidelines for progress towards improving the degree of independence of a child's educational attainment to his/her parent's educational level, and improving the pathway enabling children to exceed the educational level of their most educated parent in low income and lower-middle-income countries. Efforts should be made to ameliorate economic development, such as promoting more industrialization and training programs, and trade exchange in favour of technology import. Industrial improvement requires labour and education, which may in turn create more opportunities and a more higher education-oriented generation. An increase in GDP is therefore a vital input in improving on outcomes like employment, decent work and economic growth, and empowering educational decisions, investment, and actual mobility. In addition, education provision and the quality of education such as more teachers to student ratio, and many years of compulsory education so students spend more time at school obligatorily, contribute to increasing intergenerational mobility in education.

Access to basic education by households is also vital, as cost to school still act as hindrances to higher education. Despite the global acceptance of a free basic education, some basic learning institutions in low income and lower-middle-income countries still operate on fee collection. The governance structure such as voice and accountability should carefully be observed. In other words, the motivation to go to higher education also relates to how governance is handled in terms of freedom and rights to citizens to practice association, expression, and voting. In addition, attention should be paid to household inconvenient living 
conditions that may affect school attendance and retention such as child mortality, school attendance, cooking fuel, housing, drinking water, electricity, sanitation, and assets. Besides enabling the availability of basic services, policies could motivate and encourage students for higher education earlier.

It is our recommendation that the analysis of intergenerational correlation of education in low income and lower-middle-income countries should use a multidimensional perspective, and importantly, that these countries also place strategic focus on the SDGs. Because focusing on one factor in isolation would not provide a richer picture of improving educational mobility but a combination of multiple factors as complements to one another is relevant to public policy. 


\section{Acknowledgements}

I would like to give heartfelt gratitude to all the persons who have contributed in one way or the other during this academic journey. It has been an overwhelmingly beneficial and productive couple of years' experience of academic development and knowledge accumulation.

The assistance of informed, inspired, motivated and highly experienced people to walk us through is very essential, if we must succeed. I would like to thank and appreciate my supervisors who have made it possible for me to have this much needed academic coaching. Thank you Prof. Dr. Wim Groot for the great mentoring and direction. Your patient endurance has also been a driving force and motivation to keep pressing on even when discouragement comes. Thank you Dr. Sofie Cabus for your coaching. It was a privilege to learn from you considering the wonderful experience and knowledge I gained in the course of my research. My gratitude also extends to others who contributed their academic knowledge and assistance, namely; Prof. Dr. Kristof De Witte, and Dr. Iryna Rud.

My gratitude to the assessment committee for devoting part of their valuable time to assess and validate my thesis. Thank you Prof. Dr. Rolf van der Velden, Prof. Dr. Louis Volante, Prof. Dr. Carla Haelermans, Prof. Dr. Harry Patrinos, and Prof. Dr. Pauline Rose.

I would like to thank all my family members, both close and extended, who have supported me in one way or the other through this journey. Special thanks to my mum Alice Bessem; my brothers and sister Dr. Remi Momo, Webber Atem, Valerie Momo, and Charlotte Ndip.

Besides loved ones, friends are indispensable in any environment. At each stage of the academic cycle, we meet new friends and colleagues with whom we spend quality time, share concerns, ideas, worries, and also learn in areas of weakness. Am grateful for all the friends that have been a part of this PhD journey. Thank you all Hiwot Mesfin, Racky Balde, Davina Osei, Victor Osei, Tatenda Zinyemba, Solomon Owusu, Gideon Ndubuisi, Godsway Tetteh, Ornalia Osei, Rumbidzai Ndoro, Giulia Rossello, Silas Nsanzumuhire, Robert Djidonou, Emmanuel Mensah, Michelle Gonzalez, and Chuks Otioma. 
Acknowledgements

I am very much grateful to God Almighty for the successful completion of this dissertation. A steadfast look to the crucified One does not look in vain. Thank You, Lord, for the sufficient grace. 


\begin{abstract}
About the Author
Michelle Momo was born in a city called Mamfe, in Cameroon. She holds a bachelor's degree in Monetary and Financial Economics from the University of Yaounde II in Cameroon. She obtained a Master's degree in Business and Management at the Liverpool Hope University in the United Kingdom, and a Master's degree in Business Administration at the University of Chester in the United Kingdom. During her time as a Master's student, she worked for international corporations and organizations such as TESCO and IATEFL (International Association of Teachers of English as a Foreign Language).

Her research interest lies in the inequality in educational attainment that transcends generations in the countries with low income or lower-middle-income. Her $\mathrm{PhD}$ research includes the relationship of the characteristics of institutions and household deprivations with the existence of educational attainment. Her research has been published in the Review of Education Journal, the International Journal of Educational Development, the International Journal of Educational Research, and the International Journal of Educational Research Open.
\end{abstract}




\section{Publications}

1. Momo, M. S. M., Cabus, S. J., \& Groot, W. (2021). Household deprivation and the intergenerational correlation of education: an analysis of developing countries. International Journal of Educational Research, 109, 1-17. https://doi.org/10.1016/j.ijer.2021.101797

2. Momo, M. S. M., Cabus, S. J., \& Groot, W. (2021). Evidence on the marginal impact of a compulsory secondary education reform in Senegal on years of education and changes in high school decisions. International Journal of Educational Research Open, 2, 1-10. https://doi.org/10.1016/j.ijedro.2021.100058

3. Momo, M. S. M., Rud, I., Cabus, S. J., De Witte, K., \& Groot, W. (2019). The relationship between contextual characteristics and the intergenerational correlation of education in developing countries. International Journal of Educational Development, 66, 173-183. https://doi.org/10.1016/j.ijedudev.2018.10.002

4. Momo, M. S. M., Cabus, S. J., De Witte, K., \& Groot, W. (2018). A systematic review of the literature on the causes of early school leaving in Africa and Asia. Review of Education, 7(3), 496-522. https://doi.org/10.1002/rev3.3134

5. Momo, M. S. M., Cabus, S. J., De Witte, K., \& Groot, W. (2018). Context and Implications Document for: A systematic review of the literature on the causes of early school leaving in Africa and Asia. Review of Education, 7(3), 523-524. https://doi.org/10.1002/rev3.3135 


\section{UNU-MERIT/MGSoG Dissertation Series}

2021

\section{Michelle S. M. Momo}

A Multidimensional Perspective on

Education in Developing Countries

UNU-MERIT/MGSoG Dissertation Series № 266

\section{Gideon Onyewuchi Ndubuisi}

Essays on International Trade: The Role of Institutions and Imported Intermediate Inputs UNU-MERIT/MGSoG Dissertation Series № 265

\section{Solomon Owusu}

Powering Structural Transformation and Economic Development in Africa: The Role of Services, Manufacturing and Global Value Chains

UNU-MERIT/MGSoG Dissertation Series № 264

\section{Halefom Yigzaw Nigus}

Markets and Human Behavior: Evidence from Artefactual Field Experiments

UNU-MERIT/MGSoG Dissertation Series № 263

\section{Iulia Falcan}

Transition towards a renewable European electricity system

What are the implications for the power technology mix, pan-European power trade and the electricity market?

UNU-MERIT/MGSoG Dissertation Series № 262

\section{Anne-Lore Fraikin}

The effect of financial retirement incentives originating from the social security system on the retirement behavior of older Belgian workers

UNU-MERIT/MGSoG Dissertation Series № 261

\section{Bart Kleine Deters}

A Quantitative approach to the right to education: Concept, Measurement, and Effects UNU-MERIT/MGSoG Dissertation Series № 260

\section{Eliana Rubiano-Matulevich}

Essays on Conflict-Induced Displacement and Gender in Colombia

UNU-MERIT/MGSoG Dissertation Series № 259

\section{Njagi Purity Muthoni}

Financial Risk, Vulnerability and Equity of Access to Healthcare Services in Kenya UNU-MERIT/MGSoG Dissertation Series № 258

\section{María José Espinosa-Romero}

The Shadow of Hierarchy in Marine Fisheries Governance

UNU-MERIT/MGSoG Dissertation Series № 257

\section{Lorena Rivera León}

Unveiling the Determinants of Scientific Productivity in Middle-Income Countries: An Economics of Science Perspective UNU-MERIT/MGSoG Dissertation Series № 256

\section{Racky Balde}

Essays on Informal versus formal Economy Choices

UNU-MERIT/MGSoG Dissertation Series № 255

\section{Caio Torres Mazzi}

Learning, Capabilities and Governance in Global Value Chains

UNU-MERIT/MGSoG Dissertation Series № 254 


\section{Giulia Rossello}

Social Transformations and Labour Market

Entry

An Investigation into University Systems in

Emerging Economies

UNU-MERIT/MGSoG Dissertation Series

№ 253

2020

\section{Rose Camille Vincent}

Essays in Public Economics

Multi-Layer Tax Structure and Implications UNU-MERIT/MGSoG Dissertation Series № 252

\section{Emmanuel Mensah}

Structural change in developing countries: patterns, causes, and consequences

UNU-MERIT/MGSoG Dissertation Series № 251

\section{Ornsaran Manuamorn}

Governance of International Adaptation Finance for local Climate Change Adaptation: An Analysis of Adaptation Fund Projects UNU-MERIT/MGSoG Dissertation Series № 250

\section{Gillian McFarland}

Doing policy in Further Education

An exploration of the enactment of the GCSE resits policy in Further Education colleges in England

UNU-MERIT/MGSoG Dissertation Series № 249

\section{Omar Rodriguez Torres}

Essays on Entrepreneurship in Colombia UNU-MERIT/MGSoG Dissertation Series № 248

\section{Elaine Lebon-McGregor}

International Organizations and Global Migration Governance

UNU-MERIT/MGSoG Dissertation Series № 247

\section{Janyl Moldalieva}

Playing the 'Game'of Transparency and Accountability in Kyrgyzstan's Resource Governance

UNU-MERIT/MGSoG Dissertation Series № 246

\section{Kaleab Kebede Haile}

Essays on Rural Household Decision-Making under Climate Risk

UNU-MERIT/MGSoG Dissertation Series № 245

\section{Nora Jasmin Ragab}

Diaspora Mobilisation in a Conflict Setting UNU-MERIT/MGSoG Dissertation Series № 244

\section{Mary Kaltenberg}

From Micro to Macro: Essays on

Technological Change and Income Divergence UNU-MERIT/MGSoG Dissertation Series № 243

\section{Ayla E. Bonfiglio}

Student migrant, refugee or both?

Exploring Refugee Agency and Mobility through Tertiary Education in Kenya, South Africa and Uganda UNU-MERIT/MGSoG Dissertation Series № 242

\section{Danilo Sartorello Spinola}

Cycles, Economic Structures and External Constraints.

A Structuralist study on the causes of economic volatility in Latin America UNU-MERIT/MGSoG Dissertation Series № 241 
2019

\section{Jemal Adem}

Livelihood Vulnerability to Shocks, Behaviour and Investment in Education: Essays in

Behavioural Development Economics

UNU-MERIT/MGSoG Dissertation Series № 240

\section{Davina Osei}

Corrupt or corrupted networks?

An empirical enquiry

UNU-MERIT/MGSoG Dissertation Series № 239

\section{Patima Chongcharoentanawat}

Beyond Static Inequality

Public policies and economic mobility in

Thailand

UNU-MERIT/MGSoG Dissertation Series № 238

\section{Charlotte Guillard}

Rethinking economic growth

and structural change.

The role of boundaries and linkages between industries

UNU-MERIT/MGSoG Dissertation Series № 237

\section{Nicolas Echarti}

Employment Effects or Vocational

Rehabilitation in Germany:

A quantitative analysis

UNU-MERIT/MGSoG Dissertation Series № 236

\section{Shellie E. Solomon}

Neighborhoods Matter:

Crime, collective efficacy and foreclosures in Miami

UNU-MERIT/MGSoG Dissertation Series № 235

\section{Michał Kazimierczak}

Regional Innovation and Entrepreneurship Patents, trade marks, entry and entrants' growth in European manufacturing industries UNU-MERIT/MGSoG Dissertation Series № 234

\section{Fernanda Soares}

The Influence of Within School and Across Schools' Collaborative Practices on Student Learning and Teaching Outcomes in West Africa

UNU-MERIT/MGSoG Dissertation Series № 233

\section{Mira Bierbaum}

New Mindsets to Innovate Activation UNU-MERIT/MGSoG Dissertation Series № 232

\section{Norman Dytianquin}

Technology in the Asian Miracle and Crisis Debates: Applications of and Insights from the Field of Influence Approach to Input-Output Analysis

UNU-MERIT/MGSoG Dissertation Series № 231

\section{Nga Le}

The implications of health insurance for the labour market and patient satisfaction with medical care in Vietnam

UNU-MERIT/MGSoG Dissertation Series № 230

\section{Jinhyuck Park}

Intellectual Property right protection and cross-border RED investments by multinational enterprises UNU-MERIT/MGSoG Dissertation Series № 229 


\section{Richard de Groot}

Show me the Money:

Essays on the Impact of Cash Transfers on

Child Nutrition and the Role of Intra-

Household Dynamics

UNU-MERIT/MGSoG Dissertation Series

№ 228

\section{Catie Lott}

Diamonds are a Women's Best Friend

Broadening Measures of Women's Access to

Formal Political Decision-Making

UNU-MERIT/MGSoG Dissertation Series № 227

\section{Ana Cristina Calderon Ramirez}

Public Management Reforms

Three stories about public procurement agencification in Latin America

UNU-MERIT/MGSoG Dissertation Series № 226

\section{Camilo Nicanor Carrillo Purin}

Teachers' in-service training and student achievement:

The effect of in-service training of Peruvian teachers on student achievement

UNU-MERIT/MGSoG Dissertation Series № 225

\section{Hugo Confraria}

Developing scientific capacity in the Global South

UNU-MERIT/MGSoG Dissertation

Series № 224

\section{Alison Cathles}

Educational Pathways and Skills:

Past, Present, and Future

UNU-MERIT/MGSoG Dissertation Series № 223

\section{Ibrahima Sory Kaba}

Aggregate Fluctuations and Development:

Essays on Macroeconomic Volatility and

Economic Growth

UNU-MERIT/MGSoG Dissertation Series № 222

\section{Charlotte Keijser}

Firm Participation, Learning and Innovation in Heterogenous Value Chains of IT-enabled Services

UNU-MERIT/MGSoG Dissertation Series № 221

\section{Salih Çevikarslan}

Innovation Strategies and Their Implications for Technological Change and Market Outcomes:

An Evolutionary Multi-Agent Based Modelling Approach

UNU-MERIT/MGSoG Dissertation Series № 220

\section{Wondimagegn Mesfin Tesfaye}

Essays on the Impacts of Climate-Smart

Agricultural Innovations on Household

Welfare

UNU-MERIT/MGSoG Dissertation Series № 219

\section{Tatevik Poghosyan}

How Board Networks Affect Firm

Performance and Innovation Incentives in Transition Economies: The Case of Armenia UNU-MERIT/MGSoG Dissertation Series № 218

\section{Arip Muttaqien}

Essays on Inequality and Polarization: Empirical Studies in Developing Asia UNU-MERIT/MGSoG Dissertation Series № 217 
2018

\section{Katrin Marchand}

Essays on Forced Migration and Labour

Market Participation in Developing Countries

UNU-MERIT/MGSoG Dissertation Series № 216

\section{Ortrun Merkle}

The Myth of Gender Neutral Power:

Corruption and Gender Norms

UNU-MERIT/MGSoG Dissertation Series

№ 215

\section{Biljana Meshkovska}

Life after Trafficking:

(re)integration processes of women that have

been trafficked for the purpose of sexual

exploitation in Europe

UNU-MERIT/MGSoG Dissertation Series

№ 214

\section{Vincenzo Vinci}

The Relevance of Institutions and People's

Preferences for Social Protection

UNU-MERIT/MGSoG Dissertation Series

№ 213

\section{Silke Heuser}

The Effectiveness of Environmental Policies on Reducing Deforestation in the Brazilian

Amazon

UNU-MERIT/MGSoG Dissertation Series № 212

\section{Jennifer Waidler}

Social Assistance and Remittances and Their

Role in the Fight Against Poverty

UNU-MERIT/MGSoG Dissertation Series № 211

\section{Choolwe Muzyamba}

The role of community mobilization in the promotion of maternal health of women living with HIV in Zambia

UNU-MERIT/MGSoG Dissertation Series № 210
Juan Carlos A. Castillo Sánchez

Assessing the Role of the Export Sector in

Mexican Economic Development,1965-2014

UNU-MERIT/MGSoG Dissertation

Series № 209

\section{Tareq Abuelhaj}

Food Security Policy Impact Analysis: The

Econometrics of Cash and Food Assistance

Cost Effectiveness

UNU-MERIT/MGSoG Dissertation

Series № 208

Marta Férnandez de Arroyabe Arranz

Essays on MEAS and Innovation

UNU-MERIT/MGSoG Dissertation

Series № 207

\section{Clotilde Mahé}

Essays on Migration and Occupational Choice UNU-MERIT/MGSoG Dissertation

Series № 206

\section{Simone Sasso}

Talent on the move. Essays on Human

Capital, Graduate Mobility and Economic

Development

UNU-MERIT/MGSoG Dissertation

Series № 205

\section{Khaled Walid Rajab}

Strategic Planning under Fragility

UNU-MERIT/MGSoG Dissertation

Series № 204

\section{Mutinta Hambayi Nseluke}

A Tall Order: Improving Child Linear Growth UNU-MERIT/MGSoG Dissertation

Series № 203

\section{Elvis Korku Avenyo}

Innovations and Firm Performance in sub-Saharan Africa: Empirical Analyses UNU-MERIT/MGSoG Dissertation

Series № 202 


\section{Ni Zhen}

Employment Dynamics, Firm Performance and Innovation Persistence in the Context of Differentiated Innovation Types: Evidence from Luxembourg

UNU-MERIT/MGSoG Dissertation

Series № 201

\section{Caroline Wehner}

Too Scared to Achieve: The Relation Between Neuroticism, Conscientiousness and Socioeconomic Outcomes UNU-MERIT/MGSoG Dissertation Series № 200

\section{Stefania Innocenti}

On Institutional Persistence

UNU-MERIT/MGSoG Dissertation Series № 199

\section{Hassen Abda Wako}

Economic Globalization, Institutions and Development: Essays on Aid, Foreign Direct Investment and Trade UNU-MERIT/MGSoG Dissertation Series № 198

2017

\section{Hans-Erik Edsand}

Winds of Change

UNU-MERIT/MGSoG Dissertation Series № 197

\section{Ana Patricia Silva Vara}

Redressing the Gender Gap

UNU-MERIT/MGSoG Dissertation Series № 196

\section{Andrés Iván Mideros Mora}

Essays on the Economic Effects of Noncontributory Social Protection UNU-MERIT/MGSoG Dissertation Series № 195

\section{Tobias Broich}

New Actors in the Global Economy

UNU-MERIT/MGSoG Dissertation Series № 194

\section{Bernard Nikaj}

From No-government to E-government

UNU-MERIT/MGSoG Dissertation Series № 193

\section{Ali Safarnejad}

Prioritizing the HIV Response

UNU-MERIT/MGSoG Dissertation Series № 192

\section{Clovis Freire}

Diversification and Structural Economic

Dynamics

UNU-MERIT/MGSoG Dissertation Series № 191

\section{Michael Verba}

Innovation and Knowledge Dynamics: Essays on the Knowledge Economy

UNU-MERIT/MGSoG Dissertation Series № 190

\section{Pui Hang Wong}

The Hearts and Minds in Conflict and Peace: The Economics of Counterinsurgency and the Psychology of Reconstruction

UNU-MERIT/MGSoG Dissertation Series № 189

\section{Brenda Yamba}

Schooling Despite All Odds: Evidence from Lesotho on Female Child Carers who Stayed in School

UNU-MERIT/MGSoG Dissertation Series № 188

\section{Sheng Zhong}

Moving towards An Energy Efficient Future: Essays on Energy Efficiency, Technology and Development

UNU-MERIT/MGSoG Dissertation Series № 187 


\section{Julieta Marotta}

Access to Justice and Legal Empowerment of Victims of Domestic Violence through Legal

Organizations in the City of Buenos Aires: A Qualitative Empirical Legal Study

UNU-MERIT/MGSoG Dissertation Series, № 186

\section{Andrea Franco-Correa}

On the Measurement of Multidimensional

Poverty as a Policy Tool: Empirical

Applications to Chile, Colombia, Ecuador and

Peru

UNU-MERIT/MGSoG Dissertation Series, № 185

2016

Yesuf Awel

Insurance for Growth: Empirical Essays on Insurance Demand and Impacts in Africa UNU-MERIT Dissertation Series, № 108

\section{Tigist Mekonnen Melesse}

Grow More Food using Fewer Resources: Agricultural Technology Adoption and Innovation Practices for Inclusive and Sustainable Development

UNU-MERIT Dissertation Series, № 107

\section{Eleni Yitbarek}

Getting Ahead or left Behind? Essays on Poverty Dynamics and Social Mobility in Africa

UNU-MERIT Dissertation Series, № 106

\section{Thuy Dieu Nguyen}

Firm-Level Theory and Evidence of

Corruption

UNU-MERIT Dissertation Series, № 105

\section{Raquel Tsukada Lehman}

Essays on Household Production with LaborSaving Technology

UNU-MERIT Dissertation Series, № 104

\section{Eva Barteková}

Multi-Problem Challenges for a Renewable Future: Empirical Studies on Competitive Disadvantages from Electricity Price

Differentials and Mineral Supply Risk in an Open Economy

UNU-MERIT Dissertation Series, № 103

\section{Jocelyn Olivari}

Entrepreneurial Traits and Innovation:

Evidence from Chile

UNU-MERIT Dissertation Series, № 102

\section{Muhammad Shafique}

Essays on the role of knowledge, $R \mathcal{E} D$, and Technology-based Firms in the Evolution of Socio-techno-economic System

UNU-MERIT Dissertation Series, № 101

Serdar Türkeli

Governance of Innovation Policy: Empirical Studies on Applied Political Economy by Multi-Methods Analysis

UNU-MERIT Dissertation Series, № 100

\section{Ayokunu Adedokun}

Pathways to Sustainable Peace building in Divided Societies: Lessons and Experiences from Mozambique MGSoG Dissertation Series, № 75

\section{Luiz Rothier Bautzer}

Organizing Concurrent Engineering through ICT Platforms Blueprinting Product Lifecycle Management Platforms across Disciplinary Agencies

MGSoG Dissertation Series, № 74

\section{Natalia Popova}

Migration in the Periphery of the European Union: Determinants of Successful and Sustainable Labour Market Integration of Return Migrants in Albania, Egypt, Moldova and Tunisia

MGSoG Dissertations Series, № 73 
Richard A. Martina

Uncertainty and Resource Constraint in the Small Island Developing States:

Essays in Entrepreneurial Cognition

MGSoG Dissertations Series, № 72

\section{Cécile Cherrier}

The Expansion of Basic Social Protection in Low-income Countries:

An Analysis of Foreign Aid Actors' Role in the Emergence of Social Transfers in SubSaharan Africa

MGSoG Dissertations series, № 71

\section{Paul Caldron}

The Tacit Bargain in Short-Term Medical Missions: Why U.S. physicians go and what it costs

MGSoG Dissertation Series, № 70

\section{Mahmut Kobal}

Customs E Excellence: A Comparative Approach on Administrative and Regulatory Compliance Perspectives of the EU-Turkey Customs Union

MGSoG Dissertation Series, № 69

\section{Craig Loschmann}

Essays on Conflict-related Migration and Development in the Case of Afghanistan MGSoG Dissertations Series, № 68

\section{Andrea Milan}

Rural Livelihoods, Location and Vulnerable Environments: Approaches to Migration in Mountain areas of Latin America MGSoG Dissertation Series, № 67

\section{Farida Lada}

On Guarding the Welfare of Clinical Trial Subjects While Promoting Novel Drug Innovation

A Game Theoretical Approach MGSoG Dissertation Series, № 66
2015

Hibret Belete Maemir

Dissecting Aggregate Productivity:

International Integration and Growth with Heterogeneous Firms

UNU-MERIT Dissertation Series, № 96

\section{Giorgio Triulzi}

Looking for the Right Path: Technology

Dynamics, Inventive Strategies and Catchingup in the Semiconductor Industry

UNU-MERIT Dissertation Series, № 95

Abdul Baseer Qazi

Knowledge flows and networks in the ICT sector: The case of Pakistan

UNU-MERIT Dissertation Series, № 94

\section{Ajay Thutupalli}

Technology Paradigm Shifts in Agriculture:

Drivers of Sustainability and Catch up

UNU-MERIT Dissertation Series, № 93

\section{Eduardo Urias}

Improving access to HIVIAIDS treatment in Brazil: When are Compulsory Licenses effective in Price Negotiations?

UNU-MERIT Dissertation Series, № 92

\section{Francesca Guadagno}

Why have so few Countries Industrialised? UNU-MERIT Dissertation Series, № 91

\section{Daniel Opolot}

The Evolution of Beliefs and Strategic

Behaviour

UNU-MERIT Dissertation Series, № 90
Alejandro Lavopa
Structural Transformation and Economic Development: Can Development Traps be Avoided
UNU-MERIT Dissertation Series, № 89 


\section{Jinjin Zhao}

Urban water management reform: The Case of China

UNU-MERIT Dissertation Series, № 88

\section{Simona Vezzoli}

Borders, Independence and Post-colonial Ties: the Role of the State in Caribbean Migration MGSoG Dissertation Series, № 65

\section{Silvia Consuelo Gómez Soler}

Civil Conflict and Education: How Does Exposure to Civil Conflict Affect Human Capital Accumulation? Evidence from Standardized Exit Exams in Colombia MGSoG Dissertation Series, № 64

\section{Paula Nagler}

Occupational Choice in the Developing World MGSoG Dissertation Series, № 63

\section{Jasmin Kientzel}

Determinants of Professional Commitment to Environmental Sustainability

MGSoG Dissertation Series, № 62

\section{Mehmet Güney Celbiş}

Regional Policies: Convergence, Trade, and the Allocation of Public Capital

MGSoG Dissertation Series, № 61

\section{Florian Henning}

Living Up to Standard: Interoperability Governance and Standards Adoption in Government Information Networks MGSoG Dissertation Series, № 60

\section{Niels P. Groen}

The Never-Ending Project

Understanding E-Government Project

Escalation

MGSoG Dissertation Series, № 59

\section{Derek Copp}

Teacher-Based Reactivity to Provincial Largescale Assessment in Canada

MGSoG Dissertation Series, № 58

\section{Michaella Vanore}

Family-Member Migration and the Psychosocial Health Outcomes of Children in Moldova and Georgia

MGSoG Dissertation Series, № 57

\section{Sonja Fransen}

The Economic and Social Effects of Remittances and Return Migration in Conflict-Affected Areas: The Case of Burundi MGSoG Dissertation Series, № 56

\section{Ibrahim Khalil Conteh}

The Impact of Floods on Primary School

Education in Zambia

MGSoG Dissertation Series, № 55

\section{Richard Bluhm}

Growth Dynamics and Development Essays in Applied Econometrics and Political Economy

MGSoG Dissertation Series, № 54

\section{Nevena P. Zhelyazkova}

Work-Family Reconciliation and Use of Parental Leave in Luxembourg: Empirical Analysis of Administrative Records MGSoG Dissertation Series, № 53

2014

\section{Dirk Crass}

The Impact of Brands on Innovation and Firm Performance: Empirical Evidence from Germany

UNU-MERIT Dissertation Series, № 87

\section{Samyukta Bhupatiraju}

The Geographic Dimensions of Growth and Development

UNU-MERIT Dissertation Series, № 86

\section{François Lafond}

The Evolution of Knowledge Systems

UNU-MERIT Dissertation Series, № 85 


\section{Annalisa Primi}

Promoting Innovation in Latin America:

What Countries Have Learned (and What

They Have Not) in Designing and

Implementing Innovation and Intellectual

Property Policies

UNU-MERIT Dissertation Series, № 84

\section{Fatoumata Lamarana Diallo}

Evaluation of Meal and Deworming Programs for Primary Schools in Rural Senegal

UNU-MERIT Dissertation Series, № 83

\section{Sachin Kumar Badkas}

Metachoice and Metadata: Innovating with

Environmental Policy Analysis in Europe

MGSoG Dissertation Series, № 52

\section{Irina S. Burlacu}

An Evaluation of Tax-Benefit Systems Impact on the Welfare of Frontier Worker:

The Case of Luxembourg and Belgium

MGSoG Dissertation Series, № 51

\section{Özge Bilgili}

Simultaneity in Transnational Migration

Research: Links Between Migrants' Host and Home Country Orientation

MGSoG Dissertation Series, № 50

\section{Yulia Privalova Krieger}

Reshaping the Big Agenda: Transnational Politics and Domestic Resistance Financial crisis and social protection reform in Bosnia and Herzegovina

MGSoG Dissertation Series, № 49

\section{Marieke van Houte}

Moving Back or Moving Forward? Return migration after Conflict

MGSoG Dissertation Series, № 48

\section{Oxana Slobozhan}

Global Governance in the Management of

Natural Resources: The Case of the Extractive

Industries Transparency Initiative (EITI)

MGSoG Dissertation Series, № 47

\section{Luis Bernardo Mejia Guinand}

The Changing Role of the Central Planning

Offices in Latin America: A Comparative

Historical Analysis Perspective (1950-2013)

MGSoG Dissertation Series, № 46

\section{Cheng Boon Ong}

Ethnic Segregation in Housing, Schools and

Neighbourhoods in the Netherlands

MGSoG Dissertation Series, № 45

\section{Luciana V. Cingolani}

Bureaucracies for Development: Oxymoron or Reality? Studies on State Capacity in

Challenging Governance Contexts

MGSoG Dissertation Series, № 44

\section{Carlos Cadena Gaitán}

Green Politics in Latin American Cities -

Sustainable Transport Agendas

MGSoG Dissertation Series, № 43

\section{Katie Kuschminder}

Female Return Migration and Reintegration Strategies in Ethiopia

MGSoG Dissertation Series, № 42

\section{Metka Hercog}

Highly-Skilled Migration and New

Destination Countries

MGSoG Dissertation Series, № 41

\section{Margaret Agaba Rugadya}

Can Remittances Influence the Tenure and

Quality of Housing in Uganda?

MGSoG Dissertation Series, № 40

\section{Ilire Agimi}

New Governance Under Limited Statehood:

The Case of Local Government Reform in

Kosovo

MGSoG Dissertation Series, № 39 


\section{Laura Torvinen}

Assessing Governance Assessments: The Case of Mozambique: Governance Assessments in the Context of Aid Effectiveness Discourse MGSoG Dissertation Series, № 36

\section{Biniam Egu Bedasso}

Institutional Change in the Long Shadow of Elite: Essays on Institutions, Human Capital and Ethnicity in Developing Countries MGSoG Dissertation Series, № 35

\section{Sepideh Yousefzadeh Faal Deghati} Childhoods Embargoed: Constructing and Reconstructing Multidimensional Child Poverty in Iran 1984-2009

MGSoG Dissertation Series, № 34

\section{Robert Bauchmüller}

Investing in Early Childhood Care and Education: The Impact of Quality on Inequality

MGSoG Dissertation Series, № 33

\section{Martin Rehm}

Unified Yet Separated: Empirical Study on the Impact of Hierarchical Positions within Communities of Learning

MGSoG Dissertation Series, № 32

2012

\section{Abdul Waheed}

Innovation Determinants and Innovation as a

Determinant: Evidence from Developing

Countries

UNU-MERIT Dissertation Series, № 77

Bilal Mirza

Energy Poverty and Rural Energy Markets in Pakistan

UNU-MERIT Dissertation Series, № 76

\section{Benjamin Engelstätter}

Enterprise Software and Video Games: An

Empirical Analysis

UNU-MERIT Dissertation Series, № 75 
Fulvia Farinelli

Natural Resources, Innovation and Export

Growth: The Wine Industry in Chili and

Argentina

UNU-MERIT Dissertation Series

\section{Rodolfo Lauterbach}

Innovation in Manufacturing: From Product Variety and Labor Productivity Growth to Economic Development in Chile

UNU-MERIT Dissertation Series

\section{Kirsten Wiebe}

Quantitative Assessment of Sustainable

Development and Growth in Sub-Saharan

Africa

UNU-MERIT Dissertation Series, № 74

\section{Julio Miguel Rosa}

Organizational Strategies, Firms'

Performance and Spatial Spillovers: The

Canadian Case in Research and Development.

UNU-MERIT Dissertation Series, № 73

\section{Johannes Wilhelmus Marie Boels}

Joseph Schumpeter, Honderd Jaar

Economische Ontwikkeling: Een Historisch-

theoretische Beschouwing.

UNU-MERIT Dissertation Series

\section{Dorcas Mbuvi}

Utility Reforms and Performance of the Urban Water Sector in Africa

MGSoG Dissertation Series, № 31

\section{Lina Salanauskaite}

Distributional Impacts of Public Policies:

Essays in Ex-Ante and Ex-Post Evaluation

MGSoG Dissertation Series, № 30

\section{Esther Schüring}

To Condition or not - is that the Question?

An Analysis of the Effectiveness of Ex-Ante and Ex-Post Conditionality in Social Cash

Transfer Programs

MGSoG Dissertation Series, № 29
Joe Abah

Strong Organisations in Weak States:

Atypical Public Sector Performance in

Dysfunctional Environments

MGSoG Dissertation Series, № 28

\section{Zina Samih Nimeh}

Social Citizenship Rights: Inequality and

Exclusion

MGSoG Dissertation Series, № 27

2011

\section{Daniel Vertesy}

Interrupted Innovation: Emerging Economies in the Structure of the Global Aerospace

Industry

UNU-MERIT Dissertation Series, № 72

\section{Tina Saebi}

Successfully Managing Alliance Portfolios:

An Alliance Capability View

UNU-MERIT Dissertation Series, № 71

\section{Nora Engel}

Tuberculosis in India: A Case of Innovation and Control

UNU-MERIT/MGSoG Dissertation Series, № 70

\section{Evans Mupela}

Connectivity and growth in Sub-Saharan

Africa: The Role of Communication Satellites

UNU-MERIT Dissertation Series, № 69

\section{Nantawan Kwanjai}

Cross Cultural Intelligence amid Intricate

Cultural Webs: A Tale of the UnDutchables in the Land of 1002 Smiles

UNU-MERIT Dissertation Series, № 68

\section{Lina Sonne}

Innovation in Finance to Finance Innovation:

Supporting Pro-poor Entrepreneur-based

Innovation

UNU-MERIT Dissertation Series, № 67 


\section{Lenka Eisenhamerová}

Legitimacy of 'Humanitarian Military

Intervention'

MGSoG Dissertation Series, № 26

\section{Sonila Tomini}

Informal Payments for Health Care Services in Albania

MGSoG Dissertation Series, № 25

\section{Jinjing Li}

Dynamic Microsimulation in Public Policy

Evaluation

MGSoG Dissertation Series, № 24

\section{Aziz Atamanov}

Rural Nonfarm Employment and International Migration as Alternatives to Agricultural Employment: The Case of Kyrgyzstan

MGSoG Dissertation Series, № 23

\section{Frieda Vandeninden}

Poverty Alleviation: Aid and Social Pensions

MGSoG Dissertation Series, № 22

\section{Juliana Nyasha Tirivayi}

The Welfare Effects of Integrating AIDS

Treatment with Food Transfers: Evidence from Zambia

MGSoG Dissertation Series, № 21

\section{Agnieska Ewa Sowa}

Who's Left Behind? Social Dimensions of Health Transition and Utilization of Medical Care in Poland

MGSoG Dissertation Series, № 20

\section{Emmanaouil Sfakianakis}

The Role of Private Actors in the Provision of Public Goods with Applications to Infrastructure and Financial Stability MGSoG Dissertation Series, № 19

\section{Siu Hing Lo}

White Collars Green Sleeves: An Interorganizational Comparison of Determinants of Energy-Related Behaviors among Office Workers

MGSoG Dissertation Series, № 18

\section{Treena $\mathbf{W u}$}

Constraints to Human Capital Investment in Developing Countries: Using the Asian Financial Crisis in Indonesia as a Natural Experiment

MGSoG Dissertation Series, № 17

\section{Henry Espinoza Peña}

Impact Evaluation of a Job-Training

Programme for Disadvantaged Youths:

The Case of Projoven

MGSoG Dissertation Series, № 16

2010

\section{Fernando Santiago}

Human Resources Management Practices and Learning for Innovation in Developing Countries: Pharmaceutical Firms in Mexico UNU-MERIT Dissertation Series, № 66

\section{Zakaria Babutsidze}

Essays on Economies with Heterogeneous Interacting Consumers

UNU-MERIT Dissertation Series, № 65

\section{Bertha Vallejo}

Learning and Innovation Under Changing Market Conditions: The Auto Parts Industry in Mexico

UNU-MERIT Dissertation Series, № 64

\section{Donatus Ayitey}

Technical Change, Competitiveness and Poverty Reduction: A Study of the Ghanaian Apparel Industry

UNU-MERIT Dissertation Series, № 63 


\section{Sergey Filippov}

Multinational Subsidiary Evolution:

Corporate Change in New EU Member States

UNU-MERIT Dissertation Series, № 62

\section{Asel Doranova}

Technology Transfer and Learning under the

Kyoto Regime: Exploring the Technological

Impact of CDM Projects in Developing

Countries

UNU-MERIT Dissertation Series, № 61

\section{Florian Tomini}

Between Family and Friend: Understanding the Interdependency of Private Transfers

MGSoG Dissertation Series, № 15

\section{Michał Polalowski}

The Institutional Transformation of Social

Policy in East Central Europe: Poland and

Hungary in Comparative and Historical

Perspective

MGSoG Dissertation Series, № 14

\section{Maha Ahmed}

Defining, Measuring and Addressing

Vulnerability: The Case of Post Conflict

Environments

MGSoG Dissertation Series, № 13

\section{Pascal Beckers}

Local Space and Economic Success: The Role of Spatial Segregation of Migrants in the

Netherlands

MGSoG Dissertation Series, № 12

\section{Victor Cebotari}

Conflicting Demands in Ethnically Diverse Societies: Ethno political Contention and Identity Values in Europe

MGSoG Dissertation Series, № 11

\section{Dennis Gyllensporre}

Competing and Complementary Perspectives on the EU as a Crisis Management Actor:

An Examination of the Common Security and Defence Policy through the Lenses of Idealism and Realism

MGSoG Dissertation Series, № 10

\section{Judit Vall Castello}

Business Cycle and Policy Effects on Labour Market Transitions of Older and Disabled Workers in Spain

MGSoG Dissertation Series, № 9

\section{Keetie Roelen}

False Positives or Hidden Dimensions: The Definition and Measurement of Child Poverty MGSoG Dissertation Series, № 8

Denisa Maria Sologon

Earning Dynamics in Europe

MGSoG Dissertation Series, № 7

\section{Melissa Siegel}

Money and Mobility: Migration and

Remittances

MGSoG Dissertation Series, № 6

\section{Jessica S. Hagen-Zanker}

Modest Expectations: Causes and Effects of Migration on Migrant Households inSource Countries

MGSoG Dissertation Series, № 5

2009

\section{Alexis Habiyaremye}

From Primary Commodity Dependence to

Diversification and Growth: Absorptive Capacity and Technological Catch Up in Botswana and Mauritius.

UNU-MERIT Dissertation Series, № 60

\section{Yoseph Getachew}

The Role of Public Capital in Economic

Development

UNU-MERIT Dissertation Series, № 59 


\section{Sandra Leitner}

Embodied Technological Change and Patterns of Investment in Austrian Manufacturing UNU-MERIT Dissertation Series, № 58

\section{Semih Akçomak}

The Impact of Social Capital on Economic and Social Outcomes

UNU-MERIT Dissertation Series, № 57

\section{Abraham Garcia}

The Role of Demand in Technical Change

UNU-MERIT Dissertation Series, № 56

\section{Saurabh Arora}

Coherence in Socio-technical Systems: A

Network Perspective on the Innovation

Process

UNU-MERIT Dissertation Series, № 55

Mirtha R. Muniz Castillo

Human Development and Autonomy in Project Aid: Experiences from four bilateral projects in Nicaragua and El Salvador MGSoG Dissertation Series, № 4

\section{Christiane Arndt}

Governance Indicators

MGSoG Dissertation Series, № 3

\section{Britta Augsburg}

Microfinance: Greater Good or Lesser Evil?

MGSoG Dissertation Series, № 2

\section{8}

\section{Rutger Daems}

Medicines for the Developing World

UNU-MERIT Dissertation Series, № 54

\section{Johannes Hanel}

Assessing Induced Technology: Sombart's Understanding of Technical Change in the History of Economics

UNU-MERIT Dissertation Series, № 53

\section{Rifka Weehuizen}

Mental Capital: the Economic Significance of Mental Health

UNU-MERIT Dissertation Series, № 52

\section{Danielle Cloodt}

The Relationship between RED Partnership Formation, Social Embeddedness and Innovative Performance

UNU-MERIT Dissertation Series, № 51

\section{Sabine Fuss}

Sustainable Energy Development under

Uncertainty

UNU-MERIT Dissertation Series, № 50

\section{Geranda Notten}

Measuring and Managing Poverty Risks

MGSoG Dissertation Series, № 1

2007

\section{Tobias Kronenberg}

Reconciling Environmental Conservation with Economic Prosperity: The Feasibility of Double Dividends in the Short and Long Run UNU-MERIT Dissertation Series, № 49

\section{Viktoria Kravtsova}

Assessing the Impact of Foreign Direct Investment in Transition Economies UNU-MERIT Dissertation Series, № 48

\section{Suhail Sultan}

The Competitive Advantage of Small and Medium Sized Enterprises: The Case of Jordan's Natural Stone Industry UNU-MERIT Dissertation Series, № 47

2006

\section{Bulat Sanditov}

Essays on Social Learning and Imitation UNU-MERIT Dissertation Series, № 46 


\section{Mamata Parhi}

Dynamics of New Technology Diffusion: A

Study of the Indian Automotive Industry

UNU-MERIT Dissertation Series, № 45

\section{Andreas Reinstaller}

Social Structures and the Innovation Process:

Their Role in the Demand of Firms and

Consumers

UNU-MERIT Dissertation Series, № 44

\section{Rose Kiggundu}

Innovation systems and Development: The

Journey of a Beleaguered Nile Perch Fishery in Uganda

UNU-MERIT Dissertation Series, № 43

\section{Thomas Pogue}

The Evolution of Research Collaboration in South African Gold Mining: 1886-1933

UNU-MERIT Dissertation Series, № 42

\section{Geoffrey Gachino}

Foreign Direct Investment, Spillovers and Innovation: The Case of Kenyan

Manufacturing Industry

UNU-MERIT Dissertation Series, № 41

\section{Önder Nomaler}

Technological Change, International Trade and Growth: An Evolutionary, Multi-AgentsBased Modeling Approach

UNU-MERIT Dissertation Series, № 40

2005

\section{Samia Satti Osman Mohamed-Nour}

Change and Skill Development in the Arab

Gulf Countries

UNU-MERIT Dissertation Series, № 39

\section{Elad Harison}

Intellectual Property Rights: Economics and Policy Analysis

UNU-MERIT Dissertation Series, № 38

\section{Daniel Dalohoun}

Learning to innovate: agricultural innovation and entrepreneurship: the case of Songhai farmers in Benin

UNU-MERIT Dissertation Series, № 37

\section{Müge Ozman}

Networks, Organizations and Knowledge

UNU-MERIT Dissertation Series, № 36

\section{Bas Straathof}

Product Variety and Economic Growth: The

Counteracting Effects of Scale and

Idiosyncrasy

UNU-MERIT Dissertation Series, № 35

\section{Wilfred Schoenmakers}

Knowledge Flows between Multinational

Companies: A Patent Data Analysis

UNU-MERIT Dissertation Series, № 34

\section{Myriam Cloodt}

Mergers and Acquisitions ( $M$ and As) in

High-Tech Industries: Measuring the Post-M and A Innovative Performance of Companies

UNU-MERIT Dissertation Series, № 33

2004

\section{Paola Criscuolo}

RED Internationalisation and Knowledge

Transfer: Impact on MNEs and their Home

Countries

UNU-MERIT Dissertation Series, № 32

\section{Maarten Verkerk}

Trust and Power on the Shop Floor

UNU-MERIT Dissertation Series, № 31

\section{Gottfried Leibbrandt}

Adoption, Harmonization and Succession of

Network Technologies across Countries

UNU-MERIT Dissertation Series, № 30 
Mark Sanders

Skill Biased Technical change: Its Origins, the Interaction with the Labour Market and Policy Implications

UNU-MERIT Dissertation Series, № 29

2003

\section{Nadine Roijakkers}

Inter-firm Cooperation in High-tech

Industries: a Study of RED Partnerships in

Pharmaceutical Biotechnology

UNU-MERIT Dissertation Series, № 28

Viki Sonntag

Speed, Scale and Sustainability

UNU-MERIT Dissertation Series, № 27

\section{Masaru Yarime}

From End-of-Pipe Technology to Clean

Technology

UNU-MERIT Dissertation Series, № 26

\section{Stéphane Malo}

The Combinatorial Chemistry Revolution:

Sustaining a Superior Performance Position through Technological Learning

UNU-MERIT Dissertation Series, № 25

2002

\section{Annelies Hogenbirk}

Determinants of Inward Foreign Direct Investment: the Case of the Netherlands UNU-MERIT Dissertation Series, № 24

\section{Bastiaan Johan terWeel}

The Computerization of the Labour Market UNU-MERIT Dissertation Series

2001

\section{John Adeoti}

Technology Investment in Pollution Control in Sub-Saharan Africa: The Case of the

Nigerian Manufacturing Industry

UNU-MERIT Dissertation Series, № 23

\section{Edward Huizenga}

Innovation Management: How Frontrunners Stay Ahead: An Empirical Study on Key Success Factors in the ICT sector UNU-MERIT Dissertation Series, № 22

2000

\section{Machiel van Dijk}

Technological Change and the Dynamics of Industries: Theoretical Issues and Empirical evidence from Dutch Manufacturing UNU-MERIT Dissertation Series, № 21

1999

\section{Jan Cobbenhagen}

Managing Innovation at the Company Level: A Study on Non-Sector-Specific Success Factors

UNU-MERIT Dissertation Series, № 20

\section{Marjolein Caniëls}

Regional Growth Differentials: The Impact of Locally Bounded Knowledge Spillovers UNU-MERIT Dissertation Series, № 19

1998

\section{Aldo Geuna}

Resource Allocation and Knowledge production: Studies in the Economics of University Research UNU-MERIT Dissertation Series, № 18 1996

\section{Reinoud Joosten}

Dynamics, Equilibria, and Values

UNU-MERIT Dissertation Series, № 17

\section{Hugo Kruiniger}

Investment, $R \mathcal{E} D$, and the Financing

Decisions of the Firm

UNU-MERIT Dissertation Series, № 16 


\section{Hans van Meijl}

Endogenous Technological Change: The Case of Information Technology, Theoretical Considerations and Empirical Results UNU-MERIT Dissertation Series, № 15

\section{René Kemp}

Environmental Policy and Technical Change: A Comparison of the Technological Impact of Policy Instruments

UNU-MERIT Dissertation Series, № 14

\section{Rohini Acharya}

The Impact of New Technologies on Economic Growth and Trade: A Case Study of

Biotechnology

UNU-MERIT Dissertation Series, № 13

\section{Geert Duysters}

The Evolution of Complex Industrial Systems:

The Dynamics of Major IT Sectors

UNU-MERIT Dissertation Series, № 12

\section{Marjan Groen}

Technology, Work and Organisation: A Study of the Nursing Process in Intensive Care Units

UNU-MERIT Dissertation Series, № 11

1994

\section{Huub Meijers}

On the Diffusion of Technologies in a Vintage Framework: Theoretical Considerations and Empirical Results

UNU-MERIT Dissertation Series, № 10

\section{Theon van Dijk}

The Limits of Patent Protection: Essays on the Economics of Intellectual Property Rights UNU-MERIT Dissertation Series, № 9

\section{Hans Voordijk}

Naar Integrale Logistiek in Bedrijfsketens:

Ontwikkelingen in de Bouw

UNU-MERIT Dissertation Series, № 8

\section{Paul Diederen}

Technological Progress in Enterprises and Diffusion of Innovation: Theoretical Reflections and Empirical Evidence UNU-MERIT Dissertation Series, № 7

\section{Ben Dankbaar}

Economic Crisis and Institutional Change: The Crisis of Fordism from the Perspective of the Automobile Industry UNU-MERIT Dissertation Series, № 6

\section{Hanno Roberts}

Accountability and Responsibility: The Influence of Organisation Design on Management Accounting UNU-MERIT Dissertation Series, № 5

1992

\section{Bart Verspagen}

Uneven Growth between Interdependent Economies: An Evolutionary View on Technology Gaps, Trade and Growth UNU-MERIT Dissertation Series, № 4

\section{Sjoerd Romme}

A Self-organization Perspective on Strategy Formation

UNU-MERIT Dissertation Series, № 3

1989

\section{John Spangenberg}

Economies of Scale, and Atmosphere in Research Organisations

UNU-MERIT Dissertation Series, № 2

1988

\section{John Hagedoorn}

Evolutionary and Heterodox Innovation Analysis: A Study of Industrial and Technological Development in Process Control and Information Technology UNU-MERIT Dissertation Series, № 1 
